\title{
Characteristics of Activated Carbons Produced from Herbaceous Biomass Feedstock
}

Oluwatosin Jerry Oginni

ojoginni@mix.wvu.edu

Follow this and additional works at: https://researchrepository.wvu.edu/etd

Part of the Bioresource and Agricultural Engineering Commons, and the Other Forestry and Forest Sciences Commons

\section{Recommended Citation}

Oginni, Oluwatosin Jerry, "Characteristics of Activated Carbons Produced from Herbaceous Biomass Feedstock" (2018). Graduate Theses, Dissertations, and Problem Reports. 3719.

https://researchrepository.wvu.edu/etd/3719

This Dissertation is protected by copyright and/or related rights. It has been brought to you by the The Research Repository @ WVU with permission from the rights-holder(s). You are free to use this Dissertation in any way that is permitted by the copyright and related rights legislation that applies to your use. For other uses you must obtain permission from the rights-holder(s) directly, unless additional rights are indicated by a Creative Commons license in the record and/ or on the work itself. This Dissertation has been accepted for inclusion in WVU Graduate Theses, Dissertations, and Problem Reports collection by an authorized administrator of The Research Repository @ WVU.

For more information, please contact researchrepository@mail.wvu.edu. 
Characteristics of Activated Carbons Produced from Herbaceous Biomass Feedstock

Oluwatosin Jerry Oginni

\author{
Dissertation submitted to the \\ Davis College of Agriculture, Natural Resources and Design \\ at West Virginia University \\ in partial fulfilment of the requirements for the degree of \\ Doctor of Philosophy in \\ Forest Resources Science
}

\title{
Kaushlendra Singh, Ph.D., Chair \\ Benjamin Dawson-Andoh, Ph.D. \\ Louis, M. McDonald, Ph.D. \\ Edward Sabolsky, Ph.D. \\ Gloria Oporto, Ph.D.
}

Department of Wood Science and Technology

\section{Morgantown, West Virginia}

2018

Keywords: Biomass, Pyrolysis, Activation, Activated carbon, Adsorption

Copyright 2018 Oluwatosin Jerry Oginni 


\title{
ABSTRACT \\ Characteristics of Activated Carbons Produced from Herbaceous Biomass Feedstock
}

\author{
Oluwatosin Jerry Oginni
}

Energy security and environmental protection are at the forefront of research due to the forecasted depletion of fossil fuel reserves and the growing concern of its adverse environmental impacts. The use of renewable sources for energy applications has centered on the use of biomass feedstocks and this include from herbaceous, woody, agricultural waste, forest residues and municipal wastes. The thermochemical conversion (pyrolysis) of these biomass feedstocks has potential to produce liquid fuel, a solid residue (biochar) and non-condensable gas. The biochar is primarily composed of renewable porous carbon and other inorganic compounds. The biochar is used for soil amendment, adsorption applications, electrochemical applications, and as a matrix for catalysts development. This dissertation has documented utilization of herbaceous biomass for biochar and activated carbon production and its use for adsorption applications. Chapter 1 provides basic introduction of the research presented in latter chapters while the chapter 2 provides comprehensive review of status of knowledge in the area of activated carbon production, characterization techniques, and application.

Chapter 3 discusses distribution and properties of pyrolysis products obtained from herbaceous biomass feedstocks harvested from reclaimed mine lands in West Virginia. In this study, samples of Miscanthus sterile varieties (Private and Public) and Switchgrass sterile varieties (Bomaster and Kanlow), grown on reclaimed mine land in West Virginia were used. The oven-dried samples were pyrolyzed in a fixed-bed batch reactor under an inert condition and at a temperature of $500{ }^{\circ} \mathrm{C}$ to produce biochar and bio-oil. Statistical analysis of the pyrolysis data showed that there were no significant difference in the biochar yields (about 30\% yield) obtained from the two varieties of Switchgrass and Miscanthus. The bio-oil yields were in the range of 45 to $51 \%$. The carbon content of the biomass, biochar and bio-oil were found to be $46.80-48.02 \%, 77.72-80.23 \%$ and 54.68 - 59.68\%, respectively. Average heating values were found to be $19.49 \mathrm{MJ} / \mathrm{kg}, 29.01 \mathrm{MJ} / \mathrm{kg}$ and $24.98 \mathrm{MJ} / \mathrm{kg}$ for the biomass, biochar and bio-oil, respectively.

Chapter 4 focused on investigating the effect of pyrolysis temperatures $\left(500,700 \& 900{ }^{\circ} \mathrm{C}\right)$ on the thermal stability and physicochemical characteristics of biochars produced from herbaceous biomass. The produced biochars were thermally degraded in air at a temperature of $950{ }^{\circ} \mathrm{C}$ to compare their thermal recalcitrance with graphite. The thermal recalcitrance of the biochars were found to increase with the pyrolysis temperature. The $\mathrm{pH}$ values increased with the pyrolysis temperature from slightly alkaline to highly alkaline. The aromaticity of the biochars increased and the biochars became more hydrophobic due to the loss of oxygen as the pyrolysis temperature increased. The BET surface area of the biochars increased with an increase in pyrolysis temperature.

Chapter 5 documents the effect of impregnation route on activated carbon properties from herbaceous biomass. The objective of this study was to investigate the effect of activating agent 
and impregnation route on the properties of activated carbons synthesized from herbaceous biomass. The precursors for the activated carbon synthesis were Kanlow Switchgrass (KSBM) and Public Miscanthus (PMBM) biomass and their biochars (KSBC and PMBC respectively). The precursors were impregnated with either potassium hydroxide or phosphoric acid. Thereafter, the impregnated precursors were activated at a temperature of $900{ }^{\circ} \mathrm{C}$ in inert condition. The surface morphology, textural properties and surface chemistry of the activated carbons were characterized. Also, the activated carbons were used in adsorbing two pharmaceutically active compounds; acetaminophen and caffeine. The results of the study showed that the biomass derived activated carbons had the highest BET surface area, which comprised of both micropores and mesopores. The biomass derived activated carbons were found to have better adsorption capacities for both caffeine and acetaminophen. 


\section{Acknowledgements}

First, I would like to express my profound gratitude to the academic and research community, dedicated to the advancement of science for becoming the foundation for the research presented in this dissertation and for becoming the guide throughout the course of my doctoral program and for the successful completion of this degree. I would like to dedicate my Doctor of Philosophy degree to my parents, Mr. Franklin and Mrs. Clara Oginni for all their sacrifices in helping me achieve my academic dreams. I am happy to make both of you proud. Many thanks to my siblings Ayodeji (for being the pace setter), Titilope (for your encouragement), Mayowa and Tolulope. Academically, my sincere appreciation goes to my advisor, Dr. Kaushlendra Singh for his guidance and patience in directing me throughout this program. I appreciate all the opportunities you provided for me to explore during my doctorate program.

My sincere gratitude also goes to all the members of my dissertation committee, Dr. Gloria Oporto, Dr. Benjamin Dawson-Andoh, Dr. Louis McDonald, and Dr. Ed Sabolsky. Thank you for accepting to serve on this committee and allowing me to use your laboratory equipment for my experiments. I am also grateful to you all for the insightful comments, questions and suggestions, which had steered me in the right direction. I would also love to appreciate Dr. Babatunde Ogunsina and Dr. Oladiran Fasina for setting me on the course of becoming a researcher and your selfless service in paving the way for younger generation like me.

This marathon research was not possible without constant support from my friends. To Felix and Sohrab, I appreciate the time we spent working together as a research team. Thank you for your friendship. A special thank you to all my friends in Morgantown and the RCCG Morgantown family. Worth mentioning are Akhona, Bolaji, Damian, Dianne, Aurelie and Bekibecca; thank you guys for your friendship and for becoming a family.

To the author and finisher of my faith, he very essence of my existence, I would like to thank God for his grace and mercy throughout my academic pursuit. To God be the glory!!! 


\section{Table of Contents}

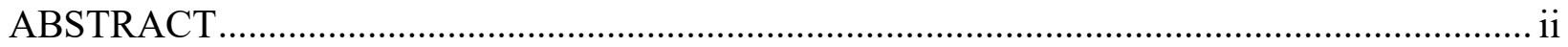

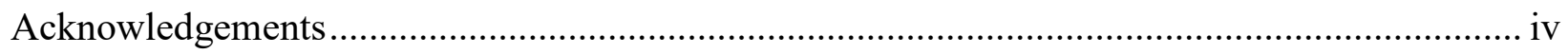

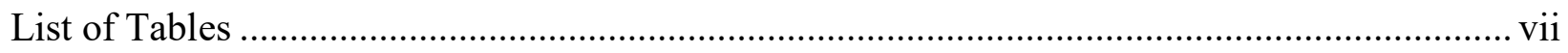

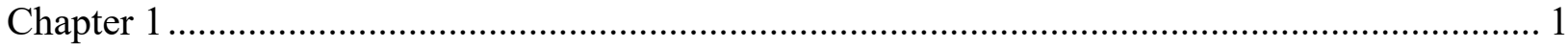

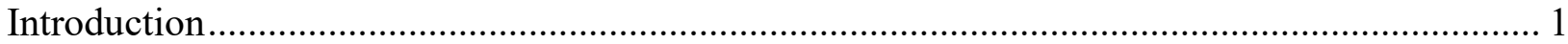

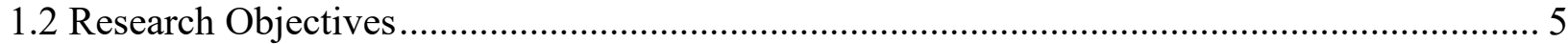

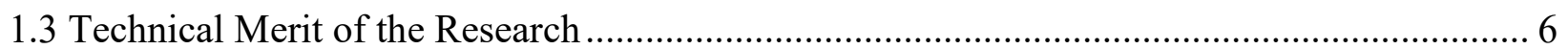

1.4 Broader Impacts of Research on Society and on U.S Agriculture..................................... 6

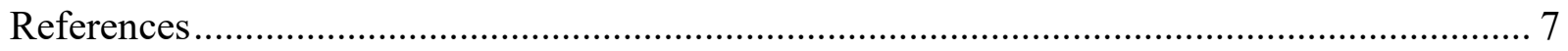

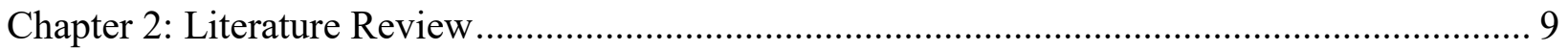

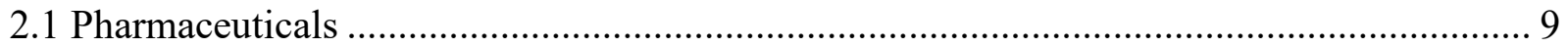

2.2 Treatment Methods for Pharmaceutical Compounds ................................................... 11

2.3 Recent Studies on Adsorption of Pharmaceutical Compounds using Activated Carbon ... 12

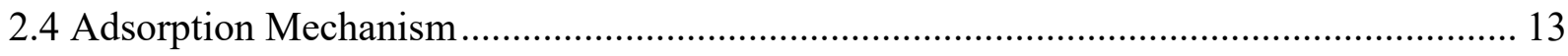

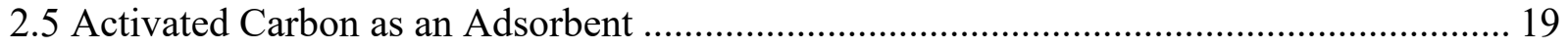

2.6 Activated Carbon Production: Carbonization and Activation ....................................... 21

2.7 Properties of Activated Carbon...................................................................................... 23

2.8 Effect of Process Parameters on the Properties of Activated Carbons ............................. 29

2.9 Modification of Activated Carbon Surfaces ................................................................ 32

2.10 Textural and Surface Chemistry Characterization of Activated Carbon ........................ 35

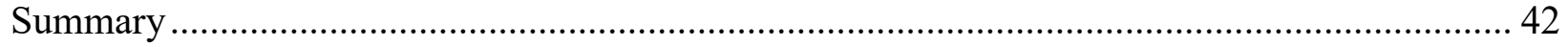

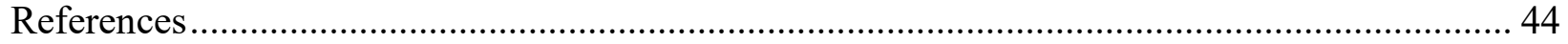

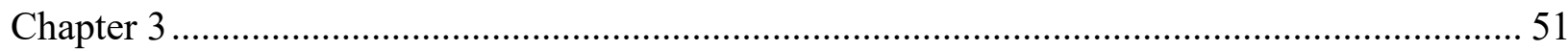

Pyrolysis of dedicated bioenergy crops grown on reclaimed mine land in West Virginia.......... 51

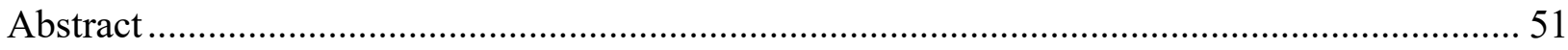

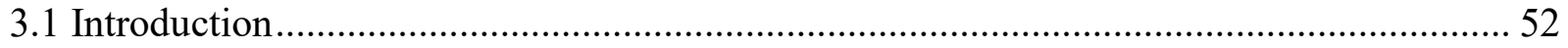

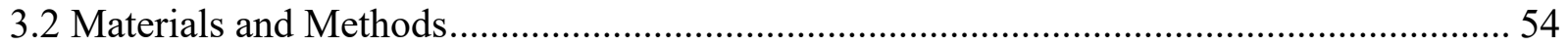

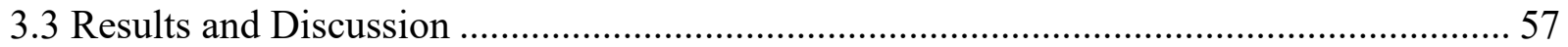

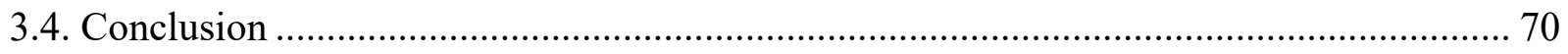

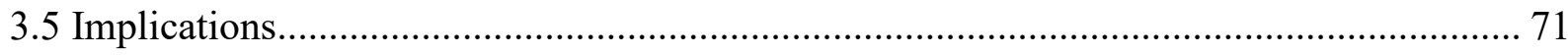

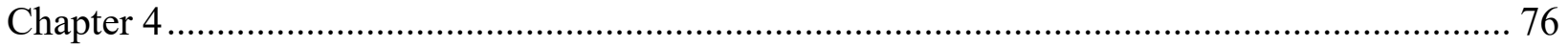


Effect of pyrolysis temperature on the thermal stability and physicochemical characteristics of biochars produced from herbaceous biomass ................................................................ 76

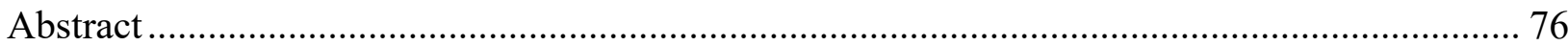

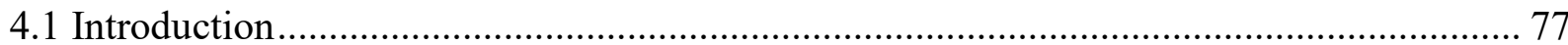

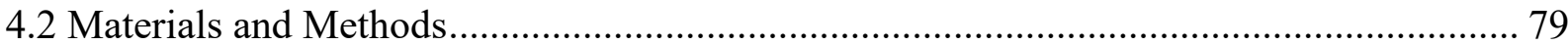

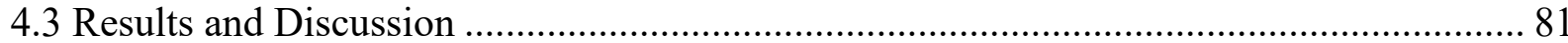

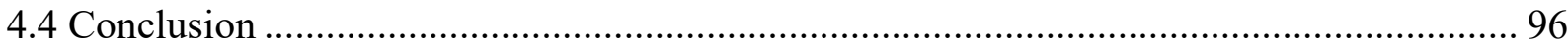

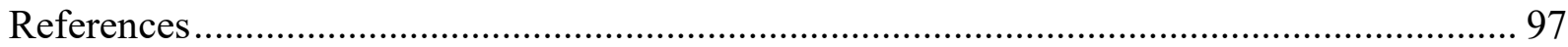

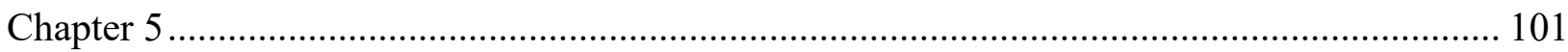

Effect of Activating Agent Type and Impregnation Route on Properties of Activated Carbon Synthesized from Herbaceous Biomass ......................................................................... 101

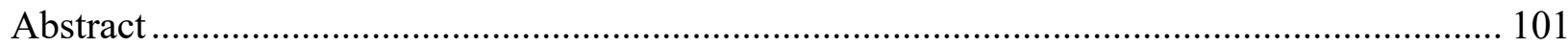

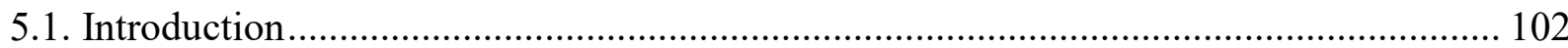

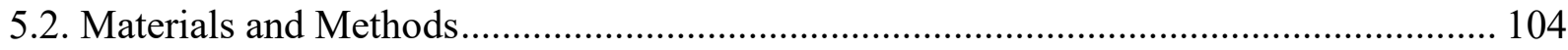

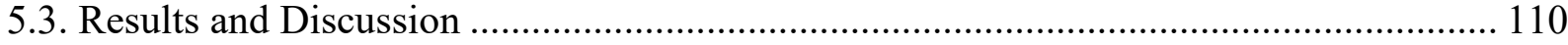

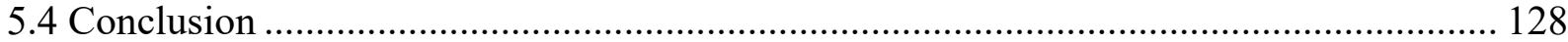

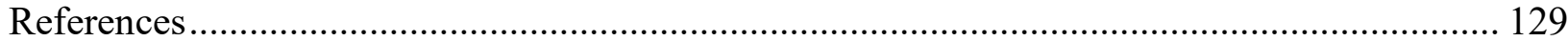

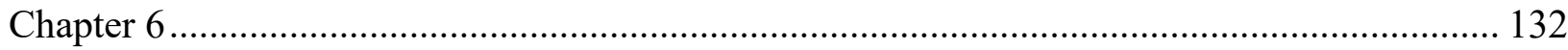

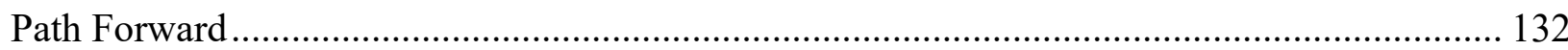

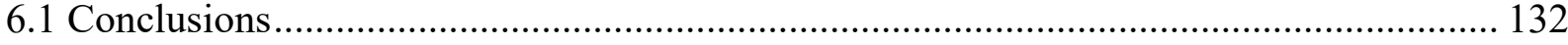

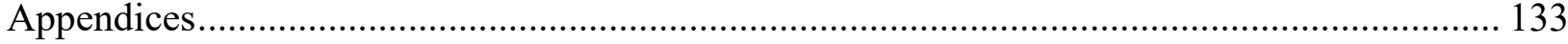




\section{List of Tables}

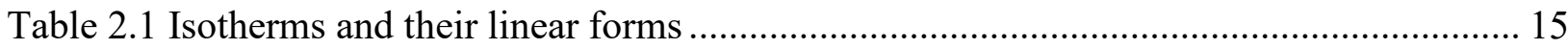

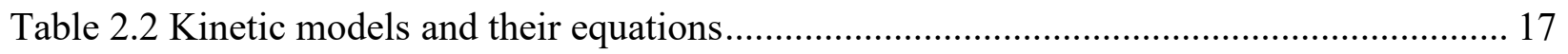

Table 2.3: Influence of process parameters on activated carbon properties produced via chemical

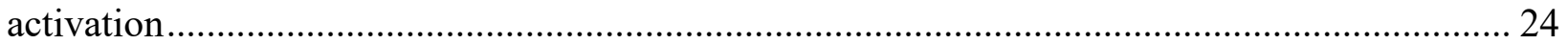

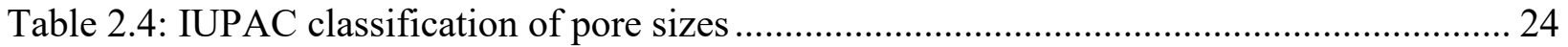

Table 2.5 Techniques available for activated carbon characterization ........................................ 37

Table 2.6: Total surface acidity and basicity of activated carbons (meq $/ \mathrm{g}$ ) ................................. 41

Table 3.1: Characterization of two varieties of Miscanthus and Switchgrass feedstock ............... 58

Table 3.2: Mineral composition in percent (\%) and parts per million (ppm) of Miscanthus ....... 60

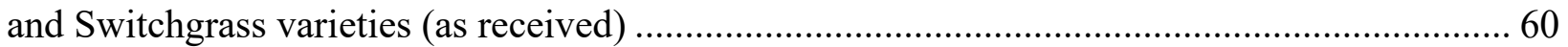

Table 3.3: Characterization of biochars from Miscanthus and Switchgrass pyrolysis .................. 63

Table 3.4: Characterization of bio-oil obtained from Miscanthus and Switchgrass varieties

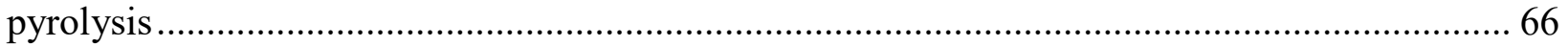

Table 4.1: Chemical composition of Kanlow Switchgrass and Public Miscanthus ...................... 82

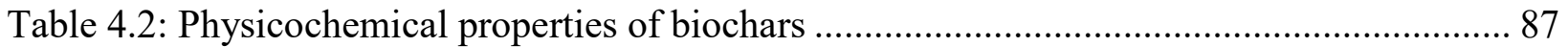

Table 4.3: Raman Spectra D and $G$ band positions and the corresponding intensity ratios ......... 92

Table 4.4: XPS C1s and O1s surface functional groups of biochars ........................................... 95

Table 5.2: Physico-chemical characteristics of acetaminophen and caffeine .............................. 107

Table 5.3: Surface area and pore characteristics of activated carbons ....................................... 114

Table 5.4: Raman D and G band positions, and the intensity ratios for activated carbons ........ 120

Table 5.5: Carbon and oxygen surface functional groups of activated carbons ......................... 123

Table 5.6: Kinetic model parameters for the adsorption of caffeine on activated carbons ........ 124

Table 5.7: Kinetic model parameters for the adsorption of acetaminophen on activated carbons

Table 5.8: Langmuir and Freundlich isotherm parameters for the adsorption of caffeine ......... 126

Table 5.9: Langmuir and Freundlich isotherm parameters for adsorption of acetaminophen.... 126

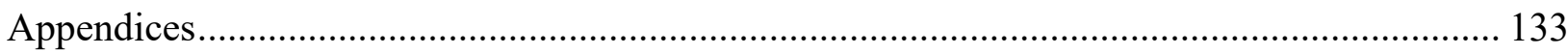




\section{List of Figures}

Figure 2.1: Major pathways for pharmaceutical compounds into the environment [8].............. 10

Figure 2.2: Schematic diagram of pore structure of activated carbon [55] ............................. 23

Figure 2.3: Micropore size distributions of activated carbons $[49,68]$.................................. 25

Fig 2.4: Acidic and basic surface functional groups on activated carbon basal plane [76] ......... 29

Figure 3.1: Experimental setup for biomass pyrolysis [18] ............................................ 55

Figure 3.2: Percent cellulose, hemicellulose and lignin contents of Miscanthus and Switchgrass varieties

Figure 3.3: Percent yield (on dry biomass basis) of pyrolysis products of Miscanthus and

Switchgrass varieties 62

Figure 3.4: Elemental composition of Miscanthus and Switchgrass biochars

Figure 3.5: Van Krevelen diagram showing the cross-plot of $\mathrm{H} / \mathrm{C}$ and $\mathrm{O} / \mathrm{C}$ atomic ratios for biomass, bio-oil and biochar. 65

Figure 3.6: Percent yield of gas given off during pyrolysis of Kanlow Switchgrass .................. 68

Figure 3.7: Percent yield of gas given off during pyrolysis of Bomaster Switchgrass............... 69

Figure 3.8: Carbon and energy yields of Miscanthus and Switchgrass biochars........................ 70

Figure 4.1: TGA- percent mass loss of Kanlow Switchgrass and Public Miscanthus at heating rate of $5^{\circ} \mathrm{c} / \mathrm{min}$. 82

Figure 4.2: DTG curve for Kanlow Switchgrass and Public Miscanthus at heating rate of 5

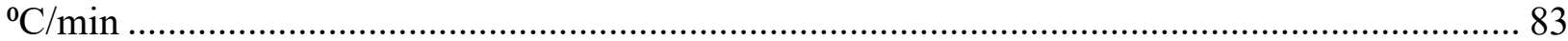

Figure 4.3: Plot of activation energy versus fractional conversion ratio .................................. 85

Figure 4.4: Moisture and ash content corrected thermogram for biochars ................................. 86 Figure 4.5: SEM of (A) PM 500, (B) PM 700, (C) PM 900, (D) KS 500, (E) KS 700, (F) KS900

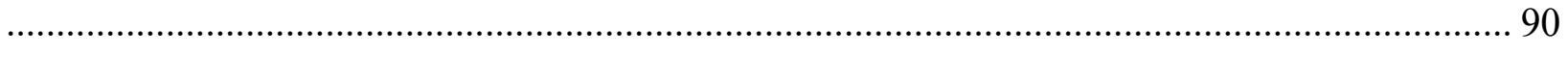

Figure 4.6: Pore size distribution of biochars .............................................................. 91

Figure 4.7: Raman spectra of Kanlow Switchgrass and Public Miscanthus biochars ................ 92

Figure 4.8: Effect of pyrolysis temperature on intensity ratio of biochars .............................. 93

Figure 4.9: XPS C1s deconvolved spectra of Kanlow Switchgrass and Public Miscanthus

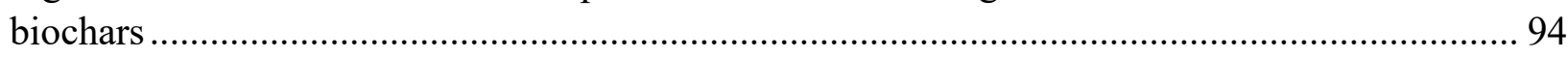

Figure 5.1: Calibration curves for Acetaminophen and Caffeine solutions............................. 108

(E) KOH-PMBM, (F) H3 $\mathrm{PO}_{4}-\mathrm{PMBM}$, (G) KOH-KSBM, (H) $\mathrm{H}_{3} \mathrm{PO}_{4}-\mathrm{KSBM} \ldots \ldots \ldots \ldots \ldots \ldots \ldots . . . . . . . . . . .111$

Figure 5.3: $\mathrm{N}_{2}$ adsorption/desorption isotherm curves at $77 \mathrm{k}$ for activated carbons ................ 112

Figure 5.4: Surface area distribution of (A) biochar-derived and (B) biomass-derived activated

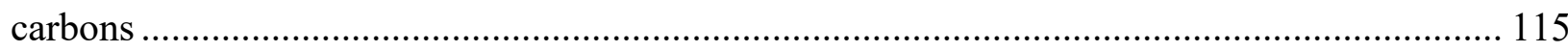

Figure 5.5: Pore size distributions of biochar-derived activated carbons .............................. 117

Figure 5.6: Raman spectra of biochar-derived activated carbons (A \& B); biomass-derived activated carbons (C \& D) ......................................................................................... 119

Figure 5.7: C1s and O1s Spectra of: $\mathrm{KS} 900, \mathrm{H}_{3} \mathrm{PO}_{4}-\mathrm{KSBC}_{\text {and }} \mathrm{H}_{3} \mathrm{PO}_{4}-\mathrm{KSBM}$................... 121

Figure 5.8: Plot of separation factor $\left(\mathrm{R}_{\mathrm{L}}\right)$ against initial concentration of adsorbates .............. 127 


\section{Chapter 1}

\section{Introduction}

Energy security is one of the most important issues of modern times for every country in the world. Energy security is also directly tied with the nexus of food, water, and social security. Given the finite supply of fossil-based energy resources, significant investment is being made by various governments to diversify their energy portfolios to incorporate renewable energy resources, which is assisted by amicable energy policies and acts [1]. For example, in the United States, the total primary energy consumption per year for all sectors has been projected to increase from 97.1 quadrillion Btu in 2013 to 105.7 quadrillion Btu in 2040, the majority of which is expected to be supplied from fossil resources, a leading source for greenhouse gas emissions [2]. According to one estimate, consumption of gasoline and diesel in the United States resulted in 1522 million metric tons of $\mathrm{CO}_{2}$ greenhouse gas emissions, which was equivalent to $83 \%$ of the total $\mathrm{CO}_{2}$ emissions by the U.S. transportation sector and $28 \%$ of total U.S. energy-related $\mathrm{CO}_{2}$ emissions [3].

To address issues relating to energy security and climate change, the United States government has enacted legislation, including the Energy Independence and Security Act (EISA) of 2007, National Environmental Policy Act, Recovery Acts and Clean Energy, American Renewable Energy and Efficiency Act, Renewable Fuel Standard (RFS) and Renewable Portfolio Standards (RPS). The EISA [4] mandates an increase in the amount of renewable fuels used in the United States transportation sector from 2012 level of 15 billion gallons to 36 billion gallons by 2022 . The mandate further stipulates that, of the 36 billion gallons of renewable fuel, the goal is to produce 21 billion gallons of advanced biofuels derived mainly from cellulosic feedstock (forest residues, woody biomass, dedicated energy crops, agriculture residues, etc). The United States has the potential to produce over 1 billion dry tons of biomass annually for bioenergy applications, which can be converted into 90 billion gallons of liquid fuels, enough to meet more than $30 \%$ of the 2015 U.S. petroleum consumption (297.36 billion gallons) $[5]$.

The portion of the $\mathrm{CO}_{2}$ released from the biomass derived fuel is $\mathrm{CO}_{2}$ that has been recently sequestered from the atmosphere by plant growth. In contrast, the large amounts of $\mathrm{CO}_{2}$ released by fossil fuel combustion is from long-term stored carbon. The use of renewable energy resources will thus result in a relatively large net reduction of atmospheric carbon emission, hence mitigating the threats of global climate change [6]. For example, the $\mathrm{CO}_{2}$ emissions from using dedicated energy crops 
for energy generation are about 7, 12, and 13 times lower than those produced by gas, petroleum, and coal respectively [7]. Specifically, $\mathrm{CO}_{2}$ emissions from switchgrass is $1.9 \mathrm{~kg} \mathrm{C} / \mathrm{GJ}$ compared with 13.8 , 22.3 and $24.6 \mathrm{~kg} \mathrm{C} / \mathrm{GJ}[6]$

However, it is noteworthy that the production of these biomass resources will compete with food production in terms of cultivable land use. This has led to investigation on the potential use of marginal lands (including abandoned mine lands and other non-arable lands) for growing dedicated energy crops to reduce competition for land between energy and food production. Marginal lands are usually described as unproductive or unsuitable for crop production due to inherent edaphic or climatic limitations or because they are located in areas that are vulnerable to erosion or other environmental risks when cultivated [8,9]. Marginal lands are characterized as having little or no agricultural importance with poor soil qualities, hence making them unsuitable for food production. According to Blanco-Canqui [10], reclaimed mine land is considered marginal because they are often rocky and gravelly, with low soil organic matter concentrations and adverse soil physical and chemical properties. While the United States has about 4.4 million ha of mine lands, West Virginia is estimated to have about 81,200 ha of mine lands. Out of these 81,200 hectares of land, about 200 acres had been reclaimed and planted with biomass crops $[11,12]$. The current state of reclaimed mine lands in West Virginia used for herbaceous biomass production has shown a great potential for high yield. Target yields of $5,000 \mathrm{~kg} / \mathrm{ha}$ for Switchgrass and 15,000 kg/ha for Miscanthus has been established for reclaimed lands by the WV Department of Environmental Protection [13]. In a study by Skousen et al. [13], 4,900 kg/ha yield was obtained for a variety of Switchgrass and $21,880 \mathrm{~kg} /$ ha yield was achieved for a variety of Miscanthus in 2012.

The intention of growing these dedicated bioenergy crops with significant capital investment was to supply a bioethanol plant to be opened in near future, however, there is currently no outlet for the harvested bioenergy crops. Therefore, there is a need to provide an alternate use of these available biomass feedstock to generate an economic return. The thermochemical conversion of biomass feedstocks have been reported to produce bio-oil, biochar and incondensable gas [14]. The use of biochar for soil amendment, animal feed and fuel [15] can serve an alternate option for generating economic returns for the biomass feedstocks. In recent times, the need for producing activated carbon from cheap and available precursors have led to significant research on the use of biomass for activated carbon production. This is also a viable valued-added use of the biomass feedstocks. 
Activated carbon is broadly defined to include a wide range of amorphous carbon-based materials prepared in such a way that they exhibit a high degree of porosity and an extended surface area [16]. It is a versatile adsorbent that is used for removal, recovery, separation and modification of harmful constituents from gases and liquid solutions. The structure of activated carbon is best described as a twisted network of defective carbon layer planes, cross linked by aliphatic bridging groups. This structure contributes to its highly developed and accessible internal pore structure [17]. These intrinsic features are responsible for its exceptional adsorptive capability, which has found application in adsorbing molecules from both the liquid and gas phase [18,19]. As a result, its adsorption application is as diverse as pharmaceuticals, food, chemical as well as treatment of drinking water, industrial and urban waste water, and industrial flue gases [16,17].

The detection of pharmaceutically active compounds and endocrine disrupting compounds in waste water and finished drinking water albeit at trace levels; and the potential of these compounds to cause harm to human health if they accumulate in human bodies [20], have led to greater interest in the application of activated carbon for water treatment. In 2008, there was a published report that the drinking water supplies for at least 41 million Americans had pharmaceuticals in them. Although, the concentrations of these pharmaceuticals were in trace levels (parts per billion), their presence in drinking water has heightened the concerns of researchers about the long term consequences to human health [21]. The growing concern about these compounds in recent times is not solely a result of increase in the concentration of these compounds in drinking water but also by the improved ability to detect them at very low concentrations. Also, another factor for the growing concern is the potential for synergistic effects of mixtures of these compounds [22]. In a study conducted by Kim et al. [23] on degradability of 30 pharmaceuticals and personal care products, it was reported that certain compounds that coexist in water pose greater threats than if they exist alone.

Activated carbon adsorption, a surface phenomenon by which components of a fluid (gas or liquid) is attracted to the surface of an adsorbent and forms attachments via physical or chemical bonds, has been recognized as the most efficient, promising and widely used fundamental approach in drinking water and waste water treatment processes, mainly due to its simplicity, economic viability, technical feasibility and social acceptability $[24,25]$. The activated carbon adsorption involves two types of forces: physical forces that may be dipole moments, polarization forces, dispersive forces, or short range repulsive interactions and chemical forces that are valency forces arising out of the redistribution of electrons between the solid surface and the adsorbed atoms [16]. Depending upon the nature of the 
forces involved, the adsorption is of two types: physical adsorption and chemisorption. In the case of physical adsorption, the adsorbate is bound to the surface by relatively weak van der Waals forces, which are similar to the molecular forces of cohesion and are involved in the condensation of vapors into liquids. Chemisorption, on the other hand, involves exchange or sharing of electrons between the adsorbate molecules and the surface of the adsorbent resulting in a chemical reaction. The bond formed between the adsorbate and the adsorbent is essentially a chemical bond and is thus much stronger than in physisorption [16].

The adsorption process is usually described through isotherms, which shows the amount of adsorbate on the adsorbent as a function of its pressure (if gas) or concentration (if liquid) at constant temperature [24]. Established isotherm models such as Langmuir, Freundlich and Brunauer-EmmettTeller (BET) isotherm models are used in assessing the suitability of an adsorbent in an adsorption system, where the experimental data are fitted to any of these models [26]. The isotherms are critical for optimization of the adsorption mechanism pathways, expression of the surface properties and capacities of the adsorbents, and effective design of the adsorption systems [24].

Despite the prolific use of activated carbon in adsorption processes, its use is faced with challenges ranging from high cost of production and unavailability of precursors due to its nonrenewable source to difficulties associated with regeneration of the activated carbon for reuse [24,27]. The commercial activated carbon is generally derived from coal and lignite as $90 \%$ of its constituents is made of carbon. In light of this, research attention has shifted to the possibility of using agricultural wastes, forest residues and biomass feedstock as the precursor for activated carbon production.

These raw materials are being explored because they are inexpensive, abundant, renewable and their use pose no threat to the environment. The several published works on the use of biomass feedstocks for activated carbon preparation have been on biomass feedstocks harvested on agriculturally viable lands. To the best of our knowledge, there are no published research work on the use of biomass feedstocks harvested on marginal or reclaimed mine lands for the production of activated carbon. Large scale production of activated carbon will require a large quantity of precursors, which will ultimately compete with agricultural lands needed for food production. These biomass feedstocks can be produced on marginal lands if the properties of the activated carbon produced from them are similar to the properties of commercial activated carbon. This is the basis for this research work 


\subsection{Research Objectives}

The aim of this research is to test the efficacy of activated carbons produced from various herbaceous biomass grown on marginal and reclaimed mine lands of West Virginia through different activation agents. The specific objectives are outlined below:

Objective 1: Evaluate the yield and properties of pyrolysis products obtained from bioenergy crops harvested on reclaimed mine land in West Virginia.

Rationale: While literature is available on pyrolysis of switchgrass harvested from agricultural viable soil at Mead, NE [28,29] and Miscanthus grown in Tifton, Georgia [30], the distribution and properties of the pyrolysis products from biomass harvested on a marginal land (such as reclaimed mine land) might differ from that harvested on cultivable soils. The results of the biochar yield and the carbon conversion efficiency will allow for accurate estimation of the economic feasibility of activated carbon production from these feedstocks.

Objective 2: Effect of pyrolysis temperature on the thermal stability and physico-chemical characteristics of biochars produced from herbaceous biomass.

Rationale: The significance of biochar as soil amendment and carbon sink is due to its resistance to abiotic and biotic degradation. The recalcitrant nature of the biochar determines its stability and its rate of mineralization. A highly recalcitrant biochar has high carbon content, very low volatile content and low content of oxygen and hydrogen in relation to the carbon content. This type of recalcitrant nature is directly related to the temperature at which the biochar is produced. Therefore, this work investigates the recalcitrance and agronomic properties of biochars produced at three different pyrolysis temperatures. The results of the work can be used in the selection of an appropriate biochar for soil amendment.

Objective 3: Effect of activating agent and impregnation route on activated carbons properties using acidic and alkaline activating agents

Rationale: The production of activated carbon from biomass using chemical activation process can be divided into two pathways. The first pathway involves impregnation of the biomass with chemical agent and subsequent carbonization of the impregnated biomass at an elevated temperature to produce the activated carbon. The second pathway involves the initial biochar production, biochar impregnation with chemical agent and the activation of the impregnated biochar to produce the activated carbon. While there are reports of the chemical activation of biomass precursors [31-34] and biochar precursors [35-38] for the production of activated carbons, there is a sparsity of literature where both pathways 
were evaluated for the same biomass. Therefore, this study aimed at investigating the effect of impregnation route on activated carbon properties using an acidic and alkaline activating agent.

\subsection{Technical Merit of the Research}

The technical merit of this research is in the fact that it seeks to elucidate how the type of chemical activating agents and impregnation route play a significant role in influencing not only the total specific surface area and proportion of disordered carbon clusters of an activated carbon but also the distribution of the surface area in various pore sizes, which directly influence the adsorption characteristics of the activated carbon.

Another technical merit of this research is that it unravels how processing temperature changes both the pore characteristics and surface functionalities of biochars produced from herbaceous biomass.

\subsection{Broader Impacts of Research on Society and on U.S Agriculture}

This research will provide a basis to process biomass crops currently grown in the state of West Virginia into usable activated carbons, thereby, promoting rural economic development in the state. 


\section{References}

[1] N. Abdoulmoumine, Fate and Remediation of Biomass Gasification Gas Contaminants, Dissertation Auburn University, Biosystems Engineering, 2014, 289.

[2] U.S.E.I. Administration, in U.S.D.o. Energy (Ed.), Washington, DC, 2015.

[3] U.S.E.I. Administration, in, 2014, p. 269.

[4] in, http://www.energy.wsu.edu/documents/EnergyIndependenceAndSecurityActOf2007.pdf USA, 2007.

[5] U.S.D.o. Energy, in M.H. Langholtz, B.J. Stokes and L.M. Eaton (Eds.), Oak Ridge National Laboratory, Oak Ridge, TN, 2016, p. 448.

[6] A.F. Turhollow and R.D. Perlack, Biomass and Bioenergy, 1, (1991) 129.

[7] Z. Ma, C.W. Wood and D.I. Bransby, Biomass and Bioenergy, 18, (2000) 469.

[8] I. Gelfand, R. Sahajpal, X. Zhang, R.C. Izaurralde, K.L. Gross and G.P. Robertson, Nature, 493, (2013) 514.

[9] M.A. Mehmood, M. Ibrahim, U. Rashid, M. Nawaz, S. Ali, A. Hussain and M. Gull, Sustainable Production and Consumption, (2016).

[10] H. Blanco-Canqui, Soil Science Society of America Journal, 80, (2016) 845.

[11] R. Lemus and R. Lal, Critical Reviews in Plant Sciences, 24, (2005) 1.

[12] J.G. Skousen, C.D. Johnson and K. Garbutt, Journal of Environmental Quality, 23, (1994) 1224.

[13] J. Skousen, T. Keene, M. Marra and B. Gutta, Journal American Society of Mining and Reclamation, 2, (2012) 177.

[14] O. Oginni, K. Singh and J.W. Zondlo, Journal of Analytical and Applied Pyrolysis, 123, (2017) 319.

[15] J.H. Windeatt, A.B. Ross, P.T. Williams, P.M. Forster, M.A. Nahil and S. Singh, Journal of Environmental Management, 146, (2014) 189.

[16] R.C. Bansal and M. Goyal, Activated Carbon Adsoprtion CRC Press, Boca Raton, FL, USA, 2005, p.

[17] F. Çeçen, in Kirk-Othmer Encyclopedia of Chemical Technology, John Wiley \& Sons, Inc., 2000.

[18] P.J. Johnson, D.J. Setsuda and R.S. Williams, in T.D. Burchell (Ed.), Carbon Materials for Advanced Technologies, Elsevier Science Ltd, Oxford, 1999, p. 235.

[19] F. Çeçen and Ö. Aktaş, in Activated Carbon for Water and Wastewater Treatment, Wiley-VCH Verlag GmbH \& Co. KGaA, 2011, p. 1.

[20] Z. Yu, S. Peldszus and P.M. Huck, Environmental Science \& Technology, 43, (2009) 1467.

[21] J. Donn, M. Mendoza and J. Pritchard, in Pharmawater, Associated Press, 2008.

[22] C.O. Lee, K.J. Howe and B.M. Thomson, in, New Mexico Environment Department, 2009.

[23] I.H. Kim, H. Tanaka, T. Iwasaki, T. Takubo, T. Morioka and Y. Kato, Water Sci Technol, doi, (2008) 10.

[24] K.Y. Foo and B.H. Hameed, Chemical Engineering Journal, 156, (2010) 2.

[25] K.Y. Foo and B.H. Hameed, Journal of Hazardous Materials, 171, (2009) 54.

[26] A.H. Sulaymon and K.W. Ahmed, Environmental Science \& Technology, 42, (2008) 392.

[27] A.L. Cazetta, A.M.M. Vargas, E.M. Nogami, M.H. Kunita, M.R. Guilherme, A.C. Martins, T.L. Silva, J.C.G. Moraes and V.C. Almeida, Chemical Engineering Journal, 174, (2011) 117.

[28] A.A. Boateng, D.E. Daugaard, N.M. Goldberg and K.B. Hicks, Industrial \& Engineering Chemistry Research, 46, (2007) 1891.

[29] B.S. Dien, H.-J.G. Jung, K.P. Vogel, M.D. Casler, J.F.S. Lamb, L. Iten, R.B. Mitchell and G. Sarath, Biomass and Bioenergy, 30, (2006) 880. 
[30] G.S. Groenewold, K.M. Johnson, S.C. Fox, C. Rae, C.A. Zarzana, B.R. Kersten, S.M. Rowe, T.L. Westover, G.L. Gresham, R.M. Emerson and A.N. Hoover, Energy \& Fuels, 31, (2017) 1620.

[31] A. Kumar and H. Mohan Jena, Applied Surface Science, 356, (2015) 753.

[32] S. Yorgun and D. Y1ld1z, Journal of the Taiwan Institute of Chemical Engineers, 53, (2015) 122.

[33] M.N. Mahamad, M.A.A. Zaini and Z.A. Zakaria, International Biodeterioration \& Biodegradation, 102, (2015) 274.

[34] J. Xu, L. Chen, H. Qu, Y. Jiao, J. Xie and G. Xing, Applied Surface Science, 320, (2014) 674.

[35] J. Park, I. Hung, Z. Gan, O.J. Rojas, K.H. Lim and S. Park, Bioresource Technology, 149, (2013) 383.

[36] R. Azargohar and A.K. Dalai, Microporous and Mesoporous Materials, 110, (2008) 413.

[37] D. Angın, E. Altintig and T.E. Köse, Bioresource Technology, 148, (2013) 542.

[38] P. Nowicki, J. Kazmierczak and R. Pietrzak, Powder Technology, 269, (2015) 312. 


\section{Chapter 2: Literature Review}

\subsection{Pharmaceuticals}

Pharmaceuticals are regarded as emerging contaminants on our aquatic ecosystems and are described as large class of chemical contaminants arising from products such as prescription medicines, over-the-counter medications, fungicides and disinfectants used for domestic, industrial, and agricultural practices [1]. Pharmaceuticals are defined as used primarily to prevent or treat human and animal diseases. This group includes antibiotics, hormones, anti-inflammatory drugs, antiepileptic drugs, blood lipid regulators, cytostatic drugs [2].

Pharmaceuticals are widely released into the aquatic environment, where they mix at low concentrations over extended time via diverse pathways, resulting in a very complex fate [3]. Significant sources of pharmaceutical compounds include pharmaceuticals and chemical manufacturing facilities, hospital, pharmacies, veterinary facilities, and runoff from confined animal feeding operations or farms, where large quantities of antibiotics and other drugs are used. One of the largest sources of pharmaceutical compounds has been identified to be typical households where

pharmaceutical compounds enter wastewater treatment plants through human excrement, flushing of unused medications and washing chemicals down the drains [4]. The major pathways in which these compounds are release into the environment are illustrated in Figure 2.1.

In 2008, there was a published report that the drinking water supplies for at least 41 million Americans contained pharmaceuticals [5]. Although, the concentrations of these pharmaceuticals were in trace levels (parts per billion), their presence in drinking water has heightened the concerns about the long-term consequences to human health [5]. The growing concern about these compounds in recent times is not solely a result of increase in the concentration of these compounds in drinking water but also by the improved ability to detect them at very low concentrations. Also, another factor for the growing concern is the potential for synergistic effects of mixtures of these compounds [6]. In a study conducted by Kim et al. [7] on degradability of 30 pharmaceuticals and personal care products, it was reported that certain compounds that coexist in water pose greater threats than if they exist alone. 


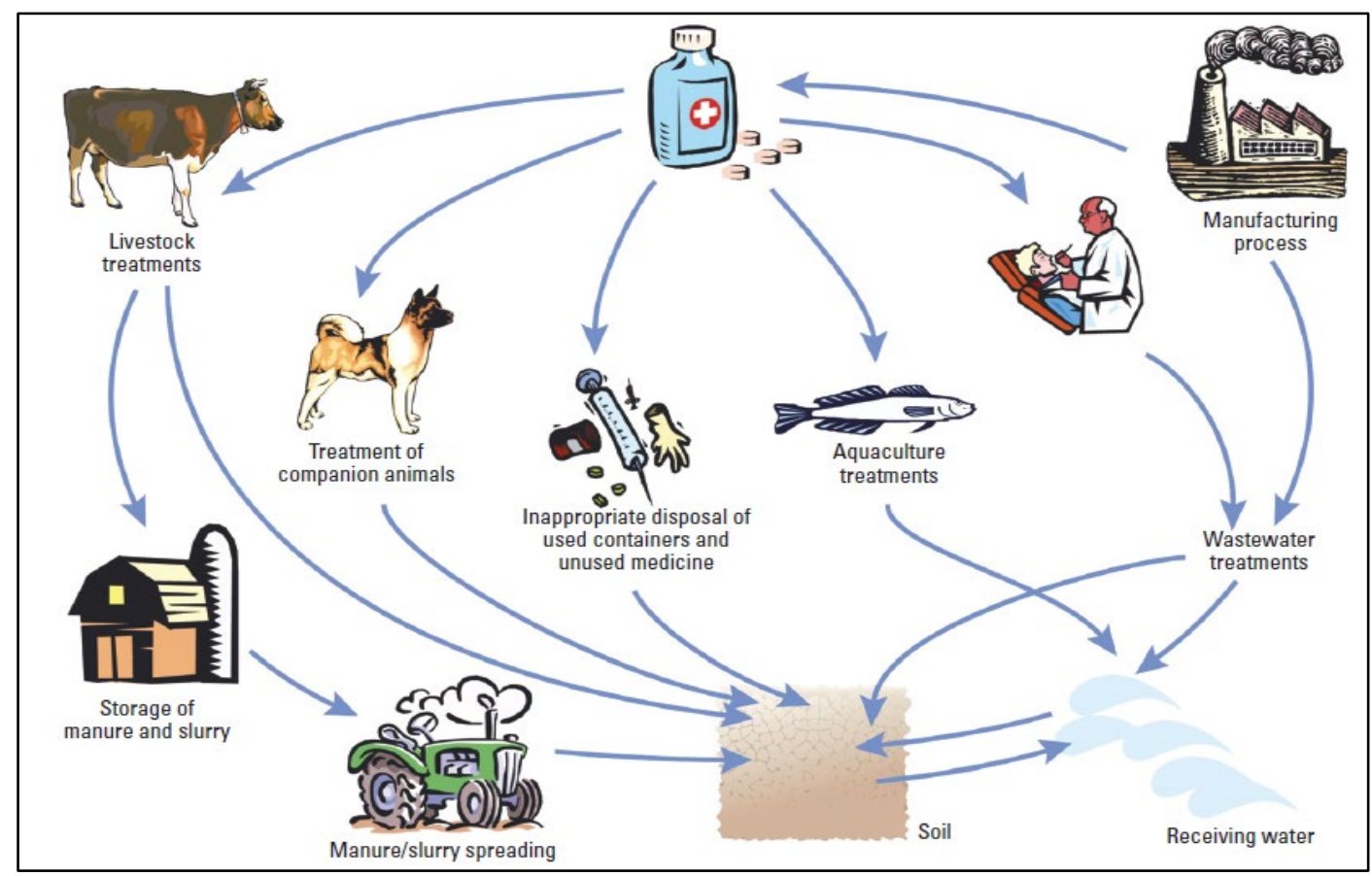

Figure 2.1: Major pathways for pharmaceutical compounds into the environment [8]

The assessment of the potential adverse effects on human health associated with chronic exposure to trace levels of the pharmaceutical compounds in drinking water ranked the number 1 question among the 22 scientific priorities regarding pharmaceutical compounds in the environment as part of a 'big question exercise' hosted by the Society of Environmental Toxicology and Chemistry, involving more than 500 environmental scientists from 57 countries [3]. These compounds are soluble in water due to their low concentration and polar nature; therefore, a large number of the compounds have been detected in the aquatic environment, worldwide [9]. Pharmaceutical compounds consistently produce sublethal effects even at low concentrations but usually do not present clear evidence of lethality even a high concentration. The complexity of the fate of pharmaceutical compounds and their sublethal effects pose important challenges to the present understanding of pollutant mixture effects [3].

There is no statutory maximum concentration limit for pharmaceutically active compounds in drinking water $[1,10]$. Therefore, the removal of these compounds is an emerging concern and poses a unique challenge for analytical detection and assessment of removal performance by available conventional water treatment technologies for several reasons. Firstly, the number of compounds detected is large and it is continuously increasing. Secondly, their physicochemical properties are highly diverse and lastly, they occur in water at concentrations as low as part per trillion [10, 11]. 


\subsection{Treatment Methods for Pharmaceutical Compounds}

Common conventional water treatment technologies employed in the removal of pharmaceutical compounds are similar to those contaminants such as phenolic compounds and dyes. These technologies can be divided into three main categories; biological, chemical and physical.

The biological method includes microbial degradation and bioremediation systems. These methods involve the use of microorganisms that are capable of accumulating and degrading different contaminants. However, the effectiveness of biological treatment is hampered by its large land area requirement, sensitivity towards toxicity of chemicals and less flexibility in design and operation. Also, although many organic molecules are degraded, many others are recalcitrant due to their complex chemical structure and synthetic organic origin [12].

The chemical methods include coagulation, sedimentation, filtration, electroflotation, conventional oxidation methods by ozone, irradiation or electrochemical processes [11, 12]. Chemical coagulation helps in the removal of suspended solids (turbidity) from water and aid in removing dissolved organic carbon (DOC). This procedure employs aluminum or iron based salts, which precipitate as metal hydroxides. Chemical lime softening removes dissolved calcium and magnesium, using lime and soda ash to precipitate calcium carbonate at lower $\mathrm{pH}$ and magnesium at hydroxide at $\mathrm{pH}>11$. Coagulation and softening alone are generally not effective in the removal of trace levels of pharmaceutical compounds [11]. Chemical techniques are often expensive and there is usually an accumulation of concentrated sludge creating disposal problem. There is also a possibility of secondary pollution problem arising due to excessive chemical use [12].

The physical methods widely used include membrane filtration processes (such as nanofiltration, reverse osmosis, electro-dialysis) and adsorption techniques. The major disadvantage of the membrane processes is that they have limited lifetime before membrane fouling occurs and the cost of periodic replacement must be considered and reduces economic viability [12]. However, the adsorption technique has been considered to be superior to other techniques in the removal of the emerging contaminants during drinking water and wastewater treatment. This is due to its simplicity of design and operation, ease of operation, no addition of undesirable by-products (since it is a mass transfer process which involves the accumulation of substances at the interface of two phases), insensitivity to toxic contaminants, applicability at very low concentrations, suitability for both batch and continuous processes, possibility of regeneration and low initial cost $[10,12]$. 
The most widely used adsorbent for the adsorption process is activated carbon. Activated carbon adsorption is a surface phenomenon by which multicomponent fluid mixture is attracted to the surface of the adsorbent and forms attachment via physical or chemical bonds [13, 14]. The activated carbon adsorption involves two types of forces: physical forces that may be dipole moments, polarization forces, dispersive forces, or short range repulsive interactions and chemical forces that are valency forces arising out of the redistribution of electrons between the solid surface and the adsorbed atoms [15]. Depending upon the nature of the forces involved, the adsorption is of two types: physical adsorption and chemisorption. In the case of physical adsorption, the adsorbate is bound to the surface by relatively weak van der Waals forces. Chemisorption, on the other hand, involves exchange or sharing of electrons between the adsorbate molecules and the surface of the adsorbent resulting in a chemical reaction. The bond formed between the adsorbate and the adsorbent is essentially a chemical bond and is thus much stronger than in the physisorption [15].

\subsection{Recent Studies on Adsorption of Pharmaceutical Compounds using Activated Carbon}

Extensive research studies have been conducted on the adsorption of pharmaceutical compounds using activated carbons. The common categories of pharmaceuticals that have been investigated in recent times includes antibiotics, pain killers, muscle relaxants and hormonal drugs [16]. Since the mere disappearance of the parent pharmaceutical compounds cannot be considered as a certain sign of the complete removal of these compounds, but as an indication of the biotransformation of the compounds, intensive research focus had been more on the use of powdered activated carbon on the removal of these compounds [9].

Alvarez-Torrellas et al. [17] studied the adsorption of non-biodegradable pharmaceuticals (carbamazepine and ciprofloxacin) from hospital wastewater using both commercial granular activated carbon and laboratory prepared activated carbons. The kinetic tests revealed that the equilibrium time was established in the first 4 hours for both compounds. So, the adsorption process seemed to be an efficient technology for the removal of these micropollutants from water. Also, the result of the multicomponent adsorption study showed that all the activated carbons achieved a removal efficiency above $60 \%$. The removal efficiency was reported to have decreased in comparison to the one obtained for the single component adsorption study and this decrease was attributed to the competitive effect among the contaminants for the active sites in the activated carbon.

Rakic et al. [9] studied the adsorption of four pharmaceutically active compounds, namely; salicylic acid, acetylsalicylic acid, atenolol and diclofenac-Na using three different commercial 
activated carbons. The study showed that the maximum adsorption capacities of investigated activated carbons for all target pharmaceuticals were in the range of 0.1 and $0.4 \mathrm{mmol} / \mathrm{g}$. The obtained maximum retention capacities were correlated with the textural properties of applied activated carbon. The authors concluded that the results showed the possibility of using the activated carbons for removal of the investigated pharmaceuticals from waters.

Boudrahem et al. [18] conducted a study on the single and multicomponent adsorption of clofibric acid, tetracycline and paracetamol onto activated carbon developed from cotton cloth residue. The activated carbons were chemically prepared using $\mathrm{H}_{3} \mathrm{PO}_{4}$ at different impregnation ratios. The results showed that the activated carbon produced at $50 \% \mathrm{H}_{3} \mathrm{PO}_{4}$ impregnation ratio adsorbed $97.03 \%$ of tetracycline, $84 \%$ of paracetamol and $83 \%$ of clofibric acid. This high adsorption performance was attributed to the high surface area, microporosity development and availability of more active sites in the activated carbon. The adsorption equilibrium was attained after $20 \mathrm{~min}$ at low concentrations and $60 \mathrm{~min}$ at concentrations above $50 \mathrm{mg} / \mathrm{L}$ regardless of the tested molecule. The amount of clofibric acid, tetracycline and paracetamol adsorbed increased with the increase in their initial concentration. The authors also reported a decrease in the adsorption capacities of the activated carbon when used in multicomponent adsorption tests. This reduction was explained to be the effect of competition for the available adsorption sites.

\subsection{Adsorption Mechanism}

Adsorption is the accumulation or concentration of substances at a surface or interface. Adsorption can also be said to be the process in which molecules accumulate in the interfacial layer [19]. For a liquid phase adsorption, the solute transfer or adsorption rate is usually characterized by either external mass transfer (boundary layer diffusion) or intra-particle diffusion or both. Sotelo et al. [20] stated that stirring or agitation in a batch adsorption process favors external diffusion. This allows the equilibrium between the adsorbate and the adsorbent to be reached in a lower operation time and increases the adsorption of the adsorbate onto the adsorbent. Also, for the fixed bed adsorption process, mainly the intra-particle diffusion controls the adsorption process and this implies longer operation time and lower adsorption capacities due to mass transfer resistance inside the smaller pores.

The adsorption mechanism can be explained in three consecutive steps described below [21]; (i) transport of the adsorbate from bulk solution to the exterior surface of the adsorbent (film diffusion);

(ii) transport into the adsorbent by either pore diffusion and/or surface diffusion (intra-particle 
diffusion); (iii) adsorption on the surface of the adsorbent. The overall rate of adsorption is controlled by the slowest step, which would either be film diffusion or pore diffusion controlled [12]

\subsubsection{Adsorption isotherms}

The adsorption isotherm describes how the adsorbed molecules are distributed between the liquid phase and the solid phase when the adsorption process reaches an equilibrium state [18]. Adsorption isotherm is the most extensively employed method for representing the equilibrium states of an adsorption system [22]. It can give useful information regarding the adsorbate, the adsorbent, and the adsorption process. The analysis of the isotherm data is important to develop an equation which accurately represents the results and which could be used for design purposes [15, 23]. The commonly used two- parameter adsorption isotherms include Langmuir, Freundlich, Temkin, and DubininRadushkevich [24] while the widely used three- parameter isotherms include Redlich-Peterson, Sips and Toth $[13,23]$. The isotherms and their respective linear forms are shown in Table 2.1.

Langmuir equation is based on the following assumptions; (i) during an entire adsorption process, only monolayer adsorption occurs; (ii) the adsorbed entities are attached to the surface at definite localized sites with no adsorbate-adsorbate interactions; (iii) The heat of adsorption is independent of surface coverage, that is, the adsorbent has an energetically homogenous surface [15, 22].

The Freundlich isotherm model was originally developed to overcome some of the limitations of Langmuir model, by taking into account the surface heterogeneity and that there might exist intermolecular interactions between the adsorbate molecules [25]. It is of greater significance for chemisorption although some physical adsorption has also been explained using this equation. The constant ' $n$ ' in the Freundlich equation is called the Freundlich constant, which represents the quasiGaussian energetic heterogeneity of the adsorption surface [15].

The Redlich-Peterson isotherm model is a three-parameter empirical model which incorporates both the Langmuir and the Freundlich isotherms. Due to the versatility of the model, it can be used to represent adsorption equilibrium over a wide range of concentration irrespective of whether the active sites are homogenous or heterogeneous in nature [13].

The Sips isotherm model is also a three-parameter model combining Freundlich and Langmuir isotherms equations in explaining a heterogeneous adsorption system and also circumventing the limitation of the rising adsorbate concentration associated with Freundlich isotherm [13]. Sips isotherm 
functions as Freundlich at a low adsorbate concentration and at a high adsorbate concentration, it functions as Langmuir, predicting the monolayer adsorption capacity [13, 26].

Mestre et al. [1] investigated the adsorption of ibuprofen on two activated carbons prepared via chemical activation using $\mathrm{K}_{2} \mathrm{CO}_{3}$ (CAC) and physical activation with steam (CPAC). The linear Langmuir and Freundlich isotherms for the adsorption of ibuprofen onto CAC and CPAC, at different temperatures, were fitted to the experimental data. The choice of the best adsorption isotherm was based on the coefficient of determination $\left(\mathrm{R}^{2}\right)$ of the linear plots. The authors reported that the experimental data fit better with the Langmuir model based on the coefficient of determination of the Langmuir plots $\left(\mathrm{R}^{2} \geq 0.997\right)$. The Langmuir monolayer adsorption capacity $\left(\mathrm{q}_{\mathrm{m}}\right)$ ranged between $139-153 \mathrm{mg} / \mathrm{g}$ and $378-417 \mathrm{mg} / \mathrm{g}$ for CAC and CPAC respectively over a temperature range of 25 to $40^{\circ} \mathrm{C}$. The Langmuir constant $b$, which defines the measure of the adsorption affinity or heterogeneity of the activated carbon surface was reported to be $0.262-0.356 \mathrm{dm}^{3} / \mathrm{mg}$ and $0.104-0.123 \mathrm{dm}^{3} / \mathrm{mg}$ for CAC and CPAC respectively. This showed that the CAC activated carbon had a higher adsorption affinity to ibuprofen as compared to the CPAC activated carbon. The authors further noted that although the Freundlich isotherm did not fit the experimental data as well as the Langmuir model, the Freundlich $1 / n$ values, (which also represents adsorption affinity or surface heterogeneity) showed that the CAC activated carbon had higher adsorption affinity than the CPAC activated carbon. The $1 / n$ values were obtained from the slope of the Freundlich linear plots.

Table 2.1 Isotherms and their linear forms $[13,23,24]$

\begin{tabular}{lll}
\hline Isotherm & Equation & Linear form \\
\hline Langmuir-1 & $q_{e}=\frac{q_{m} K_{a} C_{e}}{1+K_{a} C_{e}}$ & $\frac{C_{e}}{q_{e}}=\frac{1}{q_{m}} C_{e}+\frac{1}{K_{a} q_{m}}$ \\
Langmuir-2 & $\frac{1}{q_{e}}=\left(\frac{1}{K_{a} q_{m}}\right) \frac{1}{C_{e}}+\frac{1}{q_{m}}$ \\
Freundlich & $q_{e}=K_{F} C_{e}^{\frac{1}{n}}$ & $\log \left(q_{e}\right)=\log \left(K_{F}\right)+\frac{1}{n} \log \left(C_{e}\right)$ \\
Temkin & $q_{e}=\frac{R T}{B_{T}} \ln A_{T} C_{e}$ & $q_{e}=\frac{R T}{B_{T}} \ln A_{T}+\left(\frac{R T}{B_{T}}\right) \ln C_{e}$ \\
Dubinin-Radushkevich & $q_{e}=q_{s} \exp \left(-k_{a d} \varepsilon^{2}\right)$ & $\ln q_{e}=\ln q_{S}-k_{a d} \varepsilon^{2}$ \\
Redlich-Peterson & $q_{e}=\frac{A C_{e}}{1+B C_{e}^{g}}$ & $\ln \left(A \frac{C_{e}}{q_{e}}-1\right)=g \ln \left(C_{e}\right)+\ln (B)$ \\
Toth & $q_{e}=\frac{K_{T} C_{e}}{\left(a_{T}+C_{e}\right)^{1 / t}}$ & $\ln \left(\frac{q_{e}}{K_{T}}\right)=\ln C_{e}-\frac{1}{t} \ln \left(a_{T}+C_{e}\right)$ \\
Sips & $q_{e}=\frac{K_{S} C_{e}^{\beta_{S}}}{1+a_{S} C_{e}^{\beta_{S}}}$ & $\beta_{S} \ln C_{e}=-\ln \left(\frac{K_{S}}{q_{e}}\right)+\ln a_{S}$ \\
\hline
\end{tabular}


Llado et al. [27] studied the role of activated carbon properties in atrazine and paracetamol adsorption equilibrium and kinetics. Three activated carbons were employed; two were commercial activated carbons (F-400 and NPK) and the third was a sludge derived activated carbon (SBC). The equilibrium adsorption studies were conducted at a temperature of $25^{\circ} \mathrm{C}$ varying the concentration of the compounds between $1-150 \mathrm{mg} / \mathrm{L}$. The experimental adsorption data were fitted into three isotherm models; Langmuir, Freundlich and Dubinin-Radushkevich (DR). The authors reported that Langmuir isotherm provided the best description of the atrazine and paracetamol adsorption onto F-400 and SBC activated carbon and Freundlich isotherm explains better the adsorption of these compounds onto NPK activated carbon. The DR isotherm gave a lower fitting in comparison to the other models for all the studied cases, which was an indication that the model did not offer a satisfactory description of the experimental behavior. For both atrazine and paracetamol adsorption, F400 activated carbon had the highest the Langmuir monolayer adsorption capacity $\left(q_{m}\right)$ of $212.26 \mathrm{mg} / \mathrm{g}$ and $261.04 \mathrm{mg} / \mathrm{g}$ respectively. Also, the Langmuir constant $b$, was reported to be the highest for F400 activated carbon, which is an indication that the F400 activated carbon has a greater affinity for the two compounds in comparison to the other two activated carbons.

$\mathrm{Yu}$ et al. [28] studied the adsorption characteristics of naproxen, carbamazepine, and nonylphenol on two granular activated carbons. The activated carbons were derived from bituminous coal (F400) and coconut shell (CTIF). Three isotherm models (Langmuir, Freundlich and threeparameter Langmuir-Freundlich (LF)) were used in evaluating the adsorption behaviors of the target compound onto the activated carbons. The selection of the best isotherm model was based on the examination of the minimum sum of squares residuals (SSE) for each isotherm model. The authors reported that the Freundlich isotherm demonstrated the best fit for the target compounds adsorption. The Freundlich sorption constant $K_{F}$ was estimated to range between 2.49 and $73.15(\mathrm{ng} / \mathrm{mg})(\mathrm{L} / \mathrm{ng})^{1 / \mathrm{n}}$ for the adsorption of the three target compounds on the activated carbons. Naproxen and Carbamazepine had the highest Freundlich sorption constants for the two activated carbons while Nonylphenol had the lowest Freundlich sorption constants. The Freundlich constant $1 / n$ values for both Naproxen and Carbamazepine were also reported to be higher than those for Nonylphenol. This value represents the adsorption affinity of the target compounds to the activated carbons.

Rakic et al. [9] conducted an experiment on the adsorption of four pharmaceutically active compounds; salicylic acid, acetylsalicylic acid, atenolol and diclofenac-Na using three commercial activated carbons. The adsorption isotherms employed in this study were Langmuir, Freundlich and 
Sips isotherm models. The authors reported that for the majority of the investigated adsorption systems, the Sips isotherm model gave the best description of the adsorption behavior of the target compounds on to the activated carbons. The Freundlich isotherm model was also found to fit the experimental adsorption data for some of the investigated adsorption systems. The authors explained that both Sips and Freundlich isotherm models are used in interpreting the adsorption on energetically heterogeneous systems. The Sips isotherm is postulated on the assumptions of surface heterogeneity and definite number of active sites, where one molecule of adsorbate interacts with the active site on the adsorbent surface. The Freundlich isotherm is an experimental model which can be applied to non-ideal adsorption on heterogeneous surfaces as well as for multi-layer adsorption. The authors further clarified that since the experimental adsorption data generally fit to either Sips or Freundlich isotherm, it indicates the significant heterogeneity of the active sites on the activated carbons used in the study.

\subsubsection{Adsorption kinetics}

Modeling adsorption kinetics helps in determining the time necessary for reaching equilibrium and to elucidate the mechanism of the adsorption process [25]. Its knowledge is of great importance in designing appropriate adsorption technologies. Several models have been used to fit kinetic data. The kinetic data is gathered by measuring the change in concentration as a function of time for a given initial solute concentration and mass of adsorbent. Some of the models used for adsorption kinetics include pseudo-first-order, pseudo-second-order, Elovich and Intra-particle diffusion. Table 2.2 shows the kinetic models and their respective equations.

Table 2.2 Kinetic models and their equations [29]

\begin{tabular}{|c|c|}
\hline Kinetic Model & Equation \\
\hline Pseudo-first order & $\log \left(q_{e}-q_{t}\right)=\log q_{e}-\frac{k_{1}}{2.303} x t$ \\
\hline Pseudo-second order & $\frac{t}{q_{t}}=\frac{1}{k_{2} q_{e}^{2}}+\frac{1}{q_{e}} t$ \\
\hline Intra-particle diffusion & $q_{t}=k_{p} t^{1 / 2}+C$ \\
\hline Elovich & $q_{t}=\frac{1}{\beta} \ln (\alpha \beta)+\frac{1}{\beta} \ln t$ \\
\hline \multicolumn{2}{|c|}{$\begin{array}{l}\text { equilibrium adsorption capacity }(\mathrm{mg} / \mathrm{g}) ; q_{t} \text { - amounts of the sorbate adsorbed }(\mathrm{mg} / \mathrm{g}) \text { at time } t \\
\left.\mathrm{~min}^{-1}\right) \text { is the pseudo-first order rate constant; } k_{2}(\mathrm{~g} / \mathrm{mg}) \text { is the pseudo-second-rate constant } \\
\mathrm{s} \text { the intercept; } k_{p}\left(\mathrm{mg} / \mathrm{g} \mathrm{m^{1/2 }}\right) \text { is the intra-particle diffusion rate constant. } \\
\mathrm{mg} / \mathrm{g} \text { min) is the initial sorption rate; } \beta(\mathrm{g} / \mathrm{mg}) \text { is related to the extent of surface coverage and activation energy } \\
\text { chemisorption. The value of }(1 / \beta) \text { is indicative of the available number of sites for adsorption while }(1 / \beta) \ln (\alpha \\
\mathrm{s} \text { the adsorption quantity when } \ln t=0 \text {. }\end{array}$} \\
\hline
\end{tabular}


Mestre et al. [1] studied the adsorption of ibuprofen using two activated carbons (CAC and CPAC). The pseudo- first order and pseudo- second order kinetic models were employed to fit the adsorption kinetics data. The initial concentration of the ibuprofen solution was varied between 20 and $60 \mathrm{mg} / \mathrm{dm}^{3}$ in order to test the effect of initial concentration on the equilibrium adsorption capacity $\left(q_{e}\right)$ of the activated carbons. The results of the study showed that the adsorption of ibuprofen by the tested activated carbons obeyed the pseudo-second order kinetic model $\left(\mathrm{R}^{2} \geq 0.997\right)$. It was found that as the initial solution concentration increased from 20 to $60 \mathrm{mg} / \mathrm{dm}^{3}$, the equilibrium adsorption capacity $\left(q_{e}\right)$ increased from 29.4 to $85.5 \mathrm{mg} / \mathrm{g}$ for CAC and from 30.1 to $89.3 \mathrm{mg} / \mathrm{g}$ for CPAC. This showed that the initial concentration provided a powerful driving force to overcome the mass transfer resistance between the solution and the solid phases. The pseudo-second order rate constant $\left(k_{2}\right)$ values reported for CAC $(0.14-0.96 \mathrm{~g} / \mathrm{mg} / \mathrm{h})$ and CPAC $(0.31-1.10 \mathrm{~g} / \mathrm{mg} / \mathrm{h})$ decreased with an increase in the initial concentration of the ibuprofen solution. However, for the same initial concentration, the $k_{2}$ value obtained for CPAC was higher than the CAC, which is an indication that a higher quantity of CPAC will be needed to adsorb a given amount of ibuprofen in comparison to CAC.

Llado et al. [27] performed a series of kinetic studies to compare the rates of adsorption of atrazine and paracetamol on three activated carbons (F-400, NPK and SBC). The experimental kinetic data were fitted with three kinetic models; pseudo-second order, intra-particle diffusion and diffusionadsorption model. The authors reported that pseudo-second and diffusion-adsorption models had the best fittings for the experimental adsorption kinetics data. The SBC activated carbon had an adsorption capacity of $43.70 \mathrm{mg} / \mathrm{g}$ and $46.20 \mathrm{mg} / \mathrm{g}$ for both atrazine and paracetamol respectively. These values were lower in comparison to the other two tested activated carbons. However, the authors reported that the SBC activated carbon had the highest $k_{2}$ values of $3.94 \times 10^{-4}$ and $3.7010^{-4}$ for both atrazine and paracetamol respectively, which is an indication of its adsorption rate. The authors noted that with its similar adsorption rate for both compounds, the SBC activated carbon could be an interesting economic alternative due to the lower time required for it to attain equilibrium adsorption. The results of the intraparticle model were used in explaining the stages of the adsorption of the tested compounds on the activated carbons. Three adsorption stages were identified for the adsorption of atrazine on F-400 and NPK, whereas only two were observed for SBC activated carbon. Similarly, SBC was identified to have three adsorption stages for the adsorption of paracetamol while the other two carbons had four adsorption stages. The higher number of adsorption stages identified in NPK activated carbon was explained to be an illustration of the different behavior of the adsorption process through mesopores 
and micropores of the activated carbon. Generally, three adsorption stages are identified for activated carbon adsorption which includes; the external mass transfer which is the first stage, followed by the intraparticle diffusion as the second stage and finally the equilibrium stage.

Calisto et al. [30] investigated the adsorption of three psychiatric pharmaceuticals (carbamazepine, paroxetine, and oxazepam) using a commercial activated carbon and a paper mill sludge-derived activated carbon. The pseudo-first and pseudo-second kinetic models were used in fitting the experimental adsorption data. The authors reported a correlation coefficient above 0.97 for both kinetic models, in which they inferred that both models satisfactorily fitted the experimental data. However, the pseudo-second order kinetic model presented the highest correlation coefficients for most of the adsorption test, hence the explanation of the adsorption kinetic behavior of the activated carbons was based on this model. The authors reported that for the three tested compounds, the equilibrium was quickly attained with maximum equilibrium times of 15 and $120 \mathrm{~min}$ for the waste-based and the commercial carbons, respectively. The adsorption capacity $\left(q_{e}\right)$ values of the commercial activated carbon for three tested compounds ranged between 203 to $558 \mu \mathrm{mol} / \mathrm{g}$ while the paper mill sludge derived activated carbon had adsorption capacity values of $60.6-72.8 \mu \mathrm{mol} / \mathrm{g}$ for the three tested compounds. The pseudo-second order rate constant $\left(k_{2}\right)$ for the commercial activated carbon $(2.6$ - 7.0 $\mathrm{x} 10^{-4} \mathrm{~g} / \mu \mathrm{mol} / \mathrm{min}$ ) were found to be lower than the ones obtained for sludge derived activated carbon $(0.016-0.037 \mathrm{~g} / \mu \mathrm{mol} / \mathrm{min})$

\subsection{Activated Carbon as an Adsorbent}

Activated carbon as defined by International Union of Pure and Applied Chemistry (IUPAC), is a "porous carbon material which has been subjected to reaction with gases, sometimes with the addition of chemicals before, during or after carbonization in order to increase its adsorptive properties" [31]. Activated carbon can be produced from nearly all carbon-rich and inexpensive precursors with low inorganic content. Activated carbons can be divided into two classes: (1) Gaseous phase adsorbing carbons, which are used for purification applications in the vapor or gas phase such as solvent recovery, gas separation or cigarette filter tips; (2) Liquid-phase adsorbing carbons, which are used to decolorize or purify liquids, solutions and liquefiable materials such as waxes [32].

The main difference between these two classes of activated carbon is based on their pore size distribution. The gaseous phase adsorbing carbons usually have the most pore volume in the micropore and macropore ranges, with little mesoporous volume. The liquid phase adsorbing carbons have 
significant mesoporous volume permitting easy access of target adsorbates to the micropore structure resulting in rapid attainment of adsorption equilibrium for smaller adsorbates [32].

Activated carbons are available in different physical forms including granular activated carbon (GAC), powdered activated carbon (PAC), and activated carbon fiber (ACF) [33]. Some adsorption problems are best handled by passing the liquid through a bed of granular carbon. Others are handled most effectively and economically by stirring the powdered activated carbon with the liquid to be treated and then removing the activated carbon by filtration or settling.

Powdered activated carbons (PAC) are made in particulate form such as powders or fine granules of size less than $100 \mu \mathrm{m}$ and average diameter between 15 and $25 \mu \mathrm{m}$. Therefore, they present a large external surface to volume ratio. Powdered activated carbons have a high rate of adsorption and are generally preferred for use in liquid phase adsorption. PAC offers the advantage of providing fresh activated carbon continuously since it is supplied as a new product and not recycled through treatment process. Also, since PAC is added to the water treatment plant as a feed chemical, it can be used seasonally when the risk of PPCPs presence in the effluent water is high [10]

Granular activated carbon (GAC) can be prepared from hard materials such coconut shells and normally includes particles retained on 80 -mesh sieve $(0.177 \mathrm{~mm})$. Consequently, it presents a smaller external surface. It is commonly used as column filler; suitable for adsorption of gases and vapors, because they diffuse rapidly [32,33]. The United States Environmental Protection Agency identifies packed-bed granular activated carbon as "Best Available Technology" for treating numerous regulated organic pollutants [11]. GAC can be used as a replacement for anthracite media in conventional filters, thus providing both adsorption and filtration [34]. Granular activated carbons are also used in packed bed filters and they are found to be highly effective adsorbent. However, more hydrophilic contaminants can break through the GAC filter much more rapidly than strongly bound hydrophobic contaminants [10,34]. Also, after a series of adsorption process, the active sites in the GAC are fully occupied, which will require replacement of the GAC or regeneration via thermal or biological regeneration process. Generally, the spent GAC is regenerated ex situ by heating or steaming and after several regenerations, the GAC is managed as a waste and is incinerated [10, 35].

Activated carbon fiber can be prepared from homogenous polymeric raw materials and compared to both PAC and GAC, it shows a monodispersed pore size distribution. Its thin fiber shape enhances intra-particle adsorption and therefore improved contact efficiencies between the aqueous media and the adsorbent can be achieved [33]. 


\subsection{Activated Carbon Production: Carbonization and Activation}

Activated carbons generally have some impurities and the quantity of non-carbon materials is dependent on the parent material and activation process. Carbon is the major element present in activated carbons and the principal impurities of an activated carbon are oxygen, hydrogen, nitrogen and ash. The ash is composed mainly of alkali and alkaline earth metals $[15,36]$. The production of activated carbon involves two main steps; carbonization and activation.

The carbonization process involves the thermal decomposition of the raw materials at a temperature below $800^{\circ} \mathrm{C}$ in an inert atmosphere. The thermal decomposition leads to release of volatile organic compounds in gaseous form and creation of pores in the resulting chars. As a result of deposition or decomposition of tar substances, pores become filled, or at least partially blocked, by the disorganized carbon. Such materials have low adsorption capacity [15, 37]. Francesca et al. [38] attributed the low surface area of olive pomace biochar to particle conglomeration and blocking of pores by decomposition and deposition of tars during pyrolysis process.

The pore structure of the carbonized material can be further enhanced during the activation stage when the spaces between the aromatic sheets are cleared of various carbonaceous compounds and disorganized carbon. The activation process converts the carbonized char into a form that contains the largest possible number of randomly distributed pores and extremely high surface area [15]. It also serves to open up the connections of the pores to the surface. The objective during the activation is both to increase the number of pores and to increase the size of the existing pores, so that the resulting activated carbon has a high adsorption capacity [39]. The activation process can be classified into two, based on the procedure and types of activating agent used; physical and chemical activation.

\subsubsection{Physical activation}

Physical activation involves carbonization of the precursor in an inert atmosphere followed by partial gasification of the resulting char with steam, $\mathrm{CO}_{2}$ or a mixture of both at temperatures in the range $800-1000{ }^{\circ} \mathrm{C}$ to form a complex array of micropores and mesopores [40, 41]. It is a complex heterogeneous process encompassing the transport of the activating gas to the char's surface, the diffusion of the activating gas into the pores of the char, sorption on the pore surface, reaction with carbon component, desorption of the reaction products and diffusion of these products to the atmosphere [42].

Carbon dioxide $\left(\mathrm{CO}_{2}\right)$ is commonly used as the activating gas because it is clean, easy to handle and it facilitates control of activation process due to the slow reaction rate at temperatures around 800 
${ }^{\circ} \mathrm{C}$ [43]. As an activating agent, the molecular size of $\mathrm{CO}_{2}$ is smaller than that of steam. This is an indication that the $\mathrm{CO}_{2}$ molecules can penetrate deeply into the microstructures of the precursor, resulting in homogenous oxidation and widening effects of the micropores [44]. Also, physical activation using $\mathrm{CO}_{2}$ results in homogenous porosity development in comparison to physical activation with steam [45]. However, further gasification of the carbonized precursor during activation with $\mathrm{CO}_{2}$ results in decrease of the micropore volume [46].

For steam activation, there is a continuous increase with burn-off, which indicates enlargement of micropores and the size shift towards mesopores. Also, the inhomogeneous gasification that occurs during physical activation with steam results in lower activated carbon yield and limited porosity [45]. The development of microporosity of activated carbon, however, is relatively similar for physical activation with steam and $\mathrm{CO}_{2}[46]$.

\subsubsection{Chemical activation}

In chemical activation process, the precursor is impregnated with a chemical activating agent prior to activation. The precursor can be impregnated with the chemical agent without first being carbonized into intermediate biochar. The activating agent can either be acidic or alkaline in nature. The most widely used activating agents include potassium hydroxide $(\mathrm{KOH})$, phosphoric acid $\left(\mathrm{H}_{3} \mathrm{PO}_{4}\right)$, and zinc chloride $\left(\mathrm{ZnCl}_{2}\right)$ [47]. These activating agents are dehydrating agents, influencing the pyrolytic decomposition of the precursor and inhibit tar formation [46].

The impregnated precursor is activated under an inert atmosphere at a lower temperature and shorter time than those required for physical activation [48]. The chemical activation mechanism involves the dehydration of the cellulosic components of the precursor during activation resulting in aromatization of the carbon skeleton and creation of the porous structure [46]. The activating agents incorporated into the interior of the precursor particles also reduces the evolution of volatiles and inhibits the shrinkage of the particles leading to high activated carbon yield [42]. This yield exceeds that of the physical activation by up to $30 \%$ mass [46]. Upon completion of the activation process, the resulting activated carbon is washed with acid/base solution and deionized water to remove the activating agent and its salts, which makes the pore structure available [47]. Table 2.3 shows the properties of activated carbons produced via different chemical activation conditions. 


\subsection{Properties of Activated Carbon}

\subsubsection{Textural properties}

Textural characterization of activated carbon involves the determination of $\mathrm{N}_{2}$ and $\mathrm{CO}_{2}$ adsorption isotherms and the use of mathematical models to quantify the pore size distribution (PSD), pore volume and surface area [49]. The pore size distribution of the activated carbon determines the fraction of the carbon structure that a molecule of a given size and shape can access, i.e., it determines the pore volume accessible to a molecule of a given size. The PSD and the pore volume are important properties considered in the manufacture of activated carbon for specific applications [50]. Pelekani and Snoeyinki [51] stated that a good understanding of the impact of pore size distribution on competitive adsorption is required as a basis for selecting the best activated carbon and applying it in an optimal way. Pore size distribution given by the IUPAC $[31,33,52]$ is based on the width of the pores, which represents the distance between the walls of a slit shaped pore or the radius of a cylindrical pore. The pores are divided into three groups; micropore, mesopore and macropore (Table 2.4 and Figure 2.2).

Activated carbon with high macropore volume permits adsorbate to diffuse more quickly into the mesopores and micropores. Therefore, such an activated carbon is primarily employed for liquid phase application. The mesopores, also regarded as the transitional pores, are those in which capillary condensation with the formation of a meniscus of the liquefied adsorbate can take place. The micropores generally constitute about $90 \%$ of the total surface area of the activated carbon $[53,54]$. The micropore volume can be further divided into two categories namely; ultramicropore volume (width less than $0.7 \mathrm{~nm}$ ) and supermicropore volume (width between 0.7 and $2 \mathrm{~nm}$ ) [49]. The physical adsorption mechanism in micropores is mainly by pore filling because the overlapping of pore wall potentials resulting in stronger binding of the adsorbate, or enhanced adsorption [50].

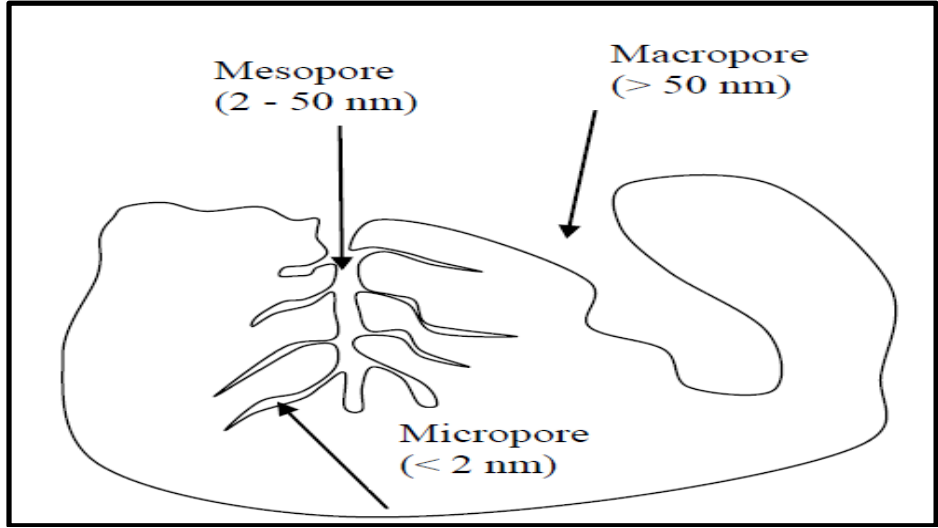

Figure 2.2: Schematic diagram of pore structure of activated carbon [55] 
Table 2.3: Influence of process parameters on activated carbon properties produced via chemical activation

\begin{tabular}{|c|c|c|c|c|c|c|c|c|c|c|}
\hline $\mathrm{s} / \mathrm{n}$ & Precursor & $\begin{array}{c}\text { Activating } \\
\text { agent }\end{array}$ & $\begin{array}{l}\text { Impregna } \\
\text {-tion ratio }\end{array}$ & $\begin{array}{l}\text { Activation } \\
\text { Temp }\left({ }^{\circ} \mathrm{C}\right)\end{array}$ & $\begin{array}{c}\text { Activation } \\
\text { Time } \\
\text { (Hour) }\end{array}$ & $\begin{array}{c}\mathrm{V} \\
\text { Mesopore } \\
\left(\mathrm{cm}^{3} / \mathrm{g}\right)\end{array}$ & $\begin{array}{c}\mathrm{V} \\
\text { Micropore } \\
\left(\mathrm{cm}^{3} / \mathrm{g}\right)\end{array}$ & $\begin{array}{l}\mathrm{V}_{\text {Total }} \\
\left(\mathrm{cm}^{2} / \mathrm{g}\right)\end{array}$ & $\begin{array}{c}\text { BET } \\
\text { Surface } \\
\text { Area } \\
\left(\mathrm{m}^{2} / \mathrm{g}\right) \\
\end{array}$ & Ref. \\
\hline 1 & Birch Biomass & $\mathrm{H}_{3} \mathrm{PO}_{4}$ & 1.5 & 600 & 1 & 0.321 & 0.297 & 0.618 & 761 & {$[56]$} \\
\hline 2 & $\begin{array}{l}\text { Macadamia } \\
\text { Nut Endocarp } \\
\text { Biochar }\end{array}$ & $\mathrm{ZnCl}_{2}$ & $3: 1$ & $\begin{array}{l}\text { Microwave } \\
\text { Power of } \\
720 \mathrm{~W}\end{array}$ & 0.33 & 0.023 & 0.277 & 0.3 & 598 & {$[57]$} \\
\hline \multirow{2}{*}{3} & \multirow{2}{*}{$\begin{array}{c}\text { Macadamia } \\
\text { Nutshell }\end{array}$} & $\mathrm{KOH}$ & & 500 & 1 & & 0.529 & & 1169 & \multirow{2}{*}[58]{} \\
\hline & & $\mathrm{ZnCl}_{2}$ & $1: 1$ & 800 & 1 & & 0.723 & & 1718 & \\
\hline \multirow{2}{*}{4} & \multirow{2}{*}{ Cocoa shells } & $\mathrm{ZnCl}_{2}$ & $1: 2$ & 500 & 0.67 & & & 0.37 & 642 & \multirow{4}{*}[59]{} \\
\hline & & $\mathrm{H}_{3} \mathrm{PO}_{4}$ & $1: 1$ & 500 & 0.67 & & & 0.68 & 1077 & \\
\hline \multirow{2}{*}{5} & \multirow{2}{*}{ Siriguela seed } & $\mathrm{ZnCl}_{2}$ & $1: 2$ & 500 & 0.67 & & & 0.48 & 956 & \\
\hline & & $\mathrm{H}_{3} \mathrm{PO}_{4}$ & $1: 1$ & 500 & 0.67 & & & 0.95 & 1549 & \\
\hline 6 & $\begin{array}{c}\text { Safflower Seed } \\
\text { Press Cake } \\
\text { Biochar }\end{array}$ & $\mathrm{ZnCl}_{2}$ & $4: 1$ & 900 & 1 & 0.109 & 0.284 & 0.393 & 801.5 & [48] \\
\hline 7 & $\begin{array}{c}\text { Loblolly Pine } \\
\text { Biochar }\end{array}$ & $\mathrm{NaOH}$ & $40 \mathrm{ml}: 3 \mathrm{~g}$ & 800 & 2 & 0.783 & 0.289 & & 1250 & {$[60]$} \\
\hline 8 & Spruce Biochar & $\mathrm{KOH}$ & $1.23: 1$ & 680 & & & 0.35 & 0.41 & 837 & [47] \\
\hline 9 & $\begin{array}{l}\text { Euphorbia } \\
\quad \text { rigida }\end{array}$ & $\mathrm{H}_{2} \mathrm{SO}_{4}$ & & 850 & 0.5 & & 0.273 & 0.301 & 741.2 & [29] \\
\hline 10 & $\begin{array}{l}\text { Orange Peel } \\
\text { Biochar }\end{array}$ & $\mathrm{K}_{2} \mathrm{CO}_{3}$ & & $\begin{array}{c}\text { Microwave } \\
\text { Power of } \\
600 \mathrm{~W} \\
\end{array}$ & 0.1 & 0.368 & 0.247 & 0.615 & 1104.45 & {$[61]$} \\
\hline 11 & Cassava Peel & $\mathrm{KOH}$ & $5: 2$ & 750 & 1 & & 0.513 & 0.691 & 1605 & {$[62]$} \\
\hline \multirow{2}{*}{12} & \multirow{2}{*}{ Date stones } & $\mathrm{FeCl}_{3}$ & $1.5: 1$ & 700 & 1.25 & 0.105 & 0.468 & & 780.06 & \multirow{2}{*}{63} \\
\hline & & $\mathrm{ZnCl}_{2}$ & $2: 1$ & 500 & 1.25 & 0.129 & 0.512 & & 1045.61 & \\
\hline 13 & $\begin{array}{c}\text { Cork powder } \\
\text { waste }\end{array}$ & $\mathrm{K}_{2} \mathrm{CO}_{3}$ & $1: 1$ & 700 & 1 & 0.03 & 0.39 & 0.42 & 891 & [1] \\
\hline \multirow[b]{2}{*}{14} & \multirow{2}{*}{$\begin{array}{l}\text { Sucrose } \\
\text { Hydrochar }\end{array}$} & $\mathrm{KOH}$ & $4: 1$ & 800 & 1 & 0.06 & 1.08 & 1.14 & 2431 & \multirow[b]{2}{*}[64]{} \\
\hline & & $\mathrm{K}_{2} \mathrm{CO}_{3}$ & $4: 1$ & 800 & 1 & 0.01 & 0.62 & 0.63 & 1375 & \\
\hline 15 & $\begin{array}{c}\text { Coconut shell } \\
\text { biochar }\end{array}$ & $\mathrm{NaOH}$ & $3: 1$ & 700 & 1.5 & 0.355 & 1.143 & 1.498 & 2825 & [65] \\
\hline 16 & $\begin{array}{l}\text { Chinese fir } \\
\text { hydrochar }\end{array}$ & $\mathrm{ZnCl}_{2}$ & $6: 1$ & 700 & 1 & 0.566 & 0.376 & 0.953 & 1423 & [66] \\
\hline
\end{tabular}

Table 2.4: IUPAC classification of pore sizes

\begin{tabular}{|l|l|}
\hline Macropore & Pores with width exceeding $50 \mathrm{~nm}$ or $0.05 \mu \mathrm{m}(500 \AA)$ \\
\hline Mesopore & Pores with width between $2 \mathrm{~nm}(20 \AA)$ and $50 \mathrm{~nm}(500 \AA)$ \\
\hline Micropore & Pores with width not exceeding $2 \mathrm{~nm}(20 \AA)$ \\
\hline
\end{tabular}


For liquid phase adsorption applications, the assessment of the micropore size distribution (MPSD) of the activated carbon allows for a deeper understanding of the diffusion and adsorption mechanism particularly when the adsorption of molecules of small dimensions is envisaged [49]. The micropore size distribution is obtained from $\mathrm{CO}_{2}$ adsorption isotherm data instead of the $\mathrm{N}_{2}$ adsorption isotherm data due to the diffusion limitations of $\mathrm{N}_{2}$ in carbons with narrow micropores [49, 67]. The MPSD clearly quantifies the amount of micropores with different pore widths. For example, Figure 2.1 shows the MPSD of three activated carbons reported by Pinto et al. [68]. It is evident from the figure that carbon A (between 0.5 to $1.4 \mathrm{~nm}$ ) and B have a monomodal distributions (between 0.5 to $0.8 \mathrm{~nm}$ ), centered at $0.72 \mathrm{~nm}$ and $0.62 \mathrm{~nm}$ respectively. This indicates that a higher portion of the micropore volume for both activated carbons are ultramicropores and will give a good adsorption result for target molecules having a molecular size within that width range. Carbon $\mathrm{C}$ presents a bimodal distribution with micropore width between 0.4 and $0.9 \mathrm{~nm}$, and micropore width above $1.2 \mathrm{~nm}$ [49]. According to Mestre et al. [64], the broadening of the micropore size distribution, changing from a monomodal to bimodal distribution is because of the activation temperature in regardless of the chemical activating agents used.

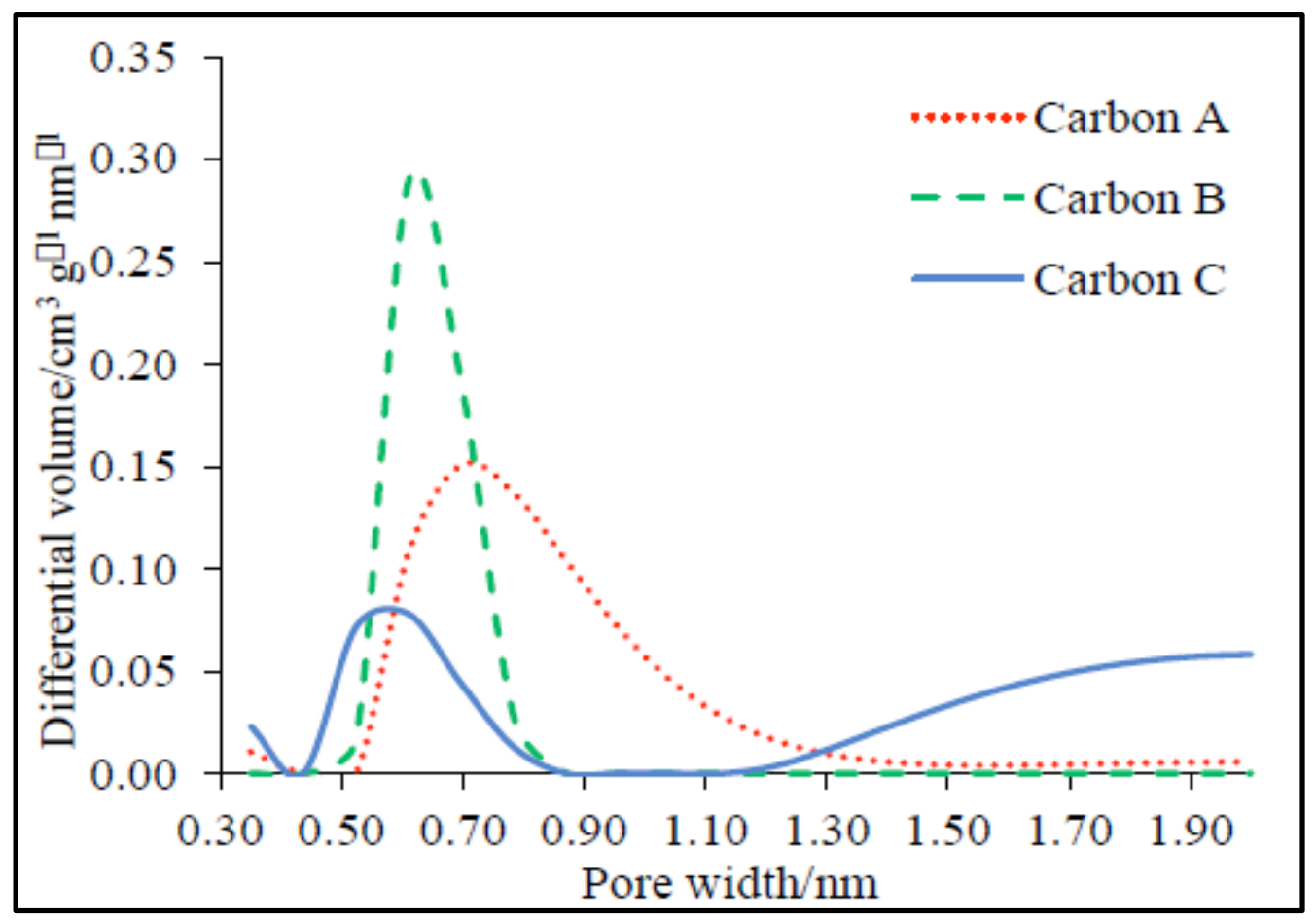

Figure 2.3: Micropore size distributions of activated carbons [49, 68] 
The micropore size distribution plays an important role in obtaining deeper insight into the physical adsorption mechanism of pharmaceutically active compounds by activated carbons. For example, the three activated carbons in Figure $2.3 \mathrm{had}$ micropore volumes between 0.27 and $0.32 \mathrm{~cm}^{3} / \mathrm{g}$ and were used in adsorbing ibruprofen with a dimension of $0.72 \mathrm{~nm}$. The authors reported that the uptake trend of the target molecule was dependent on the MPSD of the activated carbons mainly occurring in pores with widths between 0.72 and $1.40 \mathrm{~nm}$. This implies that the activated carbons having a higher percentage of micropores between these widths presented a higher value of Langmuir constant $\left(\mathrm{K}_{\mathrm{L}}\right)$, a measure of the adsorption affinity [69]. Mestre et al. [64] also reported that the high removal efficiencies of iopamidol molecules by a sucrose-derived activated carbons were due to their micropore size distributions. The large amount of wider micropores allowed the adsorption of the iopamidol species.

Surface area is a very important parameter because the sorption and ion exchange characteristics of the activated carbon are directly related to its surface area [70]. Based on the size and accessibility of pores, the exposed surface area is measured in two distinct forms; internal and external surface area. The external surface area considers all the prominences, wider cracks and pores (mesopores and macropores), while the internal surface area only takes the walls of cracks and cavities which are deeper and less accessible (micropores) [15]. Since the mesopores and macropores contribute very little to the total porous structure of the activated carbon, especially in terms of the adsorption capacity (they act as means of access for the adsorbate to the micropores), therefore the internal surface area is prominently reported.

\subsubsection{Polarity}

Adsorbent polarity is expressed as the sum of oxygen and nitrogen $(\mathrm{O}+\mathrm{N})$ contents because oxygen- and nitrogen-containing surface functional groups can serve as hydrogen-bond donor and/or acceptor sites that facilitate water adsorption [71]. It is expressed in $\mathrm{mmol} / \mathrm{g}$. The polarity of activated carbon is categorized into two; hydrophobicity and hydrophilicity. Hydrophobic activated carbon is characterized by low oxygen and nitrogen contents. This activated carbon is not effectively wetted by water. Mestre et al. [72] stated that activated carbon surface is constituted of graphitic layers that are highly hydrophobic; however, the edges of the basal planes generally contain higher amounts of heteroatoms that favor electrostatic interactions. The amount of the heteroatoms defines the hydrophilicity of activated carbon surface. 
Hydrophilic activated carbon preferentially adsorbed water molecules at the entrance of the pores, hence competing with target molecules for the adsorption active sites. Mestre et al. [72] reported that water adsorption can lead to pore blocking due to formation of water clusters thereby limiting the adsorption of caffeine.

According to $\mathrm{Li}$ et al. [71], to ensure that activated carbons are sufficiently hydrophobic to effectively remove organic contaminants from aqueous solution, the $\mathrm{O}+\mathrm{N}$ content of the adsorbent should be less than $2-3 \mathrm{mmol} / \mathrm{g}$. Therefore, polarity can serve as a useful activated carbon selection criterion. Quinlivan et al. [73] stated that hydrophobic adsorbents are more effective for the removal of relatively hydrophobic and hydrophilic pollutants from natural water.

\subsubsection{Surface chemistry}

At the edges of the condensed, polyaromatic sheets that constitute the building blocks of activated carbons, heteroatoms (i.e., atoms other than carbon) are incorporated. These heteroatoms can also be incorporated within the carbon layers forming heterocyclic ring systems. Because these edges constitute the main adsorbing surface, the presence of these heteroatoms greatly dictates the surface characteristics of the activated carbon $[15,71]$.

The heteroatoms found in the activated carbon surfaces include primarily oxygen and hydrogen with minute amounts of sulfur, nitrogen and halogens. These heteroatoms are derived from the parent raw materials and become an integral part of the chemical structure because of carbonization and activation processes [15]. Common surface functional groups formed by the heteroatoms with the carbon layers or edges include carbon-oxygen, carbon-hydrogen, carbon-nitrogen, carbon-sulfur and carbon-halogen surface compounds. The carbon-oxygen surface groups are the most important and very common surface functional groups in activated carbon and they may be easily introduced by various post-activation treatment methods [74, 75]. Some examples of the oxygen surface functionalities include the following; carboxylic, lactone, phenol, carbonyl, pyrone, chromene, quinone and ether groups [76]. The oxygen surface functional groups can be categorized into three groups namely; acidic, basic and neutral. Figure 2.4 shows the acidic and basic surface functional groups on an activated carbon basal plane.

The acidic surface oxygen groups are formed when activated carbon is subjected to oxidation by gases and/or aqueous oxidants. During low temperature oxidation, gaseous oxidants such as oxygen, air, carbon dioxide and steam are used to produce strong acidic groups (e.g carboxylic) while high temperature oxidations leads to creation of weak acidic groups (e.g phenolic). The liquid phase 
oxidations introduce the oxygen functionalities into the carbon surface at lower temperatures compared to the gaseous oxidation [76]. Common liquid oxidants used includes nitric acid, nitric acid and sulfuric acid mixtures in aqueous solution, hydrogen peroxide, potassium permanganate, ammonium persulphate and other nitrogen containing substances [15, 71, 77].

Shafeeyan et al [76] reported that there are demonstrated differences between the gaseous and liquid phase oxidation of activated carbon. The gaseous phase oxidation increases mainly the concentration of hydroxyl and carbonyl surface groups while the liquid phase oxidation results in incorporation of higher amounts of carboxylic and phenolic hydroxyl groups onto the carbon surface. Also, the liquid phase oxidation is carried out at a lower temperature as compared to the gaseous phase oxidation. Bansal and Goyal [15] stated that the acidic surface oxygen groups are thermally less stable and decompose on heat treatment at a temperature range of 350 to $750{ }^{\circ} \mathrm{C}$ evolving $\mathrm{CO}_{2}$. The acidic surface oxygen groups make the activated carbon surface hydrophilic and polar in character.

The basic surface oxygen groups are obtained by removal of oxygen groups in the activated carbon surface by heat treatment in vacuum or in inert atmosphere $[15,71]$. The basic nature of activated carbons arises primarily from delocalized $\pi$-electrons of graphene layers. These $\pi$-electrons could act as Lewis bases. It is also noteworthy that certain oxygen functional groups contribute to the basicity of the activated carbon surface and this includes chromene, ketone and pyrone [76]. The basic surface oxygen group makes the surface of the activated carbon hydrophobic and less polar in nature. This is a desirable trait when the adsorption of organic contaminants from aqueous solution is the primary objective. The heat treatment of activated carbon in inert atmosphere in order to remove the surface oxygen groups results in the activated carbon having highly reactive sites such as free-radical edge sites. As a result, when the activated carbon is re-exposed to the atmosphere, it will chemisorb oxygen from the atmosphere and consequently leading to loss of basic and hydrophobic properties [71].

The neutral surface oxygen groups are formed by the irreversible chemisorption of oxygen at the ethylene type unsaturated sites present on the carbon surface. The neutral surface groups are more stable than the acidic surface groups and has the tendency to decompose upon heat treatment within a temperature range of 500 to $600{ }^{\circ} \mathrm{C}$, releasing $\mathrm{CO}_{2}[15]$ 


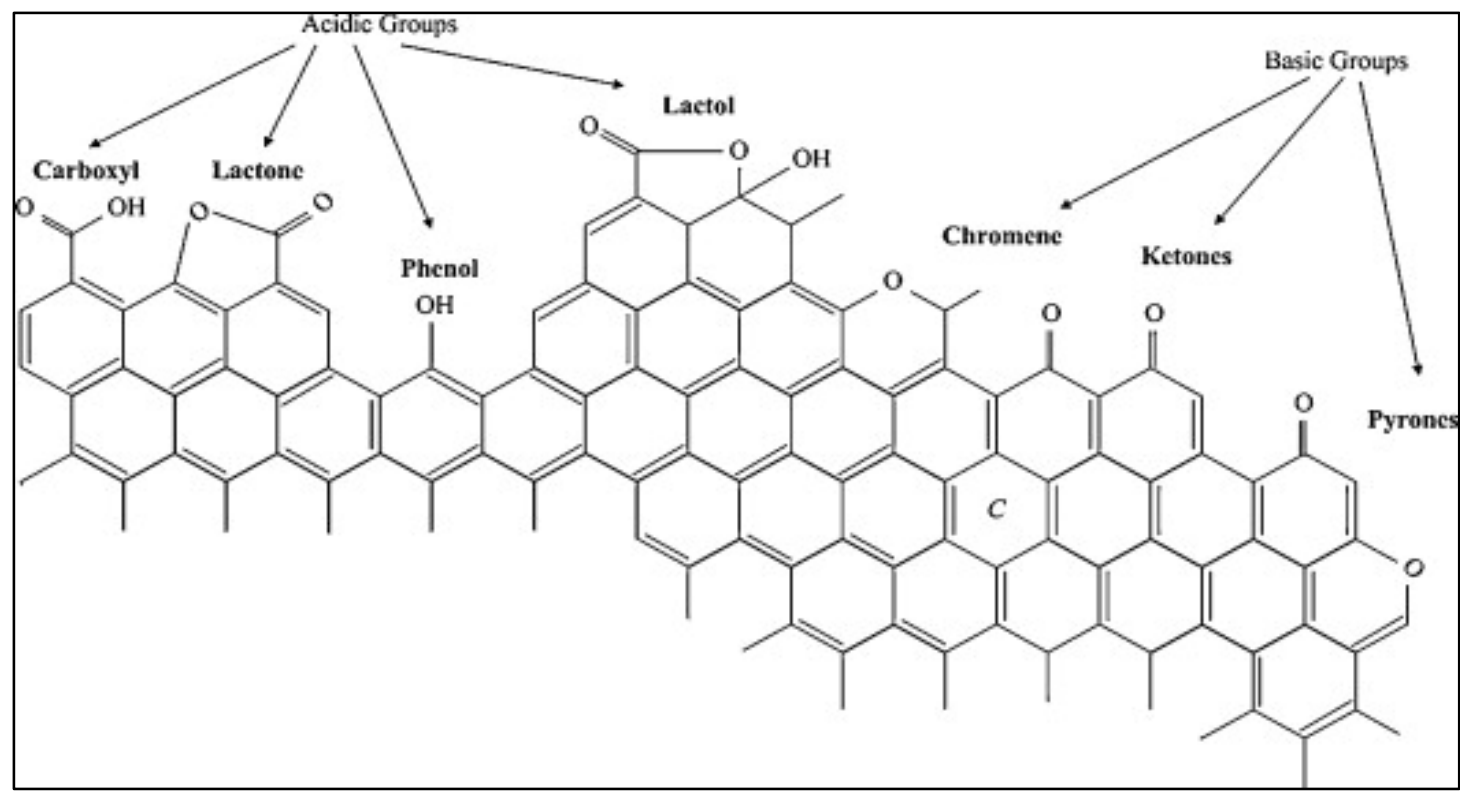

Fig 2.4: Acidic and basic surface functional groups on activated carbon basal plane [76]

\subsection{Effect of Process Parameters on the Properties of Activated Carbons}

Depending on the nature of the precursor and by adjustment of the process parameters, different pore sizes can be obtained. The specific surface areas and porosities of AC are greatly affected by the precursors of carbonaceous materials and methods of preparation. The adsorption capacity and the adsorption rate of an $\mathrm{AC}$ are directly associated with the specific surface areas and the pore size distribution of the AC. In general, the larger the specific surface area, the greater the adsorption capacity. However, for the adsorption of larger molecules, the adsorption capacity and the adsorption rate are largely dependent on the mesoporous (and macroporous) volumes [78].

\subsubsection{Activating agents}

Nowicki et al. [79] studied the physical activation of cherry stone-derived biochars produced at pyrolysis temperature of $500{ }^{\circ} \mathrm{C}$ and $800{ }^{\circ} \mathrm{C}$. The physical activation of the biochars were carried out at a temperature of $800{ }^{\circ} \mathrm{C}$ under a stream of $\mathrm{CO}_{2}$. The authors reported a surface area of $367 \mathrm{~m}^{2} / \mathrm{g}$ and $361 \mathrm{~m}^{2} / \mathrm{g}$ for the activated carbons produced from $500{ }^{\circ} \mathrm{C}$-biochar and $800{ }^{\circ} \mathrm{C}$-biochar respectively. The authors asserted that the physical activation of the biochars does not permit a substantial development of the porous structure of the activated carbons.

Similarly, Sun and Jang [80] investigated the physical activation of rubber-seed shell using steam. The precursor was pyrolyzed to produce biochar at a temperature range of $450-650{ }^{\circ} \mathrm{C}$ prior to activation. The activation was carried out in a flow of vapor steam at a temperature range of $800-900$ 
${ }^{\circ} \mathrm{C}$. The authors reported an increase in the creation of mesopores and decrease in the micropores as the activation temperature increased. At high temperature, the micropores were enlarged and the walls between the pores collapsed and formed mesopores.

For chemical activation, activating agents can be alkaline or acidic in nature. For the physical activation, the activating agents are steam or $\mathrm{CO}_{2}$. The effect of the activating agent on the properties of the activated carbon are evident on its surface area, porosity and surface chemistry. Bazan-Wozniak et al. [81] investigated the effect of physical and chemical activating agents on the surface area, porosity and surface functional groups of activated carbon produced from pistachio nutshells and its biochar. The biochars were produced at a temperature of 500 and $700{ }^{\circ} \mathrm{C}$. The physical activating agent used was $\mathrm{CO}_{2}$ with a flow rate of $0.250 \mathrm{~L} / \mathrm{min}$ and the chemical activating agents used were $\mathrm{H}_{3} \mathrm{PO}_{4}$ and $\mathrm{K}_{2} \mathrm{CO}_{3}$. The authors reported the highest surface area of $1204 \mathrm{~m}^{2} / \mathrm{g}$ for activated carbons obtained from the physical activation of pistachio nutshell-biochar at an activation temperature of $900{ }^{\circ} \mathrm{C}$. The activated carbons obtained from the direct impregnation of the precursor with $\mathrm{K}_{2} \mathrm{CO}_{3}$ was also reported to have a high surface area of $1093 \mathrm{~m}^{2} / \mathrm{g}$.

Among the chemical activating agents, $\mathrm{ZnCl}_{2}$ and $\mathrm{H}_{3} \mathrm{PO}_{4}$ are commonly used for activation purpose for lignocellulosic materials, whereas compounds such as potassium hydroxide $(\mathrm{KOH})$ are used for the activation of coal precursors or chars. When compared to zinc chloride, phosphoric acid is preferred because of the environmental disadvantages associated with zinc chloride which includes problems of corrosion, inefficient chemical recovery and the carbons obtained using zinc chloride cannot be used in pharmaceutical and food industries as they may contaminate the product $[82,83]$. It also gives higher yield of activated carbon and has non-toxic properties [84]. However, the use of $\mathrm{ZnCl}_{2}$ have been reported to produce higher surface area and more microporous structure [85] while $\mathrm{H}_{3} \mathrm{PO}_{4}$ is effective in producing the mesopores, and resulting in higher pore volumes and diameter.

The use of $\mathrm{KOH}$ as activating agents has been found to be effective in production of activated carbon with large microporosity and narrow pore size distribution but its yield is lower than carbon activated with zinc chloride or phosphoric acid, and at high temperature, i.e. $\pm 650{ }^{\circ} \mathrm{C}$, the carbon content is lower than the fixed carbon in the initial precursor. The presence of metallic potassium will intercalate to the carbon matrix $[82,86,87]$. 


\subsubsection{Effect of impregnation ratio}

Impregnation ratio represents the mass ratio of the activating agent to precursor or vice versa. The impregnation ratio ensures that the chemical is able to penetrate totally into the precursor and react with the components (i.e cellulose, hemicellulose and lignin for lignocellulosic precursor). The effect of the impregnation ratio on the porosity of the resulting product is evident from the fact that the volume of salt (obtained from the activation agent) in the carbonized material is equal to the volume of pores, after the salt has been extracted.

Patnuko and Pavasant [88] investigated the effect of impregnation ratio on the production of activated carbon from Eucalyptus camaldulensis Dehn bark using phosphoric acid. It was reported that activated carbons with better adsorption capacity were obtained with impregnation ratio of 1:1 while a reduction in the adsorption capacity of the carbon at higher impregnation ratio was observed. Also, a higher BET surface area of $1239 \mathrm{~m}^{2} / \mathrm{g}$ was obtained at the impregnation ratio of 1:1. In a similar research, Kalderis et al. [89] investigated the production of activated carbon from bagasse and rice husk using zinc chloride, sodium hydroxide and phosphoric acid with impregnation ratio 0.25:1, 0.5:1, 0.75:1 and 1:1 (i.e. ratio of activating agent to precursor). BET surface areas obtained with $\mathrm{ZnCl}_{2}$ as activating agent and impregnation ratio of $1: 1$ for rice husk and $0.75: 1$ for bagasse were reported to be $750 \mathrm{~m}^{2} / \mathrm{g}$ and $674 \mathrm{~m}^{2} / \mathrm{g}$ respectively.

\subsubsection{Effect of carbonization temperature}

Juejun et al. [90] conducted a physical activation of coconut shell-derived biochars (produced at a carbonization temperature range of $250-750{ }^{\circ} \mathrm{C}$ ) using $\mathrm{CO}_{2}$ at a temperature of $850{ }^{\circ} \mathrm{C}$ for 60 and $120 \mathrm{~min}$. The authors reported that the porosity of the activated carbon decreased with increase in the carbonization temperature. The char produced at the lowest carbonization temperature of $250{ }^{\circ} \mathrm{C}$ and activated at $850{ }^{\circ} \mathrm{C}$ for $120 \mathrm{~min}$ gave the highest BET surface area and pore volume of $1056 \mathrm{~m}^{2} / \mathrm{g}$ and $0.533 \mathrm{~cm}^{3} / \mathrm{g}$ respectively. A comparison of the work done by Nowicki et al. [79] on physical activation

of cherry stone-derived activated carbon showed that pyrolysis of the cherry stones at temperature of $500{ }^{\circ} \mathrm{C}$ and $800{ }^{\circ} \mathrm{C}$ respectively before activation using $\mathrm{CO}_{2}$ produced activated carbons with surface areas of 367 and $361 \mathrm{~m}^{2} / \mathrm{g}$ respectively. Meanwhile, the chemical activation of the cherry stone-derived biochars (pyrolysis temperature of $500{ }^{\circ} \mathrm{C}$ and $800{ }^{\circ} \mathrm{C}$ ) using $\mathrm{KOH}$ as chemical agents produced activated carbons with surface areas of $1324 \mathrm{~m}^{2} / \mathrm{g}$ and $1173 \mathrm{~m}^{2} / \mathrm{g}$ respectively. In both activation cases, the biochars produced at pyrolysis temperature of $800{ }^{\circ} \mathrm{C}$ resulted in activated carbons with low surface area. 
Furthermore, Bazan-Wozniak et al. [81] reported a surface area of $1204 \mathrm{~m}^{2} / \mathrm{g}$ for activated carbon produced from physical activation of biochar obtained at a carbonization temperature of 700 ${ }^{\circ} \mathrm{C}$. The activated carbon from biochar obtained at a carbonization temperature of $500{ }^{\circ} \mathrm{C}$ under similar activating condition was reported to have a surface area of $277 \mathrm{~m}^{2} / \mathrm{g}$. The authors attributed the significant difference in the surface areas of the activated carbon to the carbonization temperature used. When the biochars were chemically activated, the biochar obtained at a carbonization temperature of $700{ }^{\circ} \mathrm{C}$ gave an activated carbon with a surface area of $530 \mathrm{~m}^{2} / \mathrm{g}$, which is not significantly different when compared to the activated carbon from biochar obtained at a carbonization temperature of 500 ${ }^{\circ} \mathrm{C}\left(513 \mathrm{~m}^{2} / \mathrm{g}\right)$. The authors explained that the negligible difference in the chemically obtained activated carbons may due to the fact that carbon structure of the biochars is ordered enough so that the activating agent used $\left(\mathrm{K}_{2} \mathrm{CO}_{3}\right)$ or the impregnation ratio used (2:1) were insufficient for effective development of the porous structure.

\subsection{Modification of Activated Carbon Surfaces}

Apart from the textural characteristics of activated carbon, it is well known that the applicability of activated carbon is determined by its surface chemistry. The surface chemistry of the activated carbon plays an important role in determining how efficient the activated carbon can be in the adsorption of a specific compound. Since the surface chemistry influences certain features of activated carbon such as wettability, hydrophobicity-hydrophilicity, adsorptive, catalytic, acid/base and redox properties, the modification of its surface can therefore enable the control of these features [9].

For example, chemical species removal by activated carbon adsorption is due predominantly to the surface complex formation between the species and the surface functional groups. This is especially significant in the case of removing inorganics and metals from aqueous solutions where activated carbons are generally less effective as compared to removing organic compounds [91, 92]. This is because metals often exist in solution either as ions or as hydrous ionic complexes [91]. Also, it is a known fact that surface oxygen functional groups decrease the adsorption of organic compounds in aqueous solution, while their absence favors adsorption, independently of the compounds polarity. This implies that while the acidic functional groups on the activated carbon surface augment their metal adsorptive capacities, the presence of these functional groups do not favor adsorption of organic compounds like phenolic compounds [91].

Surface modification of the activated carbon simply talks about the treatment processes carried out to modify the chemical characteristics of the activated carbon surface in order to enhance or improve 
its adsorption capacity for a specific compound. For example, $\mathrm{CO}_{2}$ adsorption capacity of activated carbon can be increased by the introduction of basic nitrogen functionalities into the carbon surface. This is based on the premise that, due to the acidic role of $\mathrm{CO}_{2}$ (weak Lewis acid), the introduction of Lewis bases onto the activated carbon surfaces will favor the $\mathrm{CO}_{2}$ capture performance [76]. Also, acidic treatment of activated carbon has been reported to enhance its uptake of metal contaminants from aqueous solution [91].

The modification can be carried out by formation of different types of surface functional groups. For instance, surface oxygen functional groups are formed by oxidation of the carbon surface with oxidizing gases or solutions; carbon-hydrogen surface groups by treatment with hydrogen gas at elevated temperatures; carbon-nitrogen surface groups by treatment with ammonia. In addition, degassing and impregnation of the surfaces of the activated carbons are other methods by which the carbon surfaces can be modified [15].

\subsubsection{Effect of surface modification on pore volume}

Stravropoulos et al. [74] reported the modification of a commercial activated carbon using four methods, namely thermal partial oxidation by oxygen, liquid phase oxidation by nitric acid solution, thermal treatment of urea pre-impregnated samples and thermal treatment under a urea saturated helium flow. The authors reported the initial surface area, total pore volume and micropore volume of the activated carbon to be $1003 \mathrm{~m}^{2} / \mathrm{g}, 0.374 \mathrm{~cm}^{3} / \mathrm{g}$ and $0.338 \mathrm{~cm}^{3} / \mathrm{g}$ respectively. After the modification, it was found that there was a smaller change in the pore structures of the activated carbon modified via thermal partial oxidation by oxygen as compared to the other methods. For the urea modified activated carbon, the nitrogen enrichment led to increase in the microporous volume of the activated carbon.

The significant reduction in the pore structure development was observed during liquid phase nitric acid treatment. The surface area, total pore volume and micropore volume of the modified activated carbon reached values as low as $260 \mathrm{~m}^{2} / \mathrm{g}, 0.116 \mathrm{~cm}^{3} / \mathrm{g}$ and $0.104 \mathrm{~cm}^{3} / \mathrm{g}$ respectively. According to El-Hendawy [75], the loss of the surface area and the reduction in the pore volume can be attributed to the incorporation of oxygen functionalities in pore walls and the erosive effect of nitric acid on the carbon structure. The incorporated oxygen functional groups will increase the weight of the modified activated carbon and the extent of oxygen-carbon formation will naturally affect the accessibility of the adsorbate to the modified activated carbon.

El-Hendawy [75] also reported a similar finding for the modification of a corncob-based activated carbon using nitric acid. The author concluded that liquid phase oxidation leads to fixation of 
large amounts of oxygen functionalities on the carbon surface, with simultaneous partial destruction or degradation of the porous structure of the activated carbon. Meanwhile Jaramillo et al. [93] estimated the percentage of microporosity loss of a cherry stone-derived activated carbon modified by nitric acid solution to be $43.3 \%$ and $6.7 \%$ for activated carbon modified by ozone gas. The microporosity loss is explained to be the widening and transformation of the micropores into large size mesopores. Hence, there was a significant mesoporosity development but no significant difference in the macroporosity of the activated carbon. Therefore, the inference concerning the effect of the oxidizing agents during surface modification of activated carbon on its porous structure is that it leads to widening of narrower pores, causing microporosity loss and mesoporosity development [93]

\subsubsection{Effect of surface modification on surface chemistry}

The surface modification of activated carbon results in the activated carbon surface becoming either more acidic or more basic in nature. The incorporation of oxygen functionalities will render the activated carbon more acidic and hydrophilic, decrease the $\mathrm{pH}$ of their point of zero charge and increase the surface charge density [94]. The removal of the oxygen functionalities from the activated carbon through heat treatment will result in the activated carbon surface becoming more basic and hydrophobic in nature [71]. The surface oxygen functionalities generally decompose upon heating by releasing $\mathrm{CO}$ and $\mathrm{CO}_{2}$ at different temperatures.

Figueiredo et al. [95] investigated the modification of a NORIT activated carbon using gas phase oxidation $\left(\mathrm{O}_{2}\right.$ and $\left.\mathrm{N}_{2} \mathrm{O}\right)$ and liquid phase oxidation (hydrogen peroxide and nitric acid solution). The authors reported that there was an increase in the oxygen functional groups of the modified activated carbon. Specifically, the authors noted that the gas phase oxidation led to an increase in the concentration of hydroxyl and carbonyl surface groups while the liquid phase oxidation increased the concentration of the carboxylic acids.

Jaramillo et al. [93] asserted that the main factor in surface chemistry change during surface modification is the oxidizing agents and not whether the process was carried out in the dry phase or liquid phase. In their own investigation on the modification of cherry stone-derived activated carbon with nitric acid $\left(\mathrm{HNO}_{3}\right)$, hydrogen peroxide $\left(\mathrm{H}_{2} \mathrm{O}_{2}\right)$, ozone $\left(\mathrm{O}_{3}\right)$ and oxygen $\left(\mathrm{O}_{2}\right)$, Jaramillo et al. [93] reported that $\mathrm{O}_{3}$ and $\mathrm{HNO}_{3}$ treatments were the most effective in forming acidic oxygen surface groups. For the $\mathrm{O}_{2}$ modified activated carbon, the presence of phenolic and carbonylic groups were detected; carboxylic acid groups and lactone groups were found in $\mathrm{HNO}_{3}$ modified activated carbon while $\mathrm{O}_{3}$ modified activated carbon showed increase in the carboxylic, lactone and anhydride groups [93, 96]. 


\subsection{Textural and Surface Chemistry Characterization of Activated Carbon}

Since the adsorption application of activated carbon is greatly influenced by its surface chemistry and porous structure, a considerable amount of effort has been directed towards identifying and quantifying the surface functional groups that exists on carbon surfaces. The various qualitative and quantitative techniques employed by researchers in characterizing the textural properties and surface chemistry of activated carbon are summarized in Table 2.5 [95].

Some of the techniques are complimentary in their functions. For example, while the Fourier transform infrared spectroscopy and X-ray photoelectron spectroscopy (XPS) are used in the identification of functional groups on the activated carbon surface, the Boehm titration is used in quantifying these surface functional groups. Similarly, the scanning electron microscopy can be used to visually assess the porous structure of the activated carbon and the gas adsorption technique is used in quantifying the pore size distribution, pore volume and surface area of the activate carbon.

\subsubsection{Scanning electron microscopy}

Scanning electron microscope (SEM) is the type of characterization technique that gives a comprehensive microstructural examination of the high surface area ordered carbon materials. While the SEM is used in examining the pore structure and morphology of carbon surfaces, the images are limited to the surface structures and it cannot detect pore size distribution. It produces images of a sample by scanning it with a focused beam of electrons. The electrons interact with atoms in the sample, producing various signals that contain information about the sample's surface topography and composition. The micrograph images are rapidly and easily obtained. Data are collected over a selected area of the surface of the sample, and a 2-dimensional image is generated that displays spatial variations in these properties. Areas ranging from approximately $1 \mathrm{~cm}$ to 5 microns in width can be imaged in a scanning mode using conventional SEM techniques (magnification ranging from 20X to approximately $30,000 X$, spatial resolution of 50 to $100 \mathrm{~nm}$ ).

The SEM is also capable of performing analyses of selected point locations on the sample; this approach is especially useful in qualitatively or semi-quantitatively determining chemical compositions (using Energy Dispersive X-ray Spectroscopy), crystalline structure, and crystal orientations (using Electron Backscatter Diffraction).

The limitation with this technique is that microstructural examination of most biological samples requires them to be dehydrated before being placed in the equipment. This can distort cellular 
features or create artifacts. Samples need to be coated in a conductive material before viewed in the SEM. The thickness of the material can obscure important cellular details.

\subsubsection{Gas adsorption}

Textural characteristics of activated carbon are determined from $\mathrm{N}_{2}$ and $\mathrm{CO}_{2}$ adsorption isotherms. The characterization of these properties is based on the physical adsorption of the probe molecules $\left(\mathrm{N}_{2}\right.$ and $\left.\mathrm{CO}_{2}\right)$ into the pores of the activated carbon at a defined temperature and relative pressure. Prior to the gas adsorption measurement, the carbon is outgassed/degassed at a temperature range between 200 and $350{ }^{\circ} \mathrm{C}$ under vacuum $[29,75]$. The activated carbon is subjected to adsorption of $\mathrm{N}_{2}$ at a temperature of $77 \mathrm{~K}$ using an adsorption instrument. The surface area of the activated carbon is commonly estimated by the BET (Brunauer-Emmett-Teller) method. The BET model assumes a multilayer adsorption in a porous media in which first layer of adsorbed molecules acts as a base for the adsorption of the second layer of molecules, which in turn acts as a base for the third layer, and so on, so that the concept of localization is maintained in all layers [15]. However, this assumption is not totally fulfilled for activated carbon. This is due to the fact that the adsorption in micropores takes place through volume filling of micropores at very low relative vapor pressures. Moreover, the formation of adsorption layers does not exceed some finite value $n$ due to inadequate space available in the micropores [15].

The pore size distribution is commonly determined by the BJH (Barret-Joymer-Hanlenda) and DFT (Density Functional Theory) models $[25,97]$. The $t$-plot method is often used in estimating the micropore volume [81] while the total pore volume is estimated from the volume of $\mathrm{N}_{2}$ held at a relative pressure range between $0.95-0.99[60,75]$. The micropore size distribution is assessed from $\mathrm{CO}_{2}$ adsorption isotherms at $273.15 \mathrm{~K}$ and estimated using the Dubinin-Radushkevich (DR) and DubininRadushkevich-Stoeckli (DRS) equation [25, 49]. The Dubinin-Radushkevich (DR) isotherm is an empirical model applied to express the adsorption mechanism of subcritical vapors onto micropore solids following a pore filling mechanism with a Gaussian energy distribution [13].

Iodine number is also used to measuring the internal surface area of activated carbon. The iodine number refers to milligrams of elemental iodine adsorbed per gram of dry carbon when it is in equilibrium with a $0.010 \mathrm{M}$ solution of $\mathrm{I}_{2}$ [98]. $1 \mathrm{mg}$ of iodine adsorbed is considered to represent $1 \mathrm{~m}^{2}$ internal surface. It also measures the volume present in pores from 10 to $28 \AA$ in diameter. Carbons with a high percentage of pore sizes in this range would be suitable for adsorbing low-molecular-weight substances [99]. For an activated carbon to be used for adsorption of low molecular weight compounds, 
it must have a minimum iodine number of $500 \mathrm{mg} / \mathrm{g}$ [77]. Adsorption of methylene blue from aqueous solution is also used in characterizing the mesopore capacity (pore diameters greater than $13 \AA$ ) and serves as a model compound for adsorption of medium size organic compounds from aqueous solutions [77].

Table 2.5 Techniques available for activated carbon characterization [100]

\begin{tabular}{|c|c|c|}
\hline $\mathbf{s} / \mathbf{n}$ & Test Method & Characterization \\
\hline 1 & Boehm titration & Surface oxygen functionality \\
\hline 2 & Computer simulation & $\mathrm{pKa}$ of functional groups \\
\hline 3 & Electron energy-loss spectroscopy & Bonding states and band gaps \\
\hline 4 & $\begin{array}{l}\text { Electron spin resonance or electron } \\
\text { paramagnetic resonance }\end{array}$ & Free spins and dangling bonds \\
\hline 5 & Electrophoresis & Separation - analysis \\
\hline 6 & Flow adsorption & Average polarity \\
\hline 7 & Fourier transform infrared spectroscopy & Surface group functionality \\
\hline 8 & Gas adsorption & $\begin{array}{l}\text { Surface areas and energetics, pore-size } \\
\text { distributions }\end{array}$ \\
\hline 9 & Immersion calorimetry & Surface areas and energetics \\
\hline 10 & Inverse gas chromatography & Average acidity \\
\hline 11 & Magneto-resistance & Electronic properties \\
\hline 12 & Nuclear magnetic resonance & Molecular structure, atom groups \\
\hline 13 & Potentiometric titration & $\mathrm{pKa}$ (acid strength) of functional groups \\
\hline 14 & Scanning electron microscopy (SEM) & Surface characterizations \\
\hline 15 & Scanning tunneling microscopy & Atomic scale structure \\
\hline 16 & Small angle $X$-ray scattering & $\begin{array}{l}\text { Total surface area including closed porosity, } \\
\text { pore sizes }\end{array}$ \\
\hline 17 & Temperature programmed desorption & Surface functionalities mainly for oxygen \\
\hline 18 & Transmission electron microscopy & Fringe imaging, diffraction, light and dark field \\
\hline 19 & X-ray absorption fine structure & Atomic distances and coordination chemistry \\
\hline 20 & X-ray diffraction (wide-angle X-ray diffraction) & $\begin{array}{l}\text { Crystallite sizes, carbon-carbon distribution } \\
\text { functions }\end{array}$ \\
\hline 21 & X-ray photoelectron spectroscopy (XPS) & Identification of surface functional groups \\
\hline 22 & Gravimetric Adsorption Energy Distribution & $\begin{array}{l}\text { Pore size, total pore volume and surface area of } \\
\text { extruded wood carbon. }\end{array}$ \\
\hline 23 & Elemental analysis & $\begin{array}{l}\text { Carbon, hydrogen, nitrogen, sulfur and oxygen } \\
\text { content }\end{array}$ \\
\hline
\end{tabular}

In general, the iodine numbers are similar in magnitude to the BET surface areas and are a measure of the carbon activity in the high capacity range. The iodine number is a rough measure of the quality of the activated carbon and is useful in determining the extent to which a spent activated carbon 
has been reactivated. However, it is not a good index for activated carbon performance in a low-capacity applications such as adsorption of pharmaceutical compounds in water [98].

The mercury intrusion porosimetry is another technique used in characterizing the pore structure of activated carbon. The probe molecule (mercury) does not wet most substances and will not spontaneously penetrate pores by capillary action, it must be forced into the pores by the application of external pressure. The required equilibrated pressure is inversely proportional to the size of the pores, only slight pressure being required to intrude mercury into large macropores, whereas much greater pressures are required to force mercury into small pores. The technique involves the intrusion of a nonwetting liquid (often mercury) at high pressure into a material through the use of a porosimeter. The pore size can be determined based on the external pressure needed to force the liquid into a pore against the opposing force of the liquid's surface tension. From the pressure versus intrusion data, the instrument generates volume and size distributions using the Washburn equation. Clearly, the more accurate the pressure measurements, the more accurate the resulting pore size data.

The major limitation with this technique is that it measures the largest entrance towards a pore but not the actual inner size of a pore. It cannot also be used to analyze closed pores since the mercury has no way of entering that pore.

\subsubsection{X-ray photoelectron spectroscopy (XPS)}

XPS is a non-destructive ultrahigh vacuum surface-sensitive quantitative in which the electron binding energies of atoms presented in the surface are used to provide an estimate of the chemical composition of the few uppermost layers of the material [76, 95]. Essentially, the technique is based on photoelectric effect that uses soft x-rays (with a photon energy of 200-2000 eV) to investigate the elemental composition at the parts per thousand range, empirical formula, and electronic state of the elements that exist within a material. The spectroscopic method has been used extensively to study the surface oxygen functional groups.

The analysis is based on the changes of the intensities of $1 \mathrm{~s}$ peaks of carbons, oxygen or other heteroatoms such as nitrogen. Those peaks are at specific irradiation energies related to the binding energies of core electrons ejected from atoms located on the external surfaces. The identification of

functional groups is based on the deconvolution of their peaks. The amount of species detected using the XPS method is usually given as the atomic ratio evaluated from the peak area ratios.

For example, substantial changes in the surface chemistry of activated carbon due to oxidation can be identified through examination of the $\mathrm{C} 1 \mathrm{~s}$ core region [101]. The reconstruction of the $\mathrm{C} 1 \mathrm{~s}$ 
region is generally difficult, not only as a result of the peak broadness, but also because it is necessary make an assumption regarding its nature after oxidation, namely if the surface graphite-like structure remains unchanged or not. This will affect the curve fitting procedure as an asymmetric peak shape is needed for graphite-like structure and a Gaussian peak is required for an aliphatic structure [95].

A further insight into the surface functional groups can be achieved by quantifying the binding energies of nitrogen $(\mathrm{N} 1 \mathrm{~s})$, oxygen $(\mathrm{O} 1 \mathrm{~s})$ and carbon $(\mathrm{C} 1 \mathrm{~s})$ photoelectrons on the carbon surface and also performing a reconstruction of their respective peaks [76, 102]. For example, the deconvolution of the $\mathrm{C} 1 \mathrm{~s}$ spectra can reveal the presence of four peaks: graphitized carbon (C-C or C-H), Hydroxyl or ether (C-O), Carbonyl $(\mathrm{C}=\mathrm{O})$ and Carboxyl or ester $(\mathrm{O}-\mathrm{C}=\mathrm{O})$. Likewise, the deconvolution of the $\mathrm{O} 1 \mathrm{~s}$ spectra can show five groups: carbonyl oxygen in quinones, carbonyl oxygen atoms in esters, anhydrides and oxygen atoms in hydroxyl groups, non-carbonyl (ether-type) oxygen atoms in esters and anhydrides; oxygen atoms in carboxyl groups [103]. The binding energies for $\mathrm{C} 1 \mathrm{~s}$ and $\mathrm{O} 1 \mathrm{~s}$ deconvolved peaks reported by different researchers are summarized in the Table 2.3.

\subsubsection{Chemical titration}

Chemical titration used for characterizing surface chemistry of carbon surface as proposed by Boehm is used in determining the acidic and basic functional groups of the carbon surface. The basic principle of Boehm titration is that different basic/acidic functionalities can be distinguished by their neutralization behaviors [76]. The amounts of acidic sites or oxygen functional groups are quantified based on the assumption that $\mathrm{NaOH}$ neutralizes carboxylic, phenolic and lactone groups; $\mathrm{Na}_{2} \mathrm{CO}_{3}$ neutralize carboxylic and lactone groups and $\mathrm{NaHCO}_{3}$ neutralizes only carboxylic groups. The carboxylic group is estimated by the amount of $\mathrm{NaHCO}_{3}$ consumed; the phenolic group is determined by difference between $\mathrm{NaOH}$ and $\mathrm{Na}_{2} \mathrm{CO}_{3}$ consumption; and the lactone group is determined by the difference between $\mathrm{Na}_{2} \mathrm{CO}_{3}$ and $\mathrm{NaHCO}_{3}$ consumption $[56,76]$. The number of the basic sites is estimated by the amount of hydrochloric acid consumed by the carbon. The difference between the $\mathrm{HCl}$ consumption by the blank and samples is considered as the surface basicity of the activated carbon [104].

The major drawback in this method is that it is not practicable when using small amount of samples. Also, this method can only quantify about half of the total oxygen functional groups on the activated carbon surface [76]. The units used for the measurement include meq $/ \mathrm{g}, \mu \mathrm{eq} / \mathrm{g}$ and $\mathrm{mmol} / \mathrm{g}$. Table 2.6 shows the surface functional groups quantified by the Boehm's method. 


\subsubsection{Temperature programmed desorption (TPD)}

Surface oxygen groups on carbon surfaces decompose upon heating by releasing $\mathrm{CO}$ at lower temperature and $\mathrm{CO}_{2}$ at higher temperature and in some cases $\mathrm{H}_{2} \mathrm{O}$ and $\mathrm{H}_{2}$, at different temperatures. Therefore, the relative stability of the surface functional groups is often used as a measurement of the concentration of these functional groups on the carbon surface. The technique used for this process is called temperature programmed desorption (TPD) [95, 103].

Due to the influence of carbon textural properties, heating rate and geometry of the experimental system used on the peak temperatures, there seems to exist confusion in the assignment of the TPD to specific surface groups. However, the general established trends are: $\mathrm{CO}_{2}$ evolution at low temperatures $\left(200-500{ }^{\circ} \mathrm{C}\right.$ ) has been attributed to carboxylic acids; $\mathrm{CO}_{2}$ evolution at higher temperatures is an indication of the existence of lactones and carboxylic anhydrides; $\mathrm{CO}$ peak has been attributed to phenolic, anhydrite, ethers (at $350-450{ }^{\circ} \mathrm{C}$ ) and quinones, carbonyls (at $450-700{ }^{\circ} \mathrm{C}$ ) $[74,95]$.

\subsubsection{Fourier transform infrared spectroscopy (FTIR)}

The FTIR spectroscopy is a qualitative method employed in the identification of the functional groups present on activated carbon surface $[76,94]$. The FTIR spectrum is a plot of the measured infrared intensity (transmittance unit) versus wavenumber of light (inverse of wavelength) [76].

The peaks obtained in the FTIR spectra represents the functional groups present on the activated carbon [76]. The interpretation of the spectra is complicated by the fact that each functional group originates several bands at different wavenumbers, therefore each band may include contributions from various groups [95]. The infrared region in which the spectra information is collected, is always stated, usually between $4000-400 \mathrm{~cm}^{-1}$ wavenumber range [105]. The use of FTIR spectroscopy is a complimentary technique to augment other quantitative techniques used in quantifying the surface functional groups on activated carbon surfaces. 
Table 2.6: Total surface acidity and basicity of activated carbons (meq/g)

\begin{tabular}{|c|c|c|c|c|c|c|c|c|}
\hline $\mathbf{s} / \mathbf{n}$ & Sample & Carboxyl & Lactone & Hydroxyl & Carbonyl & $\begin{array}{c}\text { Total } \\
\text { Surface } \\
\text { Acidity } \\
\end{array}$ & $\begin{array}{c}\text { Total } \\
\text { Surface } \\
\text { Basicity } \\
\end{array}$ & Ref. \\
\hline \multirow{3}{*}{1} & Cherry stone AC & 0.016 & 0.006 & 0.074 & 0.042 & 0.138 & 0.385 & \multirow{3}{*}{ [93] } \\
\hline & $\begin{array}{l}\mathrm{HNO}_{3} \text { Modified } \\
\text { Cherry stone } \mathrm{AC}\end{array}$ & 0.639 & 0.072 & 0.086 & 0.069 & 0.662 & 0.175 & \\
\hline & $\begin{array}{c}\mathrm{O}_{3} \text { modified Cherry } \\
\text { stone } \mathrm{AC}\end{array}$ & 0.487 & 0.014 & 0.098 & 0.063 & 0.662 & 0.302 & \\
\hline 2 & Birch derived AC & 0.744 & 0.126 & 0.480 & 2.234 & 3.584 & 0.083 & {$[56]$} \\
\hline 3 & Granulated $\mathrm{AC}$ & 0.027 & 0.026 & 0.018 & & 0.071 & - & {$[78]$} \\
\hline 4 & $\begin{array}{c}\text { Coconut shell } \\
\text { derived AC }\end{array}$ & 0.37 & 0 & - & - & 0.75 & 0.73 & {$[65]$} \\
\hline 5 & $\begin{array}{c}\text { Modified Furfural } \\
\text { derived AC }\end{array}$ & 0.148 & 0.02 & 1.63 & 2.53 & 5.66 & - & [106] \\
\hline 6 & $\begin{array}{c}\text { Urea Modified } \\
\text { Commercial AC }\end{array}$ & 0.29 & 0.15 & 0.34 & 1.15 & 1.93 & 0 & {$[74]$} \\
\hline 7 & $\begin{array}{l}\text { Macademia nut } \\
\text { endocarp derived } \\
\text { AC }\end{array}$ & 0.66 & 0.16 & 0.26 & - & 1.07 & 0.38 & {$[57]$} \\
\hline \multirow{2}{*}{8} & $\begin{array}{c}\text { Commercial } \\
\text { Granulated AC }\end{array}$ & 0.387 & 0.089 & 0.404 & - & 0.88 & 1.79 & \multirow{2}{*}{$\begin{array}{c}{[9,} \\
107]\end{array}$} \\
\hline & $\begin{array}{l}\text { Commercial } \\
\text { Powdered AC }\end{array}$ & 0.56 & 0195 & 0.865 & - & 1.62 & 1.49 & \\
\hline \multirow{2}{*}{9} & $\begin{array}{c}\text { Activated Carbon } \\
\text { cloth }\end{array}$ & 0.04 & 0.12 & 0.02 & 0.66 & 0.84 & 0.43 & \multirow{2}{*}{ [107] } \\
\hline & $\begin{array}{l}\mathrm{NaOCl} \text { modified AC } \\
\text { cloth }\end{array}$ & 0.56 & 0.42 & 0.19 & 0.51 & 1.68 & 0.28 & \\
\hline \multirow{3}{*}{10} & Coal-based AC & 0.85 & 0.55 & 0.20 & - & 1.60 & 0.05 & \multirow{3}{*}{ [108] } \\
\hline & $\mathrm{NH}_{3}$ Modified CAC & 0.48 & 0.30 & 0.15 & - & 0.78 & 0.30 & \\
\hline & $\begin{array}{c}\text { Microwave } \\
\text { modified CAC }\end{array}$ & 0.25 & 0.13 & 0.02 & - & 0.40 & 0.50 & \\
\hline \multirow[b]{2}{*}{11} & Cotton based AC & 2.579 & 0.3805 & 0.7245 & - & 4.176 & 1.043 & \multirow[b]{2}{*}{ [109] } \\
\hline & $\begin{array}{c}\mathrm{NH}_{3} \text { Modified } \\
\text { Cotton based AC }\end{array}$ & 3.136 & 0.7048 & 0.4913 & - & 4.850 & 4.798 & \\
\hline \multirow{2}{*}{12} & $\begin{array}{c}\text { Commercial } \\
\text { Granulated AC }\end{array}$ & 0.15 & 0.05 & 0.95 & - & 1.15 & 2.60 & \multirow{2}{*}{ [110] } \\
\hline & $\begin{array}{l}\mathrm{HNO}_{3} \text { Modified } \\
\text { Granulated AC }\end{array}$ & 1.07 & 1.50 & 1.24 & - & 3.81 & 1.40 & \\
\hline \multirow{3}{*}{13} & $\begin{array}{c}\text { Commercial } \\
\text { Anthracite AC }\end{array}$ & 0.027 & 0.086 & 0.146 & - & 0.259 & 0.742 & \multirow{3}{*}{ [111] } \\
\hline & $\begin{array}{c}10 \% \mathrm{NH}_{3} \text { Modified } \\
\text { Anthracite AC }\end{array}$ & 0.015 & 0.023 & 0.08 & - & 0.118 & 0.886 & \\
\hline & $\begin{array}{c}10 \% \mathrm{HCl} \text { Modified } \\
\text { Anthracite AC }\end{array}$ & 0.115 & 0.142 & 0.467 & - & 0.724 & 0.315 & \\
\hline
\end{tabular}




\subsubsection{X-ray diffraction}

This is a rapid analytical technique that uses the diffraction of X-rays for structural characterization of a powder or a crystalline material. When an incident beam of monochromatic Xrays interacts with a target material, a scattering of those $\mathrm{X}$-rays from atoms within the target material occurs. In materials with regular structure (i.e. crystalline), the scattered X-rays undergo constructive and destructive interference. This is the process of diffraction. The diffraction of X-rays by crystals is described by Bragg's Law, $\mathrm{n} \lambda=2 \mathrm{~d} \sin (\theta)$. The directions of possible diffractions depend on the size and shape of the unit cell of the material. The intensities of the diffracted waves depend on the kind and arrangement of atoms in the crystal structure. However, most materials are not single crystals, but are composed of many tiny crystallites in all possible orientations called a polycrystalline aggregate or powder. When a powder with randomly oriented crystallites is placed in an X-ray beam, the beam will see all possible interatomic planes. If the experimental angle is systematically changed, all possible diffraction peaks from the powder will be detected.

\section{Summary}

This chapter reviews literatures relating to the presence of pharmaceuticals and personal care products in waste and drinking water, conventional water treatment technologies and the use of adsorption process in the removal of these compounds in water. The adsorption of PPCPs using activated carbon was reviewed and adsorption parameters used in explaining the adsorption behaviors of the activated carbons were also discussed. The production, properties and characterization of activated carbons for adsorption of pharmaceuticals and personal care products in aqueous solution were also discussed.

The process parameters of great influence in the production of activated carbon are; precursor, activating agents, activation temperature and impregnation ratio. The variation of these process parameters influences the properties of the activated carbon and its application. The availability and cost of purchasing the raw materials determines to a large extent the type of raw materials to be used for activated carbon. Biomass feedstocks have become a viable source of raw material for activated carbon in recent time. The activating agents used for activated carbon production are either physical or chemical agents. The physical agents include $\mathrm{CO}_{2}$ and steam. The chemical agents can either be alkaline or acidic in nature. 
The major properties of activated carbon needed in its adsorption application are its morphology, surface chemistry, polarity, surface area and porosity. The porosity is classified into micropore, mesopore and macropore in increasing order of size. The surface chemistry defines the type of surface functional groups present on the activated carbon surface. These surface functional groups can be modified by oxidizing agents to suit specific purpose.

The adsorption application of activated carbon especially in the removal of pharmaceutical and personal care products (PPCPs) has gained significant interest in recent time due to the adverse effect these compounds may have on human health and the environment. For effective adsorption, the pores size of the activated carbon must be at least 1.7 to 2 times larger than the size of target molecule. The other significant factors that impacts the adsorption application of the activated carbon includes; initial $\mathrm{pH}$ of the solution, temperature, adsorbent dosage and contact time. The understanding of the intrinsic properties of the target contaminants and the activated carbon will greatly enhance the effective adsorption/removal of these compounds especially during waste water and drinking water treatment. 


\section{References}

[1] A.S. Mestre, J. Pires, J.M.F. Nogueira, A.P. Carvalho, Activated carbons for the adsorption of ibuprofen, Carbon, 45 (2007) 1979-1988.

[2] J.L. Liu, M.H. Wong, Pharmaceuticals and personal care products (PPCPs): A review on environmental contamination in China, Environment International, 59 (2013) 208-224.

[3] I. Rodea-Palomares, M. Gonzalez-Pleiter, S. Gonzalo, R. Rosal, F. Leganes, S. Sabater, M. Casellas, R. Muñoz-Carpena, F. Fernández-Piñas, Hidden drivers of low-dose pharmaceutical pollutant mixtures revealed by the novel GSA-QHTS screening method, Science Advances, 2 (2016).

[4] N.E.S. Center, Pharmaceuticals and Personal Care Products: An Overview, in: Pipeline, WVU Reserahc Corporation, Morgantown WV, 2007, pp. 1-8.

[5] J. Donn, M. Mendoza, J. Pritchard, Pharmaceuticals found in drinking water, affecting wildlife and maybe humans, in: Pharmawater, Associated Press, 2008.

[6] C.O. Lee, K.J. Howe, B.M. Thomson, State of Knowledge of Pharmaceutical, Personal Care Products and Endocrine Disrupting Compound Removal during Municipal Wastewater Treatment, in, New Mexico Environment Department, 2009.

[7] I.H. Kim, H. Tanaka, T. Iwasaki, T. Takubo, T. Morioka, Y. Kato, Classification of the degradability of 30 pharmaceuticals in water with ozone, UV and H2O2, Water Sci Technol, doi (2008) 10.

[8] A.B. Boxall, M.A. Rudd, B.W. Brooks, D.J. Caldwell, K. Choi, S. Hickmann, E. Innes, K. Ostapyk, J.P. Staveley, T. Verslycke, G.T. Ankley, K.F. Beazley, S.E. Belanger, J.P. Berninger, P. Carriquiriborde, A. Coors, P.C. Deleo, S.D. Dyer, J.F. Ericson, F. Gagne, J.P. Giesy, T. Gouin, L. Hallstrom, M.V. Karlsson, D.G. Larsson, J.M. Lazorchak, F. Mastrocco, A. McLaughlin, M.E. McMaster, R.D. Meyerhoff, R. Moore, J.L. Parrott, J.R. Snape, R. Murray-Smith, M.R. Servos, P.K. Sibley, J.O. Straub, N.D. Szabo, E. Topp, G.R. Tetreault, V.L. Trudeau, G. Van Der Kraak, Pharmaceuticals and personal care products in the environment: what are the big questions?, Environ Health Perspect, 120 (2012) 1221-1229.

[9] V. Rakić, V. Rac, M. Krmar, O. Otman, A. Auroux, The adsorption of pharmaceutically active compounds from aqueous solutions onto activated carbons, Journal of Hazardous Materials, 282 (2015) 141-149.

[10] L.F. Delgado, P. Charles, K. Glucina, C. Morlay, The removal of endocrine disrupting compounds, pharmaceutically activated compounds and cyanobacterial toxins during drinking water preparation using activated carbon-A review, Science of The Total Environment, 435-436 (2012) 509-525.

[11] P. Westerhoff, Y. Yoon, S. Snyder, E. Wert, Fate of endocrine-disruptor, pharmaceutical, and personal care product chemicals during simulated drinking water treatment processes, Environ Sci Technol, 39 (2005) 6649-6663.

[12] M. Ahmaruzzaman, Adsorption of phenolic compounds on low-cost adsorbents: A review, Advances in Colloid and Interface Science, 143 (2008) 48-67.

[13] K.Y. Foo, B.H. Hameed, Insights into the modeling of adsorption isotherm systems, Chemical Engineering Journal, 156 (2010) 2-10.

[14] K.Y. Foo, B.H. Hameed, An overview of landfill leachate treatment via activated carbon adsorption process, Journal of Hazardous Materials, 171 (2009) 54-60.

[15] R.C. Bansal, M. Goyal, Activated Carbon Adsoprtion CRC Press, Boca Raton, FL, USA, 2005.

[16] M.A. Mehmood, M. Ibrahim, U. Rashid, M. Nawaz, S. Ali, A. Hussain, M. Gull, Biomass production for bioenergy using marginal lands, Sustainable Production and Consumption, (2016).

[17] S. Álvarez-Torrellas, J.A. Peres, V. Gil-Álvarez, G. Ovejero, J. García, Effective adsorption of non-biodegradable pharmaceuticals from hospital wastewater with different carbon materials, Chemical Engineering Journal, 320 (2017) 319-329. 
[18] N. Boudrahem, S. Delpeux-Ouldriane, L. Khenniche, F. Boudrahem, F. Aissani-Benissad, M. Gineys, Single and mixture adsorption of clofibric acid, tetracycline and paracetamol onto Activated carbon developed from cotton cloth residue, Process Safety and Environmental Protection, 111 (2017) 544-559.

[19] F. Çeçen, Ö. Aktaş, Fundamentals of Adsorption onto Activated Carbon in Water and Wastewater Treatment, in: Activated Carbon for Water and Wastewater Treatment, Wiley-VCH Verlag GmbH \& Co. KGaA, 2011, pp. 13-41.

[20] J.L. Sotelo, G. Ovejero, A. Rodríguez, S. Álvarez, J. Galán, J. García, Competitive adsorption studies of caffeine and diclofenac aqueous solutions by activated carbon, Chemical Engineering Journal, 240 (2014) 443-453.

[21] D. Kołodyńska, R. Wnętrzak, J.J. Leahy, M.H.B. Hayes, W. Kwapiński, Z. Hubicki, Kinetic and adsorptive characterization of biochar in metal ions removal, Chemical Engineering Journal, 197 (2012) 295-305.

[22] H. Marsh, F. Rodríguez-Reinoso, Chapter 4 - Characterization of Activated Carbon, in: Activated Carbon, Elsevier Science Ltd, Oxford, 2006, pp. 143-242.

[23] Y.S. Ho, Selection of optimum sorption isotherm, Carbon, 42 (2004) 2115-2116.

[24] M.J. Ahmed, Adsorption of non-steroidal anti-inflammatory drugs from aqueous solution using activated carbons: Review, Journal of Environmental Management, 190 (2017) 274-282.

[25] A.S. Mestre, J. Pires, J.M.F. Nogueira, J.B. Parra, A.P. Carvalho, C.O. Ania, Waste-derived activated carbons for removal of ibuprofen from solution: Role of surface chemistry and pore structure, Bioresource Technology, 100 (2009) 1720-1726.

[26] A.B. Pérez-Marín, V.M. Zapata, J.F. Ortuño, M. Aguilar, J. Sáez, M. Lloréns, Removal of cadmium from aqueous solutions by adsorption onto orange waste, Journal of Hazardous Materials, 139 (2007) 122-131.

[27] J. Lladó, C. Lao-Luque, B. Ruiz, E. Fuente, M. Solé-Sardans, A.D. Dorado, Role of activated carbon properties in atrazine and paracetamol adsorption equilibrium and kinetics, Process Safety and Environmental Protection, 95 (2015) 51-59.

[28] Z. Yu, S. Peldszus, P.M. Huck, Adsorption characteristics of selected pharmaceuticals and an endocrine disrupting compound-Naproxen, carbamazepine and nonylphenol—on activated carbon, Water Research, 42 (2008) 2873-2882.

[29] Ö. Gerçel, A. Özcan, A.S. Özcan, H.F. Gerçel, Preparation of activated carbon from a renewable bio-plant of Euphorbia rigida by $\mathrm{H}_{2} \mathrm{SO}_{4}$ activation and its adsorption behavior in aqueous solutions, Applied Surface Science, 253 (2007) 4843-4852.

[30] V. Calisto, G. Jaria, C.P. Silva, C.I.A. Ferreira, M. Otero, V.I. Esteves, Single and multicomponent adsorption of psychiatric pharmaceuticals onto alternative and commercial carbons, Journal of Environmental Management, 192 (2017) 15-24.

[31] A.D. McNaught, A. Wilkinson, IUPAC Compendium of Chemical Terminology, 2nd ed. (the "Gold Book"), Blackwell Scientific Publications, Oxford, 1997.

[32] J.R. Perrich, Activated carbon adsorption for wastewater treatment, CRC Press, 1981.

[33] J.M. Dias, M.C.M. Alvim-Ferraz, M.F. Almeida, J. Rivera-Utrilla, M. Sánchez-Polo, Waste materials for activated carbon preparation and its use in aqueous-phase treatment: A review, Journal of Environmental Management, 85 (2007) 833-846.

[34] S.A. Snyder, S. Adham, A.M. Redding, F.S. Cannon, J. DeCarolis, J. Oppenheimer, E.C. Wert, Y. Yoon, Role of membranes and activated carbon in the removal of endocrine disruptors and pharmaceuticals, Desalination, 202 (2007) 156-181. 
[35] C. Moreno-Castilla, J. Rivera-Utrilla, J.P. Joly, M.V. López-Ramón, M.A. Ferro-García, F. Carrasco-Marín, Thermal regeneration of an activated carbon exhausted with different substituted phenols, Carbon, 33 (1995) 1417-1423.

[36] R.J. Holmes, Chemical Modification of Activated Carbon Adsorbents, in: Chemical and Biological Defence Establishment, Brunel University, Porton Down, 1991.

[37] S. Balci, T. Dogu, H. Yucel, Characterization of Activated Carbon Produced from Almond Shell and Hazelnut Shell, Journal of Chemical Technology and Biotechnology 60 (1994) 419-426.

[38] P. Francesca, M. Sara, T. Luigi, New biosorbent materials for heavy metal removal: Product development guided by active site characterization, Water Research, 42 (2008) 2953-2962.

[39] D. Lozano-Castello, J.P. Marco-Lozar, C. Falco, M.-M. Titirici, D. Cazorla-Amoros, Porous Biomass-Derived Carbons: Activated Carbons, in: M.-M. Titirici (Ed.) Sustainable Carbon Material from Hydrothermal Processes Wiley \& Sons, Ltd, 2013.

[40] F. Rodriguez-Reinoso, M. Molina-Sabio, M.T. Gonzalez, The use of steam and CO2 as activating agents in the preparation of activated carbons, Carbon, 33 (1995) 15-23.

[41] T.J. Mays, Chapter 3 - Active Carbon Fibers, in: T.D. Burchell (Ed.) Carbon Materials for Advanced Technologies, Elsevier Science Ltd, Oxford, 1999, pp. 95-118.

[42] M.L. Sekirifa, M. Hadj-Mahammed, S. Pallier, L. Baameur, D. Richard, A.H. Al-Dujaili, Preparation and characterization of an activated carbon from a date stones variety by physical activation with carbon dioxide, Journal of Analytical and Applied Pyrolysis, 99 (2013) 155-160.

[43] T. Zhang, W.P. Walawender, L.T. Fan, M. Fan, D. Daugaard, R.C. Brown, Preparation of activated carbon from forest and agricultural residues through $\mathrm{CO} 2$ activation, Chemical Engineering Journal, 105 (2004) 53-59.

[44] J.H. Bang, H.-M. Lee, K.-H. An, B.-J. Kim, A study on optimal pore development of modified commercial activated carbons for electrode materials of supercapacitors, Applied Surface Science, 415 (2017) 61-66.

[45] T. Yang, A.C. Lua, Characteristics of activated carbons prepared from pistachio-nut shells by physical activation, Journal of Colloid and Interface Science, 267 (2003) 408-417.

[46] A. Dąbrowski, P. Podkościelny, Z. Hubicki, M. Barczak, Adsorption of phenolic compounds by activated carbon-A critical review, Chemosphere, 58 (2005) 1049-1070.

[47] R. Azargohar, A.K. Dalai, Steam and KOH activation of biochar: Experimental and modeling studies, Microporous and Mesoporous Materials, 110 (2008) 413-421.

[48] D. Angın, E. Altintig, T.E. Köse, Influence of process parameters on the surface and chemical properties of activated carbon obtained from biochar by chemical activation, Bioresource Technology, 148 (2013) 542-549.

[49] M. A.S., M. Galhetas, M.A. Andrade, Micropore size distribution of activated carbons: A key factor for deeper understanding of the adsoprtion mechanism of pharmaceuticals, Bulletin of the Spanish Coal Group, 40 (2016) 22-27.

[50] C. Pelekani, V.L. Snoeyink, Competitive adsorption between atrazine and methylene blue on activated carbon: the importance of pore size distribution, Carbon, 38 (2000) 1423-1436.

[51] C. Pelekani, V.L. Snoeyink, Competitive adsorption in natural water: role of activated carbon pore size, Water Research, 33 (1999) 1209-1219.

[52] C.J. Atkinson, J.D. Fitzgerald, N.A. Hipps, Potential mechanisms for achieving agricultural benefits from biochar application to temperate soils: a review, Plant and Soil, 337 (2010) 1-18.

[53] C. Cuhadar, Production And Characterization Of Activated Carbon From Hazelnut Shell And Hazelnut Husk, in: Chemical Engineering Middle East Technical University, 2005, pp. 129. 
[54] N.U. Yağşsi, Production and characterization of activated carbon from apricot stones, in: Chemical Engineering, The Middle East Technical University, 2004, pp. 132.

[55] J.H. Kwon, Sorption studies of the surface modified activated carbon with $\beta$-cyclodextrin, in, University of Saskatchewan, Saskatoon, 2007, pp. 164.

[56] T. Budinova, E. Ekinci, F. Yardim, A. Grimm, E. Björnbom, V. Minkova, M. Goranova, Characterization and application of activated carbon produced by H3PO4 and water vapor activation, Fuel Processing Technology, 87 (2006) 899-905.

[57] O. Pezoti Junior, A.L. Cazetta, R.C. Gomes, É.O. Barizão, I.P.A.F. Souza, A.C. Martins, T. Asefa, V.C. Almeida, Synthesis of $\mathrm{ZnCl2}$-activated carbon from macadamia nut endocarp (Macadamia integrifolia) by microwave-assisted pyrolysis: Optimization using RSM and methylene blue adsorption, Journal of Analytical and Applied Pyrolysis, 105 (2014) 166-176.

[58] A. Ahmadpour, D.D. Do, The preparation of activated carbon from macadamia nutshell by chemical activation, Carbon, 35 (1997) 1723-1732.

[59] R.G. Pereira, C.M. Veloso, N.M. da Silva, L.F. de Sousa, R.C.F. Bonomo, A.O. de Souza, M.O.d.G. Souza, R.d.C.I. Fontan, Preparation of activated carbons from cocoa shells and siriguela seeds using H3PO4 and ZnCL2 as activating agents for BSA and $\alpha$-lactalbumin adsorption, Fuel Processing Technology, 126 (2014) 476-486.

[60] J. Park, I. Hung, Z. Gan, O.J. Rojas, K.H. Lim, S. Park, Activated carbon from biochar: Influence of its physicochemical properties on the sorption characteristics of phenanthrene, Bioresource Technology, 149 (2013) 383-389.

[61] K.Y. Foo, B.H. Hameed, Preparation, characterization and evaluation of adsorptive properties of orange peel based activated carbon via microwave induced $\mathrm{K} 2 \mathrm{CO} 3$ activation, Bioresource Technology, 104 (2012) 679-686.

[62] Y. Sudaryanto, S.B. Hartono, W. Irawaty, H. Hindarso, S. Ismadji, High surface area activated carbon prepared from cassava peel by chemical activation, Bioresource Technology, 97 (2006) 734 739.

[63] M.J. Ahmed, S.K. Theydan, Physical and chemical characteristics of activated carbon prepared by pyrolysis of chemically treated date stones and its ability to adsorb organics, Powder Technology, 229 (2012) 237-245.

[64] A.S. Mestre, E. Tyszko, M.A. Andrade, M. Galhetas, C. Freire, A.P. Carvalho, Sustainable activated carbons prepared from a sucrose-derived hydrochar: remarkable adsorbents for pharmaceutical compounds, RSC Advances, 5 (2015) 19696-19707.

[65] A.L. Cazetta, A.M.M. Vargas, E.M. Nogami, M.H. Kunita, M.R. Guilherme, A.C. Martins, T.L. Silva, J.C.G. Moraes, V.C. Almeida, $\mathrm{NaOH}$-activated carbon of high surface area produced from coconut shell: Kinetics and equilibrium studies from the methylene blue adsorption, Chemical Engineering Journal, 174 (2011) 117-125.

[66] Z. Liu, Y. Huang, G. Zhao, Preparation and Characterization of Activated Carbon Fibers from Liquefied Wood by $\mathrm{ZnCl}_{2}$ Activation, 2016.

[67] J. Choma, M. Jaroniec, Chapter 3 Characterization of nanoporous carbons by using gas adsorption isotherms, in: T.J. Bandosz (Ed.) Interface Science and Technology, Elsevier, 2006, pp. 107-158.

[68] M.L. Pinto, A.S. Mestre, A.P. Carvalho, J. Pires, Comparison of Methods to Obtain Micropore Size Distributions of Carbonaceous Materials from $\mathrm{CO}_{2}$ Adsorption Based on the Dubinin-Radushkevich Isotherm, Industrial \& Engineering Chemistry Research, 49 (2010) 4726-4730. [69] A.S. Mestre, R.A. Pires, I. Aroso, E.M. Fernandes, M.L. Pinto, R.L. Reis, M.A. Andrade, J. Pires, S.P. Silva, A.P. Carvalho, Activated carbons prepared from industrial pre-treated cork: Sustainable 
adsorbents for pharmaceutical compounds removal, Chemical Engineering Journal, 253 (2014) 408417.

[70] David W. Rutherford, Robert L. Wershaw, L.G. Cox, Changes in Composition and Porosity Occurring During the Thermal Degradation of Wood and Wood Components, in, U.S. Geological Survey, Reston, Virginia, 2005.

[71] L. Li, P.A. Quinlivan, D.R.U. Knappe, Effects of activated carbon surface chemistry and pore structure on the adsorption of organic contaminants from aqueous solution, Carbon, 40 (2002) 20852100.

[72] A.S. Mestre, S.C.R. Marques, A.P. Carvalho, Effect of the Alcohol Cosolvent in the Removal of Caffeine by Activated Carbons, Industrial \& Engineering Chemistry Research, 51 (2012) 9850-9857.

[73] P.A. Quinlivan, L. Li, D.R.U. Knappe, Effects of activated carbon characteristics on the simultaneous adsorption of aqueous organic micropollutants and natural organic matter, Water Research, 39 (2005) 1663-1673.

[74] G.G. Stavropoulos, P. Samaras, G.P. Sakellaropoulos, Effect of activated carbons modification on porosity, surface structure and phenol adsorption, Journal of Hazardous Materials, 151 (2008) 414-421. [75] A.N.A. El-Hendawy, Influence of $\mathrm{HNO} 3$ oxidation on the structure and adsorptive properties of corncob-based activated carbon, Carbon, 41 (2003) 713-722.

[76] M.S. Shafeeyan, W.M.A.W. Daud, A. Houshmand, A. Shamiri, A review on surface modification of activated carbon for carbon dioxide adsorption, Journal of Analytical and Applied Pyrolysis, 89 (2010) 143-151.

[77] A.N.A. El-Hendawy, S.E. Samra, B.S. Girgis, Adsorption characteristics of activated carbons obtained from corncobs, Colloids and Surfaces A: Physicochemical and Engineering Aspects, 180 (2001) 209-221.

[78] Z. Jiang, Y. Liu, X. Sun, F. Tian, F. Sun, C. Liang, W. You, C. Han, C. Li, Activated Carbons Chemically Modified by Concentrated H2SO4 for the Adsorption of the Pollutants from Wastewater and the Dibenzothiophene from Fuel Oils, Langmuir, 19 (2003) 731-736.

[79] P. Nowicki, J. Kazmierczak, R. Pietrzak, Comparison of physicochemical and sorption properties of activated carbons prepared by physical and chemical activation of cherry stones, Powder Technology, 269 (2015) 312-319.

[80] K. Sun, J.c. Jiang, Preparation and characterization of activated carbon from rubber-seed shell by physical activation with steam, Biomass and Bioenergy, 34 (2010) 539-544.

[81] A. Bazan-Wozniak, P. Nowicki, R. Pietrzak, The influence of activation procedure on the physicochemical and sorption properties of activated carbons prepared from pistachio nutshells for removal of $\mathrm{NO}_{2} / \mathrm{H}_{2} \mathrm{~S}$ gases and dyes, Journal of Cleaner Production, 152 (2017) 211-222.

[82] D. Prahas, Y. Kartika, N. Indraswati, S. Ismadji, Activated carbon from jackfruit peel waste by $\mathrm{H}_{3} \mathrm{PO}_{4}$ chemical activation: Pore structure and surface chemistry characterization, Chemical Engineering Journal, 140 (2008) 32-42.

[83] P.T. Williams, A.R. Reed, High grade activated carbon matting derived from the chemical activation and pyrolysis of natural fibre textile waste, Journal of Analytical and Applied Pyrolysis, 71 (2004) 971-986.

[84] R.A. A.J., M.A. Lillo-Rodenas, C.S.M. Lecea, A. Linares-Solano, Hydrothermal and conventional $\mathrm{H}_{3} \mathrm{PO}_{4}$ activation of two natural bio-fibers, Carbon, 50 (2012) 3158-3169.

[85] E. Yagmur, M. Ozmak, Z. Aktas, A novel method for production of activated carbon from waste tea by chemical activation with microwave energy, Fuel, 87 (2008) 3278-3285. 
[86] S.M. Yakout, G. Sharaf El-Deen, Characterization of activated carbon prepared by phosphoric acid activation of olive stones, Arabian Journal of Chemistry, (2012).

[87] M.A. Yahya, Z. Al-Qodah, C.W.Z. Ngah, Agricultural bio-waste materials as potential sustainable precursors used for activated carbon production: A review, Renewable and Sustainable Energy Reviews, 46 (2015) 218-235.

[88] P. Patnukao, P. Pavasant, Activated carbon from Eucalyptus camaldulensis Dehn bark using phosphoric acid activation, Bioresource Technology, 99 (2008) 8540-8543.

[89] D. Kalderis, S. Bethanis, P. Paraskeva, E. Diamadopoulos, Production of activated carbon from bagasse and rice husk by a single-stage chemical activation method at low retention times, Bioresource Technology, 99 (2008) 6809-6816.

[90] K. Juejun, J. Supunnee, T. Chaiyot, Effect of carbonization temperature on properties of char and activated carbon from coconut shell, Qingdao Daxue Shifanxueyuan Xuebao/Journal of Teachers College Qingdao University, 20 (2013) 269-278.

[91] C.Y. Yin, M.K. Aroua, W.M.A.W. Daud, Review of modifications of activated carbon for enhancing contaminant uptakes from aqueous solutions, Separation and Purification Technology, 52 (2007) 403-415.

[92] N. Adhoum, L. Monser, Removal of cyanide from aqueous solution using impregnated activated carbon, Chemical Engineering and Processing: Process Intensification, 41 (2002) 17-21.

[93] J. Jaramillo, P.M. Álvarez, V. Gómez-Serrano, Oxidation of activated carbon by dry and wet methods, Fuel Processing Technology, 91 (2010) 1768-1775.

[94] C. Moreno-Castilla, M.V. López-Ramón, F. Carrasco-Marín, Changes in surface chemistry of activated carbons by wet oxidation, Carbon, 38 (2000) 1995-2001.

[95] J.L. Figueiredo, M.F.R. Pereira, M.M.A. Freitas, J.J.M. Orfao, Modification of the surface chemistry of activated carbons, Carbon, 37 (1999) 1379 - 1389.

[96] H. Valdés, M. Sánchez-Polo, J. Rivera-Utrilla, C.A. Zaror, Effect of Ozone Treatment on Surface Properties of Activated Carbon, Langmuir, 18 (2002) 2111-2116.

[97] A. Kumar, H. Mohan Jena, High surface area microporous activated carbons prepared from Fox nut (Euryale ferox) shell by zinc chloride activation, Applied Surface Science, 356 (2015) 753-761.

[98] M. Manes, Activated Carbon Adsorption Fundamentals, in: Activated Carbon Principles and Applications, www.pacslabs.com.

[99] Y.-T. Hung, H.H. Lo, L.K. Wang, J.R. Taricska, K.H. Li, Powdered Activated Carbon Adsorption, in: L.K. Wang, Y.T. Hung, N.K. Shammas (Eds.) Advanced Physicochemical Treatment Processes, Humana Press, Totowa, NJ, 2006, pp. 123-153.

[100] H. Marsh, F. Rodríguez-Reinoso, Chapter 2 - Activated Carbon (Origins), in: Activated Carbon, Elsevier Science Ltd, Oxford, 2006, pp. 13-86.

[101] A. Proctor, P.M.A. Sherwood, X-ray photoelectron spectroscopic studies of carbon fibre surfaces. III-Industrially treated fibres and the effect of heat and exposure to oxygen, Surface and Interface Analysis, 4 (1982) 212-219.

[102] U. Zielke, K.J. Huttinger, W.P. Hoffman, Surface-oxidized carbon fibers: I. Surface structure and chemistry, Carbon, 34 (1996) 983-998.

[103] J.H. Zhou, Z.-J. Sui, J. Zhu, P. Li, D. Chen, Y.C. Dai, W.-K. Yuan, Characterization of surface oxygen complexes on carbon nanofibers by TPD, XPS and FTIR, Carbon, 45 (2007) 785-796.

[104] S.A. Dastgheib, T. Karanfil, W. Cheng, Tailoring activated carbons for enhanced removal of natural organic matter from natural waters, Carbon, 42 (2004) 547-557. 
[105] J. Xu, L. Chen, H. Qu, Y. Jiao, J. Xie, G. Xing, Preparation and characterization of activated carbon from reedy grass leaves by chemical activation with $\mathrm{H}_{3} \mathrm{PO}_{4}$, Applied Surface Science, 320 (2014) 674-680.

[106] N. Petrov, T. Budinova, M. Razvigorova, E. Ekinci, F. Yardim, V. Minkova, Preparation and characterization of carbon adsorbents from furfural, Carbon, 38 (2000) 2069-2075.

[107] H. Guedidi, L. Reinert, Y. Soneda, N. Bellakhal, L. Duclaux, Adsorption of ibuprofen from aqueous solution on chemically surface-modified activated carbon cloths, Arabian Journal of Chemistry, 10 (2017) S3584 - S3594.

[108] X. Ge, Z. Wu, Z. Wu, Y. Yan, G. Cravotto, B.-C. Ye, Microwave-assisted modification of activated carbon with ammonia for efficient pyrene adsorption, Journal of Industrial and Engineering Chemistry, 39 (2016) 27-36.

[109] S. Yang, L. Li, T. Xiao, Y. Zhang, D. Zheng, Promoting effect of ammonia modification on activated carbon catalyzed peroxymonosulfate oxidation, Separation and Purification Technology, 160 (2016) 81-88.

[110] A.S.C. Lopes, S.M.L. Carvalho, D.S.B. Brasil, R.A. Mendes, M.O. Lima, Surface Modification of Commercial Activated Carbon (CAG) for the Adsorption of Benzene and Toluene, American Journal of Analytical Chemistry, 06, (2015) $528-538$.

[111] H. Gong, Z. Chen, Y. Fan, M. Zhang, W. Wu, W. Wang, Surface modification of activated carbon for siloxane adsorption, Renewable Energy, 83 (2015) 144-150. 


\title{
Chapter 3
}

\section{Pyrolysis of dedicated bioenergy crops grown on reclaimed mine land in West Virginia}

\begin{abstract}
Dedicated energy crops are auspicious cellulosic sources for sustainable bioenergy production. Pyrolysis, a thermochemical conversion process, of these biomass feedstock produces bio-oil and biochar to be used as a soil amendment and adsorbent for waste water treatment. In this study, pyrolysis of two Miscanthus (Miscanthus $x$ giganteus) sterile varieties (Private and Public varieties) and Switchgrass (Panicum virgatum L.) sterile varieties (Bomaster and Kanlow varieties), grown on reclaimed coal-mining land in West Virginia followed by characterization of their pyrolysis products were carried out. The oven-dried samples were pyrolyzed in a fixed-bed batch reactor under an inert condition and at a temperature of $500{ }^{\circ} \mathrm{C}$ to produce biochar and bio-oil. The product yields, energy and carbon conversion yields, elemental composition, volatile, ash and energy contents of the pyrolysis products were carried out and reported. Statistical analysis of the pyrolysis data showed that there was no significant difference in the biochar yield (about 30.00\% yield) obtained from the two varieties of Switchgrass and Miscanthus. The bio-oil yields were in the range of 45.00 to $51.00 \%$ with the Miscanthus (private variety) having the highest bio-oil yield of 50.61\%. The carbon content of the biomass, biochar and bio-oil were found to be $46.80-48.02 \%, 77.72-80.23 \%$ and $54.68-59.68 \%$, respectively. Average heating values were found to be $19.49 \mathrm{MJ} / \mathrm{kg}, 29.01 \mathrm{MJ} / \mathrm{kg}$ and $24.98 \mathrm{MJ} / \mathrm{kg}$ for the biomass, biochar and bio-oil, respectively. $\mathrm{CO}$ and $\mathrm{CO}_{2}$ were found to be the major components of the non-condensable gas and the high concentration of $\mathrm{CO}_{2}$ as a non-combustible gas makes the noncondensable gas samples unfit as a fluidizing medium.
\end{abstract}

Keywords: Pyrolysis, Switchgrass, Miscanthus, Bio-oil, Biochar, Non-condensable gas

Published: Oluwatosin Oginni, Kaushlendra Singh, John W. Zondlo. Pyrolysis of dedicated bioenergy crops grown on reclaimed mine land in West Virginia. Journal of Analytical and Applied Pyrolysis, 2017, 123: 319-329 


\subsection{Introduction}

In recent years, there has been a continuous increase in energy demand due to rising population and enhanced energy consumption in various sectors [1]. According to EIA [2], the total primary energy consumption for all sectors has been projected to increase from 97.1 quadrillion Btu in 2013 to 105.7 quadrillion Btu in 2040, majority of which is supplied from fossil resources leading to increased greenhouse gas emission. According to an estimate, consumption of gasoline and diesel in the United States resulted in 1522 million metric tons of $\mathrm{CO}_{2}$ greenhouse gas emissions, which was equivalent to $83 \%$ of total $\mathrm{CO}_{2}$ emissions by the U.S. transportation sector and $28 \%$ of total U.S. energy-related $\mathrm{CO}_{2}$ emissions [3]. Due to these adverse environmental impacts coupled with the non-renewable and finite nature of fossil fuels, it becomes imperative to develop sustainable and environmental friendly energy sources which will reduce world's dependency on fossil fuels [4-6] and $\mathrm{CO}_{2}$ emission. These energy sources are termed renewable energy sources (e.g. biomass, wind, solar and geothermal) because they are continuously replenished, if managed sustainably. About 9\% of the energy consumed (total of 97 quadrillion Btu energy) in United States was obtained from renewable resources in 2011 [7].

In the spectrum of renewable energy sources, biomass is the only renewable carbon source, which can be converted into liquid transportation fuel, a possible substitute to crude oils [8,9]. Perlack and Stokes [10] state that the United States has potential to produce over 1 billion dry tons of biomass annually for bioenergy applications, which can be converted into 90 billion gallons of liquid fuels, enough to displace about $30 \%$ of the nation's current annual petroleum consumption.

The thermochemical conversion of lignocellulosic biomass has received immense interest as a method for production of liquid fuels as compared to its biochemical counterpart. This is because thermochemical conversion processes can accommodate more diverse feedstock at a time than the biochemical conversion processes. It is also evident that the development of a cost effective biochemical conversion processes of biomass into ethanol is yet to achieve commercialization. Part of the problem is attributed to the large variability in biomass composition, which may require different enzymes or chemical processes for hydrolysis of the biomass polysaccharides into fermentable sugars,

and then the development and use of recombinant organisms that can ferment the C5 and C6 sugars produced $[11,12]$. Pyrolysis is defined as the thermochemical conversion process usually conducted at a temperature of 400 to $600{ }^{\circ} \mathrm{C}$ in the absence of oxygen to produce a bio-oil (usually contains acids, alcohols, aldehydes, ketones, esters, heterocyclic derivatives and phenolic compounds) along with some solids (char), and some gases (methane, carbon monoxide, carbon dioxide) [13, 14]. The 
proportions of the products are largely dependent on factors such as operating temperature, pressure, oxygen content and feedstock characteristics

Important factors considered in the choice of feedstock for bio-oil production includes the crop production yield, energy conversion efficiency, availability of the feedstock and properties of the pyrolysis products. This relationship has been reported in several publications. However, more interest has been on the use of dedicated energy crops for biomass pyrolysis in comparison to other feedstock type. $\mathrm{C}_{4}$ perennial grasses such as Miscanthus (Miscanthus $x$ giganteus) and Switchgrass (Panicum virgatum $\mathrm{L}$.) have been extensively studied due to their excellent conservation attributes, efficient water and nitrogen use, high biomass yields with limited inputs, high adaptability to marginal land and they do not require annual reseeding $[15,16]$.

However, with the current volatile crude oil and natural gas markets, which are driven by discoveries of new resources, coupled with the poor physico-chemical properties of bio-oil which adversely impact its use as a substitute for fossil fuel, there is a need to provide an alternate use of these available biomass feedstock by transforming them into biochar intermediate through pyrolysis, which may be latter used to produce activated carbon. Conversion of bioenergy crops to activated carbons will serve dual benefits. First, it can be used to produce commercial adsorbent, which will provide an economic benefit to the growers and second, it will sequester biomass carbon in to a stable form.

Therefore, the objective of this research is to evaluate the influence of two dedicated energy crops and their varieties on production and properties of resulting pyrolysis products. This article documents characteristics of pyrolysis products obtained from the pyrolysis of two varieties of energy crops (Switchgrass and Miscanthus) grown on reclaimed mining land in the State of West Virginia. 


\subsection{Materials and Methods}

\subsubsection{Sample preparation}

Samples used in this experiment were two sterile varieties (public and private clonal varieties) of Miscanthus x giganteus and two varieties (Kanlow and Bomaster) of Switchgrass (Panicum virgatum L.). Details of growth sites and establishment of all the Switchgrass and Miscanthus varieties used in the pyrolysis experiments have been documented by Skousen et al. [17]. To be specific, the test samples were harvested from Alton site, a reclaimed mine land in Upshur County, West Virginia. This site was mined for the Upper, Middle, and Lower Kittanning coal seams. The 30-ha area selected for Switchgrass and Miscanthus plantings was reclaimed in 1985 with less than $15 \mathrm{~cm}$ depth of soil replaced over mixed overburden. Grass and legume species were planted and the soils were fertilized and limed according to regulations at the time. This site supported a 100\% ground cover of herbaceous plants during the ensuing 25 years [17].

The biomass samples were chopped into small sizes using a kitchen meat cutting knife and then oven dried at $103{ }^{\circ} \mathrm{C}$ for 24 hours prior to the pyrolysis experiment.

\subsubsection{Pyrolysis experiment}

The pyrolysis experiments were performed in a fixed-bed batch reactor having a diameter of 22.86 $\mathrm{cm}$ and a height of $25.40 \mathrm{~cm}$. The experimental setup is showed in Figure 3.1. For a typical experiment, pre-weighed amount of the oven-dried sample, approximately $400 \mathrm{~g}$, was placed inside the airtight reactor. The sample filled reactor was placed in a furnace (Model: BF51728C, Thermo scientific, NC) and nitrogen gas was passed through the reactor to flush out any trapped air in the reactor for about 10 minutes before heating up the furnace. The furnace was heated from room temperature to a temperature of $500{ }^{\circ} \mathrm{C}$ under a nitrogen gas flow of $2 \mathrm{~L} / \mathrm{min}$. The temperature was kept constant at $500{ }^{\circ} \mathrm{C}$ for 30 minutes. A K-type thermocouple placed inside a thermal well located above $6.35 \mathrm{~cm}$ from the bottom of the reactor was used to measure biomass temperature. The temperature data was logged into the computer via a data acquisition instrument (Model: OM-DAQPRO-5300). The nitrogen flow kept the pyrolysis reaction under inert condition and swept the pyrolysis vapors generated in the reactor into a series of ice-bath condensers. The bio-oil produced during the pyrolysis were collected from the condensers and a sample of the incondensable gas products given off during the pyrolysis were collected with an airtight syringe (Model: 1000 series, Hamilton, NV) at reactor temperatures of 200, 300, 400 and $500{ }^{\circ} \mathrm{C}$ for gas composition analysis. After the experiment, the reactor was allowed to cool down to room temperature while constantly purging nitrogen gas and thereafter the mass of the 
reactor containing the biochar was measured and subtracted from the mass of empty reactor to obtain the mass of the biochar produced. In addition, the mass of the condenser and bio-oil produced were measured and subtracted from the mass of empty condensers to determine the mass of the bio-oil produced.

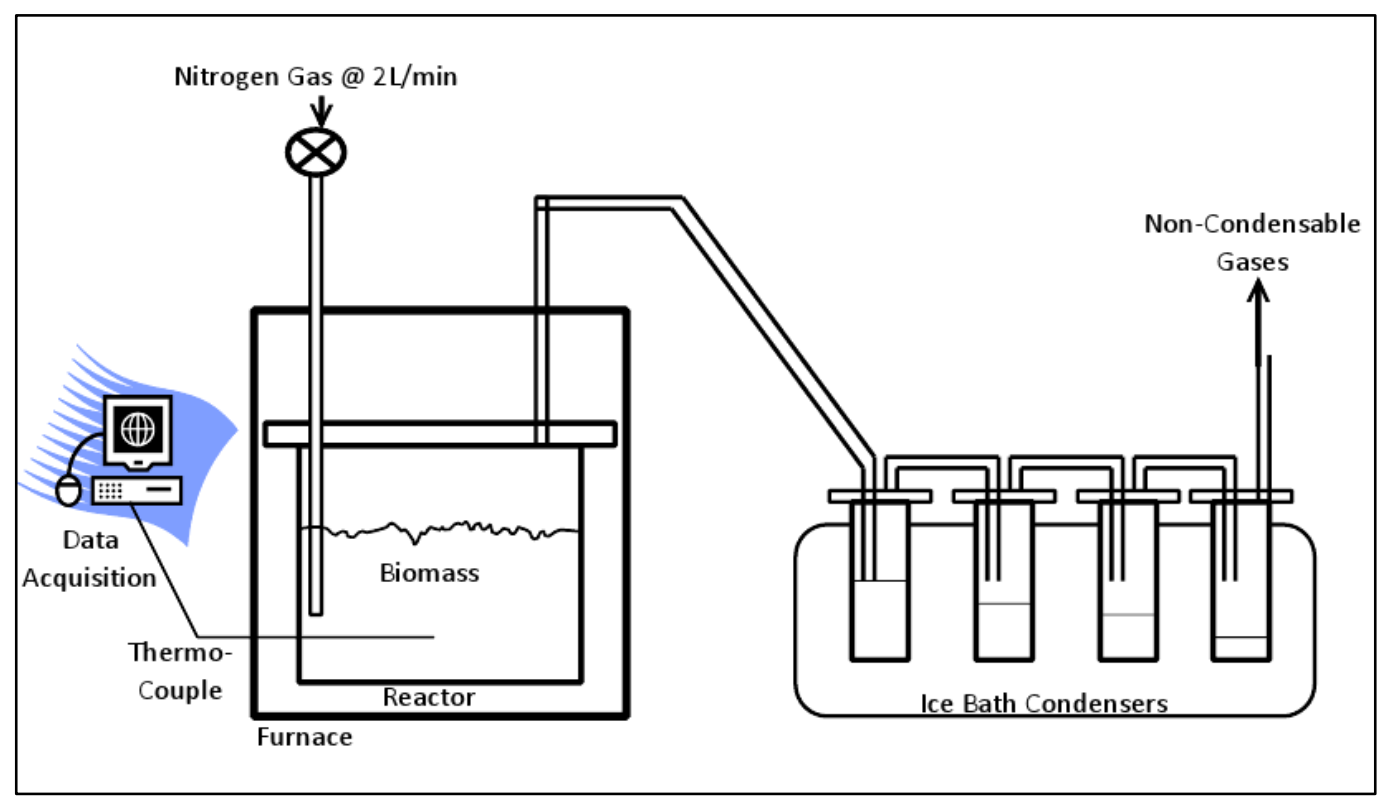

Figure 3.1: Experimental setup for biomass pyrolysis [18]

\subsubsection{Analytical measurements}

Ultimate analyses (carbon, hydrogen, nitrogen and sulfur contents) of the biomass, bio-oil and bio-char samples were determined using a CHNS analyzer (Series II CHNS/O Analyzer 2400, PerkinElmer, Waltham, MA). The calorific values of the biomass, bio-oil and bio-char samples were estimated using the unified correlation for computation of higher heating value from elemental analysis of fuels provided by Channiwala and Parikh [19]. The validity of the correlation has been established for fuels having wide range of elemental composition, i.e. C: $0.00-92.25 \%$, H: $0.43-25.1 \%$, O: 0.00 $-50.00 \%$, N: $0.00-5.60 \%$, S: $0.00-94.08 \%$ and ash: $0.00-71.4 \%$. However, beyond the specified ranges of $\mathrm{C}, \mathrm{H}, \mathrm{O}, \mathrm{N}, \mathrm{S}$ and ash, the predictive accuracy of the correlation does not hold true. Proximate analyses (fixed carbon, moisture, volatile matter and ash content) was carried out on the biomass and bio-char samples using a proximate analyzer (LECO 701, LECO Corporation, St. Joseph, MI) following the ASTM D3174 standard [20]. The $\mathrm{pH}$ value of the bio-oil was measured using an Accumet pH meter (Model: AB 15, Fisher Scientific, Pittsburgh, PA) and the viscosity of the bio-oil was also measured using a viscometer (Model: DV2T, Brookfield Middleboro, MA). The composition of the 
gas samples was analyzed using a gas chromatograph (Model: Clarus GC 580, PerkinElmer Waltham, MA).

The mineral composition, Acid Detergent Fiber (ADF), Neutral Detergent Fiber, Acid Detergent Lignin (ADL) and lignin were measured at the University of Georgia Agricultural and Environmental Services Laboratories, Athens, GA. Data on fiber analysis (obtained using the NIR method) and ash content of the varieties which were employed to determine the cellulose and hemicellulose contents according to the following equations:

$$
\begin{aligned}
& \% \text { Hemicellulose }=\% \text { NDF - \% ADF } \\
& \% \text { Cellulose }=\% \text { ADF - ( } \% \text { Lignin }+\% \text { Ash })
\end{aligned}
$$

\subsubsection{Bio-oil and biochar production efficiencies}

The biochar and bio-oil production efficiencies were defined as percent yields of bio-oil and biochars, percent feedstock carbon and energy captured by biochars and bio-oils, which are also referred as carbon yields and energy yields, respectively.

Bio-oil and bio-char yield were estimated using the following expression;

$$
\mathrm{Y}_{\text {Bio-oil/Biochar }}=\frac{\text { Mass of bio-oil/biochar }}{\text { Mass of oven dried biomass }} X 100
$$

The energy yield ( $\left.\eta_{\text {Energy }}\right)$ and carbon yield $\left(C_{\text {yield }}\right)$ of the biochar was calculated using the following expressions:

$$
\prod_{\text {Energy }}=\mathrm{Y}_{\text {Biochar }} \frac{\mathrm{HHV}_{\text {Biochar }}}{\mathrm{HHV}_{\text {Feedstock }}}
$$

where $\prod_{\text {Energy }}=$ energy yield; $\mathrm{Y}_{\text {Biochar }}=$ yield of bio-char; $\mathrm{HHV}_{\text {Biochar }}=$ calorific value of bio-char $(\mathrm{MJ} / \mathrm{kg}) ; \mathrm{HHV}_{\text {Feedstock }}=$ calorific value of the biomass feedstock $(\mathrm{MJ} / \mathrm{kg})$.

$$
\mathrm{C}_{\text {Yield }}=\mathrm{Y}_{\text {Biochar }} \frac{C_{\text {Biochar }}}{C_{\text {Feedstock }}}
$$

where $\mathrm{C}_{\text {Yield }}=$ carbon yield; $\mathrm{C}=$ carbon content of biochar or biomass feedstock.

\subsubsection{Experimental design and statistical analysis}

A completely randomized design was employed for the experiment. Two varieties of Miscanthus and Switchgrass were used for the pyrolysis experiment. The pyrolysis was carried out in triplicate for each of the variety. The properties characterization of the pyrolysis products was also carried out in triplicate. Microsoft Excel 2010 was used in summarizing and generating graphs. The $t$ test procedure in SAS statistical software (University Edition) was used in performing a $t$ test (at $95 \%$ 
confidence interval) to determine the effect of biomass types and their varieties on the yield and properties of the pyrolysis products. The results are presented in means and standard deviation.

\subsection{Results and Discussion}

\subsubsection{Proximate and ultimate analyses}

Table 3.1 shows the characterization of the Miscanthus and Switchgrass varieties. Both energy crops had similar ash and fixed carbon contents. The ash contents were not significantly different irrespective of the varieties. The ash contents of the Miscanthus varieties $(1.37-1.83 \%$ d.b) were lower than the Miscanthus varieties $(2.16$ - 3.71\%) reported by Brosse et al. [21]. The ash content of the Switchgrass varieties (1.2-2.02\%) were also relatively lower in comparison to the values reported by Fasina [22] for Switchgrass (2.96\% d.b) and Hu et al. [23] for Alamo whole Switchgrass plant (3.8\%) and Kanlow whole Switchgrass plant (4.0\%). Hu et al. [23] further reported the ash contents of the leaves portion of both Alamo and Kanlow Switchgrass to be $4.6 \%$ while the internodes and nodes portion of the two Switchgrass varieties were between 2.1 to $2.5 \%$. The method of harvesting the Switchgrass were not mentioned but the type of soil used (coarse sandy loam -fine, kaolinitic, thermic typic kanhapludults) was stated. The high ash content of the leaves portion may be due to accumulation of minerals absorbed from the soil by the plants ultimately resulting in the high ash content of the whole plant. The low ash content reported for the samples in this present research could be due to the harvesting technique employed.

The samples were hand clipped and transferred directly into bag removing any possibility of picking dirt or soil with the samples. The low ash content values obtained for the samples are an indication of a low deposit of bulk inorganic material after combustion. The alkali metals contained in the ash have been shown to be catalysts for changing the depolymerization mechanisms during pyrolysis leading to changes in the composition of pyrolysis products, hence the need to quantify the ash content of the biomass [24].

The fixed carbon, which represents the solid combustible residue that remains after the volatile matter has been expelled during a heating/combustion process, was found to be in the range of 16 17\%. This result was similar to previous published works [16, 25-27]. Kanlow Switchgrass had significantly higher volatile matter content (80.59\%) than the Bomaster Switchgrass $(79.56 \%)$ and there was no significant difference $(\mathrm{p}<0.05)$ in the volatile content of the Miscanthus varieties. While the volatile content of the Miscanthus varieties were not statistically different, less than $1 \%$ difference in volatile matter may cause a significant difference in pyrolysis product yields. Volatile matter content 
is known to greatly influence bio-oil and biochar yields [28]. The volatile content represents the components of a material, except for moisture, which are liberated at a high temperature in the absence of air.

The statistical analysis showed that there was significant difference $(p<0.05)$ in the sulfur content of the varieties with Bomaster Switchgrass having the highest sulfur content of $0.56 \%$ while the hydrogen, nitrogen and oxygen contents were not significantly different for all the varieties. The carbon content of both Switchgrass and Miscanthus varieties ranges between $46-48 \%$ while hydrogen was approximately $6 \%$. The nitrogen and sulfur contents were less than $1 \%$. A high concentration of nitrogen and sulphur can result in emissions of $\mathrm{NO}_{\mathrm{x}}$ and $\mathrm{SO}_{2}$, hence a low percentage is desirable in a biomass feedstock [21]. The remaining percentage represents the oxygen content. The elemental compositions for the Switchgrass and Miscanthus varieties were found to be higher than those reported by Imam and Capareda [29] and Bok et al. [27] except the oxygen content. Higher heating values obtained were between 19 and $20 \mathrm{MJ} / \mathrm{kg}$. The results compare favorably with other published works on heating values of biomass feedstock [30-32]. The higher heating value is the total energy content released when the fuel is burnt in air, including the latent heat contained in the water vapor and therefore represents the maximum amount of energy potentially recoverable from a given biomass source [31]. The heating value is tightly connected with the biomass elemental composition and it is also influenced by the variation in the cell wall composition and ash content. The proportion of lignin can be used as an indicator of the heating value due its relatively lower oxygen concentration than holocellulose [21]

Table 3.1: Characterization of two varieties of Miscanthus and Switchgrass feedstock

\begin{tabular}{lllll}
\hline \multirow{2}{*}{ Property } & \multicolumn{2}{c}{ Miscanthus } & \multicolumn{2}{c}{ Switchgrass } \\
\cline { 2 - 5 } & Public & Private & Bomaster & Kanlow \\
\hline Ash (\%) & $1.37 \pm 0.99^{\mathrm{a}}$ & $1.83 \pm 0.40^{\mathrm{a}}$ & $2.02 \pm 0.26^{\mathrm{a}}$ & $1.21 \pm 0.78^{\mathrm{a}}$ \\
Fixed carbon (\%) & $18.06 \pm 0.05^{\mathrm{a}}$ & $18.10 \pm 0.04^{\mathrm{a}}$ & $18.22 \pm 0.20^{\mathrm{a}}$ & $17.03 \pm 0.25^{\mathrm{a}}$ \\
Volatiles (\%) & $80.57 \pm 0.94^{\mathrm{a}, \mathrm{b}}$ & $80.06 \pm 0.37^{\mathrm{a}, \mathrm{b}}$ & $79.76 \pm 0.08^{\mathrm{b}}$ & $80.59 \pm 0.60^{\mathrm{a}}$ \\
Carbon (\%) & $47.00 \pm 0.06^{\mathrm{a}}$ & $46.80 \pm 0.11^{\mathrm{a}}$ & $48.02 \pm 2.31^{\mathrm{a}}$ & $47.03 \pm 0.17^{\mathrm{a}}$ \\
Hydrogen (\%) & $6.44 \pm 0.04^{\mathrm{a}}$ & $6.45 \pm 0.00^{\mathrm{a}}$ & $6.71 \pm 0.34^{\mathrm{a}}$ & $6.45 \pm 0.03^{\mathrm{a}}$ \\
Nitrogen (\%) & $0.44 \pm 0.07^{\mathrm{a}}$ & $0.47 \pm 0.05^{\mathrm{a}}$ & $0.52 \pm 0.12^{\mathrm{a}}$ & $0.53 \pm 0.04^{\mathrm{a}}$ \\
Sulfur (\%) & $0.50 \pm 0.01^{\mathrm{b}}$ & $0.54 \pm 0.01^{\mathrm{a}, \mathrm{b}}$ & $0.56 \pm 0.01^{\mathrm{a}, \mathrm{b}}$ & $0.54 \pm 0.03^{\mathrm{b}}$ \\
Oxygen (\%) & $45.63 \pm 0.09^{\mathrm{a}}$ & $45.74 \pm 0.12^{\mathrm{a}}$ & $44.19 \pm 2.77^{\mathrm{a}}$ & $45.46 \pm 0.16^{\mathrm{a}}$ \\
HHV (MJ/kg) & $19.29 \pm 0.04^{\mathrm{a}}$ & $19.22 \pm 0.05^{\mathrm{a}}$ & $20.11 \pm 1.50^{\mathrm{a}}$ & $19.34 \pm 0.11^{\mathrm{a}}$ \\
\hline
\end{tabular}




\subsubsection{Mineral composition}

The mineral compositions of Miscanthus and Switchgrass varieties are presented in Table 3.2. The phosphorus, potassium and calcium contents of the four varieties are similar. However, the magnesium content of the Switchgrass varieties was higher than that of Miscanthus varieties because the soils where the Switchgrass varieties were grown had higher magnesium content than the soils where Miscanthus varieties were grown [17]. It is expected that mineral composition of bioenergy crops is directly related to the mineral contents of soils in which they are grown. Meanwhile, Private Miscanthus had the highest manganese and sodium concentrations and Public Miscanthus had the highest iron concentration. Jin et al. [26] reported the mineral compositions of the bark, sapwood and heartwood for two woody biomasses (red oak and yellow poplar). The zinc and sodium concentrations reported for these two woody biomasses were lower in comparison to the Switchgrass and Miscanthus varieties in this study. However, the manganese and aluminum concentrations reported for the barks of both red oak and yellow poplar were higher than the ones for the varieties in this study. This variation in the mineral compositions of woody biomass and dedicated energy crops is an important factor, which influences the final pyrolysis products. Raveendran et al. [33] and Czernik et al. [34] showed that the main plant components which affect pyrolysis degradation are sodium, potassium, magnesium and silicates.

The percentage of potassium content in the biomass varieties is slightly below average $(0.36-$ $0.43 \%$ ) and it is higher in comparison to phosphorus, calcium and magnesium. Potassium is a strong catalyst for biochar gasification and since $\mathrm{CO}_{2}$ and $\mathrm{H}_{2} \mathrm{O}$ are primary pyrolysis products, they react with biochar in the presence of potassium to form $\mathrm{CO}$ and $\mathrm{H}_{2}$, thereby decreasing biochar yield [33]. Patwardhan et al. [35] and Nowakowski and Jones [36] showed that potassium majorly has a direct effect on the thermochemical breakdown of cellulose and this impact can lower the yields of levoglucosan and increase lower molecular weight deoxygenated compounds during the pyrolysis of cellulose. A higher production of acetic and propanoic acid alongside cyclopentene derivatives and non-methoxylated phenols such as phenol, cresols, and dimethylphenol occurs during cellulose depolymerization catalyzed by potassium. It can reduce ash melting point leading to slag and agglomeration during thermal process thereby lowering combustion efficiency [37, 38]. Bradbury et al. [39] also stated that the yield of organic matter to gas and char is dependent on the inorganic constituents. The inorganic constituents promote secondary reactions which causes break down of higher molecular compounds to smaller ones. Furthermore, Fahmi et al. [24] reported an inverse 
relationship between biomass mineral contents and lignin content. The study showed that char yield from pyrolysis increased with increase in inorganic constituents; hence, a reduction in lignin content will result in low char yield.

\begin{tabular}{lcccc}
\multirow{2}{*}{$\begin{array}{c}\text { Table 3.2: Mineral composition in percent (\%) and parts per million (ppm) of Miscanthus } \\
\text { Minerals }\end{array}$} & \multicolumn{2}{c}{$\begin{array}{c}\text { Miscanthus } \\
\text { and Switchgrass varieties (as received) }\end{array}$} \\
\cline { 2 - 5 } & Public & Private & Bomaster & Kanlow \\
\hline Phosphorus (\%) & 0.03 & 0.03 & 0.03 & 0.02 \\
Potassium (\%) & 0.41 & 0.43 & 0.41 & 0.36 \\
Calcium (\%) & 0.25 & 0.30 & 0.30 & 0.26 \\
Magnesium (\%) & 0.03 & 0.04 & 0.09 & 0.09 \\
Manganese (ppm) & 74.26 & 130.19 & 103.05 & 62.44 \\
Iron (ppm) & 130.79 & 33.77 & 37.42 & 26.38 \\
Aluminum (ppm) & 22.84 & 17.45 & 15.49 & $<12.46$ \\
Copper (ppm) & $<5.00$ & $<5.00$ & 5.73 & $<5.00$ \\
Zinc (ppm) & 24.27 & 21.00 & 33.31 & 25.53 \\
Sodium (ppm) & 351.20 & 396.50 & 352.12 & 351.95 \\
\hline
\end{tabular}

\subsubsection{Chemical composition}

Chemical makeup (cellulose, hemicellulose, lignin, and extractive contents) of biomass governs the amount of biochar and bio-oil produced from its pyrolysis [40] and kinetics of pyrolysis process [41]. In addition, the chemical makeup of biomass also dictates chemical makeup of bio-oils. Bio-oils are composed of differently sized molecules derived primarily from the depolymerization and fragmentation reactions of cellulose, hemicellulose and lignin [42]. Figure 2 shows the chemical composition (cellulose, hemicellulose and lignin contents) of the two varieties of both Miscanthus and Switchgrass. The cellulose, hemicellulose, and lignin contents were similar for all the varieties.

Cellulose content was between 34.44 - 36.94\%, hemicellulose content was between 28.84$31.56 \%$ and lignin content was between $8.84-10.31 \%$. The cellulose and hemicellulose reported for Switchgrass varieties are higher in comparison to the one reported by Imam and Capareda [29]. This implies that a higher yield of bio-oil or non-condensable gas should be expected for the Switchgrass varieties and this was confirmed in the subsequent section. While higher proportion of the cellulose and hemicellulose are converted to bio-oil and biochar, a higher percentage of the lignin content are 
converted to biochar. This has been confirmed in other literatures on pyrolysis [33, 43]. Also, since the type of herbaceous crop (Switchgrass or Miscanthus) and their varieties type did not differ significantly in their chemical compositions, there is a tendency that they would produce biochar and bio-oil with similar chemical makeup.

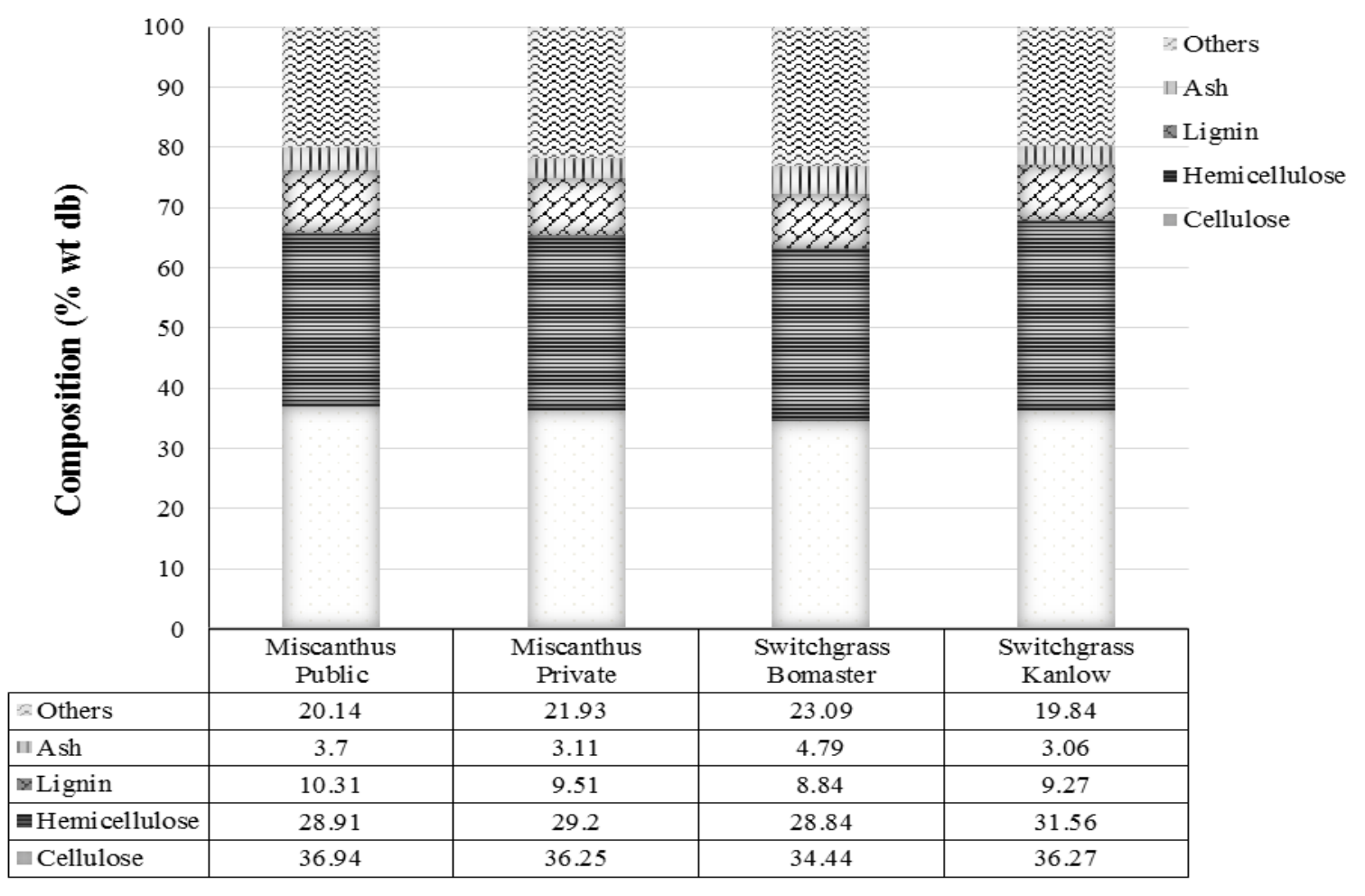

Figure 3.2: Percent cellulose, hemicellulose and lignin contents of Miscanthus and Switchgrass varieties

\subsubsection{Pyrolysis product yields}

Figure 3.3 shows the percent yield of pyrolysis products (biochar, bio-oil and non-condensable gas, NCG) for the two varieties of Miscanthus and Switchgrass. The biochar yield was about $30 \%$ on an average for all the varieties. Statistically, there was no significant difference in the biochar yield which implies that the biomass varieties did not influence the biochar yield. The result also confirmed the implication made for the chemical compositions of the varieties that similar chemical composition would result in similar biochar yield. 


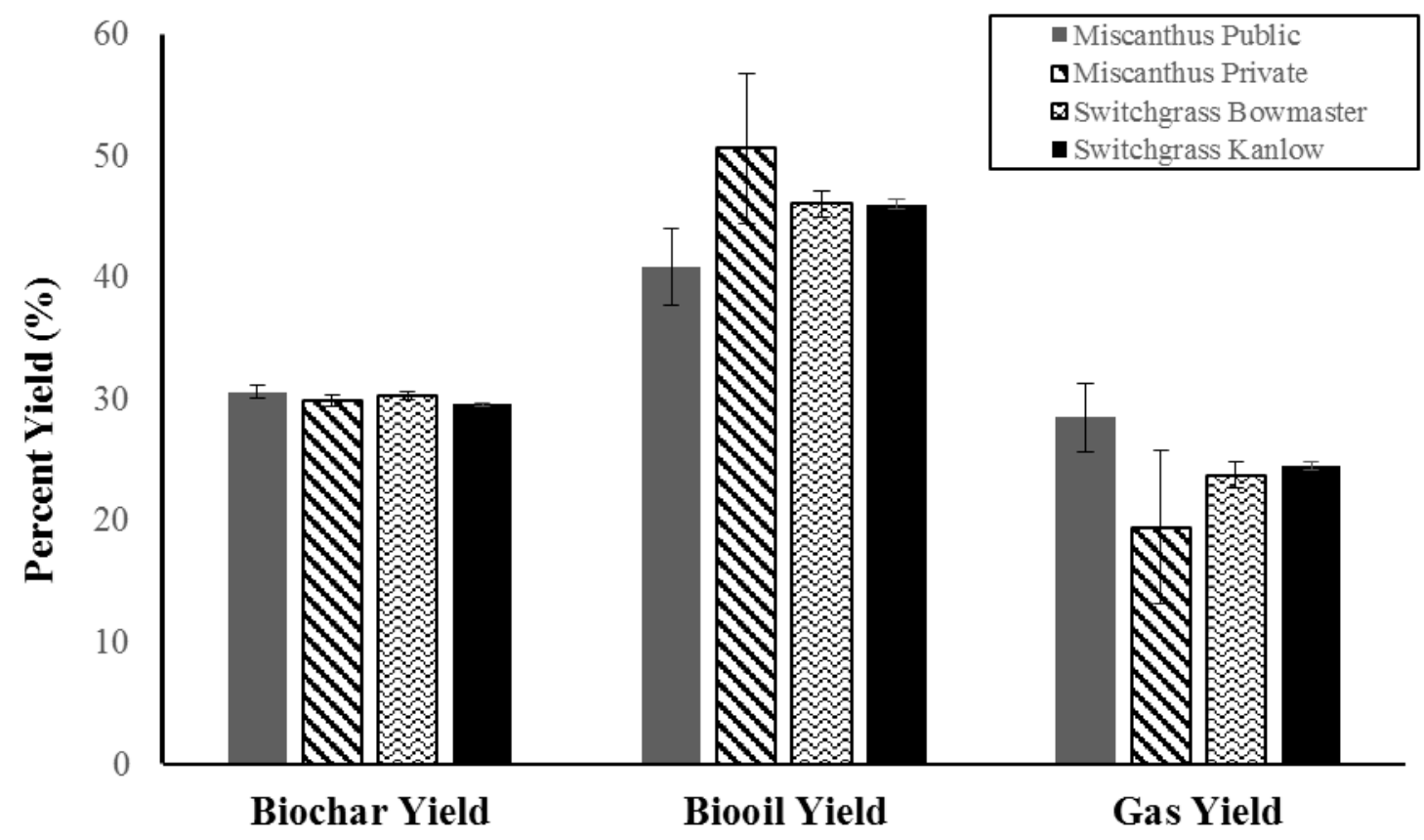

Figure 3.3: Percent yield (on dry biomass basis) of pyrolysis products of Miscanthus and Switchgrass varieties

The biochar yields observed in the present study were relatively higher than the biochar yield reported by Boateng et al [12] for Switchgrass pyrolyzed at a temperature of $480^{\circ} \mathrm{C}$ using fluidizedbed (silica sand bed) fast pyrolysis. The difference in biochar yields observed in the current study and in Boateng et al. may be due to the following factors: (1) Particle size (Boateng and his coworkers used Switchgrass sample of particle size $<2 \mathrm{~mm}$ while large chopped pieces of samples were used in the current study); (2) Sample type (Cave-in-rock Switchgrass were used by Boateng et al. whereas the present study used Bomaster and Kanlow Switchgrass); (3) Pyrolyzer type (fast fluidized bed pyrolysis was used by Boateng et al. whereas the present study used moderate pyrolysis fixed-bed pyrolysis) [44]. The effect of temperature and residence time have also been reported by other authors to influence the biochar yield $[29,45-47]$. At a higher temperature of about $500{ }^{\circ} \mathrm{C}$, the biochar yield is lower in comparison with lower temperature. This is due to the fact that the hemicellulose and cellulose decomposes at a temperature of 225 to $375^{\circ} \mathrm{C}$. Therefore, pyrolysis within that temperature range will result in higher biochar yield with lignin been the major component of the biochar composition. This is because its higher lignin decomposition occurs at higher temperature. Among feedstock properties, high fixed carbon content biomass produces high biochar yields. The Switchgrass varieties used in the 
present study had fixed carbon content of $17.63 \%$ whereas it was $13.98 \%$ for the Cave-in-Rock variety used by Boateng et al. [12].

The bio-oil yields were in the range of 45 to $51 \%$ for the two varieties of Miscanthus and Switchgrass crops. The Switchgrass bio-oil yields were higher than the Switchgrass bio-oil yield reported by Imam and Capareda [29]. They reported a bio-oil yield of 22-37\% for a Switchgrass ground through a $2 \mathrm{~mm}$ screen and pyrolyzed at a temperature range of $400-600{ }^{\circ} \mathrm{C}$. This confirmed the implication made that a lower hollocellulose content would lead to low bio-oil yield. However, Boateng et al. [12] reported bio-oil yields of about 60.7\% from Cave-in-Rock Switchgrass, which had higher volatile matter $83.41 \%$ than that in the two varieties used in the present study $(80.18 \%)$. The highest bio-oil yields (48.9\% and 50.01\%) reported by Bok et al. [27] for Miscanthus pyrolyzed in a rectangular and cylindrical reactor at a temperature range of 400 to $550{ }^{\circ} \mathrm{C}$ are similar to the yields obtained for Miscanthus in this present study. High volatile matter content is responsible for high bio-oil and gas yields.

\subsubsection{Biochar characterization}

Table 3 shows the selected properties of the biochars obtained from the pyrolysis of Miscanthus and Switchgrass varieties. on an average, the biochar produced from Miscanthus varieties contained $7.87 \%$ ash whereas biochars made from Switchgrass varieties had 6.60\% ash content.

Table 3.3: Characterization of biochars from Miscanthus and Switchgrass pyrolysis

\begin{tabular}{lllll}
\hline \multirow{2}{*}{ Property } & \multicolumn{2}{c}{ Miscanthus } & \multicolumn{2}{c}{ Switchgrass } \\
\cline { 2 - 5 } & Public & Private & Bomaster & Kanlow \\
\hline Ash (\%) & $8.72 \pm 1.21$ & $7.02 \pm 0.46$ & $7.00 \pm 0.55$ & $6.19 \pm 0.54$ \\
Fixed carbon (\%) & $74.59 \pm 2.77$ & $77.11 \pm 0.33$ & $77.50 \pm 0.77$ & $76.78 \pm 0.10$ \\
Volatile (\%) & $16.69 \pm 1.62$ & $15.62 \pm 0.42$ & $15.36 \pm 1.00$ & $16.82 \pm 0.64$ \\
HHV (MJ/kg) & $28.59 \pm 0.31$ & $28.63 \pm 0.36$ & $29.34 \pm 0.72$ & $29.46 \pm 0.55$ \\
Atomic H/C & 0.45 & 0.41 & 0.40 & 0.41 \\
Atomic O/C & 0.17 & 0.17 & 0.15 & 0.15 \\
\hline
\end{tabular}

The fixed carbon content was between $72-75 \%$ for biochars produced from Miscanthus varieties and it was between $74-76 \%$ for biochars produced from Switchgrass. On an average, all the biochars contained $15-16 \%$ volatile matter. In comparison with the parent materials, there was a significant increase in the ash and fixed carbon contents while the volatile content drastically reduced. 
The energy content represented by the HHV for the biochars were also found to be between $28-30$ $\mathrm{MJ} / \mathrm{kg}$. This is comparable to the heating value for coal [48-50].

The elemental compositions for the biochars are presented Figure 4. The carbon content for Miscanthus biochars ranged from $77-79 \%$ while Switchgrass biochars had a carbon content of approximately $80 \%$. This high carbon in biochar can be permanently sequestered in the soil. Carbon in biochar is highly stable in soil environments and may be sequestered for a long period of time to mitigate greenhouse gases. Also, biochar is able to lift soil and crop productivity. This is proven from studies of Amazonian soils that appear to have been amended with biochar, with significant improvements in soil quality and positive effects on crop yields [51-53].

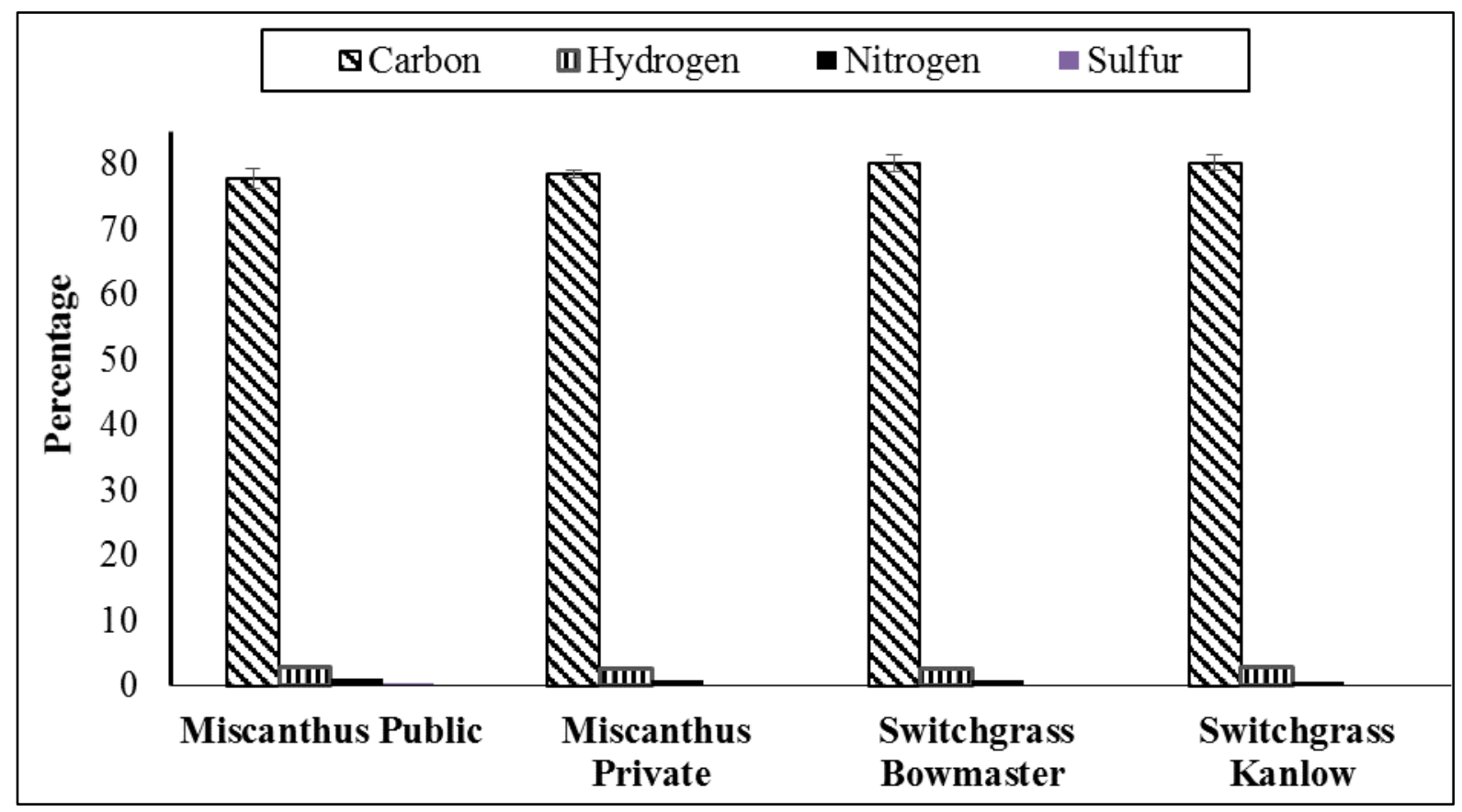

Figure 3.4: Elemental composition of Miscanthus and Switchgrass biochars

Comparing this result with the elemental composition of the parent materials, the carbon content significantly increased while there was a reduction in the other elements (i.e hydrogen, nitrogen, sulfur and oxygen). Losses in hydrogen and oxygen are explained by breaking of weaker bonds within biochar's structure and the biochar becoming highly carbonaceous [29]. The biochar produced from Switchgrass appears to be of better quality than that produced from $<2 \mathrm{~mm}$ particles of switchgrass from a fluidized bed pyrolysis by Boateng et al. [54] due to considerably low ash content, high fixed carbon and carbon content, and low volatile matter content. Boateng et al. reported ash content of 
$28.67 \%$, fixed carbon content of $43.65 \%$, total carbon content of $63.09 \%$, and volatile matter content of $29.48 \%$.

The carbon concentration of the biochars produced are clearly depicted in the Van Krevelen diagram (Figure 3.5). The biomass feedstock and the bio-oil can be seen to have a high ratio of hydrogen and oxygen to carbon. This is traceable to the presence of volatile matter and moisture. However, the biochars have a relatively low $\mathrm{H} / \mathrm{C}$ and $\mathrm{O} / \mathrm{C}$ ratio which depicts a high concentration of carbon which makes it a good candidate for carbon sequestration and activated carbon production. An important factor to note is the influence of temperature on the atomic ratio of $\mathrm{C}-\mathrm{H}-\mathrm{O}$. Increase in the pyrolysis temperature leads to expulsion of the volatile matter, hence reducing the hydrogen and oxygen content of the biochar. This is confirmed with the result obtained by Sadaka et al. [55]. The report showed a decrease in the $\mathrm{H} / \mathrm{C}$ and $\mathrm{O} / \mathrm{C}$ ratio for carbonized switchgrass as temperature increased from $350{ }^{0} \mathrm{C}$ to $400{ }^{\circ} \mathrm{C}$ and it was comparable to the composition of lignite coal. Meanwhile, the biochars obtained for the Miscanthus and Switchgrass varieties pyrolyzed at $500{ }^{\circ} \mathrm{C}$ in our present study showed a much lower atomic ratio of hydrogen and oxygen to carbon.

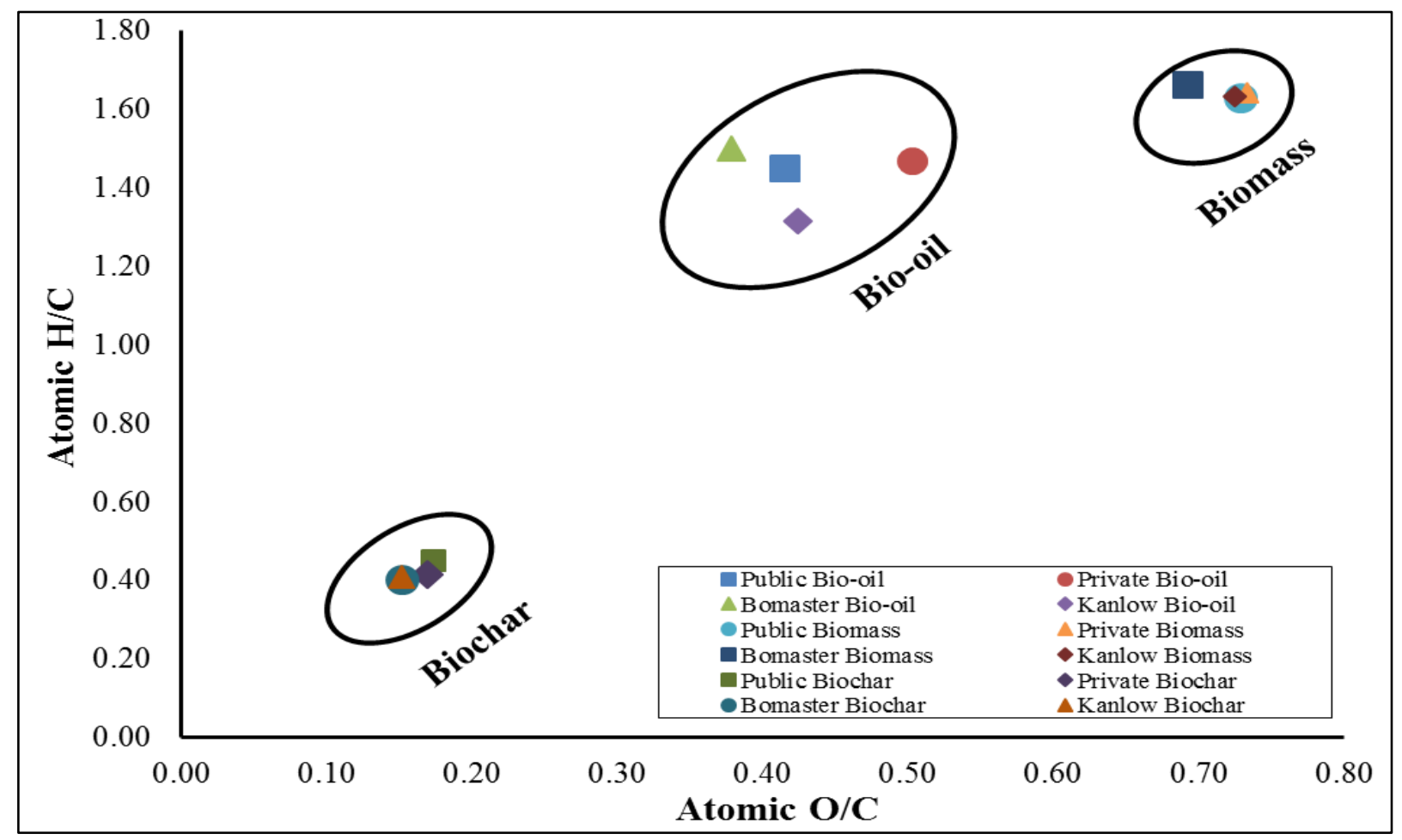

Figure 3.5: Van Krevelen diagram showing the cross-plot of $\mathrm{H} / \mathrm{C}$ and $\mathrm{O} / \mathrm{C}$ atomic ratios for biomass, bio-oil and biochar 


\subsubsection{Bio-oil characterization}

The properties ( $\mathrm{pH}$, viscosity, higher heating value, density, and elemental composition) of the bio-oil obtained from the pyrolysis of the Miscanthus and Switchgrass varieties are presented in Table 4. The $\mathrm{pH}$ values of the bio-oils were in the range of 2.55 and 2.76 . The low $\mathrm{pH}$ values of the bio-oils indicate that they are acidic in nature which can lead to equipment damage due to corrosion. Therefore, a need to upgrade the bio-oil before it can be used in fuel engines is highly imperative. A similar result was reported for bio-oil from poplar (2.8), birch (2.5) and pine (2.4) [56], Miscanthus sinensis (2.1 2.9) [27] and forest residues (2.2 - 2.6) [25]. The low $\mathrm{pH}$ value of bio-oil is as a result of the presence of substantial amount of organic acids, especially acetic and formic acid. At an elevated temperature and high moisture content, the corrosiveness of bio-oil has been found to be severe, corroding carbon steel and aluminum [57-59]

Table 3.4: Characterization of bio-oil obtained from Miscanthus and Switchgrass varieties pyrolysis

\begin{tabular}{lllll}
\hline \multirow{2}{*}{ Property } & \multicolumn{2}{c}{ Miscanthus } & \multicolumn{2}{c}{ Switchgrass } \\
\cline { 2 - 5 } & \multicolumn{1}{c}{ Public } & \multicolumn{1}{c}{ Private } & \multicolumn{1}{c}{ Bomaster } & \multicolumn{1}{c}{ Kanlow } \\
\hline $\mathrm{pH}$ & $2.76 \pm 0.08$ & $2.55 \pm 0.09$ & $2.57 \pm 0.07$ & $2.59 \pm 0.14$ \\
Viscosity (cP) & $45.17 \pm 3.01$ & $16.17 \pm 1.61$ & $23.67 \pm 1.17$ & $16.33 \pm 1.26$ \\
Density $\left(\mathrm{kg} / \mathrm{m}^{3}\right)$ & $1033.89 \pm 28.12$ & $988.76 \pm 16.87$ & $1027.06 \pm 28.56$ & $1023.47 \pm 18.21$ \\
HHV $(\mathrm{MJ} / \mathrm{kg})$ & $25.38 \pm 1.76$ & $23.42 \pm 4.39$ & $26.62 \pm 1.32$ & $24.50 \pm 2.28$ \\
Carbon $(\%)$ & $58.21 \pm 0.37$ & $54.68 \pm 4.64$ & $59.68 \pm 1.41$ & $58.15 \pm 2.84$ \\
Hydrogen (\%) & $7.10 \pm 1.30$ & $6.82 \pm 1.79$ & $7.53 \pm 0.58$ & $6.42 \pm 1.29$ \\
Nitrogen (\%) & $1.96 \pm 0.55$ & $1.86 \pm 0.44$ & $2.13 \pm 0.29$ & $2.12 \pm 0.55$ \\
Sulfur $(\%)$ & $0.55 \pm 0.09$ & $0.53 \pm 0.13$ & $0.61 \pm 0.04$ & $0.54 \pm 0.10$ \\
Oxygen (\%) & $32.19 \pm 1.97$ & $36.11 \pm 6.44$ & $30.06 \pm 1.78$ & $32.77 \pm 2.89$ \\
Atomic H/C & 1.45 & 1.47 & 1.50 & 1.32 \\
Atomic O/C & 0.42 & 0.50 & 0.38 & 0.43 \\
\hline
\end{tabular}

The heating values were in the range of $23.42-26.62 \mathrm{MJ} / \mathrm{kg}$. The heating values for the bio-oil were relatively higher than the heating value obtained for the parent materials (19.0 - 20.0 MJ $/ \mathrm{kg})$. This can be also confirmed by the Van Krevelen diagram (Figure 3.5) showing a reduction in the $\mathrm{H} / \mathrm{C}$ and $\mathrm{O} / \mathrm{C}$ ratio for bio-oil in comparison to the biomass. Bio-oil obtained from Bomaster Switchgrass had the highest heating value of $26.62 \mathrm{MJ} / \mathrm{kg}$ and this corroborate with its other elemental compositions 
(carbon, 59.68\% and hydrogen, 7.53\% in which it has the highest values while it has the lowest oxygen content of $30.06 \%$ ). The reduction in the oxygen content of the bio-oil compared to the parent feedstock is important because the high oxygen content adversely affect the quality of the bio-oil hence making it un-attractive for use as a liquid fuel [60]. The heating values $(19.0-21.9 \mathrm{MJ} / \mathrm{kg})$ reported by Ingram et al. [61] for bio-oils obtained from pine and oak woods, pine and oak barks are lower in comparison to the ones obtained for both the Miscanthus and Switchgrass varieties. Also, the carbon and hydrogen contents for the pine and oak samples were found to be lower while the oxygen contents were higher than the ones obtained for the samples in this experiment. The carbon contents of the bio-oils are higher while there was a decline in the oxygen contents in comparison to the parent materials. The difference can be attributed to the fact that a percentage of the oxygen content is given off with the incondensable gas [16]. He et al. [47] also reported a lower value (16.6-19.6 MJ/kg) for Switchgrass bio-oil and Bok et al. [27] reported a lower value (16.0 - 18.2 MJ/kg) for Miscanthus bio-oil. The heating values of biooils produced from apricot pulp (24.44 and $26.82 \mathrm{MJ} / \mathrm{kg})$ and peach pulps $(22.27$ and $25.76 \mathrm{MJ} / \mathrm{kg}$ ) under static and nitrogen atmospheres respectively reported by Ozbay et al. [62] were similar to the heating values for the samples in this present study. The $\mathrm{H} / \mathrm{C}$ and $\mathrm{O} / \mathrm{C}$ ratios were also similar. This clarifies the effect of C-H-O composition on the quality of the bio-oil.

Switchgrass pyrolysis produces bio-oils comprised of hydroxyacetaldehyde (17.4 wt.\%), levoglucosan (2.4 wt.\%), acetic acid (3.5 wt.\%), and acetol (2.7 wt.\%). In addition, traces of glyoxal, formaldehyde, and cellobiosan are also detected. [12,29]. Out of above chemical species, levoglucosan

is the product of cellulose pyrolysis, acetic acid is the product of decarboxylation of lignin and hemicelluloses, and phenolic compounds are product of lignin pyrolysis [42].

In summary, neither herbaceous grass type (Miscanthus or Switchgrass) nor their respective varieties had significant effect on properties of bio-oil produced.

\subsubsection{Non-condensable gas characterization}

The gaseous products given during the pyrolysis of the biomass samples were collected at temperatures of $200{ }^{\circ} \mathrm{C}, 300{ }^{\circ} \mathrm{C}, 400{ }^{\circ} \mathrm{C}$ and $500{ }^{\circ} \mathrm{C}$. The gas samples of Kanlow and Bomaster Switchgrass were the only ones reported in this paper. Figure 3.6 shows the composition of the noncondensable gas given during the pyrolysis of Kanlow Switchgrass. Carbon dioxide $\left(\mathrm{CO}_{2}\right)$, oxygen $\left(\mathrm{O}_{2}\right)$, nitrogen $\left(\mathrm{N}_{2}\right)$ and carbon monoxide $(\mathrm{CO})$ are the predominant components of the gas samples. Nitrogen has the highest percentage due to the fact that it was the gas used in keeping the pyrolysis 
reaction in inert condition. In the other components of the non-condensable gas samples such as $\mathrm{CO}_{2}$, $\mathrm{CH}_{4}$, and $\mathrm{CO}$, carbon is seen to be a major part of the compounds.

In terms of the temperature, carbon dioxide and carbon monoxide reached their peaks at a temperature of $400^{\circ} \mathrm{C}$ while nitrogen had the lowest yield at that same temperature. While there are no tangible variations in the percent yield of other components of the non-condensable gas, the change in the percent yield of $\mathrm{CO}$ and $\mathrm{CO}_{2}$ with increase in the temperature can be explained to be the result of the oxidation of the carbonized biochars at higher temperatures of the pyrolysis [63, 64]. Imam and Capareda [29] reported a similar increase in the percent yield of $\mathrm{CO}$ and $\mathrm{CO}_{2}$ with increase in pyrolysis temperature.

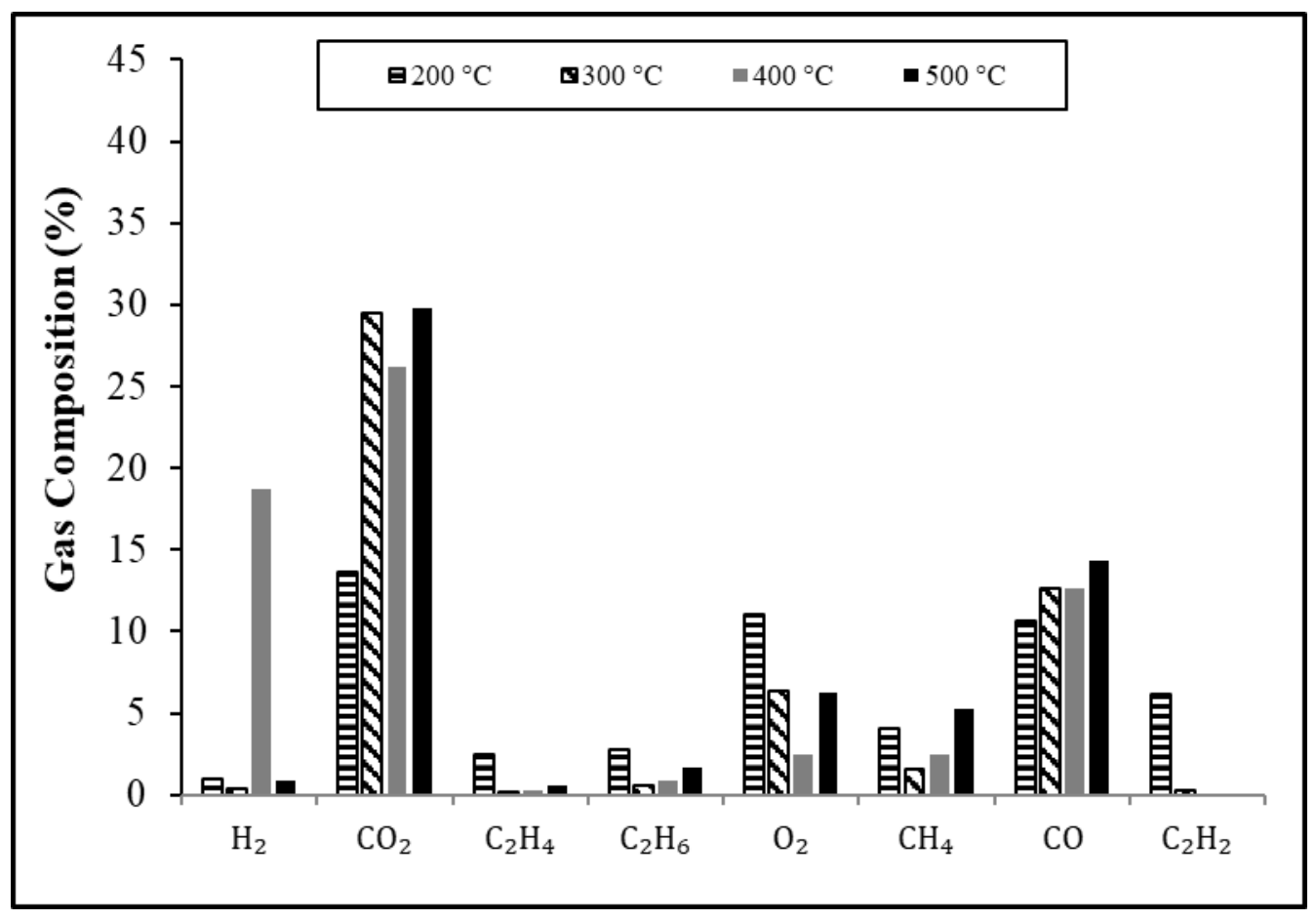

Figure 3.6: Percent yield of gas given off during pyrolysis of Kanlow Switchgrass

The percent yield of non-condensable gas during the pyrolysis of Bomaster Switchgrass is shown in Figure 3.7. Hydrogen had a peak yield of about $20 \%$ at a temperature of $400{ }^{\circ} \mathrm{C}$. The trends for carbon dioxide and carbon monoxide were different from the ones obtained for Kanlow Switchgrass. The carbon dioxide had a double peak at $300{ }^{\circ} \mathrm{C}$ and $500{ }^{\circ} \mathrm{C}$ while carbon monoxide reached its peak at a temperature of $500{ }^{\circ} \mathrm{C}$. Nitrogen had the highest percent yield. Oxygen had the highest percent yield at $200{ }^{\circ} \mathrm{C}$ temperature. This is an indication of moisture removal, which is the initial stage of pyrolysis. 
$\mathrm{CO}_{2}$ is a non-combustible component of the non-condensable gas. A high percentage of $\mathrm{CO}_{2}$ in the non-condensable gas makes it a lower quality fuel gas. The $\mathrm{CO}: \mathrm{CO}_{2}$ ratio of the non-condensable gas is used as an indicator to determine if the gas has a good combustible gas quality to be used as an fluidizing medium for an endothermic pyrolysis reaction $[12,52]$. A high $\mathrm{CO}: \mathrm{CO}_{2}$ ratio indicates that the non-condensable gas can be used as a fluidizing medium. The $\mathrm{CO}: \mathrm{CO}_{2}$ ratios of the noncondensable gas samples for switchgrass were less than 1 . This indicate that the gas samples cannot be used as a fluidizing medium. Boateng et al. [12] estimated the $\mathrm{CO}: \mathrm{CO}_{2}$ ratio for the non-condensable gas produced during a bench-scale fluidized bed pyrolysis of switchgrass to be 2:1, making it suitable as fluidizing medium. The authors further stated that the use of nitrogen as fluidizing gas is convenient, but only in pilot or demonstration experiments. In an industrial production, the use of nitrogen gas as fluidizing medium would likely incur extra cost and thereby increase the cost of bio-oil production. The use of exhaust gas for fluidization has thus far been an industrial practice.

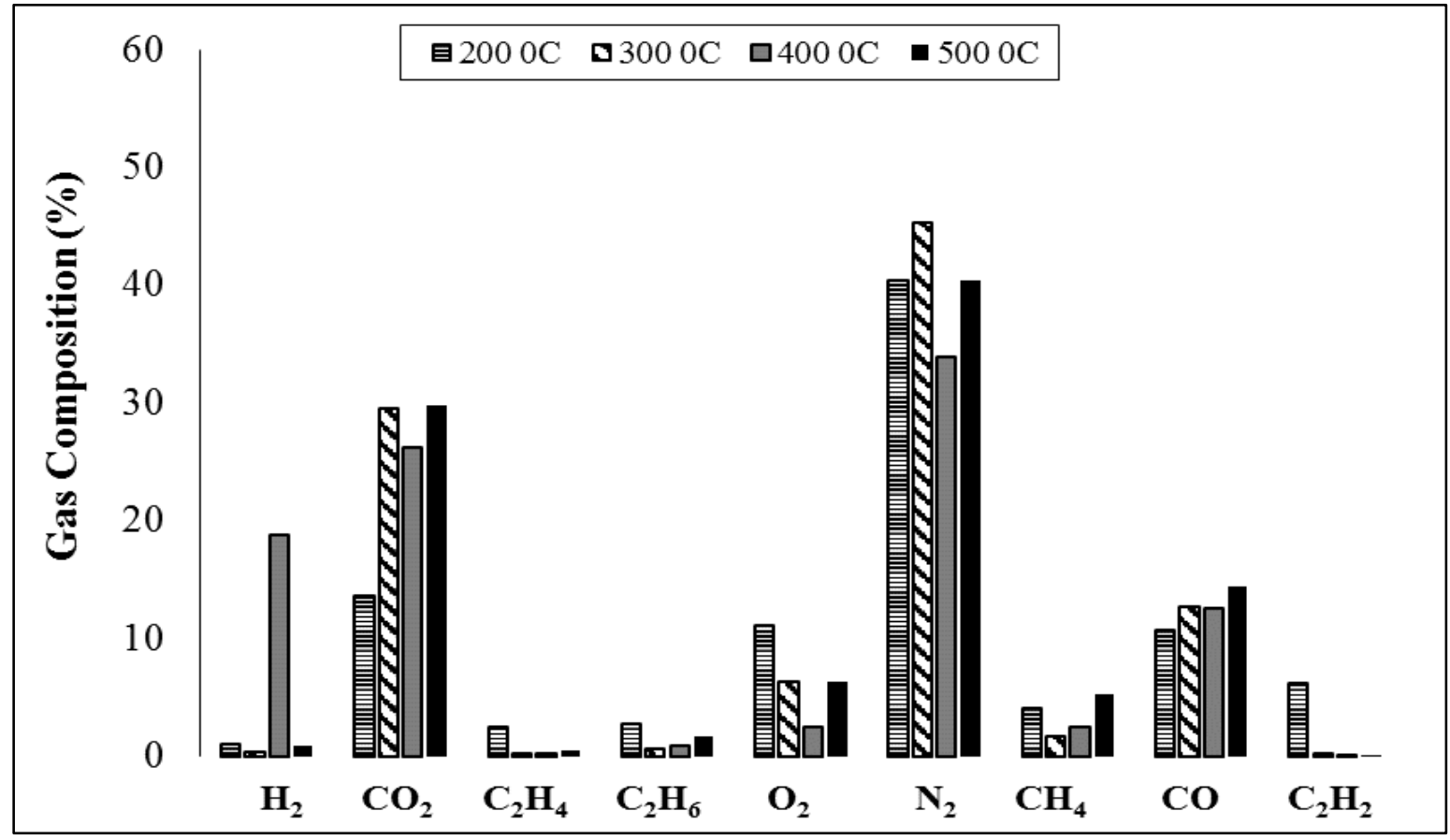

Figure 3.7: Percent yield of gas given off during pyrolysis of Bomaster Switchgrass

\subsubsection{Carbon and energy yield}

Percentage amounts of biomass energy and carbon captured in the biochars produced for each variety were calculated as a measure of efficiency of pyrolysis process excluding externally supplied heat (Figure 3.8). On an average, the biochars captured about $50 \%$ of the feedstock carbon and about 40-50\% of the feedstock energy. The remaining energy and carbon is distributed between the bio-oil 
and non-condensable gas. Jin et al. [26] reported that pyrolysis of mixed hardwood chips retained 78 $\%$ of the feedstock energy and $89 \%$ of the feedstock carbon in its biochars and bio-oils. The importance of the carbon yield of the biochar is defined in its use for carbon sequestration and gasification. From this present study, it can be implied that about 50\% of the feedstock carbon can be permanently sequestered in soil. Also, the carbon retained in the biochar can be used in the production of syngas during gasification. However, there will be a need to determine its reactivity in air and in $\mathrm{CO}_{2}$ in order to establish its potential as a combustion fuel or gasification feedstock [54]. Furthermore, based on the morphological and surface characteristics of biochar (not characterized in this present study), it has been explored as a feasible adsorbent for nutrients recovery from liquid runoff from field fertilization or effluents from anaerobic digestion. Upon adsorption of the nutrients, it can be reapplied to crop fields for slow release of the nutrients $[65,66]$. Therefore, this research concludes that neither herbaceous crop type nor their individual varieties has any influence on carbon and energy yields from biochars.

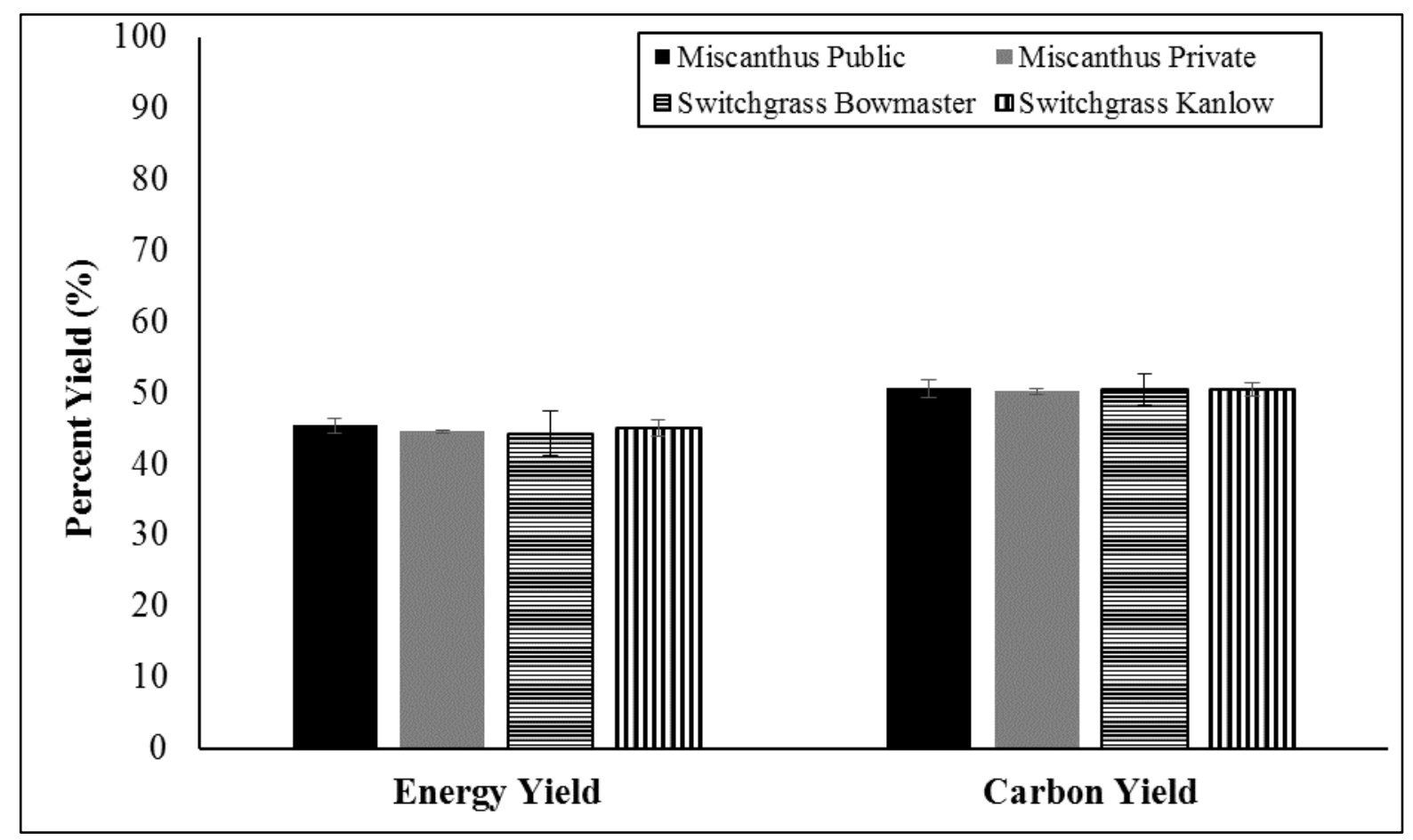

Figure 3.8: Carbon and energy yields of Miscanthus and Switchgrass biochars

\subsection{Conclusion}

The characterization of the pyrolysis products of Miscanthus and Switchgrass cultivars showed a good potential for bio-oil and bio-char production. The cultivars of Switchgrass and Miscanthus in this study showed no significant difference in pyrolysis product yields (biochars and bio-oils) and their 
properties. Therefore, pyrolysis of these two dedicated energy crops may be carried out in a single reactor simultaneously. Overall, the biochar yield was about $30 \%$ and bio-oil yields ranged from 45 to $51 \%$. On an average, the pyrolysis process converted between 40 to $50 \%$ of total feedstock energy in to biochar products and about $50 \%$ of feedstock carbon are stored in the biochars. The properties of the biochars such as the fixed carbon, porosity and the elemental composition showed that both energy crops can be employed as a raw material for the production of activated carbon.

\subsection{Implications}

Skousen et al. [17] reported the establishment and dry matter (DM) yield of biomass crops on several mined sites in West Virginia. According to the report, the Alton site ( 0.4 ha planted out of 160 ha) has three species, namely; Switchgrass (Kanlow and Bomaster), Miscanthus (Public and Private), and Giant cane planted. At this site, dry matter yield after the fourth growing season averaged 5,200 kg $\mathrm{ha}^{-1}$ for Switchgrass (Kanlow and Bomaster varieties) and 9,000 kg ha- ${ }^{-1}$ for Miscanthus (Public and Private varieties). In addition, Cave-In-Rock Switchgrass was planted on 8 ha at MeadWestvaco (MWV), WV and at The Wilds, OH. After the first growing season, Switchgrass production was 752 $\mathrm{kg} \mathrm{ha}^{-1}$ at MWV and 1,045 $\mathrm{kg} \mathrm{ha}^{-1}$ at The Wilds site.

While intention of growing these bioenergy crops with significant capital investment was to supply them to a bioethanol plant to be opened in near future, currently, there is no outlet for the harvested bioenergy crops. Conversion of bioenergy crops to activated carbons will serve dual benefits. First, it will provide an economic benefit to the growers and second, it will sequester biomass carbon in to a stable form. For example, untreated charcoal derived activated carbons are sold for about $\$ 42$ per kg (average cost from Fisher Scientific). Our preliminary data shows that Switchgrass pyrolysis

produces $30 \%$ biochar and activation of biochar yields about $62 \%$ activated carbon [67]. On an average, the Alton site in WV produces on an average $7100 \mathrm{~kg}$ per ha per year biomass (Switchgrass and Miscanthus combined), which has potential to produce $1320 \mathrm{~kg}$ per ha per year of activated carbon. Using $\$ 42$ per $\mathrm{kg}$ cost of activated carbon, the $1320 \mathrm{~kg}$ of activated carbon may be valued at $\mathbf{\$ 5 5 , 4 6 5}$ per ha per year. 


\section{References}

[1] R.C. Saxena, D.K. Adhikari, H.B. Goyal, Biomass-based energy fuel through biochemical routes: A review, Renewable and Sustainable Energy Reviews, 13 (2009) 167-178.

[2] United States E.I.A, Annual Energy Outlook 2015 With Projections to 2040, in: U.S. Department of Energy (Ed.), Washington, DC, 2015.

[3] United States E.I.A., Annual Energy Outlook 2014 with projections to 2040, in, 2014, pp. 269.

[4] E. Kirtay, Recent advances in production of hydrogen from biomass, Energy Conversion and Management, 52 (2011) 1778-1789.

[5] P. Moriarty, D. Honnery, Low-mobility: the future of transport, Futures, 40 (2008) 865-872.

[6] Q. Guo, X. Chen, H. Liu, Experimental research on shape and size distribution of biomass particle, Fuel, 94 (2012) 551-555.

[7] United States EIA, Monthly Energy Review, in, 2013.

[8] United States EIA, Annual Energy Outlook, in, Washington, DC, 2008.

[9] N. Özbay, A.E. Pütün, B.B. Uzun, E. Pütün, Biocrude from biomass: pyrolysis of cottonseed cake, Renewable Energy, 24 (2001) 615-625.

[10] R.D. Perlack, B.J. Stokes, U.S. Billion-Ton Update: Biomass Supply for a Bioenergy and Bioproducts Industry, in, U.S. Department of Energy, Tennessee 2011.

[11] A.A. Boateng, K.B. Hicks, K.P. Vogel, Pyrolysis of switchgrass (Panicum virgatum) harvested at several stages of maturity, Journal of Analytical and Applied Pyrolysis, 75 (2006) 55-64.

[12] A.A. Boateng, D.E. Daugaard, N.M. Goldberg, K.B. Hicks, Bench-Scale Fluidized-Bed Pyrolysis of Switchgrass for Bio-Oil Production, Industrial \& Engineering Chemistry Research, 46 (2007) 18911897.

[13] ASABE/ANSI, Terminology and Definitions for Biomass Production, Harvesting and Collection, Storage, Processing, Conversion and Utilization, in, American Society of Agricultural and Biological Engineers, St. Joseph, MI, 2011.

[14] D.L. Klass, Biomass for renewable energy, fuels, and chemicals, Academic Press, San Diego, CA, 1998.

[15] G.M. Pedroso, R.B. Hutmacher, D. Putnam, J. Six, C. van Kessel, B.A. Linquist, Biomass yield and nitrogen use of potential C4 and C3 dedicated energy crops in a Mediterranean climate, Field Crops Research, 161 (2014) 149-157.

[16] C.A. Mullen, A.A. Boateng, Chemical composition of bio-oils produced by fast pyrolysis of two energy crops $\dagger$, Energy \& Fuels, 22 (2008) 2104-2109.

[17] J. Skousen, C. Brown, T. Griggs, S. Byrd, Establishment and Growth of Switchgrass and other Biomass Crops on Surface Mines, Journal American Society of Mining and Reclamation, 3 (2014) 136156.

[18] W. Jin, Using bio-chars as potential catalysts for upgrading wood pyrolysis vapors, in, West Virginia University Morgantown, WV, 2013.

[19] S.A. Channiwala, P.P. Parikh, A unified correlation for estimating HHV of solid, liquid and gaseous fuels, Fuel, 81 (2002) 1051 - 1063.

[20] ASTM, Standard Test Method for Ash in the Analysis Sample of Coal and Coke from Coal; ASTM D3174-12, in, West Conshohocken, PA, 2012.

[21] N. Brosse, A. Dufour, X. Meng, Q. Sun, A. Ragauskas, Miscanthus: A fast- growing crop for biofuels and chemicals production. A Review, Biofuels, Bioproducts \& Biorefining, 1 (2012) 1-19. 
[22] O.O. Fasina, Flow And Physical Properties of Switchgrass, Peanut Hull, And Poultry Litter, Transactions of the ASABE, 49 (2006) 721-728.

[23] Z. Hu, R. Sykes, M.F. Davis, E.C. Brummer, A.J. Ragauskas, Chemical profiles of switchgrass, Bioresource Technology, 101 (2010) 3253-3257.

[24] R. Fahmi, A.V. Bridgwater, L.I. Darvell, J.M. Jones, N. Yates, S. Thain, I.S. Donnison, The effect of alkali metals on combustion and pyrolysis of Lolium and Festuca grasses, switchgrass and willow, Fuel, 86 (2007) 1560-1569.

[25] K.C. Das, K. Singh, B. Bibens, R. Hilten, S.A. Baker, W.D. Greene, J.D. Peterson, Pyrolysis characteristics of forest residues obtained from different harvesting methods, Applied Engineering in Agriculture, 27 (2011) 107-113.

[26] W. Jin, K. Singh, J. Zondlo, Pyrolysis Kinetics of Physical Components of Wood and WoodPolymers Using Isoconversion Method, Agriculture, 3 (2013) 12-32.

[27] J.P. Bok, H.S. Choi, J.W. Choi, Y.S. Choi, Fast pyrolysis of Miscanthus sinensis in fluidized bed reactors: Characteristics of product yields and biocrude oil quality, Energy, 60 (2013) 44-52.

[28] K. Raveendran, A. Ganesh, K.C. Khilar, Pyrolysis characteristics of biomass and biomass components, Fuel 75 (1996) 987 - 998

[29] T. Imam, S. Capareda, Characterization of bio-oil, syn-gas and bio-char from switchgrass pyrolysis at various temperatures, Journal of Analytical and Applied Pyrolysis, 93 (2012) 170-177.

[30] F.A. Agblevor, S. Besler, A.E. Wiselogel, Fast Pyrolysis of Stored Biomass Feedstocks, Energy \& Fuels, 9 (1995) 635-640.

[31] P. McKendry, Energy production from biomass (part 1): Overview of biomass, Bioresource Technology, 83 (2002) 37-46.

[32] F.A. Agblevor, S. Besler, Inorganic Compounds in Biomass Feedstocks. 1. Effect on the Quality of Fast Pyrolysis Oils, Energy \& Fuels, 10 (1996) 293-298.

[33] K. Raveendran, A. Ganesh, K.C. Khilar, Influence of mineral matter on biomass pyrolysis characteristics, Fuel, 74 (1995) 1812-1822.

[34] S. Czernik, A.V. Bridgwater, overview of application of biomass fast pyrolysis oil, Energy \& Fuels, 18 (2004) 590-598.

[35] P.R. Patwardhan, J.A. Satrio, R.C. Brown, B.H. Shanks, Influence of inorganic salts on the primary pyrolysis products of cellulose, Bioresource Technology, 101 (2010) 4646-4655.

[36] D.J. Nowakowski, J.M. Jones, Uncatalysed and potassium-catalysed pyrolysis of the cell-wall constituents of biomass and their model compounds, Journal of Analytical and Applied Pyrolysis, 83 (2008) 12-25.

[37] Moilanen A, Nieminen M, S. K, K. E, Ash behavior in thermal fluidized-bed conversion processes of woody and herbaceous biomass, in: Chartier P, Ferrero G.L, Henius U.M, Hultberg S, S. J, Wiinblad M. Pergamon (Eds.) Proceedings of the 9th European Bioenergy Conference, Copenhagen, Denmark, 1996, pp. 1227-1232.

[38] A. M, A. A.S, Third year growing results of C4 energy plant Miscanthus sinensis in producing energy from biomass, in: Kopetz H, Weber T, Palz W, C. P, F. G.L. (Eds.) Proceedings of the 10th European Bioenergy Conference, C.A.R.M.E.N., Würzburg, Germany, 1998, pp. 1700-1703.

[39] A.G.W. Bradbury, Y. Sakai, F. Shafizadeh, A kinetic model for pyrolysis of cellulose, Journal of Applied Polymer Science, 23 (1979) 3271-3280.

[40] K. Raveendran, A. Ganesh, K.C. Khilar, Pyrolysis characteristics of biomass and biomass components, Fuel, 75 (1996) 987-998.

[41] W. Jin, K. Singh, J. Zondlo, Pyrolysis Kinetics of Physical Components of Wood and WoodPolymers Using Isoconversion Method, Agriculture, 3 (2013) 12-32. 
[42] D. Mohan, J. Charles U.P, P.H. Steele, Pyrolysis of Wood/Biomass for Bio-oil: A Critical Review, Energy \& Fuels, 20 (2006) 848-889.

[43] F. Shafizadeh, Pyrolytic Reactions and Products of Biomass, in: R.P. Overend, T.A. Milne, L.K. Mudge (Eds.) Fundamentals of Thermochemical Biomass Conversion, Springer Netherlands, 1985, pp. 183-217.

[44] W. Jin, K. Singh, J. Zondlo, Co-processing of pyrolysis vapors with biochars for ex-situ upgrading, Renewable Energy, 83 (2015) 638-645.

[45] G. Pilon, J.M. Lavoie, Characterization of switchgrass char produced in torrefaction and pyrolysis conditions, Bioresources, 6 (2011) 4824-4839.

[46] Sun-Hoon Lee, Min-Seop Eom, Kyung-Seun Yoo, Nam-Chan Kim, Jong-Ki Jeon, Young-Kwon Park, Byung-Ho Song, S.H. Lee, The yields and composition of bio-oil produced from Quercus Acutissima in a bubbling fluidized bed pyrolyzer, Journal of Analytical and Applied Pyrolysis, 83 (2008) 110-114.

[47] R. He, X.P. Ye, B.C. English, J.A. Satrio, Influence of pyrolysis condition on switchgrass bio-oil yield and physicochemical properties, Bioresource Technology, 100 (2009) 5305-5311.

[48] Jagpinder Singh Brar, K. Singh, J. Zondlo, J. Wang, Co-Gasification of Coal and Hardwood Pellets: A Case Study, American Journal of Biomass and Bioenergy, 2 (2013) 25-40.

[49] R. Lemaire, C. Bruhier, D. Menage, E. Therssen, P. Seers, Study of the high heating rate devolatilization of a pulverized bituminous coal under oxygen-containing atmospheres, Journal of Analytical and Applied Pyrolysis, 114 (2015) 22-31.

[50] C. Buratti, M. Barbanera, P. Bartocci, F. Fantozzi, Thermogravimetric analysis of the behavior of sub-bituminous coal and cellulosic ethanol residue during co-combustion, Bioresource Technology, 186 (2015) 154-162.

[51] Kwang Ho Kim, Tae-Seung Kim, Soo-Min Lee, Donha Choi, Hwanmyeong Yeo, In-Gyu Choi, J.W. Choi, Comparison of physicochemical features of biooils and biochars produced from various woody biomasses by fast pyrolysis, Renewable Energy, 50 (2013) 188-195.

[52] C.A. Mullen, A.A. Boateng, N.M. Goldberg, I.M. Lima, D.A. Laird, K.B. Hicks, Bio-oil and biochar production from corn cobs and stover by fast pyrolysis, Biomass and Bioenergy, 34 (2010) 67-74. [53] S.P. Galinato, J.K. Yoder, D. Granatstein, The economic value of biochar in crop production and carbon sequestration, Energy Policy, 39 (2011) 6344-6350.

[54] A.A. Boateng, Characterization and Thermal Conversion of Charcoal Derived from Fluidized-Bed Fast Pyrolysis Oil Production of Switchgrass, Ind. Eng. Chem. Res., 46 (2007) 8857-8862.

[55] S. Sadaka, M.A. Sharara, A. Ashworth, P. Keyser, F. Allen, A. Wright, Characterization of Biochar from Switchgrass Carbonization, Energies, 7 (2014) 548-567.

[56] A. Oasmaa, S. Czernik, Fuel Oil Quality of Biomass Pyrolysis Oils- State of the Art for the End Users, Energy \& Fuels, 13 (1999) 914-921.

[57] H. Aubin, C. Roy, Study on Corrossiveness of Wood Pyrolysis Oils, Fuel Science and Technology International 8(1980) 77-80.

[58] J. Soltes, S.-C.K. Lin, Hydroprocessing of Biomass Tars for Liquid Engine Fuels, in: T. David A, J. Edwin C (Eds.) Progress in Biomass Conversion, Elsevier, 1984, pp. 1-68.

[59] D.C. Jay, K.H. Sipila, O.A. Rantanen, N.O. Nylund, Wood pyrolysis oil for diesel engines, in: International Combustion Engine Division of the ASME; 1995 Fall Technical Conference, 1995.

[60] B.B. Uzun, E. Apaydin-Varol, F. Ateş, N. Özbay, A.E. Pütün, Synthetic fuel production from tea waste: Characterisation of bio-oil and bio-char, Fuel, 89 (2010) 176-184.

[61] Leonard Ingram, D. Mohan, M. Bricka, Philip Steele, David Strobel, David Crocker, Brian Mitchell, Javeed Mohammad, K. Cantrell, J. Charles U. Pittman, Pyrolysis of Wood and Bark in an 
Auger Reactor: Physical Properties and Chemical Analysis of the Produced Bio-oils, Energy \& Fuels, 22 (2008) 614-625.

[62] N. Ozbay, E. Apaydın-Varol, B.B. Uzun, A.E. Putun, Characterization of bio-oil obtained from fruit pulp pyrolysis, Energy, 33 (2008) 1233- 1240.

[63] S.B. Lee, O. Fasina, TG-FTIR analysis of switchgrass pyrolysis, Journal of Analytical and Applied Pyrolysis, 86 (2009) 39-43.

[64] R.R. Baker, S. Coburn, C. Liu, J. Tetteh, Pyrolysis of saccharide tobacco ingredients: A TGAFTIR investigation, Journal of Analytical and Applied Pyrolysis, 74 (2005) 171-180.

[65] M.J. Antal, M. Grønli, The art, science, and technology of charcoal production, Industrial and Engineering Chemistry Research, 42 (2003) 1619-1640.

[66] B. Pecha, M. Garcia-Perez, Chapter 26 - Pyrolysis of Lignocellulosic Biomass: Oil, Char, and Gas, in: A. Dahiya (Ed.) Bioenergy, Academic Press, Boston, 2015, pp. 413-442.

[67] Q. Lu, Z. Wang, C. Dong, Z. Zhang, Y. Zhang, Y. Yang, X. Zhu, Selective fast pyrolysis of biomass impregnated with $\mathrm{ZnCl}_{2}$ : Furfural production together with acetic acid and activated carbon as by-products, Journal of Analytical and Applied Pyrolysis, 91 (2011) 273-279. 


\title{
Chapter 4
}

\section{Effect of pyrolysis temperature on the thermal stability and physicochemical characteristics of biochars produced from herbaceous biomass}

\begin{abstract}
Biochar's use as soil amendment is considered beneficial for soil quality improvement with an added benefit of carbon sequestration. To ensure the use of biochar for these purposes, there is a need to understand its thermal stability and resistance against abiotic and biotic degradation. This is predicated on the feedstock type and pyrolysis conditions used in producing the biochar. The objective of this study was to characterize the thermal stability and physicochemical properties of biochars produced from two herbaceous biomass feedstocks at pyrolysis temperatures of 500,700 and $900{ }^{\circ} \mathrm{C}$. The thermal stability of the biochars was estimated by thermally degrading them in air at $950{ }^{\circ} \mathrm{C}$. Physicochemical properties of the biochars were also quantified. The thermal stability of the biochars were found to increase with the pyrolysis temperature. The $\mathrm{pH}$ values increased with the pyrolysis temperature from slightly alkaline to highly alkaline. The electrical conductivities of the biochars were between 1.21 and $4.07 \mathrm{mS} / \mathrm{cm}$. The BET surface area of the Kanlow Switchgrass biochars increased from 0.91 to 519.49 $\mathrm{m}^{2} / \mathrm{g}$ with an increase in pyrolysis temperature from 500 to $900{ }^{\circ} \mathrm{C}$. Similarly, the BET surface area of Public Miscanthus biochars increased from 0.25 to $783.74 \mathrm{~m}^{2} / \mathrm{g}$ with increase in pyrolysis temperature from 500 to $900{ }^{\circ} \mathrm{C}$. The result of the Raman analysis showed that the pyrolysis temperature did not significantly caused a conversion of disordered $\mathrm{sp}^{2}$ carbon to ordered $\mathrm{sp}^{2}$ carbon crystallites. The XPS analysis showed a reduction in the atomic percentage of the oxygen functional groups as the pyrolysis temperature increased, making the biochars more hydrophobic.
\end{abstract}

Keywords: Biochar, $\mathrm{pH}$, soil amendment, thermal stability 


\subsection{Introduction}

Pyrolysis, among other thermochemical conversion processes, is characterized by its products, which include bio-oil as the liquid product, biochar as the solid residue and the non-condensable gas products [1]. The distribution of the pyrolysis products has been found to depend on the pyrolysis conditions (temperature, residence time and heating rate) and the biomass characteristics (physical, elemental and proximate composition) [2]. For example, low pyrolysis temperatures and longer residence times had been shown to result in high biochar yield [3-6]. This is because the cellulose decomposes at a temperature of 240 to $350{ }^{\circ} \mathrm{C}$, hemicellulose decomposes at a temperature of 200-260 ${ }^{\circ} \mathrm{C}$ whereas lignin decomposes at $280-550{ }^{\circ} \mathrm{C}$. Therefore, at low temperatures (below $400{ }^{\circ} \mathrm{C}$ ), significant amount of lignin remains uncarbonized, thereby, resulting in high biochar yields.

Biochar is a carbonaceous material possessing a range of chemical structures and heterogeneous elemental composition [7]. Due to its intrinsic properties, it has found wide range of applications especially in agronomy and environmental management. Biochar's use for agronomic purposes is due to its soil amendment benefits which include, enhancing soil fertility, improving soil $\mathrm{pH}$, electrical conductivity, and soil physical structure; increasing soil microbial biomass and nutrient availability [8]. Atkinson et al. [9] stated that the porous structure and surface area of biochar provide refuge for beneficial soil micro-organisms and influenced the binding of important nutrient cations and anions. This binding can enhance the availability of macro-nutrients.

The application of biochar to soils has been found to have varying effects. Biochar with alkaline $\mathrm{pH}$ have been reported to significantly influence the aboveground productivity on soils. This effect is more prominent in case of acidic soils than that of alkaline soils [10]. Increasing the $\mathrm{pH}$ of acidic soils has been shown to increase microbial activity, increase soil organic matter mineralization and increase nutrient availability to plants. This may in some circumstances, however, cause a priming effect resulting in the increased emission of $\mathrm{CO}_{2}$ from soils and may also have only a short-term effect on microbial activities [11]. The priming effect of biochar addition to soil have been reported to increase the phytoavailability of essential nutrients for plant growth [12]. Atkinson et al. [9] reported that an increase in soil $\mathrm{pH}$ due to biochar addition can reduce the availability of toxic forms of $\mathrm{Al}, \mathrm{Cu}$ and $\mathrm{Mn}$ while it increased the availability of essential nutrients such as $\mathrm{Na}, \mathrm{K}, \mathrm{Ca}, \mathrm{Mg}$, and $\mathrm{Mo}$, thereby enhancing plant growth.

The significance of biochar application for soil amendment is closely knitted to its relatively high recalcitrance or resistance to abiotic and biotic degradation [14]. The abiotic degradation of 
biochar (e.g. chemisorption of oxygen by the biochar, photo-oxidation and solubilization) is a strong exothermic reaction and under environmental conditions, this process is extremely slow [15] while the biotic degradation of biochar is attributed to the microbial degradation of labile $\mathrm{C}$ fraction. The biochar carbon is made up of recalcitrant aromatic ring carbon structures and the labile aliphatic carbon structures [16]. The labile carbon fractions are easily degradable (weeks to years) and provide an important source of energy for soil microorganisms. The recalcitrant carbon fraction is highly resistant to decomposition, largely unavailable to microorganisms and takes centuries to thousands of years to decompose [17]. A reduction in the labile carbon fraction of the biochar leading to high recalcitrant biochar with stable carbon has been identified to be very resistant to microbial degradation [17].

Zimmerman [18] studied the abiotic and biotic degradation of biochars derived from woody and herbaceous biomass feedstocks. The author reported that biochars produced at lower pyrolysis temperature were more labile than the biochars produced at higher temperatures. The pattern of the decreasing lability with increasing pyrolysis temperature held for all the woody biomass derived biochars and abiotic incubations as well. However, the abiotic and microbial incubations of herbaceous biomass derived biochars were found to release the most $\mathrm{CO}_{2}$ in 1 year.

The thermal stability of biochar can be quantified by its release of $\mathrm{CO}_{2}$ [7] and therefore, a highly recalcitrant biochar is identified as one with slow $\mathrm{CO}_{2}$ release rate. Harvey et al. [14] developed an energy-based approach for quantitatively evaluating the thermal stability/recalcitrance of biochar. The premise of this energy-based approach was that the amount of energy required to oxidize/volatilize a given quantity of biochar will depend on the bonding environment of carbon atoms in the biochar. This simply implies that thermal stability is a function of bond energy. Hence, biochar having a larger proportion of $\mathrm{C}-\mathrm{C}$ single bonded structures would have a lower thermal stability than those dominated by $\mathrm{C}=\mathrm{C}$, conjugated and aromatic structures. Therefore, the recalcitrance index $\left(\mathrm{R}_{50}\right)$ uses the energy required for thermal oxidation of the biochar (normalized to the energy required for oxidation of graphite) as a measure of recalcitrance/thermal stability.

While several published works have investigated the effect of pyrolysis temperature on the thermal stability and soil amendment characteristics of biochars, the biomass feedstocks are generally grown on arable lands. However, there is sparsity of research that have investigated the use of marginal land grown biomass for production of biochar targeted towards soil amelioration. Therefore, the objective of this study is to investigate the effect of pyrolysis temperature on the thermal stability and 
physicochemical characteristics of biochars produced from herbaceous biomass harvested on reclaimed mine land.

\subsection{Materials and Methods}

\subsubsection{Sample preparation and biochar production}

Two types of herbaceous biomass used to produce biochars in this study were Miscanthus (Miscanthus $x$ giganteus) and Switchgrass (Panicum virgatum L). The biomass samples were obtained from the Alton site, a reclaimed mine land in Upshur County, West Virginia. The samples were air dried for 3 days before they were oven dried at a temperature of $103{ }^{\circ} \mathrm{C}$ for 24 hours. The oven dried samples were subsequently ground to less than $1 \mathrm{~mm}$ particle size using a Retsch Grindomix (Model: GM 200).

The biochar production was carried out in a proximate analyzer (Model: LECO 701, LECO Corporation, St. Joseph, MI). The analyzer has a carousel consisting of 19 spaces for crucibles. The empty crucibles were weighed and thereafter filled with biomass samples. The sample filled crucibles were also weighed again and cover with the crucibles' caps.

A pyrolysis method was created to heat biomass sample from room temperature up to the target temperature of 500,700 and $900{ }^{\circ} \mathrm{C}$ at a heating rate of $10^{\circ} \mathrm{C} / \mathrm{min}$ under a continuous flow of nitrogen to keep the whole process inert. The temperature was kept constant at the target temperatures for 30 minutes before the biochar sample were cooled down and collected in a zip lock bag for further characterization.

\subsubsection{Thermogravimetric analysis of biomass and biochar}

Thermogravimetric analysis of the biomass samples was carried out using a thermogravimetric analyzer (TGA) (Model: Q50, TA Instruments, Schaumburg, IL, USA). About 8-12 mg of the samples were loaded into a platinum sample holder and heated from $30{ }^{\circ} \mathrm{C}$ to $700{ }^{\circ} \mathrm{C}$ in the combustion chamber at three heating rates of 5,15 and $25^{\circ} \mathrm{C} / \mathrm{min}$ under nitrogen flow of $30 \mathrm{~cm}^{3} / \mathrm{min}$.

The thermal degradation of the biochar samples was carried out in a thermogravimetric analyzer (Model: Q50, TA Instruments, Schaumburg, IL, USA). About 8-12 mg of the samples were loaded into a platinum sample holder and heated from $30^{\circ} \mathrm{C}$ to $950{ }^{\circ} \mathrm{C}$ in the combustion chamber at a heating rate of $10{ }^{\circ} \mathrm{C} / \mathrm{min}$ under air flow of $20 \mathrm{~cm}^{3} / \mathrm{min}$. The thermograms were adjusted for moisture and ash content. The recalcitrance index $\left(\mathrm{R}_{50}\right)$ is described in the equation below;

$$
\mathrm{R}_{50}=\mathrm{T}_{50 \mathrm{x}} / \mathrm{T}_{50 \text { graphite }}
$$


Where $\mathrm{T}_{50 \text { biochar }}$ and $\mathrm{T}_{50 \text { graphite }}$ represents the temperatures at which $50 \%$ oxidation/volatilization of the biochar and graphite mass, respectively $[14,19]$. The $\mathrm{T}_{50}$ graphite value of $886^{\circ} \mathrm{C}$ used in this experiment was obtained from Harvey et al. [14].

\subsubsection{Microstructural and physicochemical characterization of biochar}

Solid morphology characterization of the biochars were performed at the West Virginia University Shared Research Facilities using a scanning electron microscope (Model: Hitachi-S4700, Hitachi High Technologies America, Schaumburg, IL). The Raman spectra of the biochars showing the crystalline and amorphous nature of the biochars was carried out using a Raman microscope (Model: Renishaw InVia) at a 50x optical magnification. The laser beam was operated on a 1\% laser power input. The surface chemical state characterization of the biochars was carried out using X-ray photoelectron spectroscopy (Model: PHI 5000 VersaProbe XPS/UPS, ULVAC-PHI Inc., Kanagawa, Japan) in a spectral range of 0 to $1400 \mathrm{eV}$ binding energy and energy resolution of $0.50 \mathrm{eV}$. For the XPS analysis, each sample was mounted on a steel specimen disk using an Ultra High Vacuum approved spectral grade double-sided carbon tape and loaded into the introduction chamber. Afterwards, the sample was transferred to the analysis chamber where the photoelectron spectra were acquired.

The surface area and pore size distribution of the biochars were determined by nitrogen adsorption at $77 \mathrm{~K}$ using Micromeritics Accelerated Surface Area and Porosimetry System (Model: ASAP 2020, Norcross, GA, USA). Prior to the analysis, the samples were degassed at a temperature of $105{ }^{\circ} \mathrm{C}$ for 24 hours and cooled down to $30^{\circ} \mathrm{C}$. The surface area was determined with the BrunauerEmmett-Teller (BET) model. The pore size distributions of the biochars were calculated from the nitrogen adsorption isotherms using the Non-Local Density Function Theory (Carbon-N2, NLDFT, Standard Slit) model provided in the free version of SAIEUS software.

Ultimate analyses (carbon, hydrogen, nitrogen and sulfur fractions) of the biochars were determined based on the ASTM D3176-15 standard [20] using an elemental analyzer (Series II CHNS/O Analyzer 2400, PerkinElmer, Waltham, MA). Fixed carbon, volatile matter and ash content of the biochar samples were quantified using a proximate analyzer (LECO 701, LECO Corporation, St. Joseph, MI) following the ASTM D3174 standard [21].

Data from the ultimate and proximate analyses of the biochars were used in estimating their calorific values based on the unified correlation for computation of higher heating value from the elemental analysis of fuels provided by Channiwala and Parikh [22]. The validity of the correlation has 
been established for fuels having wide range of elemental compositions, i.e. C: $0.00-92.25 \%$, H: 0.43 $-25.1 \%$, O: $0.00-50.00 \%$, N: $0.00-5.60 \%$, S: $0.00-94.08 \%$ and Ash: $0.00-71.4 \%$. However, beyond the specified ranges of $\mathrm{C}, \mathrm{H}, \mathrm{O}, \mathrm{N}, \mathrm{S}$ and Ash, the predictive accuracy of the correlation does not hold true.

For the $\mathrm{pH}$ reading, a suspension of biochar was prepared with deionized water in a 1:20 mixing ratio (w/v), agitated for 30 mins and allowed to stand for about 10 mins before testing with a standard $\mathrm{pH}$ probe $[19,23]$. The $\mathrm{pH}$ reading was carried via a Mettler Toledo $\mathrm{pH}$ meter (Model: Seven Compact $\mathrm{pH} /$ ion meter S220). Each sample was measured in triplicate. The electrical conductivity of the biochar samples was determined using the same biochar solution with a Mettler Toledo Conductivity Meter (Model: Seven Compact S230).

\subsection{Results and Discussion}

\subsubsection{Thermogravimetric analysis of biomass}

The pyrolysis characteristics of Kanlow Switchgrass and Public Miscanthus biomass at heating rate of $5{ }^{\circ} \mathrm{C} / \mathrm{min}$ are shown in the Figure 4.1. Public Miscanthus can be seen to have an initial faster rate of mass loss in comparison to Kanlow Switchgrass. Significant thermal decomposition of both biomass samples started at about $240{ }^{\circ} \mathrm{C}$ and continued until the temperature reached $400{ }^{\circ} \mathrm{C}$, where the mass loss dropped to $25 \%$. For the remainder of the thermal decomposition process, Kanlow Switchgrass can be seen to be more thermally decomposed.

The residual mass after the thermal decomposition of both biomass samples were $18.1 \%$ and 19.9\% for Kanlow Switchgrass and Public Miscanthus, respectively. The residual mass represents the biochar yield of the two biomass samples. Theoretically, the biochar yield should equal the sum of fixed carbon and ash content of the biomass [24]. The estimated biochar yield reported in Table 4.1 compare favorably with the residual mass obtained from the TG graph. However, the experimental biochar yields reported for both samples in chapter 3 were higher than the estimated yield and the ones from the TG analysis. The difference in this result may be attributed to the pyrolysis temperature (500 ${ }^{\circ} \mathrm{C}$ ) being lower than the temperature used for the proximate analysis and thermogravimetric analysis. 


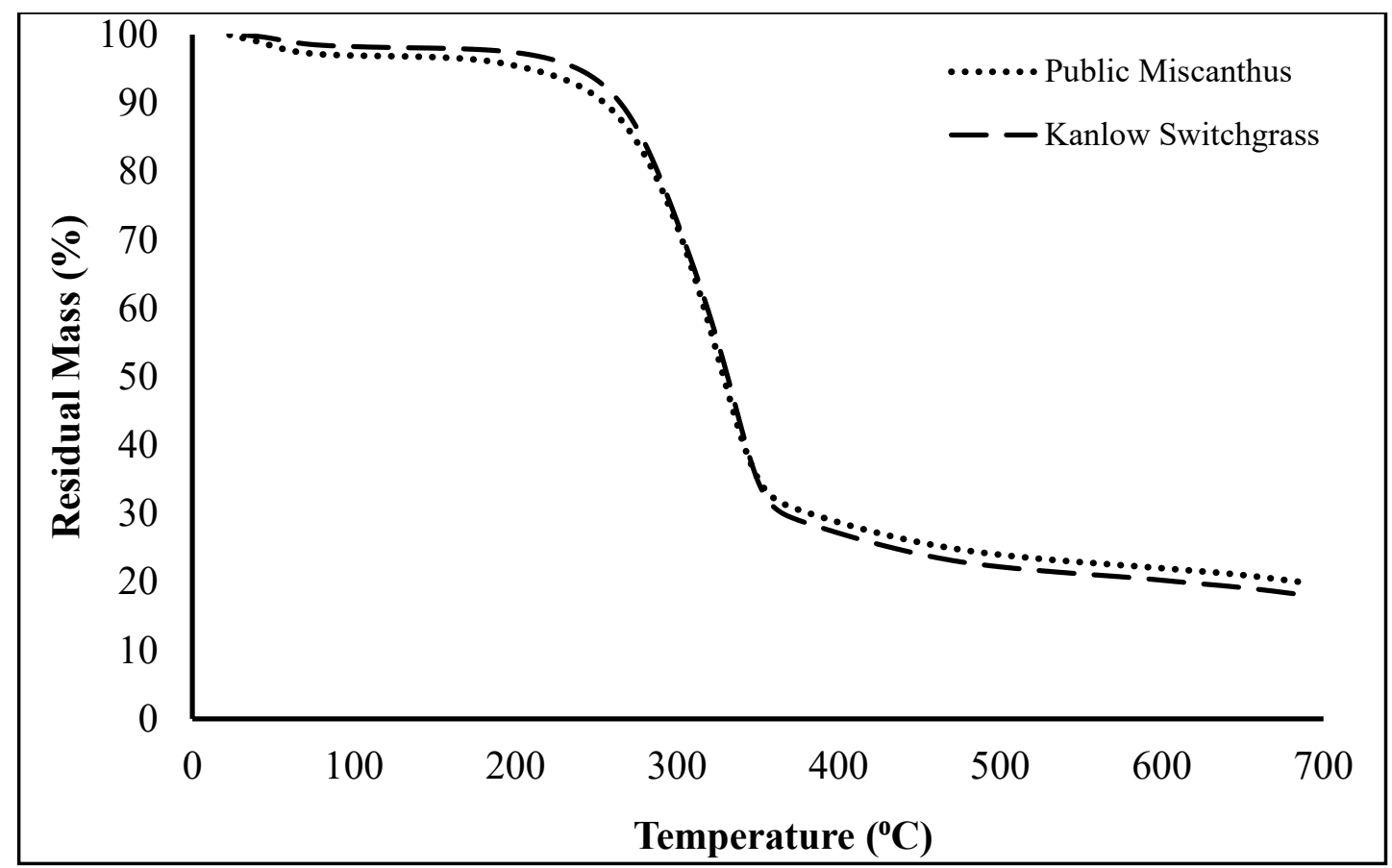

Figure 4.1: TGA- percent mass loss of Kanlow Switchgrass and Public Miscanthus at heating rate of 5 ${ }^{0} \mathrm{c} / \mathrm{min}$

Table 4.1: Chemical composition of Kanlow Switchgrass and Public Miscanthus

\begin{tabular}{lcc}
\hline \multicolumn{1}{c}{ Property } & Kanlow Switchgrass & Public Miscanthus \\
\hline Cellulose (\%) & 36.27 & 36.94 \\
Hemicellulose (\%) & 31.56 & 28.91 \\
Lignin (\%) & 9.27 & 10.31 \\
Others & 19.84 & 20.14 \\
Ash (\%) & 1.37 & 1.21 \\
Fixed Carbon (\%) & 18.06 & 17.03 \\
Estimated Biochar & 19.43 & 18.24 \\
Yield (\%) & & \\
\hline
\end{tabular}

Figure 4.2 shows the DTG curves for Kanlow Switchgrass and Public Miscanthus at a heating rate of $5{ }^{\circ} \mathrm{C} / \mathrm{min}$ under an inert atmosphere. Both biomass samples showed peak temperatures of 336 ${ }^{\circ} \mathrm{C}$ and $327^{\circ} \mathrm{C}$ for Kanlow Switchgrass and Public Miscanthus respectively. These peak temperatures correspond to the temperatures at which the peak cellulose decomposition occurs [25]. The flat right tails of the DTG curves represent the decomposition of the lignin content, which is known to occur over a wide range of temperatures. The thermal decomposition of lignin leads to significant char formation and liberation of large fractions of volatiles, which constitute tar [26]. According to Mohan [27], lignin pyrolysis produces more char than cellulose or hemicellulose. 
The hemicellulose decomposition is generally represented by the shoulder peak to the left of the DTG curve. This is visible in the DTG curve for Kanlow Switchgrass. This difference can be attributed to the higher hemicellulose content of the Kanlow Switchgrass in comparison to that of Public Miscanthus. It is also worth noting that in a demineralized sample (ash free), the anhydrosugars produced during hemicellulose decomposition, transform into vapor phase with little or no char formation due to the non-catalytic effect of mineral matter. However, in the presence of ash, these anhydrosugars rapidly decompose to form a substantial part of the biochar [26]. The chemical composition of the biomass samples in this study showed that both biomass samples have ash content of about $1.2-1.3 \%$. This implies that the hemicellulose decomposition will also contribute to the char formation.

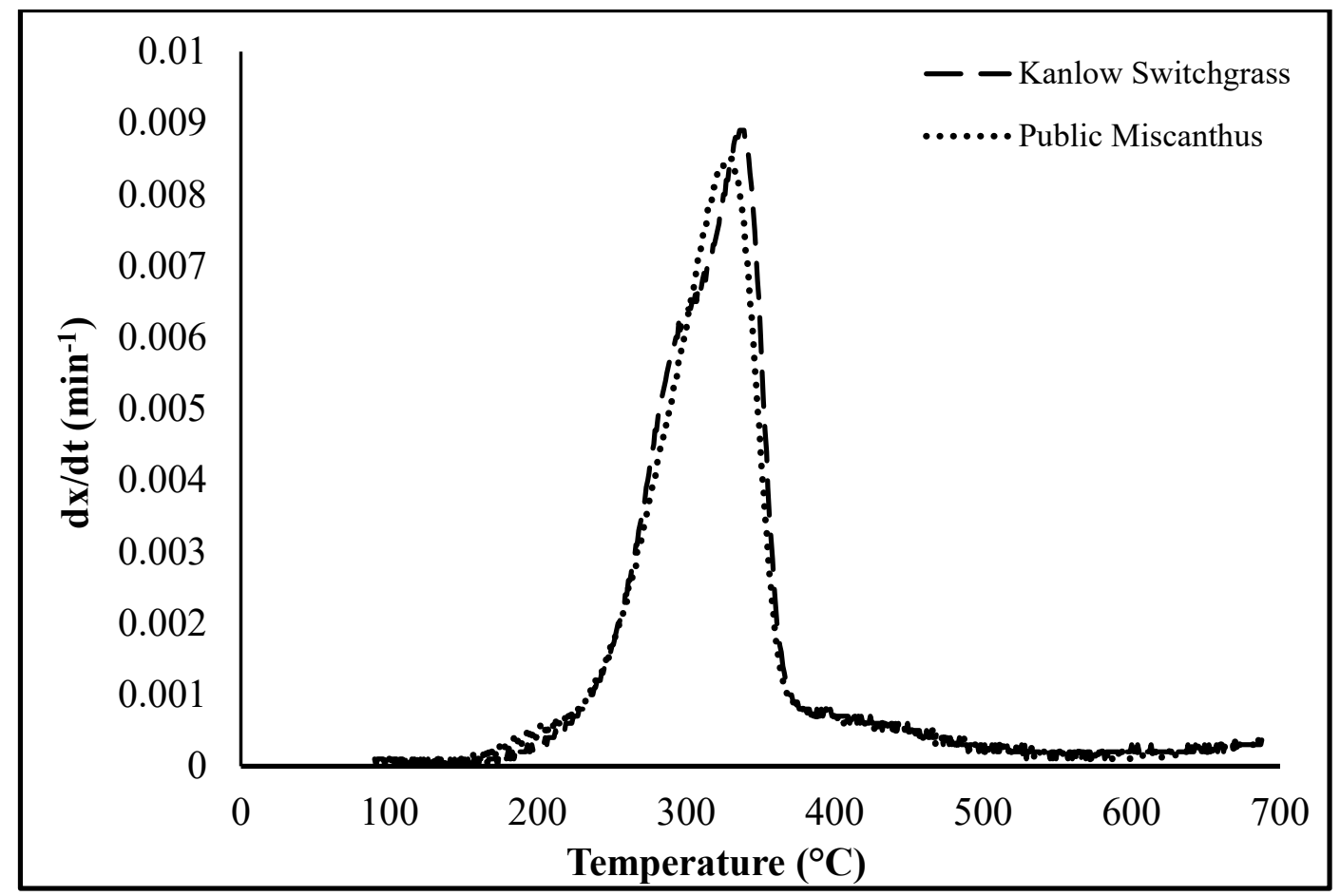

Figure 4.2: DTG curve for Kanlow Switchgrass and Public Miscanthus at heating rate of $5^{\circ} \mathrm{C} / \mathrm{min}$

\subsubsection{Thermal decomposition kinetics}

The differential isoconversional method of Friedman was used in the thermal decomposition kinetics of the biomass samples. A detailed description of the equations showing the rate of conversion and fractional conversion are provided in the works of Lee \& Fasina [28] and Kim \& Agblevor [29]. The rate of conversion described by the Arrhenius equation is given as; 


$$
\beta \frac{d X}{d t}=A \exp \left(\frac{-E}{R T}\right) f(X)
$$

Where $\mathrm{A}$ is pre-exponential factor; $\mathrm{E}$ is activation energy; $\mathrm{R}$ is universal gas constant and $\mathrm{T}$ is absolute temperature in K. The natural logarithm of Eq. (1) was taken based on the isoconversional method of Friedman [30] resulting in Eq. (2);

$$
\ln \left(\beta \frac{d X}{d t}\right)=\ln (A)+\ln f(X)-\frac{E}{R T}
$$

The activation energy $E$, was determined by the linear relationship between $\ln [\beta(\mathrm{dX} / \mathrm{dt})]$ and $1 / T$. The slope of this relationship yields $-E / R$, from which the activation energy corresponding to each conversion was estimated.

Figure 4.3 shows the activation energies as a function of the fractional conversion from 0.1 to 0.6 for Kanlow Switchgrass and Public Miscanthus biomass. The activation energy for Public Miscanthus biomass can be seen to increase from 157 to $984 \mathrm{~kJ} / \mathrm{mol}$ while for Kanlow Switchgrass, the activation energy can be seen to decrease from 341 to $270 \mathrm{~kJ} / \mathrm{mol}$. The overall activation energy values for Public Miscanthus decomposition can be attributed to its high lignin and extractives contents in comparison to Kanlow Switchgrass. The activation energy represents the energy the biomass molecules have to acquire in order to undergo the chemical reaction occurring during the pyrolysis process [26] and this is attainable with an increase in temperature. Therefore, it can be inferred that the activation energies reported for both biomass samples are the activation energies required for the thermochemical decomposition of the biomass constituents (cellulose, hemicellulose, lignin and extractives), which ultimately results in the pyrolysis products namely bio-oil, biochar and non-condensable gases. 


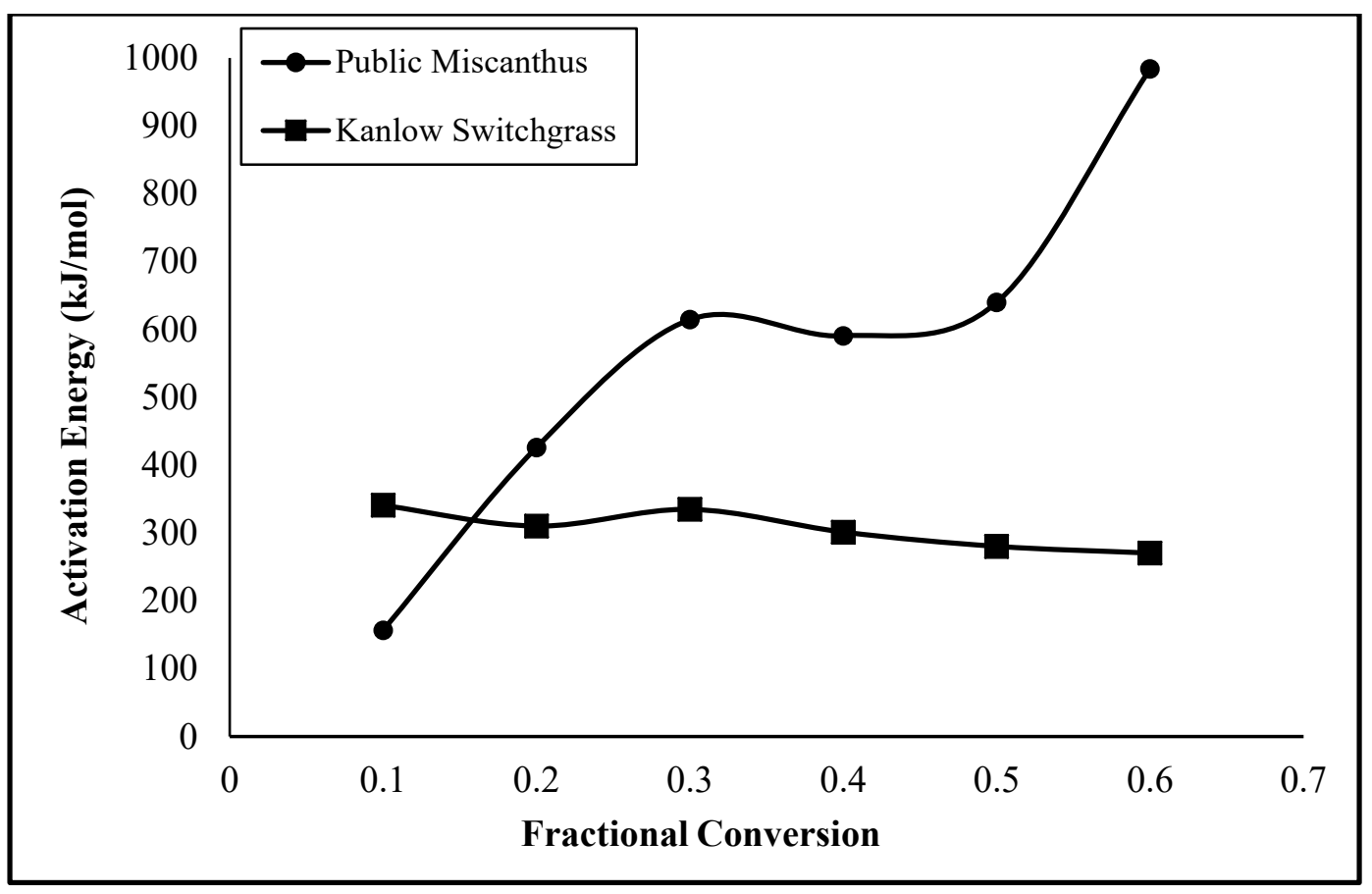

Figure 4.3: Plot of activation energy versus fractional conversion ratio

\subsubsection{Thermal stability of biochars}

Harvey et al. [14] classified the thermal stability of biochars using the Recalcitrance Index $\left(\mathrm{R}_{50}\right)$ into three groups as Class A $\left(\mathrm{R}_{50}>0.70\right)$, Class B $\left(0.50 \leq \mathrm{R}_{50}<0.70\right)$ and Class $\mathrm{C}\left(\mathrm{R}_{50}<0.50\right)$. Biochars in Class A are expected to exhibit minimal susceptibility to biodegradation while biochars in Class B are expected to exhibit some susceptibility to biodegradation. Biochars categorized into Class $\mathrm{C}$ are as susceptible to biodegradation as raw biomass. Figure 4.4 shows the thermal degradation of biochars mass on moisture- and ash-free basis in presence of air. From the Figure 4.4, the recalcitrance indices $\left(\mathrm{R}_{50}\right)$ were calculate for various biochars, which are presented in the Table 4.1. The recalcitrance indices for all the biochars tested ranged between 0.49 to 0.60. Based on Harvey et al. [14]'s classification, all the biochars produced at pyrolysis temperature of $500{ }^{\circ} \mathrm{C}$ and $700{ }^{\circ} \mathrm{C}$ were classified into Class $\mathrm{C}\left(\mathrm{R}_{50}\right.$ value $<0.50$ ), which essentially means that these biochars are expected to degrade similar to raw biomass. On other hand, the biochars produced at pyrolysis temperature of $900{ }^{\circ} \mathrm{C}$ had $\mathrm{R}_{50}$ values $>$ 0.50, which placed them in Class B. This implies that all biochars produced at $900{ }^{\circ} \mathrm{C}$ are expected to stay in soils for longer periods than biochars produced at low temperatures. 


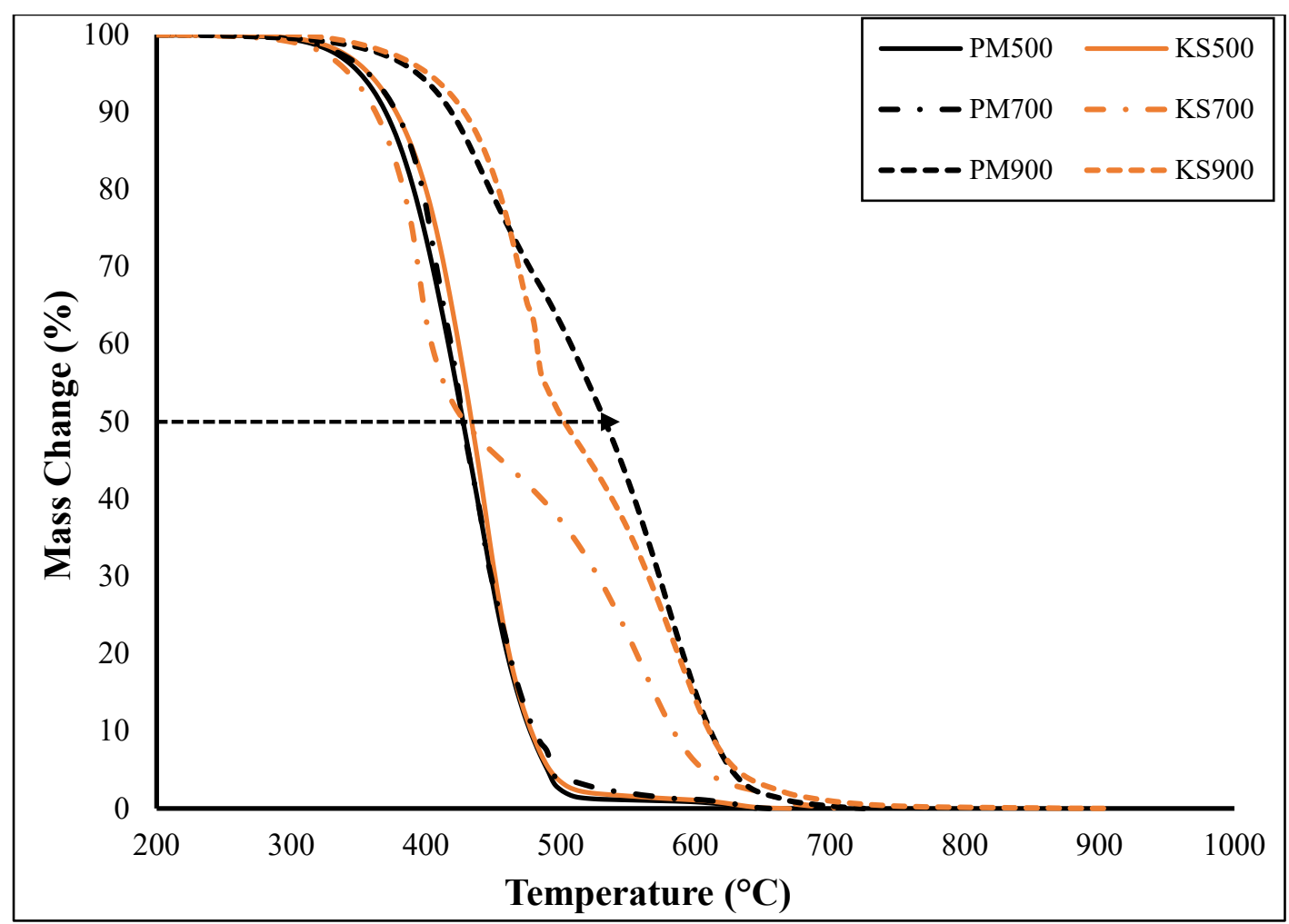

Figure 4.4: Moisture and ash content corrected thermogram for biochars

Zhao et al. [23] reported a similar finding for biochars produced from pig manure and wheat straw at pyrolysis temperature ranging from $200{ }^{\circ} \mathrm{C}$ to $650{ }^{\circ} \mathrm{C}$. The authors found that the recalcitrance indices of the biochars (measured as $\mathrm{R}_{50}$ ) increased with increase in the pyrolysis temperature. The increase in biochar thermal stability with increasing temperature is an expression of the increase in the degree of the biochar aromaticity (i.e aromatic carbon). Santin et al. [31] described the degree of biochar aromaticity as an increase in aromatic carbon of the biochar in comparison to other forms of carbon such as alkyl carbon, O-alkyl carbon and carbonyl carbon. Therefore, the energy required to degrade the biochar increases with an increase in its aromatic carbon. It is noteworthy that while the highest recalcitrance index of biochar can be achieved at higher pyrolysis temperature, there is a trade off with the amount of functional groups in the carbon structure, hence limiting the chemical properties of the biochar as soil amendment [32].

\subsubsection{Electrical conductivity and $\mathrm{pH}$}

The electrical conductivity (EC) of the biochar defines the measure of the amount of salts in the biochar, i.e. it is an indication of the biochar's salinity [33]. The electrical conductivity of the biochars were between 1.21 and $4.07 \mathrm{mS} / \mathrm{cm}$, which fall within the range of values $(0.15-8.2 \mathrm{mS} / \mathrm{cm})$ that have been reported for biochars in literatures [34-36]. The EC increased sharply with the pyrolysis 
temperature from 500 to $700{ }^{\circ} \mathrm{C}$ and then reduced for biochars produced at pyrolysis temperature of $900{ }^{\circ} \mathrm{C}$. A similar trend of increased biochar EC with pyrolysis temperature was reported by Al-Wabel et al. [37] for conocarpus waste derived biochar. High salinity in soil has a negative impact on plant growth due to low osmotic potential of the soil, water stress, salt stress and nutrient imbalances [37]. Therefore, increased EC of the biochars with pyrolysis temperature can result in excessive increase in the soil salinity, which will ultimately result in the adverse effects of high salinity on plant growth

The $\mathrm{pH}$ values of the biochars ranged between 8.96 and 10.61. The $\mathrm{pH}$ values of biochars ranged from slightly alkaline to highly alkaline. The PM 700 and KS 900 biochars had the highest pH values of 10.61 and 10.21 respectively. Yuan et al. [38] reported similar $\mathrm{pH}$ values $(9.39-11.32)$ for biochars produced at pyrolysis temperature of 500 and $700{ }^{\circ} \mathrm{C}$ for agricultural residues including canola straw, corn straw soybean straw and peanut straws. This high alkalinity suggests that the alkaline components of these biochars will be easier to release than other biochars [38]. The alkalinity of biochars produced at higher pyrolysis temperature has been reported to be due to the separation of the alkali salts from organic materials $[33,38]$. Yuan et al. [38] stated that at high pyrolysis temperature, the carbonate content of the biochar contributes to the alkalinity of the biochar while the organic anions decreases.

Table 4.2: Physicochemical properties of biochars

\begin{tabular}{|c|c|c|c|c|c|c|}
\hline Parameter & KS 500 & KS 700 & KS 900 & PM 500 & PM 700 & PM 900 \\
\hline $\begin{array}{l}\text { Electrical conductivity } \\
(\mathrm{mS} / \mathrm{cm})\end{array}$ & $1.29 \pm 0.01$ & $3.01 \pm 0.02$ & $2.68 \pm 0.00$ & $1.24 \pm 0.03$ & $4.07 \pm 0.04$ & $3.11 \pm 0.06$ \\
\hline $\mathrm{pH}$ & $9.89 \pm 0.02$ & $9.62 \pm 0.04$ & $10.29 \pm 0.01$ & $9.57 \pm 0.02$ & $10.61 \pm 0.03$ & $8.96 \pm 0.11$ \\
\hline $\mathrm{S}_{\mathrm{BET}}\left(\mathrm{m}^{2} / \mathrm{g}\right)$ & 0.91 & 27.60 & 519.49 & 0.25 & 239.24 & 783.74 \\
\hline $\mathrm{S}_{\text {Micro }}$ & 6.57 & 35.36 & 416.42 & - & 203.09 & 557.21 \\
\hline Volatile matter & $16.82 \pm 0.64$ & $10.38 \pm 0.39$ & $8.19 \pm 0.23$ & $16.69 \pm 1.62$ & $11.44 \pm 0.27$ & $9.28 \pm 0.52$ \\
\hline Fixed carbon & $76.78 \pm 0.10$ & $73.27 \pm 0.49$ & $74.06 \pm 0.55$ & $74.59 \pm 2.77$ & $78.62 \pm 0.19$ & $79.87 \pm 0.29$ \\
\hline Ash content & $6.19 \pm 0.54$ & $16.35 \pm 0.10$ & $17.75 \pm 0.73$ & $8.72 \pm 1.21$ & $9.94 \pm 0.09$ & $10.85 \pm 0.24$ \\
\hline Carbon & $80.23 \pm 1.13$ & $82.94 \pm 0.80$ & $82.75 \pm 0.58$ & $77.72 \pm 1.50$ & $79.30 \pm 0.22$ & $79.24 \pm 0.43$ \\
\hline Hydrogen & $2.77 \pm 0.07$ & $2.35 \pm 0.04$ & $1.99 \pm 0.03$ & $2.94 \pm 0.26$ & $2.64 \pm 0.05$ & $2.01 \pm 0.01$ \\
\hline Nitrogen & $0.64 \pm 0.02$ & $0.92 \pm 0.01$ & $1.20 \pm 0.33$ & $1.08 \pm 0.17$ & $1.45 \pm 0.22$ & $1.55 \pm 0.35$ \\
\hline Sulfur & $0.11 \pm 0.03$ & $0.18 \pm 0.06$ & $0.21 \pm 0.02$ & $0.38 \pm 0.10$ & $0.10 \pm 0.02$ & $0.08 \pm 0.01$ \\
\hline Oxygen & $16.24 \pm 1.17$ & $13.61 \pm 0.90$ & $13.85 \pm 0.20$ & $17.89 \pm 0.98$ & $16.51 \pm 0.74$ & $17.12 \pm 0.25$ \\
\hline Atomic $\mathrm{H} / \mathrm{C}$ & 0.41 & 0.34 & 0.29 & 0.45 & 0.40 & 0.30 \\
\hline Atomic $\mathrm{O} / \mathrm{C}$ & 0.15 & 0.12 & 0.13 & 0.17 & 0.16 & 0.16 \\
\hline Calorific value (MJ/kg) & $29.46 \pm 0.55$ & $27.40 \pm 0.11$ & $27.33 \pm 0.23$ & $28.59 \pm 0.31$ & $29.51 \pm 0.03$ & $29.60 \pm 0.02$ \\
\hline Thermal Stability $\mathrm{R}_{50}$ & 0.49 & 0.49 & 0.57 & 0.49 & 0.49 & 0.60 \\
\hline
\end{tabular}




\subsubsection{Proximate composition}

The volatile contents of the biochars decreased with increase in the pyrolysis temperature (Table 4.2). The volatile matter content defines the burning characteristics of a material such that high volatile content is an indication that the material can be easily ignited and vice versa [39]. For long term use of biochar for soil amendment, it is required that the biochar have a low volatile matter content.

The low volatile content of the biochars signifies a safe use of the material. This is because biochar with high volatile content can lead to a fire hazard. Blackwell et al [40] explained that biochar dust particles can form explosive mixtures with air in confined spaces, and there is a danger of spontaneous heating and ignition when biochar is tightly packed. However, biochar produced at about $600{ }^{\circ} \mathrm{C}$ or higher often have low volatility levels, which may reduce the risk of spontaneous combustion during storage and handling. Also, the low volatile content is a representation of the biochars' low content of labile or volatile compounds. This is an indicator that the biochar has less labile/easily degradable carbon. This was confirmed by the fixed carbon content. Spokas [7] indicated that biochars with volatile matter higher than $80 \%$ can be decomposed at much higher rates rendering them unfit for long term carbon sequestration. Enders et al [41] proposed a stability classification based on the combination of the volatile content, $\mathrm{H} / \mathrm{C}$ and $\mathrm{O} / \mathrm{C}$ ratio of biochar as follows; a volatile matter below $80 \%$ and an $\mathrm{O} / \mathrm{C}$ ratio above 0.2 or $\mathrm{H} / \mathrm{C}$ above 0.4 may indicate moderate sequestration ability; and a volatile matter below $80 \%$ and an $\mathrm{O} / \mathrm{C}$ ratio below 0.2 or $\mathrm{H} / \mathrm{C}$ below 0.4 may indicate high C sequestration potential. Based on this classification, the biochars produced in this study can be classified to have moderate to high carbon sequestration potential.

The fixed carbon, which is inversely proportional to the volatile content were in the range of 73.27 to $79.87 \%$ (Table 4.2 ). The inverse relationship between the volatile matter content and fixed carbon is because of release of volatile content of the biomass during pyrolysis leading to increase in the fixed carbon content of the biochar. The fixed carbon of the biochars increased with an increase in the pyrolysis temperature, which is an indication of increased carbonization and fixation of the biomass carbon into a slower cycling form that has the potential to exist for hundreds to thousands of years [7]. The calorific values of the biochars ranged between 27.33 and $29.60 \mathrm{MJ} / \mathrm{kg}$ (Table 4.2). The calorific values of Public Miscanthus biochars increased with an increase in temperature while the calorific values of Kanlow Switchgrass biochars decreased with the pyrolysis temperature. The decrease in the calorific values of the Kanlow Switchgrass is attributable to the reduction in its fixed carbon which was accompanied by a significant increase in the ash content of the biochars. In a similar manner, the 
increase in the calorific values of the Public Miscanthus biochars is attributed to the increase in the fixed carbon. Although, there was an increase in the ash contents of the Public Miscanthus biochars, the proportion was not as high as the ones for Kanlow Switchgrass biochars.

\subsubsection{Elemental composition}

The result for the elemental analysis of the biochars are presented in Table 4.2. The elemental carbon contents of the biochars increased with an increase in the pyrolysis temperature, which is a representation of high carbonization at high temperature. This was accompanied with a decrease in the elemental $\mathrm{H}, \mathrm{N} \& \mathrm{~S}$ while the sulfur is negligible. The atomic ratios of the elements were calculated to estimate the aromaticity $(\mathrm{H} / \mathrm{C})$ and polarity $(\mathrm{O} / \mathrm{C})$ of the biochars. The result showed that the $\mathrm{H} / \mathrm{C}$ and $\mathrm{O} / \mathrm{C}$ ratio decreased with an increase in the pyrolysis temperature. This indicates that the aromaticity of the biochars increased with temperature and the biochars also became more hydrophobic due to the loss of oxygen. Uchimiya et al. [42] stated that this observed trend can be attributed to the removal of polar surface functional groups and the formation of aromatic structures by a higher degree of carbonization. The loss of the oxygen with temperature is also an indication of the loss of acidic functional groups of the biochars, hence making the biochar more basic. This is consistent with the $\mathrm{pH}$ values of the biochars. A similar finding was reported by Ahmad et al. [43] for biochars produced from soybean stover and peanut shell at temperature of 300 and $700{ }^{\circ} \mathrm{C}$. Chen et al. [44] also reported a similar trend for pine needles biochars produced at an incremental pyrolysis temperature of 100 to 700 ${ }^{\circ} \mathrm{C}$.

\subsubsection{Surface morphology}

The morphology of the biochars are shown with the SEM micrographs in Figure 4.5. The micrographs show visible porous structures of the biochars. The removal of the volatile content of the biomass during the pyrolysis process led to the development of the pores in the biochars. All the biochars can be seen to possess pores with varying size and shape. These pores serve as the main conduit/channel that connect to the smaller pores on the inner surface of the biochars [45]. The biochars can be seen to still retain the plant structure despite the charring temperature. This shows that the pyrolysis temperature did not lead to total collapse or destruction of the cell walls of the biochars. Also, there are whitish deposits on the surfaces of the biochars. These deposits are the inorganic materials such as potassium that were volatilized during the pyrolysis process. 

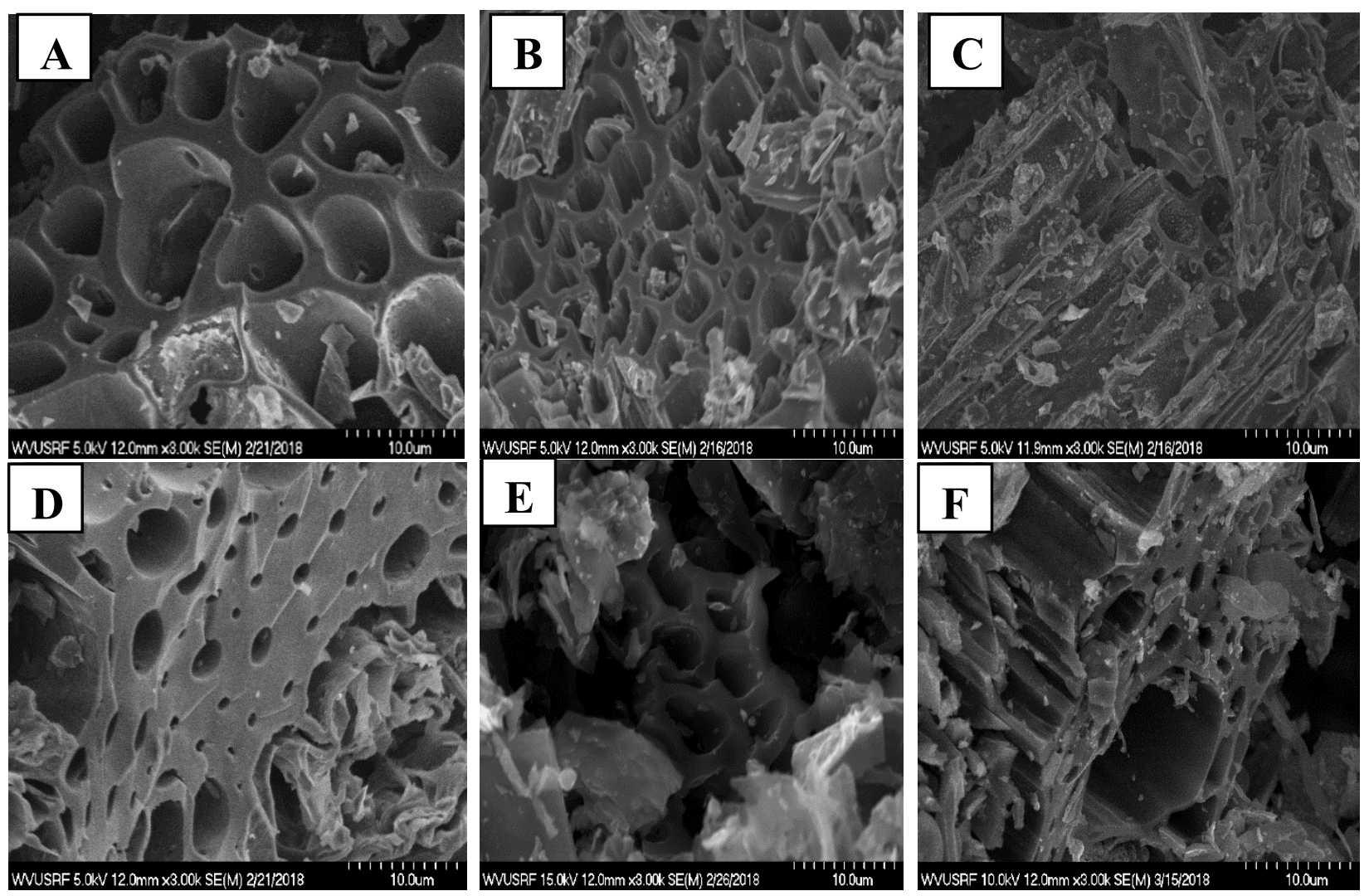

Figure 4.5: SEM of (A) PM 500, (B) PM 700, (C) PM 900, (D) KS 500, (E) KS 700, (F) KS900

\subsubsection{Surface area and pore size distribution}

The BET surface areas of the biochars are presented in Table 4.2, ranging from 0.25 to 783.74 $\mathrm{m}^{2} / \mathrm{g}$. The surface areas of the biochars increased significantly with an increase in the pyrolysis temperature. Chen et al. [44] explained that the increase in the surface of the biochars with an increase in the pyrolysis temperature can be attributed to the removal of phenolic - $\mathrm{OH}$ linked to the aromatic cores, aromatic $\mathrm{CO}-$, and the complete destruction of aliphatic alkyl and ester $\mathrm{C}=\mathrm{O}$ groups shielding the aromatic core. Wang et al. [32] investigated the effect of pyrolysis temperature and residence time on the BET surface areas of biochars produced from bamboo wood, elm wood, rice straw, wheat straw, maize straw, rice husk and coconut shell. The authors reported that an increase in the pyrolysis temperature from 500 to $700{ }^{\circ} \mathrm{C}$ led to a significant increase in the BET surface areas of the biochars.

The pore size distribution of the biochars are shown in Figure 4.6. Biochars produced at pyrolysis temperature of $500{ }^{\circ} \mathrm{C}$ can be seen to have a monomodal distribution between pore width of 4 and $10 \AA$ (equivalent of 0.4 to $1.0 \mathrm{~nm}$ ). The biochars produced at pyrolysis temperatures of 700 and $900{ }^{\circ} \mathrm{C}$ also had monomodal pore size distributions between 4 and $20 \AA$ ( 0.4 and $\left.2.0 \mathrm{~nm}\right)$. However, PM 900 biochar has a bimodal distribution which extended to about $40 \AA(0.4 \mathrm{~nm})$. The broadening of 
the pore size distribution of PM 900 biochar leading to a change from a monomodal to bimodal distribution can be attributed to the effect of the increased carbonization that occurred at this high pyrolysis temperature [46].
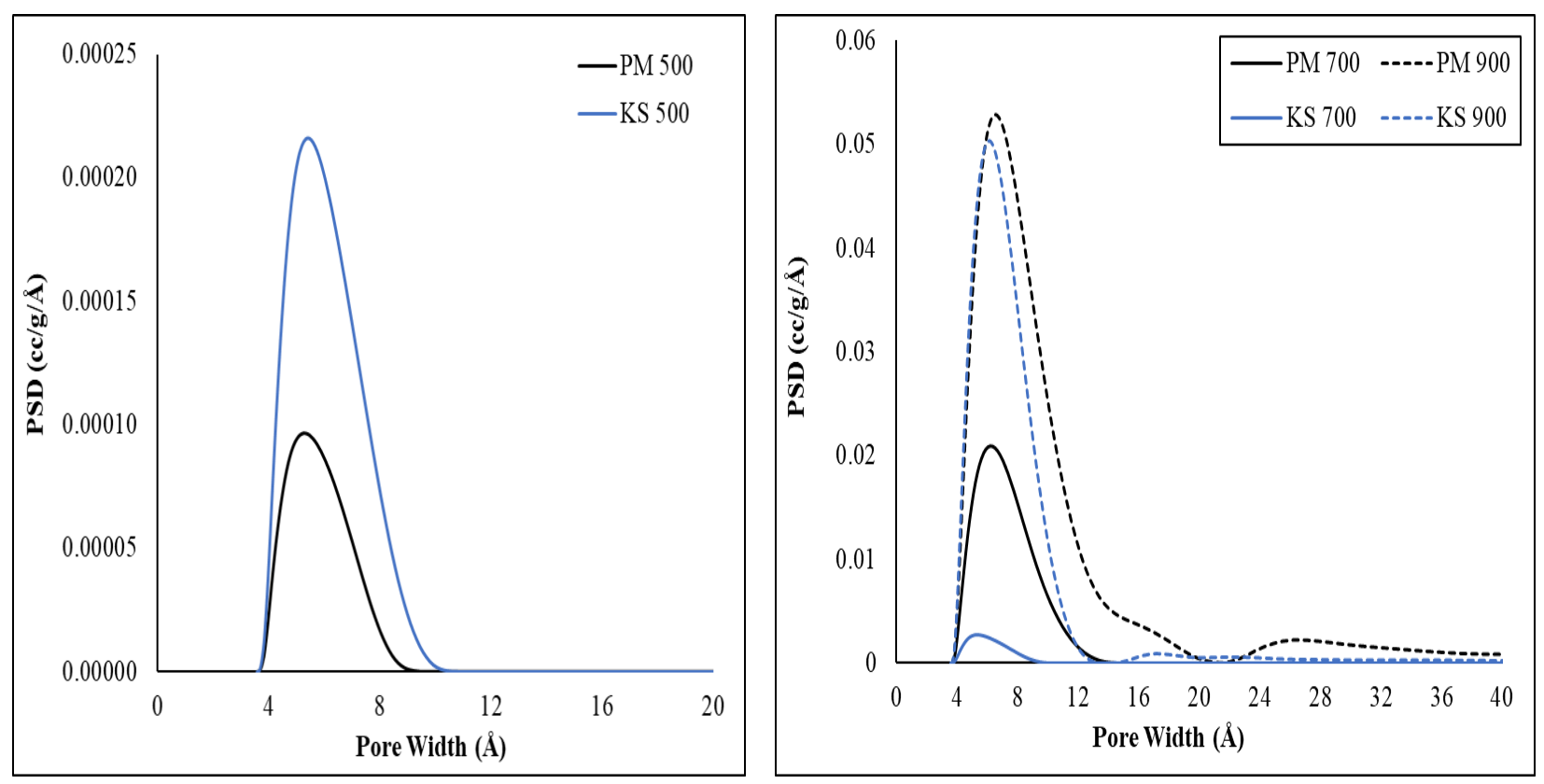

Figure 4.6: Pore size distribution of biochars

Based on IUPAC classification of pore sizes [36], pores are classified into macropore ( $>50$ $\mathrm{nm})$, mesopore $(2.0-50 \mathrm{~nm})$ and micropore $(<2.0 \mathrm{~nm})$. Based on this classification, the pores of the biochars can be classified to be microporous with PM 900 biochar having some of its pores in the mesporous range. The micropores can be further subdivided into narrow micropores or ultramicropores $(<0.7 \mathrm{~nm})$ and supermicropores ( 0.7 to $2.0 \mathrm{~nm}$ ) [36]. The centers of the monomodal distributions for all the biochars were between 0.5 and $0.6 \mathrm{~nm}$, which implies that a higher portion of the micropore volume for the biochars are ultramicropores.

Verheijen et al. [47] stated that the pore size distribution of biochar is a critical factor that affects the belowground ecosystem. The incorporation of biochars with a well-developed porosity can help to capture certain toxic compounds such as pesticides, herbicides, and PAHs which can leach into the environment, thereby increasing the risk of subsurface pollution [1].

\subsubsection{Microstructural analysis}

The microstructure of the biochars was characterized via Raman analysis, particularly the distribution and state of $\mathrm{sp}^{2}$ carbon bonded carbons, which are infused in a disordered and amorphous matrix of both $\mathrm{sp}^{3}$ and $\mathrm{sp}^{2}$ carbon [23]. Figure 4.7 shows the Raman spectra for the biochars. All the 
spectra exhibited the two typical overlapping bands, corresponding to the D-band and G-band. The Dband is labeled as the amorphous/disordered graphite while the G-band is regarded as the presence of graphitic crystallites. The D-band and G-band positions for all the biochars alongside the intensity ratio $\left(\mathrm{I}_{\mathrm{D}} / \mathrm{I}_{\mathrm{G}}\right)$ are presented in Table 4.3.
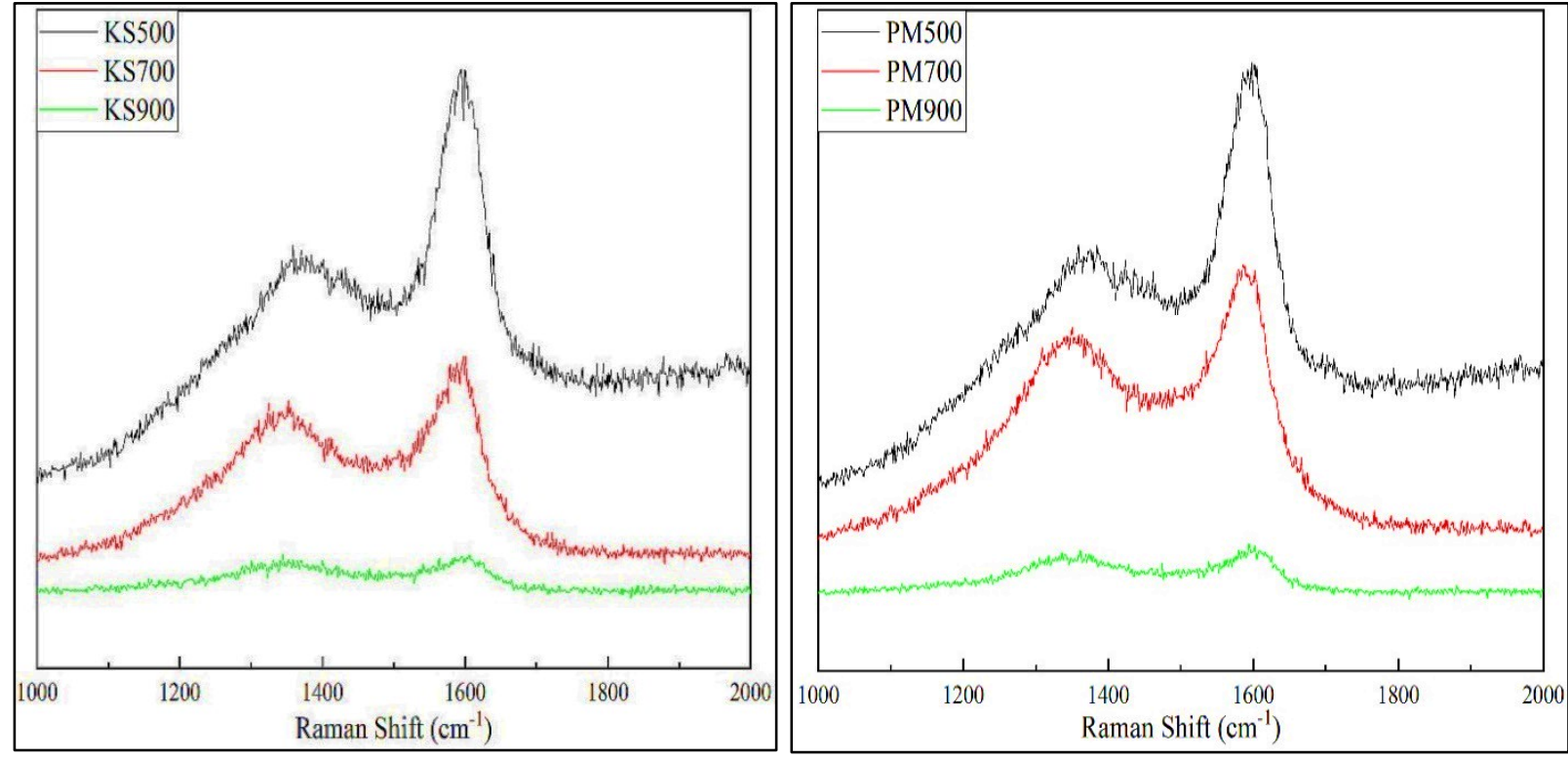

Figure 4.7: Raman spectra of Kanlow Switchgrass and Public Miscanthus biochars

Table 4.3: Raman Spectra $D$ and $G$ band positions and the corresponding intensity ratios

\begin{tabular}{lccc}
\hline Sample & D Peak $\left(\mathbf{c m}^{-\mathbf{1}}\right)$ & G Peak $\left(\mathbf{c m}^{-\mathbf{1}}\right)$ & $\mathbf{I}_{\mathbf{D}} / \mathbf{I}_{\mathbf{G}}$ \\
\hline KS500 & 1393.85 & 1595.99 & 0.61 \\
PM500 & 1390.58 & 1595.43 & 0.61 \\
KS700 & 1361.04 & 1589.41 & 0.87 \\
PM700 & 1361.37 & 1593.73 & 0.78 \\
KS900 & 1358.52 & 1596.00 & 0.87 \\
PM900 & 1354.38 & 1593.67 & 0.88 \\
\hline
\end{tabular}

The D-band positions for all the biochars were in the range of 1354 and $1394 \mathrm{~cm}^{-1}$ while the G-bands positions were in the range of 1589 and $1596 \mathrm{~cm}^{-1}$. There was a noticeable decrease in the D-band positions of the biochars as the pyrolysis temperature increased. However, there was no difference in the G-band positions. The intensity ratios $\left(\mathrm{I}_{\mathrm{D}} / \mathrm{I}_{\mathrm{G}}\right)$ is a parameter used in estimating the extent of carboncontaining defects in the biochars and used a measure of the average crystallite thickness $\left(\mathrm{L}_{\mathrm{a}}\right)$ [48]. The intensity ratio has been shown to be inversely proportional to the crystalline thickness of graphitic materials. For the biochars in this study, the intensity ratios were found to increase with an increase in 
the pyrolysis temperature (Figure 4.8), which is due to depolymerization that occurred during the pyrolysis process. The consequence of depolymerization is the formation of isolated $\mathrm{sp}^{2}$ carbon atoms [48]. The increase in the intensity ratio implies that biochars have fewer aromatic rings structures and more carbon-containing defects that lead to formation of oxygen functional groups on the biochars' surfaces [49]. Also, as the intensity ratio increases, the crystallite thickness reduces, which means there was no conversion of disordered $\mathrm{sp}^{2}$ carbon to ordered $\mathrm{sp}^{2}$ carbon crystallites [48]. Yamauchi and Kurimoto [50] reported an increase in the intensity ratio of Japanese cedar derived biochars as the pyrolysis temperature increase from 500 to $800{ }^{\circ} \mathrm{C}$, which showed that the crystallite thickness of the biochars decreased within that temperature range.

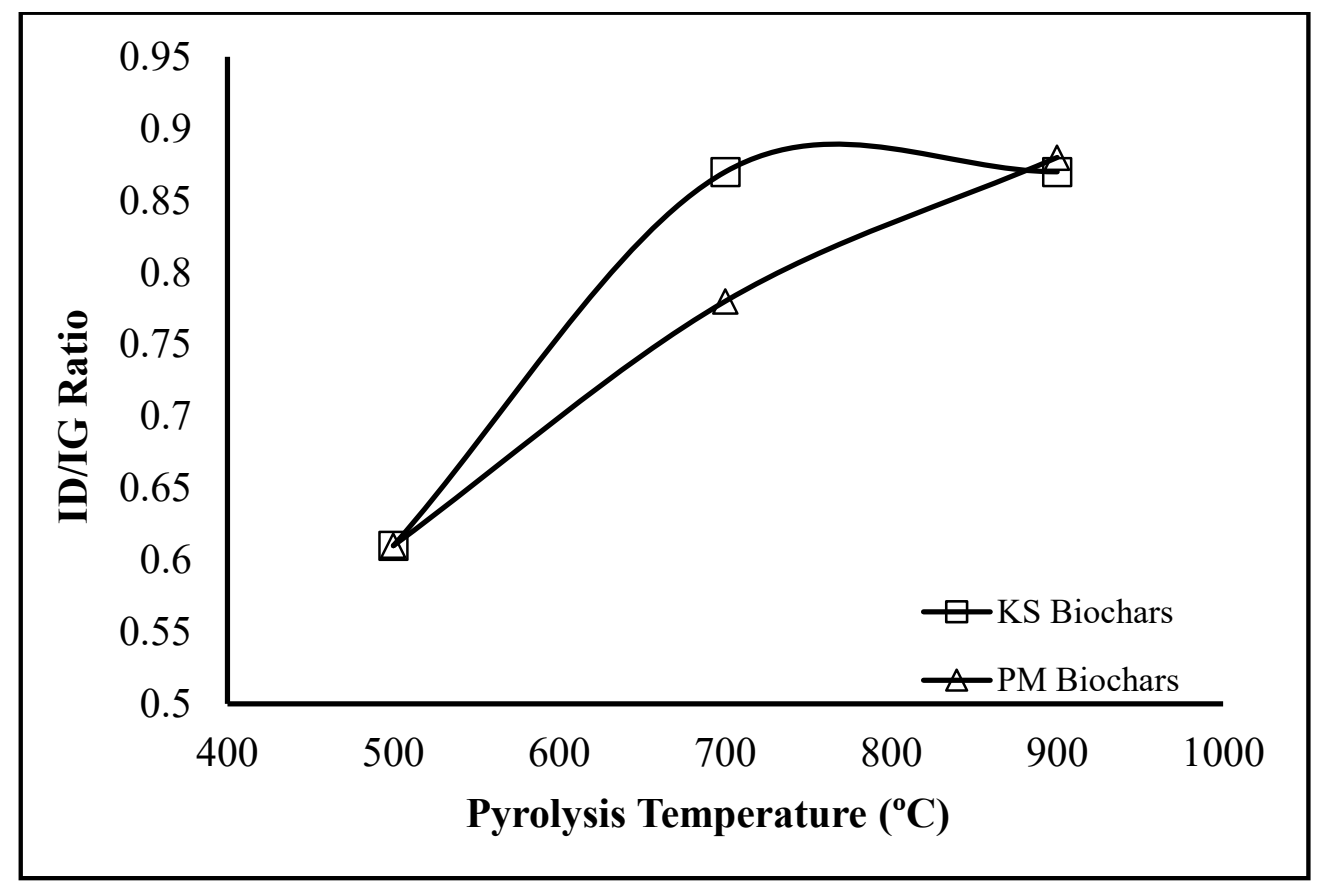

Figure 4.8: Effect of pyrolysis temperature on intensity ratio of biochars

\subsubsection{XPS analysis of biochars}

The effect of pyrolysis temperature on the surface chemistry of the biochars was evaluated by carrying out XPS analysis on the biochars. Figure 4.9 shows the C1s deconvolved peaks for both Kanlow Switchgrass and Public Miscanthus biochars. The C1s deconvolved peaks were assigned to the following known chemical shifts: Peak $1(284.0-284.9$ eV) - graphitic carbon, C-C/C-H; Peak 2 $(285.3-286.3 \mathrm{eV})-$ carbon in phenolic, alcohol, ether or $\mathrm{C}=\mathrm{N}$ groups and Peak $3(286.5-289.3 \mathrm{eV})$ - carbon in carbonyl, quinine, carboxyl or ester groups [45, 51]. 

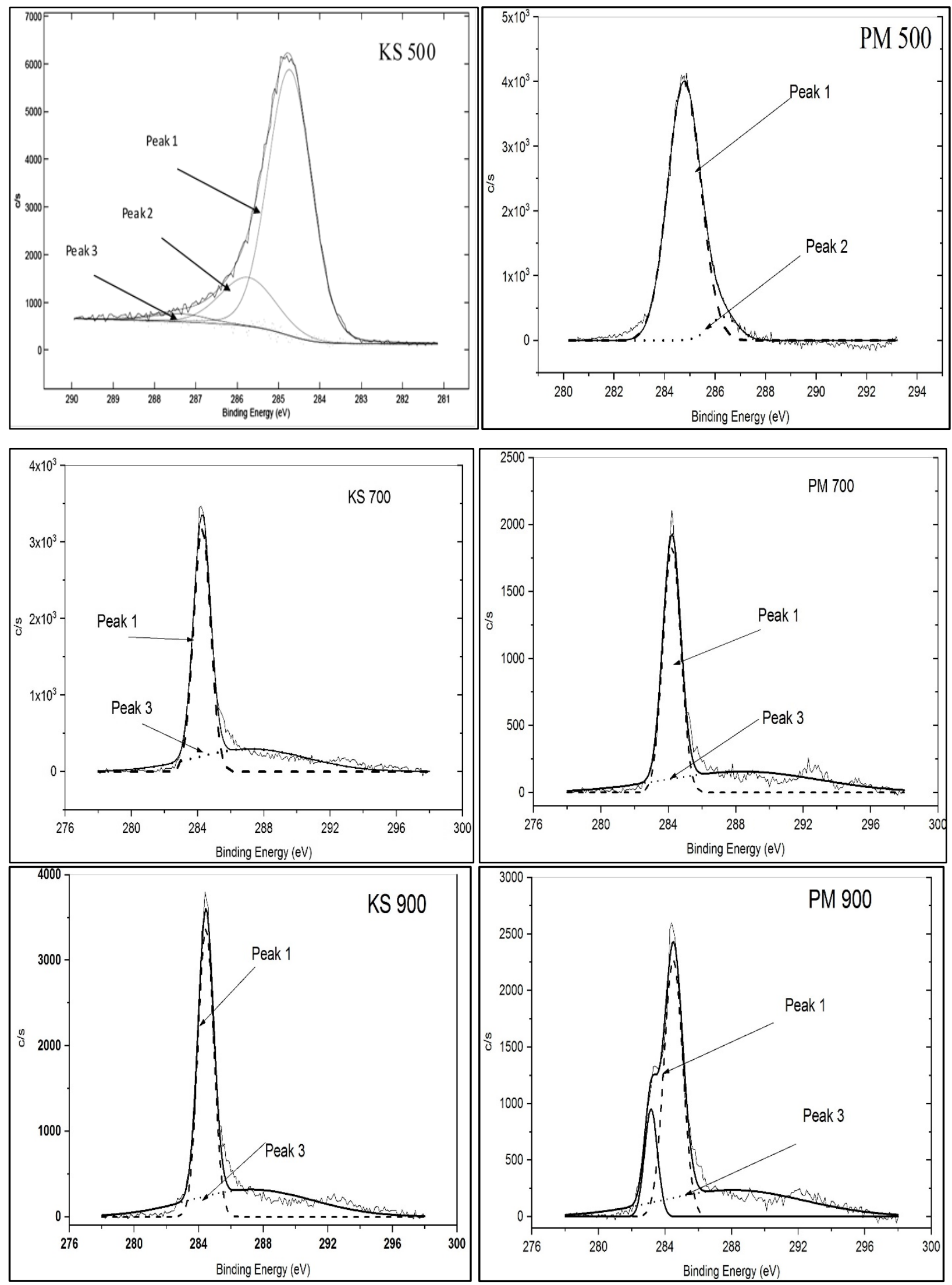

Figure 4.9: XPS C1s deconvolved spectra of Kanlow Switchgrass and Public Miscanthus biochars 
Similarly, the O1s deconvolved peaks were assigned to the following known chemical shifts; Peak I $(530.4-531.9 \mathrm{eV})$ - carbonyl oxygen of quinines, Peak II $(532.1-532.9 \mathrm{eV})$ - carbonyl oxygen atoms in esters, anhydrides and oxygen atoms in hydroxyl groups $(\mathrm{C}-\mathrm{OH} \& \mathrm{C}=\mathrm{O})$ and Peak III (533.1 - 533.8 eV) - non-carbonyl oxygen atoms in esters and anhydrides [52]. The relative content of the deconvolved $\mathrm{C} 1 \mathrm{~s}$ and $\mathrm{O} 1 \mathrm{~s}$ functional groups with the atomic concentrations are presented in Table 4.4. The relative amount of the graphitic carbon decreased while relative amount of carbon in carbonyl, quinine, carboxyl or ester groups increased with an increase in the pyrolysis temperature. The relative content of carbon in phenolic, alcohol, ether or $\mathrm{C}=\mathrm{N}$ groups shown in both $\mathrm{KS} 500$ and PM500 biochars were absent in the biochars produced at temperature of 700 and $900{ }^{\circ} \mathrm{C}$. The deconvolved O1s peaks also showed an increase in the carbonyl oxygen of quinines and a decrease in non-carbonyl oxygen atoms in esters and anhydrides as the pyrolysis temperature increased.

The atomic concentration of $\mathrm{C} 1 \mathrm{~s}$ increased with an increase in the pyrolysis temperature from 500 to $700{ }^{\circ} \mathrm{C}$ but there was no difference when the temperature increased to $900{ }^{\circ} \mathrm{C}$. Also, as the pyrolysis temperature increased, there was a decrease in the atomic concentration of the O1s. A comparison of the XPS detected carbon to the carbon reported in the elemental analysis (Table 4.2) showed that the atomic percentage of the surface carbon were higher than the elemental carbon. Atta-Obeng et al. [51] reported a similar disparity between atomic percentage of surface carbons and the elemental carbons for lignin-derived chars produced at varying hydrothermal carbonization temperature. In the same respect, the atomic percentage of the surface oxygen were lower than the elemental oxygen.

Table 4.4: XPS C1s and O1s surface functional groups of biochars

\begin{tabular}{l|ccc|ccc|cccc}
\hline \multirow{2}{*}{ Biochar } & \multicolumn{3}{|c|}{ C1s (\% wt.) } & \multicolumn{3}{c|}{ O1s (\% wt.) } & \multicolumn{3}{c}{ Atomic conc. (\%) } \\
\cline { 2 - 11 } & Peak 1 & Peak 2 & Peak 3 & Peak I & Peak II & Peak III & C1s & O1s & Si2p & P2p \\
\hline KS500 & 78.60 & 18.33 & 3.07 & 46.38 & - & 53.62 & 86.78 & 13.22 & - & - \\
\hline PM500 & 92.83 & 7.17 & - & 12.49 & - & 87.51 & 85.25 & 13.18 & 0.88 & - \\
\hline KS700 & 62.29 & - & 37.71 & 72.80 & 24.67 & 2.53 & 87.65 & 11.62 & 0.73 & - \\
\hline PM700 & 58.00 & - & 42.00 & 71.19 & 20.90 & 7.92 & 86.95 & 11.61 & - & - \\
\hline KS900 & 57.46 & - & 42.54 & 100 & - & - & 87.52 & 8.89 & 1.46 & 1.05 \\
\hline PM900 & 62.28 & - & 37.71 & 100 & - & - & 85.50 & 11.57 & - & 1.57 \\
\hline
\end{tabular}




\subsection{Conclusion}

Results from this study showed that the pyrolysis temperature plays a significant role in determining the thermal stability and physicochemical properties of the biochars. The increase in the pyrolysis temperature led to an increase in the fixed and elemental carbon of the biochars, which is an indication of the higher degree of carbonization. The $\mathrm{pH}$ of the biochars showed that they are alkaline in nature, hence making them suitable for amendment of acidic soil. The increased surface area and pore size distribution of the biochars with an increase in pyrolysis temperature showed that the biochars would enhance soil microbial activities and water holding capacity. The electrical conductivities of the biochars showed that the addition of the biochars to soil would not lead to increase in the soil salinity. The thermal stability of the biochars increased with an increase in the pyrolysis temperature, which signifies that the biochars can serve as a viable tool for carbon sequestration purpose. 


\section{References}

[1] T. Xie, B. Sadasivam, K. Reddy, C. Wang, K. Spokas, Review of the Effects of Biochar Amendment on Soil Properties and Carbon Sequestration, Journal of Hazardous, Toxic and Radioactive Waste, 04015013 (2015) 1-14.

[2] O. Oginni, K. Singh, J.W. Zondlo, Pyrolysis of dedicated bioenergy crops grown on reclaimed mine land in West Virginia, Journal of Analytical and Applied Pyrolysis, 123 (2017) 319-329.

[3] T. Imam, S. Capareda, Characterization of bio-oil, syngas and bio-char from switchgrass pyrolysis at various temperatures, Journal of Analytical and Applied Pyrolysis, 93 (2012) 170-177.

[4] G. Pilon, J.M. Lavoie, Characterization of switchgrass char produced in torrefaction and pyrolysis conditions, Bioresources, 6 (2011) 4824-4839.

[5] S.H Lee, Min-Seop Eom, Kyung-Seun Yoo, Nam-Chan Kim, Jong-Ki Jeon, Young-Kwon Park, Byung-Ho Song, S.-H. Lee, The yields and composition of bio-oil produced from Quercus Acutissima in a bubbling fluidized bed pyrolyzer, Journal of Analytical and Applied Pyrolysis, 83 (2008) 110-114.

[6] R. He, X.P. Ye, B.C. English, J.A. Satrio, Influence of pyrolysis condition on switchgrass bio-oil yield and physicochemical properties, Bioresource Technology, 100 (2009) 5305-5311.

[7] K.A. Spokas, Review of the stability of biochar in soils: predictability of O:C molar ratios, Carbon Management, 1 (2010) 289-303.

[8] Y. Wang, Y. Hu, X. Zhao, S. Wang, G. Xing, Comparisons of Biochar Properties from Wood Material and Crop Residues at Different Temperatures and Residence Times, Energy \& Fuels, 27 (2013) 5890-5899.

[9] C.J. Atkinson, J.D. Fitzgerald, N.A. Hipps, Potential mechanisms for achieving agricultural benefits from biochar application to temperate soils: a review, Plant and Soil, 337 (2010) 1-18.

[10] L.A. Biederman, W.S. Harpole, Biochar and its effects on plant productivity and nutrient cycling: a meta-analysis, GCB Bioenergy, 5 (2013) 202-214.

[11] S. Sohi, E. Loez-Capel, E. Krull, R. Bol, Biochar's roles in soil and climate change: A review of research needs, in: CSIRO Land and Water Science Report 2009, pp. 64.

[12] F.G.A. Verheijen, E.R. Graber, N. Ameloot, A.C. Bastos, S. Sohi, H. Knicker, Biochars in soils: new insights and emerging research needs, European Journal of Soil Science, 65 (2014) 22-27.

[13] O. Mašek, P. Brownsort, A. Cross, S. Sohi, Influence of production conditions on the yield and environmental stability of biochar, Fuel, 103 (2013) 151-155.

[14] O.R. Harvey, L.J. Kuo, A.R. Zimmerman, P. Louchouarn, J.E. Amonette, B.E. Herbert, An IndexBased Approach to Assessing Recalcitrance and Soil Carbon Sequestration Potential of Engineered Black Carbons (Biochars), Environmental Science \& Technology, 46 (2012) 1415-1421.

[15] E.A. Shneour, Oxidation of graphitic carbon in certain soils, Science, 151(3713) (1966) 991.

[16] J. Lehmann, Bio-energy in the black, Frontiers in Ecology and the Environment, 5 (2007) 381387. 
[17] B. Glaser, J. Lehmann, W. Zech, Ameliorating physical and chemical properties of highly weathered soils in the tropics with charcoal - a review, Biology and Fertility of Soils 35 (2002) 219230.

[18] A.R. Zimmerman, Abiotic and Microbial Oxidation of Laboratory-Produced Black Carbon (Biochar), Environmental Science \& Technology, 44 (2010) 1295-1301.

[19] J.H. Windeatt, A.B. Ross, P.T. Williams, P.M. Forster, M.A. Nahil, S. Singh, Characteristics of biochars from crop residues: Potential for carbon sequestration and soil amendment, Journal of Environmental Management, 146 (2014) 189-197.

[20] ASTM, Standard Practice for Ultimate Analysis of Coal and Coke, in, ASTM International, 2015.

[21] ASTM, Standard Test Method for Ash in the Analysis Sample of Coal and Coke from Coal; ASTM D3174-12, West Conshohocken, PA, 2012.

[22] S.A. Channiwala, P.P. Parikh, A unified correlation for estimating HHV of solid, liquid and gaseous fuels, Fuel, 81 (2002) 1051 - 1063.

[23] L. Zhao, X. Cao, O. Mašek, A. Zimmerman, Heterogeneity of biochar properties as a function of feedstock sources and production temperatures, Journal of Hazardous Materials, 256-257 (2013) 1-9.

[24] W. Jin, K. Singh, J. Zondlo, Pyrolysis Kinetics of Physical Components of Wood and WoodPolymers Using Isoconversion Method, Agriculture, 3 (2013) 12-32.

[25] O. Fasina, B. Littlefield, TG-FTIR analysis of pecan shells thermal decomposition, Fuel Processing Technology, 102 (2012) 61-66.

[26] S. Gaur, T.B. Reed, Thermal data for natural and synthetic fuels, Marcel Decker, Inc. , New York, NY, 1998.

[27] D. Mohan, C.U. Pittman, P.H. Steele, Pyrolysis of wood/biomass for bio-oil: A critical review, Energy \& Fuels, 20 (2006) 848-889.

[28] S.B. Lee, O. Fasina, TG-FTIR analysis of switchgrass pyrolysis, Journal of Analytical and Applied Pyrolysis, 86 (2009) 39-43.

[29] S.S. Kim, F.A. Agblevor, Pyrolysis characteristics and kinetics of chicken litter, Waste Management, 27 (2007) 135-140.

[30] H.L. Friedman, Kinetics of thermal degradation of char-forming plastics from thermogravimetry. Application to a phenolic plastic, Journal of Polymer Science Part C: Polymer Symposia, 6 (1964) 183195.

[31] C. Santín, S.H. Doerr, A. Merino, T.D. Bucheli, R. Bryant, P. Ascough, X. Gao, C.A. Masiello, Carbon sequestration potential and physicochemical properties differ between wildfire charcoals and slow-pyrolysis biochars, Scientific Reports, 7 (2017) 11233.

[32] K. Jindo, H. Mizumoto, Y. Sawada, M.A. Sanchez-Monedero, T. Sonoki, Physical and chemical characterization of biochars derived from different agricultural residues, Biogeosciences, 11 (2014) 6613-6621. 
[33] A.T. Tag, G. Duman, S. Ucar, J. Yanik, Effects of feedstock type and pyrolysis temperature on potential applications of biochar, Journal of Analytical and Applied Pyrolysis, 120 (2016) 200-206.

[34] M. Stefaniuk, P. Oleszczuk, Characterization of biochars produced from residues from biogas production, Journal of Analytical and Applied Pyrolysis, 115 (2015) 157-165.

[35] S. Kloss, F. Zehetner, A. Dellantonio, R. Hamid, F. Ottner, V. Liedtke, M. Schwanninger, M.H. Gerzabek, G. Soja, Characterization of Slow Pyrolysis Biochars: Effects of Feedstocks and Pyrolysis Temperature on Biochar Properties, Journal of Environmental Quality, 41 (2012) 990-1000.

[36] E.N. Yargicoglu, B.Y. Sadasivam, K.R. Reddy, K. Spokas, Physical and chemical characterization of waste wood derived biochars, Waste Management, 36 (2015) 256-268.

[37] M.I. Al-Wabel, A. Al-Omran, A.H. El-Naggar, M. Nadeem, A.R.A. Usman, Pyrolysis temperature induced changes in characteristics and chemical composition of biochar produced from conocarpus wastes, Bioresource Technology, 131 (2013) 374-379.

[38] J.-H. Yuan, R.-K. Xu, H. Zhang, The forms of alkalis in the biochar produced from crop residues at different temperatures, Bioresource Technology, 102 (2011) 3488-3497.

[39] O. Oginni, Contribution of Particle Size and Moisture Content to Flowability of Fractionated Ground Loblolly Pine, in: Biosystems Engineering, Auburn University, Auburn, 2014, pp. 138.

[40] P. Blackwell, G. Riethmuller, M. Collins, Biochar Application to Soil, in: J. Lehmann, S. Joseph (Eds.) Biochar for Environmental Management: Science and Technology, Earthscan, London, UK, 2009, pp. 207.

[41] A. Enders, K. Hanley, T. Whitman, S. Joseph, J. Lehmann, Characterization of biochars to evaluate recalcitrance and agronomic performance, Bioresource Technology, 114 (2012) 644-653.

[42] M. Uchimiya, L.H. Wartelle, I.M. Lima, K.T. Klasson, Sorption of Deisopropylatrazine on Broiler Litter Biochars, Journal of Agricultural and Food Chemistry, 58 (2010) 12350-12356.

[43] M. Ahmad, S.S. Lee, X. Dou, D. Mohan, J.-K. Sung, J.E. Yang, Y.S. Ok, Effects of pyrolysis temperature on soybean stover- and peanut shell-derived biochar properties and TCE adsorption in water, Bioresource Technology, 118 (2012) 536-544.

[44] B. Chen, D. Zhou, L. Zhu, Transitional Adsorption and Partition of Nonpolar and Polar Aromatic Contaminants by Biochars of Pine Needles with Different Pyrolytic Temperatures, Environmental Science \& Technology, 42 (2008) 5137-5143.

[45] J. Xu, L. Chen, H. Qu, Y. Jiao, J. Xie, G. Xing, Preparation and characterization of activated carbon from reedy grass leaves by chemical activation with H3PO4, Applied Surface Science, 320 (2014) 674-680.

[46] A.S. Mestre, E. Tyszko, M.A. Andrade, M. Galhetas, C. Freire, A.P. Carvalho, Sustainable activated carbons prepared from a sucrose-derived hydrochar: remarkable adsorbents for pharmaceutical compounds, RSC Advances, 5 (2015) 19696-19707. 
[47] F. Verheijen, S. Jeffery, A.C. Bastos, E.C.J.R.C.I.f. Environment, Sustainability, Biochar Application to Soils: A Critical Scientific Review of Effects on Soil Properties, Processes and Functions, Publications Office, 2010.

[48] Y.R. Rhim, D. Zhang, D.H. Fairbrother, K.A. Wepasnick, K.J. Livi, R.J. Bodnar, D.C. Nagle, Changes in electrical and microstructural properties of microcrystalline cellulose as function of carbonization temperature, Carbon, 48 (2010) 1012-1024.

[49] B. Peng, L. Chen, C. Que, K. Yang, F. Deng, X. Deng, G. Shi, G. Xu, M. Wu, Adsorption of Antibiotics on Graphene and Biochar in Aqueous Solutions Induced by $\pi-\pi$ Interactions, Scientific Reports, 6 (2016) 31920.

[50] S. Yamauchi, Y. Kurimoto, Raman spectroscopic study on pyrolyzed wood and bark of Japanese cedar: temperature dependence of Raman parameters, Journal of Wood Science, 49 (2003) 235-240.

[51] E. Atta-Obeng, B. Dawson-Andoh, M.S. Seehra, U. Geddam, J. Poston, J. Leisen, Physicochemical characterization of carbons produced from technical lignin by sub-critical hydrothermal carbonization, Biomass and Bioenergy, 107 (2017) 172-181.

[52] J.H. Zhou, Z.-J. Sui, J. Zhu, P. Li, D. Chen, Y.-C. Dai, W.-K. Yuan, Characterization of surface oxygen complexes on carbon nanofibers by TPD, XPS and FT-IR, Carbon, 45 (2007) 785-796 


\title{
Chapter 5
}

\section{Effect of Activating Agent Type and Impregnation Route on Properties of Activated Carbon Synthesized from Herbaceous Biomass}

\begin{abstract}
The objective of this study is to investigate the effect of activating agent type and impregnation route (1. Biomass + activation agent $->$ activated carbon and 2. Biomass-> Biochar + activation agent $->$ activated carbon) on the properties of activated carbons produced from herbaceous biomass. The precursors were Kanlow Switchgrass and Public Miscanthus biomass and their biochars produced at pyrolysis temperature of $500{ }^{\circ} \mathrm{C}$. The precursors were impregnated with either phosphoric acid or potassium hydroxide. The impregnated precursors were activated at a temperature $900{ }^{\circ} \mathrm{C}$ for 30 mins in inert condition. The pore characteristics, surface functionalities, and microstructure of the activated carbons were characterized. the activated carbons were used in adsorbing two pharmaceutical active compounds; acetaminophen and caffeine. The biomass-derived activated carbons had the highest BET surface areas ranging between 999 and $1597 \mathrm{~m}^{2} / \mathrm{g}$. The adsorption isotherms of the KOH/biomassderived and $\mathrm{KOH} /$ biochar-derived activated carbons showed that they are microporous in nature. The surface morphology of the biochar-derived carbons showed pores with varying sizes and that the activated carbons retained the original cell wall structure of the parent materials. The surface morphology of $\mathrm{KOH} /$ biomass-derived activated carbons showed that the cell wall structures of the parent materials were not retained. The Raman analysis showed that the $\mathrm{KOH} /$ biomass-derived and $\mathrm{KOH} /$ biochar-derived activated carbons had more disordered $\mathrm{sp}^{2}$ carbon atoms in comparison to the $\mathrm{H}_{3} \mathrm{PO}_{4}$ samples. The XPS analysis showed that the $\mathrm{KOH} /$ biomass-derived activated carbons have $\mathrm{C} 1 \mathrm{~s}$ in the hydroxyl groups and also have higher percentage of O1s in the hydroxyl and carbonyl groups. The biomass-derived activated carbons had the highest adsorption capacities of $93.73-167.17 \mathrm{mg} / \mathrm{g}$ and $85.41-152.89 \mathrm{mg} / \mathrm{g}$ for both caffeine and acetaminophen respectively.
\end{abstract}

Keyword: Activated Carbon, Surface chemistry, Adsorption, Surface Area, Impregnation 


\subsection{Introduction}

Activated carbons are highly used in advanced water treatment processes and it is highly recommended by the United States Environmental Protection Agency to remove pharmaceuticals and personal care products from water [1]. The activated carbons have well-developed porous structure and surface chemical functionalities for enhanced interaction with polar and non-polar adsorbates [1,2]. Activated carbon can be produced from nearly all carbon-rich and inexpensive precursors with low inorganic content [1]. The production of activated carbon involves two main steps; carbonization and activation. The carbonization process involves the thermal decomposition of the precursor at a temperature below $800^{\circ} \mathrm{C}$ in an inert atmosphere. The thermal decomposition leads to release of volatile content in gaseous form and creation of pores in the resulting chars. Because of deposition of tar substances, pores become filled, or at least partially blocked, by the disorganized carbon. Such materials have been reported to have low surface area [1,3]. Shaaban et al. [4] reported the low surface areas of $1.93 \mathrm{~m}^{2} / \mathrm{g}, 2.01 \mathrm{~m}^{2} / \mathrm{g}$ and $5.493 \mathrm{~m}^{2} / \mathrm{g}$ for biochars produced at pyrolysis temperatures of 300 , 500 and $700{ }^{\circ} \mathrm{C}$, respectively from rubber wood sawdust. Similarly, Zhao et al. [5] reported surface area in the range of $2.39-108.59 \mathrm{~m}^{2} / \mathrm{g}$ and pore volume range of $2.56-58.54 \mathrm{~cm}^{3} / \mathrm{g}$ for biochars produced at pyrolysis temperature of 300 to $600{ }^{\circ} \mathrm{C}$ derived from apple tree branches. The low surface area is mainly due to particle conglomeration and blocking of pores by tars [6].

Activation of chars is performed to remove tar substances from the pore spaces and to create microporosity in the carbon structure [1]. The activation process may be performed via physical activation without using any activation agent or via chemical activation with impregnation of activation agents. In the physical activation, the tar substances are cleaned with the help of high-temperature steam, $\mathrm{CO}_{2}$ or a mixture of both at temperatures in the range of 800 to $1000{ }^{\circ} \mathrm{C}[7,8]$. Physical activation has been reported to be carried out on chars produced from rice husk, corn cob, oak, corn stover, rice straw, pecan shells, peanut hulls and almond shells at the activation temperature range of 600 to 900 ${ }^{\circ} \mathrm{C}$ [9]. In chemical activation process, the chemical activating agents are used, which are mainly alkali $\left(\mathrm{KOH}, \mathrm{K}_{2} \mathrm{CO}_{3}, \mathrm{NaOH}\right.$, and $\left.\mathrm{Na}_{2} \mathrm{CO}_{3}\right)$, alkaline earth metal salts $\left(\mathrm{AlCl}_{3}, \mathrm{FeCl}_{3}\right.$, and $\left.\mathrm{ZnCl}_{2}\right)$ and acid $\left(\mathrm{H}_{3} \mathrm{PO}_{4}\right.$, and $\left.\mathrm{H}_{2} \mathrm{SO}_{4}\right)[10]$.

The commonly used alkali activating agent is $\mathrm{KOH}$. This activating agent has been reported to produce highly microporous activated carbons and enhance the formation of - $\mathrm{OH}$ functional groups on the carbon surface [11]. The effectiveness of $\mathrm{KOH}$ activation relative to other activation methods can be attributed to the ability of $\mathrm{K}$ to easily form intercalation compounds with carbon. In addition, the 
$\mathrm{K}_{2} \mathrm{O}$ formed during the process of $\mathrm{KOH}$ activation is reduced to $\mathrm{K}$ by carbon, resulting in carbon gasification with a subsequent emission of $\mathrm{CO}_{2}$ leading to the formation of pores [12]. However, while $\mathrm{KOH}$ is easily impregnated into the precursor, it does not completely vaporize as the activation temperature is generally lower than its boiling point $\left(1327^{\circ} \mathrm{C}\right)$. Thus, a considerable amount of the $\mathrm{KOH}$ will be released into the aqueous environment when the activated carbon is washed [11]. Meanwhile for alkaline earth metal salts, $\mathrm{ZnCl}_{2}$ is the commonly activating agent. $\mathrm{ZnCl}_{2}$ is a dehydrating agent, which eliminates hydrogen and oxygen atoms of the precursor as water rather than as oxygenated organic compounds, thus leading to the charring and aromatization along with creation of pores [12]. For the acidic activating agent, $\mathrm{H}_{3} \mathrm{PO}_{4}$ is commonly employed for chemical activation. This activating agent is also known to have a dehydrating effect thereby inhibiting the formation of tars and acting as a catalyst promoting bond cleavage reactions as well as facilitating crosslinking, condensation and formation of layer of linkage such as polyphosphosate esters, which can protect the internal pore structure of the activated carbon [13].

In carrying out the impregnation, the activating agents can be directly impregnated into the biomass precursor and a one-step high temperature pyrolysis is performed to produced activated carbons. Whereas, in most cases, the biochars are impregnated with certain activating agents and post heat-treatment is performed. Activation of biochars is mostly performed to enhance surface area and formation of a high degree of mesopores and micropores [11]. Azargohar and Dalai [14] used potassium hydroxide $(\mathrm{KOH})$ on whitewood derived char with an impregnation ratio of $1.23(\mathrm{KOH} /$ biochar) and an activation temperature of $680{ }^{\circ} \mathrm{C}$. As result of activation, the specific surface area of biochar increased from $10 \mathrm{~m}^{2} / \mathrm{g}$ to $783 \mathrm{~m}^{2} / \mathrm{g}$ for the resulting activated carbon. The potassium intercalated to the carbon matrix, which played a significant role in creation and increment of the activated carbon porosity. Similarly, Park et al. [15] used sodium hydroxide $(\mathrm{NaOH})$ on loblolly pine char at an activation temperature of $800{ }^{\circ} \mathrm{C}$. The surface area of the biochars produced between 300 to $700{ }^{\circ} \mathrm{C}$ were between 1.41 to $321 \mathrm{~m}^{2} / \mathrm{g}$, which increased to $57-1250 \mathrm{~m}^{2} / \mathrm{g}$ after activation.

In certain reports, the biomass was directly impregnated with the activation agents and activation/carbonization was performed in the temperature ranges of 500 to $800{ }^{\circ} \mathrm{C}$. The common feature of these activating agents used directly in impregnating the biomass precursor is that they are dehydrating and deoxygenating agents, which influences the carbonization process and inhibit the formation of tars. Therefore, use of these chemical agents directly in biomass preserves pores already existing in the biomass structure by cleaning-up the oxygenated tarry- substances. Kumar and Jena [10] 
impregnated fox nutshell with zinc chloride at various impregnation ratios ranging from $1-2.5$ (by wt) followed by carbonization/activation in the temperature range of $500-700{ }^{\circ} \mathrm{C}$. The authors reported that the highest specific surface area obtained was $2869 \mathrm{~m}^{2} / \mathrm{g}$ with the micropore surface area and volume of $2124 \mathrm{~m}^{2} / \mathrm{g}$ and $1.68 \mathrm{~cm}^{3} / \mathrm{g}$, respectively under impregnation ratio of $2: 1$ and activation temperature of $600{ }^{\circ} \mathrm{C}$. Umran et al. [16] also investigated the impregnation of Holm Oak biomass with $\mathrm{H}_{3} \mathrm{PO}_{4}, \mathrm{ZnCl}_{2}$ and $\mathrm{KOH}$. The impregnated biomass was carbonized at temperature range of 550 to 750 ${ }^{\circ} \mathrm{C}$ for 1 hour. The authors reported that the $\mathrm{ZnCl}_{2}$ derived activated carbon had the highest surface area of $1305 \mathrm{~m}^{2} / \mathrm{g}$ at a temperature of $750{ }^{\circ} \mathrm{C}$. However, the $\mathrm{KOH}$ derived activated carbon was found to have the highest percentage of its total pore volume as micropore and $\mathrm{H}_{3} \mathrm{PO}_{4}$ derived activated carbon had the highest percentage of its total pore volume as mesopore.

While there are literatures that have investigated the use of various chemical activating agents in impregnating either the biomass precursor or the biochar precursor, there is a sparsity of work distinguishing which pathway is better. Therefore, the objective of this study is to investigate the effects of activating agents and impregnation routes on the characteristics of activated carbons synthesized from herbaceous biomass. The two impregnation routes used in this study are; 1 . Biomass + activating agent $=$ activated carbon; 2 . Biochar + activating agent $=$ activated carbon .

\subsection{Materials and Methods}

\subsubsection{Sample preparation and activation}

Kanlow Switchgrass and Public Miscanthus samples were harvested from a reclaimed mine land in West Virginia. Details of growth sites and establishment of the Switchgrass and Miscanthus varieties used in the study have been documented by Skousen et al. [17]. To be specific, the test samples were harvested from Alton site, a reclaimed mine land in Upshur County, West Virginia. This site was mined for the Upper, Middle, and Lower Kittanning coal seams. The 30-ha area selected for Switchgrass and Miscanthus plantings was reclaimed in 1985 with less than $15 \mathrm{~cm}$ depth of soil replaced over mixed overburden. Grass and legume species were planted and the soils were fertilized and limed according to regulations at the time. This site supported a $100 \%$ ground cover of herbaceous plants during the ensuing 25 years [17].

The biomass samples were chopped into small sizes using a kitchen meat-cutting knife and oven dried at $103{ }^{\circ} \mathrm{C}$ for 24 hours. The oven dried samples were subsequently ground to less than $1 \mathrm{~mm}$ particle size using a Retsch Grindomix (Model: GM 200). Additionally, the biochar samples were 
prepared from the oven-dried biomass via pyrolysis. The detailed description of the pyrolysis process is provided in Chapter 3 [18].

The biomass and biochar samples were impregnated with either phosphoric acid $\left(\mathrm{H}_{3} \mathrm{PO}_{4}\right)$ or potassium hydroxide $(\mathrm{KOH})$. About $50 \mathrm{~g}$ of the samples were soaked in $200 \mathrm{ml}$ solution of phosphoric acid (85\% wt.) and continuously stirred inside a pressure reactor (Model: 4500, Parr Instrument Company, Moline, IL, USA) at a temperature of $85^{\circ} \mathrm{C}$ for 24 hours. Subsequently, the biomass and biochar samples were impregnated with $\mathrm{KOH}(100 \% \mathrm{wt}$.) at an impregnation ratio of 1:1 (weight basis). After the impregnation procedure was over, the impregnated samples were oven-dried at a temperature of $103{ }^{\circ} \mathrm{C}$ for 24 hours. The oven dried impregnated samples were thereafter activated using a thermogravimetric analyzer at a temperature of $900{ }^{\circ} \mathrm{C}$ for 1 hour under nitrogen flow to keep the process inert. In addition, activated carbon from both biomass feedstocks were prepared at a temperature of $900{ }^{\circ} \mathrm{C}$ without impregnation.

The activated carbons obtained from $\mathrm{H}_{3} \mathrm{PO}_{4}$ impregnation were washed with boiling deionized water in a lab-line multiunit extraction equipment to remove every trace of the activating agent until the $\mathrm{pH}$ of the activated carbons became neutral. In addition, the activated carbons obtained from $\mathrm{KOH}$ impregnation were washed with dilute hydrochloric acid $(\mathrm{HCl})$ and deionized distilled water to remove every trace of the activating agent. The washed activated carbons were thereafter oven-dried at a temperature of $103{ }^{\circ} \mathrm{C}$ for 24 hours. The labels and description for the activated carbon samples are presented in Table 5.1

Table 5.1: Labels and description for activated carbons

\begin{tabular}{|l|l|l|}
\hline \multicolumn{1}{|c|}{$\mathbf{s} / \mathbf{n}$} & \multicolumn{1}{|c|}{ Label } & \multicolumn{1}{c|}{ Description } \\
\hline 1 & $\mathrm{KOH}-\mathrm{KSBM}$ & Activated carbon from $\mathrm{KOH}$ impregnated Kanlow Switchgrass Biomass \\
\hline 2 & $\mathrm{KOH}-\mathrm{KSBC}$ & Activated carbon from $\mathrm{KOH}$ impregnated Kanlow Switchgrass Biochar \\
\hline 3 & $\mathrm{KOH}-\mathrm{PMBM}$ & Activated carbon from $\mathrm{KOH}$ impregnated Public Miscanthus Biomass \\
\hline 4 & $\mathrm{KOH}-\mathrm{PMBC}$ & Activated carbon from $\mathrm{KOH}$ impregnated Public Miscanthus Biochar \\
\hline 5 & $\mathrm{H}_{3} \mathrm{PO}_{4}-\mathrm{KSBM}$ & Activated carbon from $\mathrm{H}_{3} \mathrm{PO}_{4}$ impregnated Kanlow Switchgrass Biomass \\
\hline 6 & $\mathrm{H}_{3} \mathrm{PO}_{4}-\mathrm{KSBC}$ & Activated carbon from $\mathrm{H}_{3} \mathrm{PO}_{4}$ impregnated Kanlow Switchgrass Biochar \\
\hline 7 & $\mathrm{H}_{3} \mathrm{PO}_{4}-\mathrm{PMBM}$ & Activated carbon from $\mathrm{H}_{3} \mathrm{PO}_{4}$ impregnated Public Miscanthus Biomass \\
\hline 8 & $\mathrm{H}_{3} \mathrm{PO}_{4}-\mathrm{PMBC}$ & Activated carbon from $\mathrm{H}_{3} \mathrm{PO}_{4}$ impregnated Public Miscanthus Biochar \\
\hline 9 & $\mathrm{KS} 00$ & Kanlow Switchgrass Biochar at $900{ }^{\circ} \mathrm{C}$ \\
\hline 10 & $\mathrm{PM} 900^{\circ}$ & Public Miscanthus Biochar at $900{ }^{\circ} \mathrm{C}$ \\
\hline
\end{tabular}




\subsubsection{Characterization of activated carbons}

Solid morphology characterization of the activated carbons was performed at the West Virginia University Shared Research Facilities using a scanning electron microscope (Model: Hitachi-S4700, Hitachi High Technologies America, Schaumburg, IL). The micrographs were collected using the software available with the instrument. The sample was placed on a sample holder and then transferred into the sample chamber in the equipment. The instrument software is used in viewing and collecting the microstructure of the biochar sample at different magnification ranging from 30 to 500,000.

The surface chemical state characterization of the samples was carried out using X-ray photoelectron spectroscopy, XPS (Model: PHI 5000 VersaProbe XPS/UPS, ULVAC-PHI Inc., Kanagawa, Japan) in a spectral range of 0 to $1400 \mathrm{eV}$ binding energy and energy resolution of $0.50 \mathrm{eV}$. For the XPS analysis, each sample was mounted on a steel specimen disk using an Ultra High Vacuum approved spectral grade double-sided carbon tape and loaded into the introduction chamber. Afterwards, the sample was transferred to the analysis chamber where the photoelectron spectra were acquired.

The pore characteristics of the activated carbon samples were determined by nitrogen adsorption at $77 \mathrm{~K}$ using Accelerated Surface Area and Porosimetry System (Model: ASAP 2020, Norcross, GA, USA). Prior to the analysis, the samples were degassed at a temperature of $105{ }^{\circ} \mathrm{C}$ for 24 hours and cooled down to $30^{\circ} \mathrm{C}$. The $\mathrm{N}_{2}$ adsorption isotherms were obtained over a relative pressure, $\mathrm{P} / \mathrm{P}_{0}$, ranging from 0.01 to 0.99 . The surface area, total pore volume, micropore volume and average pore diameter were determined by the application of the Brunauer-Emmett-Teller (BET) model and $t$ plot models. The pore size distributions were calculated from the nitrogen adsorption isotherms with the free version of the SAIEUS program using the Non-Local Density Function Theory (NLDFT) model [19, 20].

\subsubsection{Adsorption of pharmaceutically active compounds}

The adsorbates used were Acetaminophen purchased from Acros Organics, Morris, NJ and Caffeine purchased from Fischer Science Education, Nazareth, PA. Table 5.2 shows the physico-chemical characteristics of the two compounds. 
Table 5.2: Physico-chemical characteristics of acetaminophen and caffeine

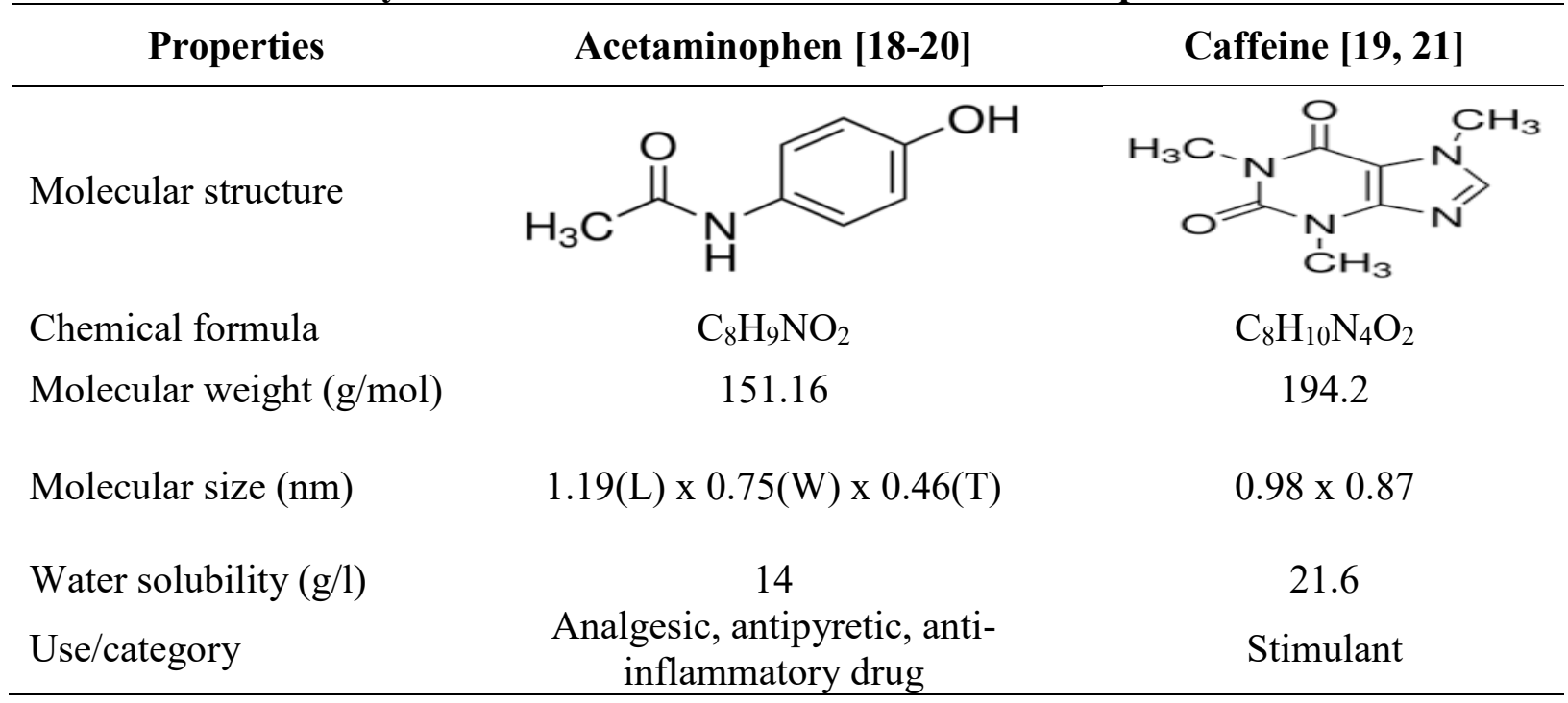

\subsubsection{Determination of adsorbate concentrations in solution}

Standard solutions were prepared by dissolving $10 \mathrm{mg}$ of each adsorbate in $50 \mathrm{ml}$ distilled deionized water to give a concentration of $200 \mathrm{ppm}$. From this solution, varying volumes were taken and adjusted with the distilled deionized water to give the desired concentration.

The selection of the appropriate wavelength for the adsorbate was carried out by scanning the standard solution in UV spectrophotometer (Model: Varian Cary 50) between $200 \mathrm{~nm}$ and $400 \mathrm{~nm}$ on the spectrum mode, using deionized water as a blank. The absorbance recorded for the solution at a specific wavelength, is proportional to its concentration, which is based on Beer-Lambert principle. The maximum wavelength $\left(\lambda_{\max }\right)$ at which the solutions showed the peak absorbance were selected. The $\lambda_{\max }$ at $242 \mathrm{~nm}$ wavelength was identified as the specific absorbance wavelength for acetaminophen while for caffeine, it was $\lambda_{\max }$ at $274 \mathrm{~nm}$ wavelength.

After identifying the specific absorbance wavelength, a calibration plot was prepared for the two adsorbates. A ten-point calibration curve was obtained in the concentration range of $0.10-50 \mathrm{ppm}$ for both adsorbates. The plot of the concentration versus the absorbance (Figure 5.1) gave a straight-line curve and the linear regression equations for both samples had correlation coefficients of 0.98 and 0.99 for acetaminophen and caffeine respectively. 

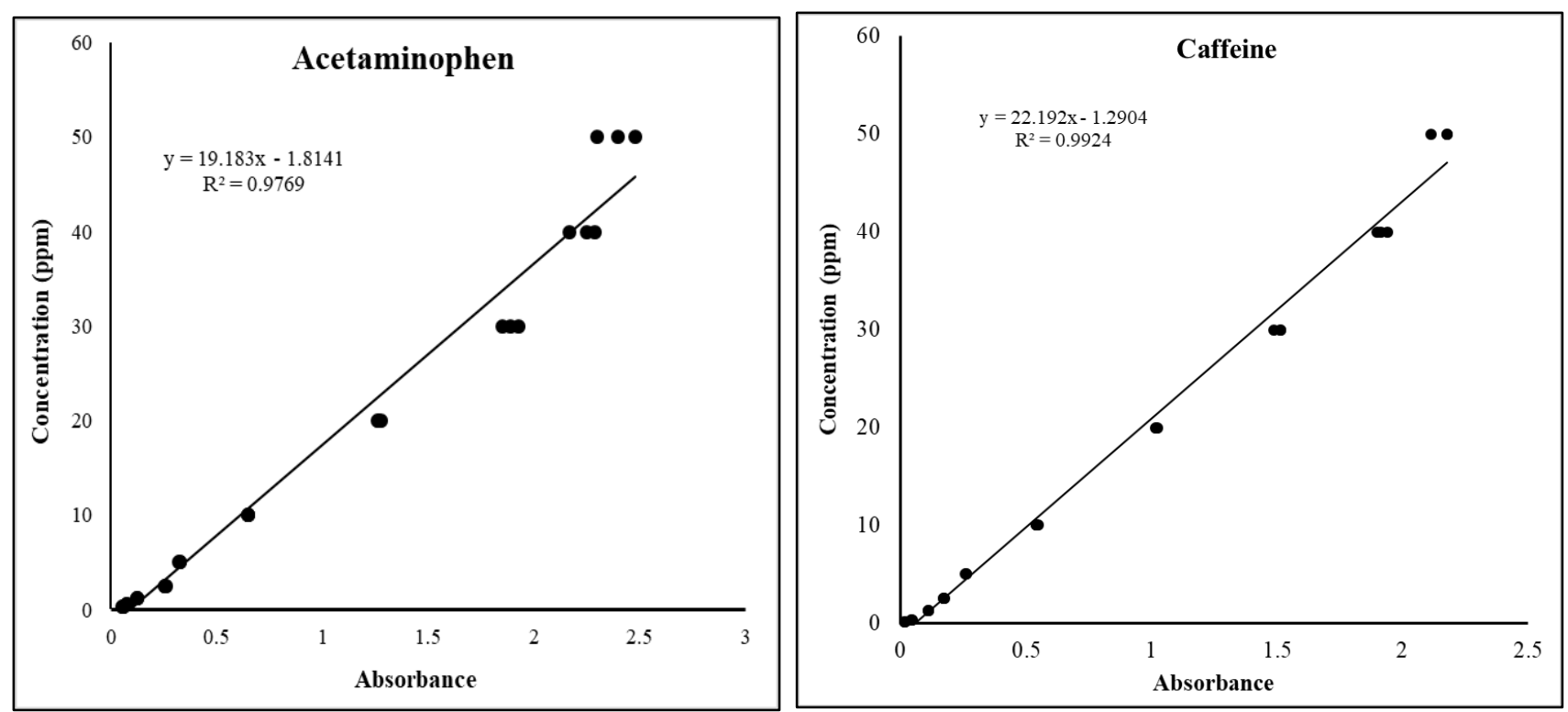

Figure 5.1: Calibration curves for Acetaminophen and Caffeine solutions

\subsubsection{Determination of adsorption kinetics}

To study the adsorption kinetics, $10 \mathrm{mg}$ of the activated carbon was added to $40 \mathrm{ml}$ of acetaminophen and caffeine solutions in glass vials (initial concentration of $40 \mathrm{ppm}$ ). The mixtures were agitated in a multipoint agitation plate at a temperature of $25^{\circ} \mathrm{C}$. The time recording started when the agitation began and several samples were collected between $15 \mathrm{~min}$ and 9 hours. The collected samples were filtered through a filter paper (Fisher Scientific, Qualitative P4) to separate activated carbon and absorbate solution. After that, the filtered absorbate solution was analyzed in the UV-Vis spectrophotometer for concertation determination. From the initial concentration and concentration values at time ' $t$ ', the amount of acetaminophen or caffeine uptake by activated carbons was calculated according to the following equation;

$$
q_{t}=\frac{C_{o}-C_{t}}{W} V
$$

Where $q_{t}$ is the amount $(\mathrm{mg} / \mathrm{g})$ of acetaminophen or caffeine adsorbed at time $t, C_{o}$ is the initial concentration (ppm), $C_{t}$ is the concentration at time $t(\mathrm{ppm}), \mathrm{V}$ is the volume $(\mathrm{ml})$ of the adsorbate solution and $\mathrm{W}$ is the weight $(\mathrm{mg})$ of the activated carbon used.

Additionally, the $q_{t}$ data for various durations ( $\mathrm{t}$ ) were fitted into the pseudo-second order kinetic model [22] expressed as;

$$
\frac{t}{q_{t}}=\frac{1}{k_{2} q_{e}^{2}}+\frac{1}{q_{e}} t
$$


Where $q_{e}$ is the maximum adsorption capacity for the pseudo-second order adsorption, $k_{2}$ is the equilibrium rate constant for the pseudo-second order adsorption. Values of $k_{2}$ and $q_{e}$ were estimated from the intercept and slope, respectively, of the plot of $t / q_{t}$ versus $t$. The product $k_{2} q_{e}{ }^{2}$, (designated as $\mathrm{h}$ in this study) represents the initial adsorption rate. The half-life time, $t_{1 / 2}$, defines the time required for the adsorbent to uptake half of the adsorbate amount that will be retained at equilibrium [22]. It is used as a measure of rate of adsorption and is determined from the equation below;

$$
t_{1 / 2}=\frac{1}{k_{2} q_{e}}
$$

\subsubsection{Determination of adsorption equilibrium}

For the equilibrium adsorption study, $10 \mathrm{mg}$ of the activated carbon was mixed with $40 \mathrm{ml}$ solution of the adsorbates (initial concentration of $10-40 \mathrm{ppm}$ ) and agitated for 5 hours. After the agitation, the concentration of the adsorbate in the solution at equilibrium was determined. The agitation time of 5 hours was selected for the equilibrium assays based on the results of the adsorption kinetics; between 5 hours and 9 hours, there was no difference in the uptake of the adsorbates. All the experiments were carried out in triplicate without $\mathrm{pH}$ adjustment.

The initial and final concentrations of adsorbate were used to calculate $q_{e}$ ( $\mathrm{t}=5$ hours) using equation 1. After that, the $q_{e}$ and equilibrium concertation $\left(C_{e}\right)$ data were fitted with Langmuir and Freundlich models. The Langmuir isotherm model may be written as equation 4 [22] in its linear form;

$$
\frac{C_{e}}{q_{e}}=\frac{C_{e}}{q_{m}}+\frac{1}{b q_{m}}
$$

where $q_{e}=$ equilibrium quantity adsorbed; $C_{e}=$ equilibrium concentration of adsorbate; $q_{m}=$ maximum adsorption capacity; $b=$ Langmuir constant. $q_{m}$ and $b$ can be determined from the linear plot of $C_{e} / q_{e}$ versus $q_{e}$. The Langmuir isotherm model is based on the assumptions that; (i) during an entire adsorption process, only monolayer adsorption occurs; (ii) the adsorbed entities are attached to the surface at definite localized sites with no adsorbate-adsorbate interactions; (iii) the heat of adsorption is independent of surface coverage, that is, the adsorbent has an energetically homogenous surface [1, 23].

In addition, Freundlich isotherm model was fitted with the $q_{e}$ and equilibrium concentration $\left(C_{e}\right)$ data as given by equation 5 [22] in its linear form.

$$
\ln q_{e}=\ln K_{f}+\frac{1}{n} \ln C_{e}
$$

Where $K_{f}$ and $n$ are indicators of adsorption capacity and adsorption intensity or surface heterogeneity, respectively. The values of $n$ and $K_{f}$ can be obtained from the slope and intercept of the linear plot of 
$\ln q_{e}$ versus $\ln C_{e}$. The Freundlich isotherm assumes that the ratio of the adsorbate adsorbed onto an adsorbent is not constant at different solution concentrations [24]. According to Freundlich equation, the amount adsorbed increases infinitely with increasing concentration. This equation is therefore satisfactory for low concentration [25]. The isotherm does not have much limitation i.e., it can deal with both homogenous and heterogeneous surfaces, and both physical and chemical adsorption [26].

\subsection{Results and Discussion}

\subsubsection{Surface morphology}

The morphological analysis performed by SEM (Figure 5.2) shows the porous structure of the activated carbons. The SEM images of the biochar-derived activated carbons (Figure 5.2A - D) show that these activated carbons have visible pores of varying sizes and still retained the cell wall structures of the parent materials. The open pore structure makes it easy for adsorbate to access maximum surface area of the activated carbon through enhanced diffusion [27].

Figure $5.2(\mathrm{E}-\mathrm{H})$ shows the SEM images of the biomass-derived activated carbons. $\mathrm{H}_{3} \mathrm{PO}_{4-}$ $\mathrm{KSBM}$ and $\mathrm{H}_{3} \mathrm{PO}_{4}-\mathrm{PMBM}$ activated carbons (Figure $5.1 \mathrm{~F} \& \mathrm{H}$ ) had similar pore structure and cell wall structure retention like the biochar-derived activated carbons. The activating agent is known to act as a catalyst promoting bond cleavage reactions as well as facilitating crosslinking, condensation and formation of layer of linkage such as polyphosphosate esters, which can protect the internal pore structure of the activated carbon [13].

However, KOH-KSBM and KOH-PMBM activated carbons (Figure 5.4E \& G) did not show any distinctive pore structure, which is an indication that the original cell wall structures of the parent materials were not retained after impregnation and activation. The non-distinctive porous structures exhibited by the $\mathrm{KOH}$-activated carbons can be attributed to the destruction of the lignin components of the biomass precursors during the impregnation process [38]. The lignin, which consists of many ester and ether bonds in crosslinked structure helps to sustain the morphology of the biomass and upon impregnation with $\mathrm{KOH}$, the lignin component was severely destroyed by $\mathrm{KOH}$. Also, during the activation process, $\mathrm{KOH}$ decompose to form metallic $\mathrm{K}$, which reacts with carbon and accelerates the gasification of the impregnated biomass, thus destroying cell wall structure. Oh et al. [38] reported a similar finding for the activated carbon obtained from the impregnation of Rice straw with $\mathrm{KOH}$ prior to activation. This effect was not evident in the biochar-derived activated carbons because the lignin content had been thermally decomposed during the biochar production. 

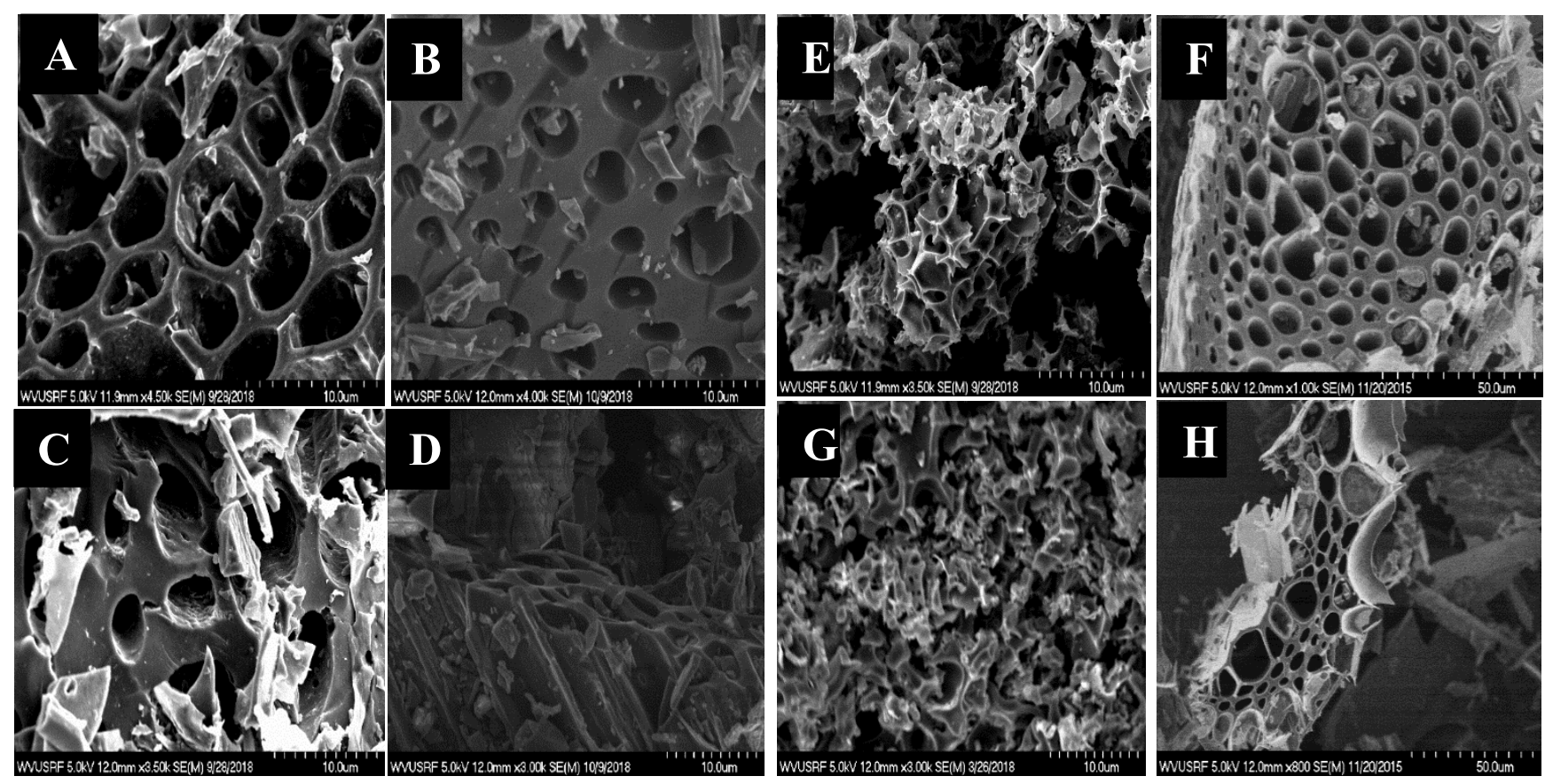

Figure 5.2: SEM Images of (A) KOH-KSBC, (B) $\mathrm{H}_{3} \mathrm{PO}_{4}-\mathrm{KSBC}$, (C) KOH-PMBC, (D) $\mathrm{H}_{3} \mathrm{PO}_{4}-\mathrm{PMBC}^{-}$ (E) KOH-PMBM, (F) $\mathrm{H}_{3} \mathrm{PO}_{4}-\mathrm{PMBM}$, (G) KOH-KSBM, (H) $\mathrm{H}_{3} \mathrm{PO}_{4}-\mathrm{KSBM}$

\subsubsection{Specific surface area and pore size distribution}

Figure 5.3(A \& B) shows the $\mathrm{N}_{2}$ adsorption-desorption isotherms for the biochars and biocharderived activated carbons while Figure 5.3(C \& D) shows the $\mathrm{N}_{2}$ adsorption-desorption isotherms for the biomass-derived activated carbons. Based on the IUPAC classification of adsorption isotherms [28], the adsorption isotherms for the biochars (KS900 and PM900) and the KOH/biochar-derived activated carbons (KOH-KSBC and KOH-PMBC) can be classified as type I isotherm, which is a typical representation of microporous materials. The $\mathrm{KOH} /$ biomass-derived activated carbons (KOH-KSBM and $\mathrm{KOH}-\mathrm{PMBM}$ ) also had similar adsorption isotherms. These adsorption isotherms showed that the porous structures of the $\mathrm{KOH}$ activated carbons are mainly microporous in nature. Hui and Zaini [11] stated that $\mathrm{KOH}$ activated carbons possess extensive microporosity, sometimes the percentage can be as high as $96 \%$.

Meanwhile, the adsorption isotherms for $\mathrm{H}_{3} \mathrm{PO}_{4} /$ biochar-derived activated carbons $\left(\mathrm{H}_{3} \mathrm{PO}_{4}-\right.$ $\mathrm{KSBC}$ and $\left.\mathrm{H}_{3} \mathrm{PO}_{4}-\mathrm{PMBC}\right)$ and $\mathrm{H}_{3} \mathrm{PO}_{4}$ /biomass-derived activated carbons $\left(\mathrm{H}_{3} \mathrm{PO}_{4}-\mathrm{KSBM}_{3}\right.$ and $\mathrm{H}_{3} \mathrm{PO}_{4}-$ PMBM) can be classified as type IV isotherm. This isotherm type is characterized by its hysteresis loop, which is associated with capillary condensation taking place in the mesopores [28]. The initial part of the isotherm (prior to the hysteresis loop) also known as the inflection point of the knee of the 
isotherm is attributed to monolayer-multilayer adsorption, which is similar to the middle section of type II isotherm and it indicate the stage at which monolayer coverage is complete and multilayer adsorption begins $[28,29]$. This is an

The adsorption hysteresis exhibited by the activated carbons has also been identified to have a wide variety of shapes, therefore, IUPAC classified this adsorption hysteresis into four classes $\left(\mathrm{H}_{1}-\right.$ $\left.\mathrm{H}_{4}\right)[28,30]$. Based on this classification, the adsorption hysteresis exhibited by the activated carbons can be classified as $\mathrm{H}_{4}$, which is associated with narrow slit-shaped pores.
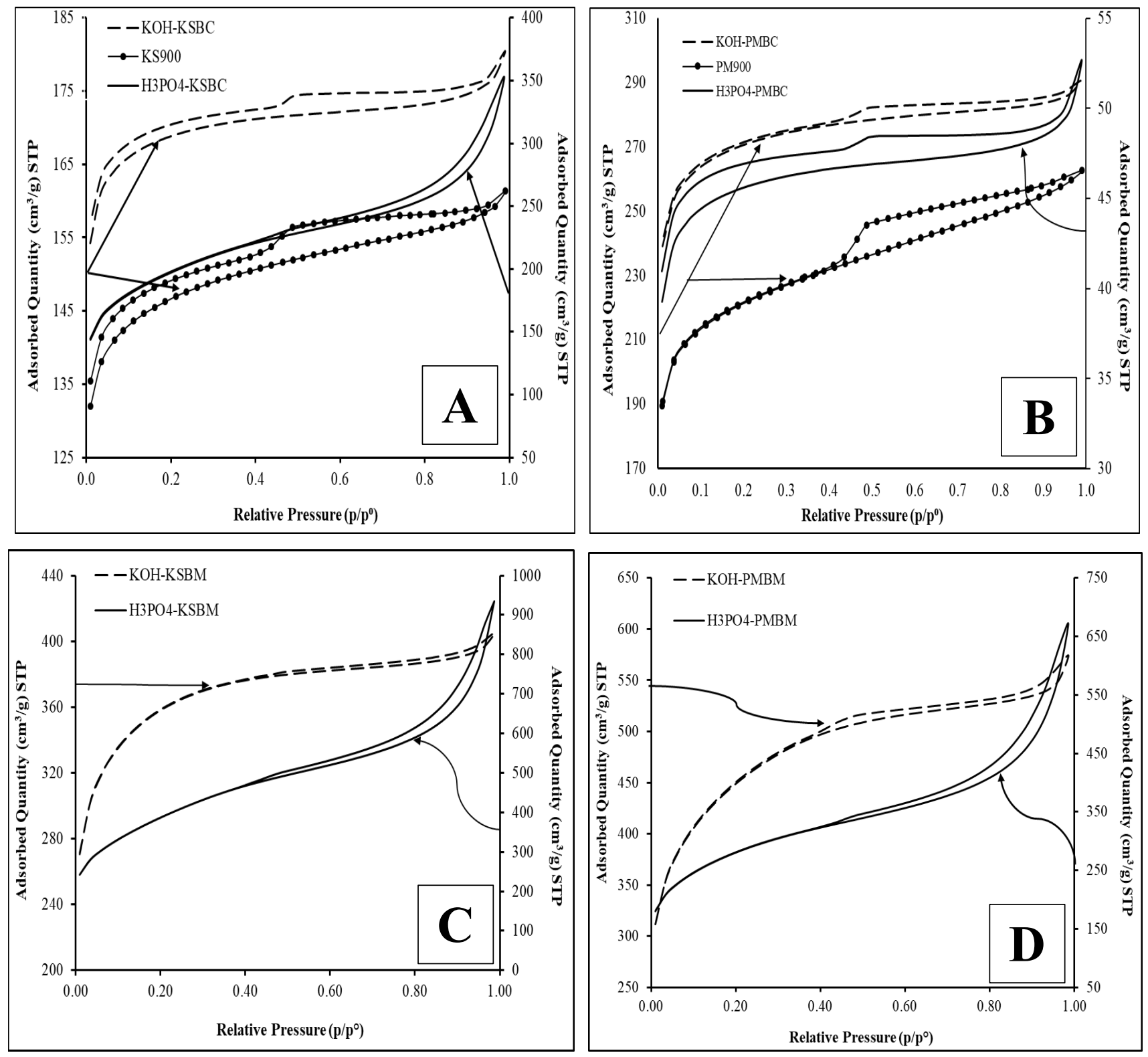

Figure 5.3: $\mathrm{N}_{2}$ adsorption/desorption isotherm curves at $77 \mathrm{k}$ for activated carbons 
Table 5.3 shows the BET surface, pore volume and average pore diameters of the activated carbons and biochars. The BET surface areas ranged between 161 and $1597 \mathrm{~m}^{2} / \mathrm{g}$. There was an increase in the BET surface areas of the biochar-derived activated carbons from both activating agents $\left(\mathrm{H}_{3} \mathrm{PO}_{4}\right.$ and $\mathrm{KOH}$ ) in comparison to the BET surfaces of the biochars, which is an indication that the impregnation and activation led to the increased surface area. However, there was a drastic reduction in the BET surface area of $\mathrm{H}_{3} \mathrm{PO}_{4}-\mathrm{PMBC}$ activated carbon. This reduction can be attributed to a high degree of burn off from the activated carbon during the activation process.

The BET surface areas of the biomass-derived activated carbons were higher than the BET surface areas of the biochar-derived activated carbons. This implies that biomass impregnation and activation was a better route for creating activated carbons with high surface areas. This effect can be attributed to chemical reaction between the chemical components of the biomass and the activating agents during the subsequent carbonization.

The acidic impregnation may lead to the hydrolysis of cellulose and hemicellulose content of the biomass precursor while the alkaline activating agent results in the removal of lignin and partial hemicellulose [39]. The phosphoric acid impregnation promotes the pyrolytic decomposition of the precursor and the formation of cross-linked structure [40, 41]. The pyrolytic decomposition is promoted by the catalytic effect of phosphoric acid on the bond cleavage reactions. The cross-linking is due to interactions between the acid and the organic material in the precursor leading to formation of phosphate linkages between the fragments in the biopolymer [40]. According to Mestre et al. [42], the $\mathrm{KOH}$ reaction mechanism involves the formation of $\mathrm{K}_{2} \mathrm{CO}_{3}, \mathrm{H}_{2} \mathrm{O}, \mathrm{CO}_{2}, \mathrm{CO}$ and $\mathrm{H}_{2}$ at a relatively low temperature $\left(\sim 400^{\circ} \mathrm{C}\right)$ and some of these compounds are commonly used as physical activating agents. The $\mathrm{K}_{2} \mathrm{CO}_{3}$ decomposes at temperatures between 700 and $800^{\circ} \mathrm{C}$, resulting in the formation of metallic $\mathrm{K}$, which remains intercalated in the carbon structure. The metallic $\mathrm{K}$ is removed during the washing of the activated carbon, hence unblocking the pore network.

The micropore surface areas $\left(\mathrm{S}_{\text {micro }}\right)$ of the activated carbons ranged from 139.39 to 747.19 $\mathrm{m}^{2} / \mathrm{g}$. The micropore surface area describes the proportion of the total surface of the activated carbon that are microporous. The micropore surface areas of the KOH samples (KOH-KSBC, KOH-PMBC, (KOH-KSBM and KOH-PMBM) were higher than their counterparts $\left(\mathrm{H}_{3} \mathrm{PO}_{4}-\mathrm{KSBC}, \mathrm{H}_{3} \mathrm{PO}_{4}-\mathrm{PMBC}\right.$, $\mathrm{H}_{3} \mathrm{PO}_{4}-\mathrm{KSBM}$ and $\left.\mathrm{H}_{3} \mathrm{PO}_{4}-\mathrm{PMBM}\right)$. This corroborate the isotherm types used in describing the adsorption isotherms of the activated carbon, where the $\mathrm{KOH}$ samples are classified as microporous materials having adsorption isotherm type I while $\mathrm{H}_{3} \mathrm{PO}_{4}$ samples have adsorption isotherm type IV. 
Table 5.3: Surface area and pore characteristics of activated carbons

\begin{tabular}{lllllll}
\hline Sample & $\mathrm{S}_{B E T}\left(\mathrm{~m}^{2} / \mathrm{g}\right)$ & $\mathrm{S}_{\text {micro }}\left(\mathrm{m}^{2} / \mathrm{g}\right)$ & $\mathrm{V}_{\text {total }}\left(\mathrm{cm}^{3} / \mathrm{g}\right)$ & $\mathrm{V}_{\text {micro }}\left(\mathrm{cm}^{3} / \mathrm{g}\right)$ & $\mathrm{V}_{\text {meso }}\left(\mathrm{cm}^{3} / \mathrm{g}\right)$ & $\mathrm{dp}(\mathrm{nm})$ \\
\hline $\mathrm{KOH}-\mathrm{KSBC}$ & 599.19 & 504.80 & 0.28 & 0.22 & 0.06 & 1.86 \\
$\mathrm{KOH}-\mathrm{PMBC}$ & 957.51 & 747.19 & 0.45 & 0.33 & 0.12 & 1.88 \\
$\mathrm{H}_{3} \mathrm{PO}_{4}$ - KSBC & 697.96 & 273.20 & 0.55 & 0.12 & 0.43 & 3.13 \\
$\mathrm{H}_{3} \mathrm{PO}_{4}$ - PMBC & 161.97 & 139.39 & 0.08 & 0.06 & 0.02 & 2.01 \\
\hline $\mathrm{KOH-KSBM}$ & 1271.66 & 647.66 & 0.63 & 0.28 & 0.35 & 1.97 \\
$\mathrm{KOH-PMBM}$ & 1596.52 & 534.29 & 0.89 & 0.23 & 0.66 & 2.23 \\
$\mathrm{H}_{3} \mathrm{PO}_{4}-\mathrm{KSBM}$ & 1372.93 & 137.05 & 1.45 & 0.10 & 1.35 & 3.42 \\
$\mathrm{H}_{3} \mathrm{PO}$-PMBM & 999.06 & 284.51 & 1.04 & 0.12 & 0.92 & 4.15 \\
\hline $\mathrm{KS} 900$ & 519.49 & 416.42 & 0.25 & 0.18 & 0.07 & 1.92 \\
$\mathrm{PM}_{400}$ & 783.74 & 557.21 & 0.41 & 0.24 & 0.17 & 2.07
\end{tabular}

*dp: Average pore diameter (4V/A by BET); V: Pore volume; S: Surface area

Figure 5.4 further shows the distribution of the surface areas within the microporous and mesoporous ranges. From the Figure 5.4A, KOH-KSBC and KOH-PMBC showed the highest micropore surface areas, followed by the biochars (KS900 and PM900). This indicates that a higher proportion of their surface areas are in the microporous range. The biochar-derived activated carbons (except $\mathrm{H}_{3} \mathrm{PO}_{4}-\mathrm{KSBC}$ ) and the biochars showed a monomodal distribution with pore width range of 4 to $20 \AA$ (equivalent of $0.4-2.0 \mathrm{~nm}$ ) with the maximum surface area associated with $6 \AA$ pores $(0.6$ $\mathrm{nm}) . \mathrm{H}_{3} \mathrm{PO}_{4}-\mathrm{KSBC}$ showed a bimodal distribution with its second peak having a pore width range from 20 to $40 \AA$ (equivalent of $2.0-4.0 \mathrm{~nm}$ ). This second peak indicates the proportion of the total surface area of the activated carbon that are in the mesoporous range.

In Figure 5.4B, the biomass-derived activated carbons showed bimodal surface area distributions, in which the larger peaks were in the micropore range and the smaller peaks were in the mesopore range. In comparison to the biochar-derived activated carbons, the biomass-derived activated carbons showed broad microporous distributions whereas the biochar-derived activated carbons showed narrow microporous distributions. Also, the biochar-derived activated carbons did not show visible mesoporous distribution, whereas the biomass-derived activated carbons showed visible broad mesoporous distributions. 

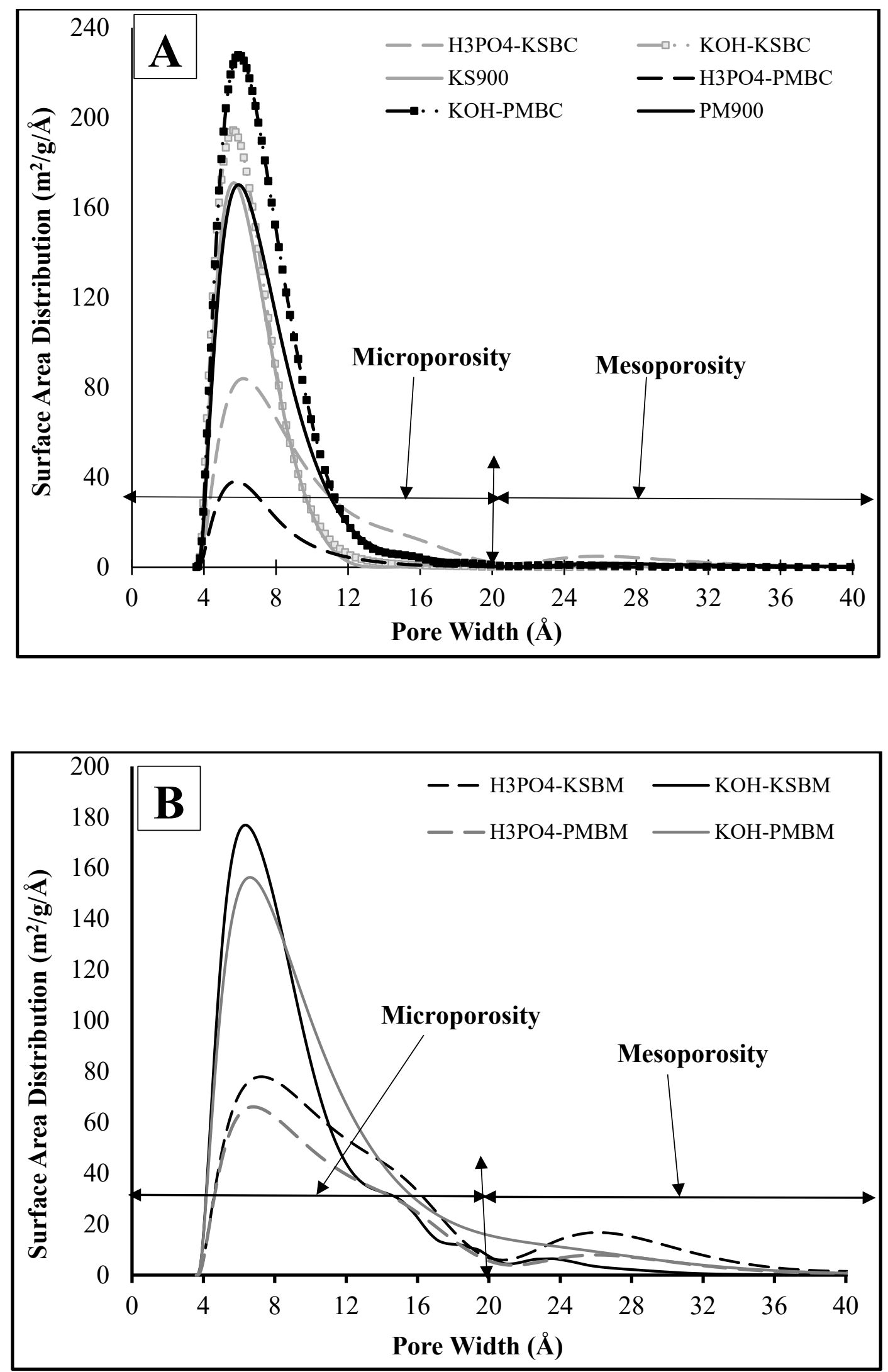

Figure 5.4: Surface area distribution of (A) biochar-derived and (B) biomass-derived activated carbons 
The total pore volume for all the activated carbons ranged between 0.08 and $1.45 \mathrm{~cm}^{3} / \mathrm{g}$ (Table 5.3). The total pore volumes of the biomass-derived activated carbons were higher than the total pore volumes of biochar-derived activated carbons and the biochars. In terms of the activating agents, the total pore volumes of the $\mathrm{KOH}$ activated carbons did not seems to improve significantly like the $\mathrm{H}_{3} \mathrm{PO}_{4}$ activated carbons, in comparison to the total pore volumes of the biochars.

The total pore volume is divided into two, namely the micropore and the mesopore. As described earlier in Figure 5.3, the activated carbons with adsorption hysteresis have some proportion of their total pore volumes to be in the mesoporous range. Mesopore, (also regarded as transport pore) is very important property of the activated carbon. It influences the adsorption kinetics in any liquid adsorption. From Table 5.3, the biomass-derived activated carbons were seen to have the highest mesoporous volume ranging between 0.35 and $1.35 \mathrm{~cm}^{3} / \mathrm{g}$. Mestre et al. [31] reported that activated carbon possessing negligible mesopores presents the slowest adsorption kinetics while the fastest adsorption rate occurred with the carbon having the most developed mesopore network.

The average pore diameters of the activated carbons were between 1.86 and $4.15 \mathrm{~nm}$ respectively (Table 5.3). The average pore diameters of the biomass-derived activated carbons were higher than the average pore diameters of the biochar-derived activated carbons and the biochars. The difference can be explained to be that the biochar precursors had an ordered porous structure, such that the effect of the activating agents on improving the porous structure of the resulting activated was minimal [43]. Katesa et al. [44] stated that biochar prepared at high carbonization temperature possesses a more densely packed structure, from which it is difficult to enlarge the small pores to larger pores.

The pore size distributions of the biochar-derived activated carbons are shown in Figure 5.5(AD). The biochar-derived activated carbons can be seen to have a monomodal distributions having single peaks between pore width range of 2 and $4 \mathrm{~nm}$. However, $\mathrm{H}_{3} \mathrm{PO}_{4}-\mathrm{KSBC}$ showed multiple peaks that cut across the microporous and mesoporous range. This mesopore can be attributed to the removal of tars and expansion of the micropore during the activation of the biochar precursor. The pore size distributions of biomass-derived activated carbons $\left(\mathrm{H}_{3} \mathrm{PO}_{4}-\mathrm{PMBM}\right.$ and $\left.\mathrm{H}_{3} \mathrm{PO}_{4}-\mathrm{KSBM}\right)$ are shown in Figure 5.5 ( $\mathrm{E} \& \mathrm{~F})$. The two biomass-derived activated carbons showed a multimodal distribution ranging between the microporous and mesoporous range. However, its $\mathrm{KOH}$ counterparts (Appendix 1), only had a monomodal distribution in the microporous range. 

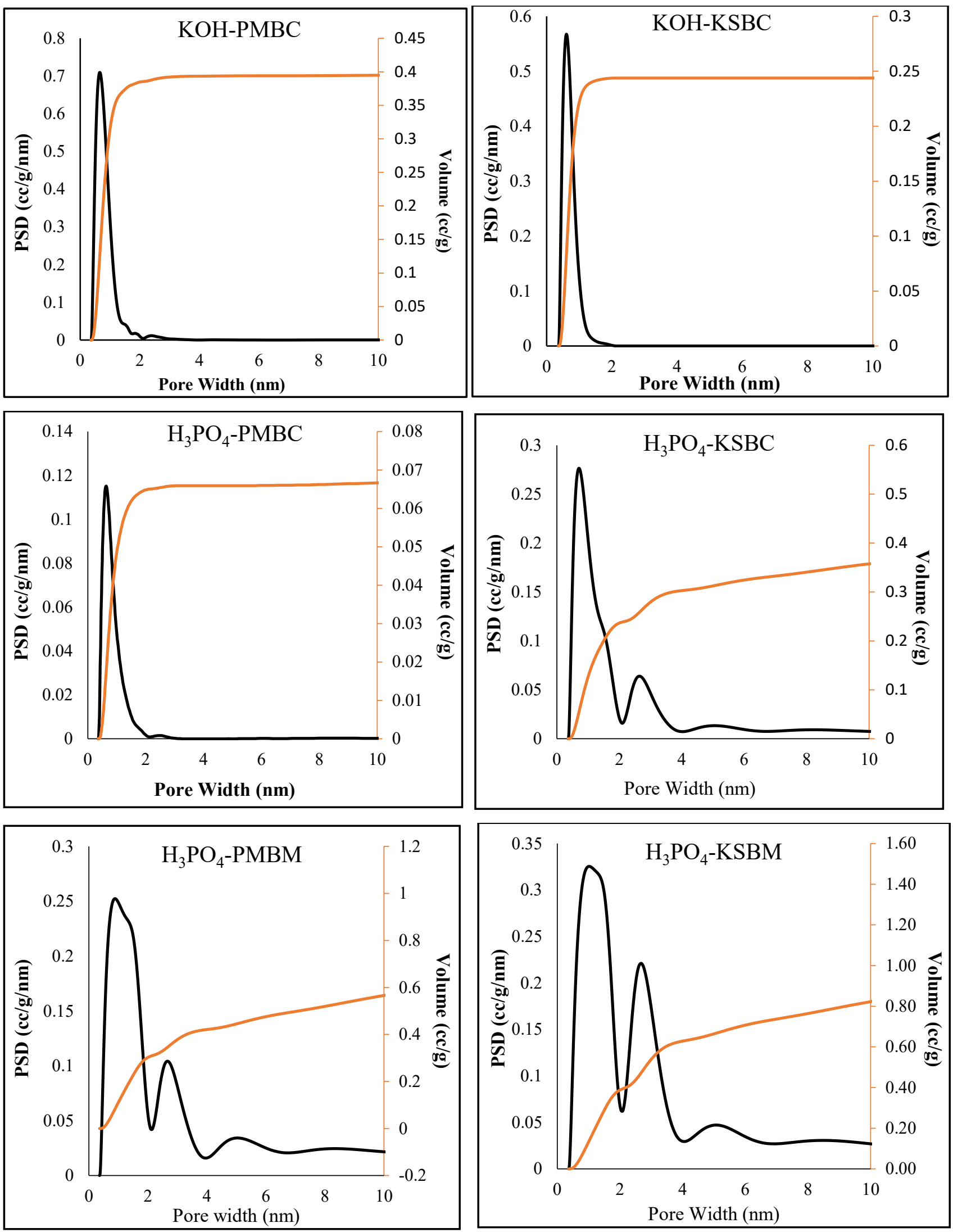

Figure 5.5: Pore size distributions of biochar-derived activated carbons 


\subsubsection{Raman analysis of activated carbons}

The Raman spectra of the biochars, biochar-derived and biomass-derived activated carbons are shown in Figure 5.6. The Raman spectra for all the samples exhibited the two-signature overlapping G (graphitic) and D (disordeered) bands, which is an indication of their heterogenous carbon microstructure, i.e., the disordered $\mathrm{sp}^{2}$ hybridized carbon atoms and structural integrity of $\mathrm{sp}^{2}$ hybridized carbon atoms respectively $[32,35]$. The D-band is attributed to in-plane vibration of $\mathrm{sp}^{2}$ bonded carbon within structural defects while the G-band arises from the in-plane vibration of the $\mathrm{sp}^{2}$ bonded crystalline carbon [33]. The D-band positions for all the samples were in the range of 1346 and $1386 \mathrm{~cm}^{-1}$ while the G-band positions were ranged from 1588 to $1598 \mathrm{~cm}^{-1}$ (Table 5.4). These values are similar to the typical band positions reported in literatures for disordered carbon materials such as biochars and activated carbons [33, 34].

The ratio of disordered or strongly distorted structure of turbostratic carbon to ordered graphite crystals in the biochars and the activated carbons can be estimated by the intensity ratio of D band to $\mathrm{G}$ band $\left(\mathrm{I}_{\mathrm{D}} / \mathrm{I}_{\mathrm{G}}\right)[33]$. The $\mathrm{I}_{\mathrm{D}} / \mathrm{I}_{\mathrm{G}}$ for all the samples are presented in Table 5.4 alongside the $\mathrm{G}$ and $\mathrm{D}$ band positions. The $\mathrm{I}_{\mathrm{D}} / \mathrm{I}_{\mathrm{G}}$ ratios for all the samples were between 0.73 and 1.51 . Lower $\mathrm{I}_{\mathrm{D}} / \mathrm{I}_{\mathrm{G}}$ ratio is an indication of more aromatic ring structures and less carbon-containing defects that leads to the formation of oxygen-containing functional groups on the surface of the carbon materials [35]. The $\mathrm{I}_{\mathrm{D}} / \mathrm{I}_{\mathrm{G}}$ ratio for the $\mathrm{KOH} /$ biomass-derived activated carbons and $\mathrm{KOH} /$ biochar-derived activated carbons were higher than their $\mathrm{H}_{3} \mathrm{PO}_{4}$ counterparts. This is an indication that the use of $\mathrm{KOH}$ as activating agent produced more disordered $\mathrm{sp}^{2}$ carbon atoms. The resulting activated carbons possess fewer aromatic ring structures and more carbon-containing defects that results in the formation of oxygen functional groups on the surface of the activated carbons. 

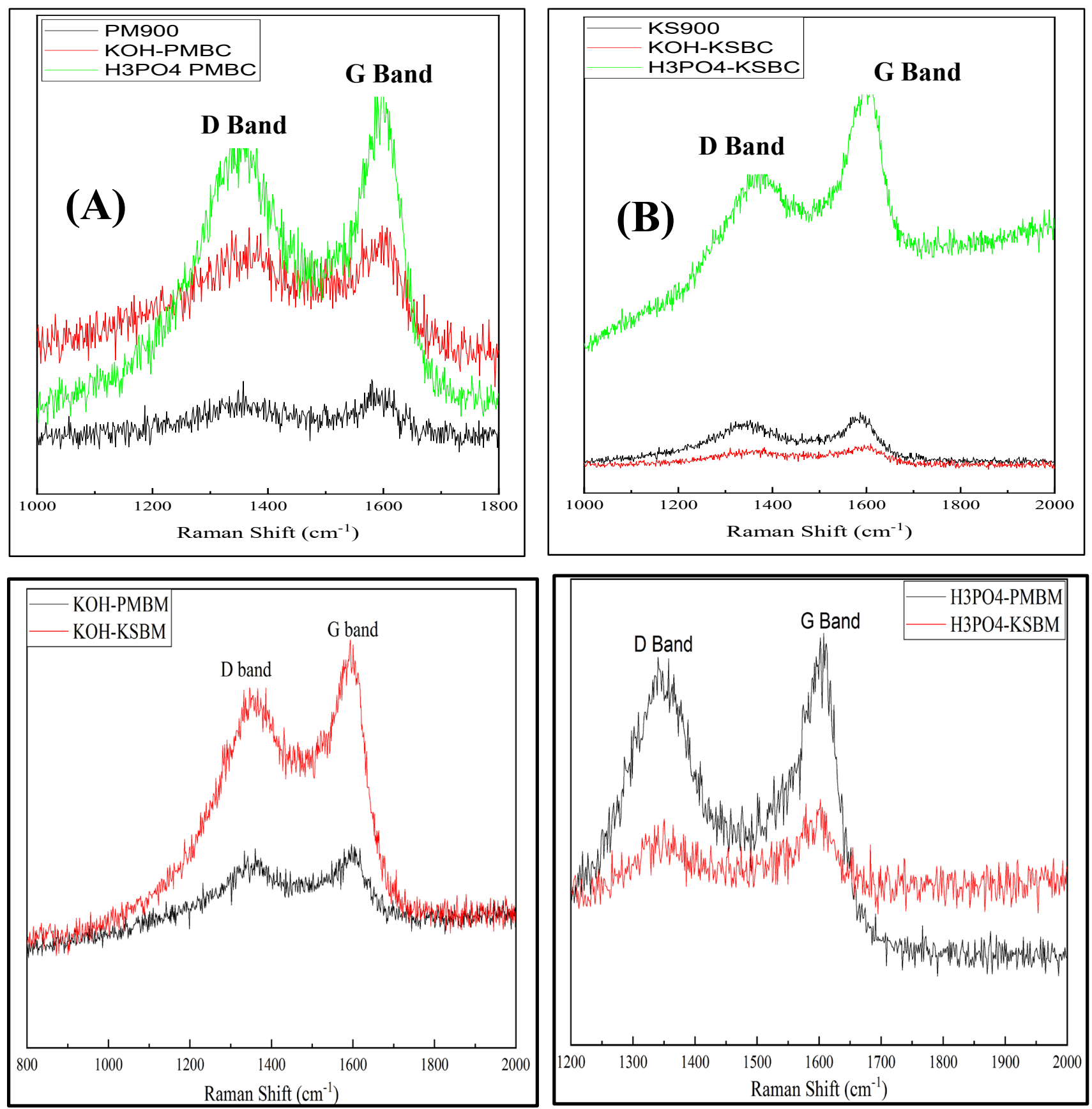

Figure 5.6: Raman spectra of biochar-derived activated carbons (A \& B); biomass-derived activated carbons (C \& D) 
Table 5.4: Raman $D$ and $G$ band positions, and the intensity ratios for activated carbons

\begin{tabular}{lccc}
\hline Sample & D Peak $\left(\mathbf{c m}^{-1}\right)$ & G Peak $\left(\mathbf{c m}^{-1}\right)$ & $\mathbf{I}_{\mathbf{D}} / \mathbf{I}_{\mathbf{G}}$ \\
\hline $\mathrm{KOH}-\mathrm{KSBC}$ & 1365.34 & 1592.73 & 0.88 \\
$\mathrm{KOH}-\mathrm{PMBC}$ & 1353.99 & 1597.55 & 1.51 \\
$\mathrm{H}_{3} \mathrm{PO}_{4}-\mathrm{KSBC}$ & 1386.16 & 1598.76 & 0.73 \\
$\mathrm{H}_{3} \mathrm{PO}_{4}-\mathrm{PMBC}$ & 1359.73 & 1593.49 & 0.89 \\
\hline $\mathrm{KOH}-\mathrm{KSBM}$ & 1381.33 & 1594.48 & 1.06 \\
$\mathrm{KOH}-\mathrm{PMBM}$ & 1349.04 & 1592.71 & 1.10 \\
$\mathrm{H}_{3} \mathrm{PO}_{4}-\mathrm{KSBM}$ & 1352.08 & 1588.97 & 0.78 \\
$\mathrm{H}_{3} \mathrm{PO}_{4}-\mathrm{PMBM}$ & 1347.61 & 1594.75 & 0.98 \\
\hline $\mathrm{KS} 900$ & 1359.10 & 1595.64 & 0.86 \\
$\mathrm{PM}$ & 13500 & 1593.67 & 0.88
\end{tabular}

\subsubsection{XPS analysis of activated carbons}

Knowledge of surface chemistry of carbon material is of fundamental importance as its behaviors in various applications (such as adsorption and electrochemical applications) are greatly influenced by the presence of chemical species on its surface. The X-ray photoelectron spectroscopy was used in analyzing the surface functional groups of the activated carbons. Figure 5.7 shows the $\mathrm{C} 1 \mathrm{~s}$ and $\mathrm{O} 1 \mathrm{~s}$ spectra for $\mathrm{KS} 900, \mathrm{H}_{3} \mathrm{PO}_{4}-\mathrm{KSBC}$ and $\mathrm{H}_{3} \mathrm{PO}_{4}-\mathrm{KSBM}$. The deconvolved $\mathrm{C} 1 \mathrm{~s}$ and $\mathrm{O} 1 \mathrm{~s}$ peaks for the other activated carbons are provided in the Appendix 2. Relatively weak peaks of other minor elements such as aluminum, phosphorus and silicon were also detected from the wide scan spectra of the surfaces of the activated carbons (not shown in figures). These minor elements may have been transferred from the parent raw material during pyrolysis and activation process. They generally influence the chemisorption properties of the activated carbon.

The $\mathrm{C} 1 \mathrm{~s}$ deconvolved peaks were assigned to the following known chemical shifts; graphitic carbon C-C (BE: $284.0-284.9 \mathrm{eV}$ ), carbon in phenolic, alcohol, ether or $\mathrm{C}=\mathrm{N}$ groups (BE: $285.3-$ $286.3 \mathrm{eV}$ ), carbon in carbonyl or quinine groups (BE: $286.5-289.3 \mathrm{eV}$ ) and carbon in carboxyl or ester groups (BE: $289.5-290.7 \mathrm{eV}$ ) [13,34]. The deconvolved sharp peaks showing the graphitic carbons for the biomass-derived activated carbons are similar to the graphitic carbon peaks of the biocharderived activated carbons. 

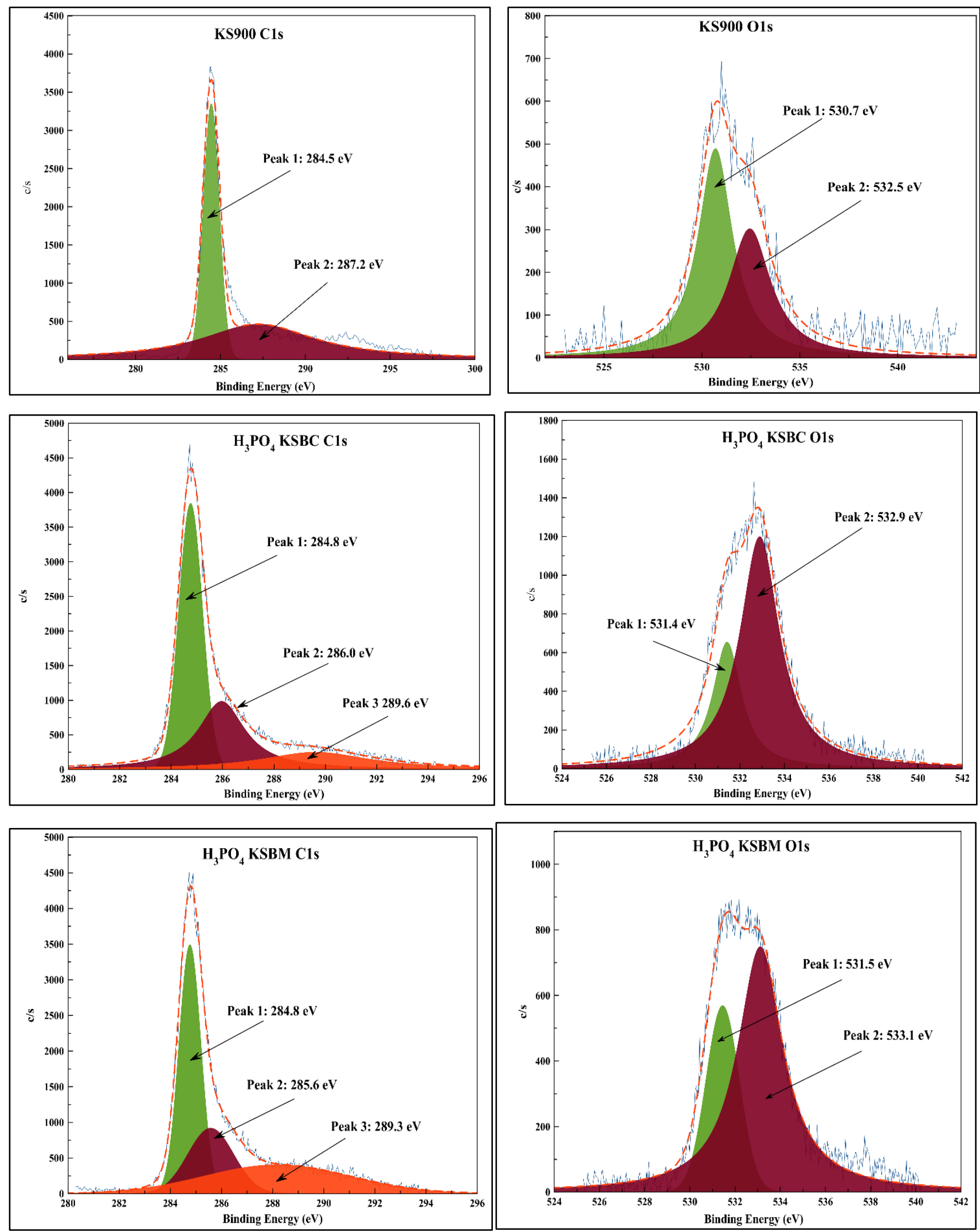

Figure 5.7: C1s and O1s Spectra of: $\mathrm{KSOOO}_{3} \mathrm{H}_{3} \mathrm{PO}_{4}-\mathrm{KSBC}$ and $\mathrm{H}_{3} \mathrm{PO}_{4}-\mathrm{KSBM}$ 
Table 5.5 summarizes the results of the $\mathrm{C} 1 \mathrm{~s}$ and $\mathrm{O} 1 \mathrm{~s}$ peaks and the atomic concentration of the detected surface functional groups. The relative amount of the graphitic carbon $(\mathrm{C}-\mathrm{C})$ of the biochars were 57.46\% and 62.28\% for KS900 and PM900 respectively. The relative amounts of the graphitic carbons for the biochar-derived activated carbons were higher than the biochars. The ratio of the graphitic carbons to the other carbons for all the biochars and the biochar-derived activated carbons was more than half. The high percentage of the graphitic carbon provides information about the high recalcitrance nature of the activated carbons [36].

The relative amounts of the graphitic carbons for the biomass-derived activated carbons were between 37.61 and $43.14 \%$. These were lower than the values for the biochars and the biochar-derived activated carbons. The higher relative amount of graphitic carbons for the biochar-derived activated carbons might be attributed to the initial heat treatment of the biochar precursors during pyrolysis and further carbonization during the activation process. The relative amount of carbon in phenolic, alcohol, ether or $\mathrm{C}=\mathrm{N}$ groups for the biomass-derived activated were between 33.31 and $41.15 \%$. The $\mathrm{KOH} /$ biomass-derived activated carbon ( $\mathrm{KOH}-\mathrm{KSBM}$ and $\mathrm{KOH}-\mathrm{PMBM}$ ) showed a higher amount of carbon in phenolic, alcohol, ether or $\mathrm{C}=\mathrm{N}$ groups in comparison to the $\mathrm{H}_{3} \mathrm{PO}_{4} /$ biomass-derived activated carbons. This chemical shift was identified in one of the biochar derived activated carbons (KOH-KSBC). Hui and Zaini [11] stated that the use of $\mathrm{KOH}$ as activating leads to formation of these functional groups on activated carbon surfaces. The relative amount of carbon in carbonyl or quinine groups for the biomass-derived activated carbons ranged between 33.31 and $41.15 \%$.

Similarly, the O1s deconvolved peaks were assigned to the following known chemical shifts; carboxyl $\left(\mathrm{COO}^{-}\right)$in carboxylate and oxygen double bond to carbon in esters and carboxylic acids $(\mathrm{O}=\mathrm{C}$ O) (BE: $530.4-531.9 \mathrm{eV})$, carbonyl oxygen atoms in esters, anhydrides and oxygen atoms in hydroxyl groups $(\mathrm{C}-\mathrm{OH} \& \mathrm{C}=\mathrm{O})(\mathrm{BE}: 532.1-532.9 \mathrm{eV})$ and oxygen single bond in esters and carboxylic acids $(\mathrm{O}-\mathrm{C}=\mathrm{O})(\mathrm{BE}: 533.1 \mathrm{eV})[32,37]$. While there was no difference in the relative amount of carbonyl oxygen for both $\mathrm{KS} 900$ and $\mathrm{KOH}-\mathrm{KSBC}$, the $\mathrm{H}_{3} \mathrm{PO}_{4}-\mathrm{KSBC}$ and the other activated carbons showed an increase in their carbonyl oxygen. For the KOH/biomass-derived activated carbons, KOH-PMBM had $100 \%$ of its $\mathrm{O} 1 \mathrm{~s}$ assigned to the carbonyl oxygen atoms while $\mathrm{KOH}-\mathrm{KSBM}$ had a small percentage $(6.77 \%)$ deconvolved into oxygen atoms double bond to carbon in esters and carboxylic acids while the remaining percentage was assigned to carbonyl oxygen group. 
Table 5.5: Carbon and oxygen surface functional groups of activated carbons

\begin{tabular}{|c|c|c|c|c|c|c|c|c|c|c|c|}
\hline \multirow{2}{*}{$\begin{array}{l}\text { Activated } \\
\text { Carbon }\end{array}$} & \multicolumn{4}{|c|}{ C1s (\% wt.) } & \multicolumn{3}{|c|}{ O1s (\% wt.) } & \multicolumn{4}{|c|}{ Atomic conc. $(\%)$} \\
\hline & $\mathrm{C}-\mathrm{C}$ & C-OH & $\mathbf{C}=\mathbf{O}$ & $\mathrm{O}-\mathrm{C}=\mathrm{O}$ & $\begin{array}{c}\mathrm{COO}-\& \\
\mathrm{O}=\mathrm{C}-\mathrm{O}\end{array}$ & $\begin{array}{c}\text { C-OH \& } \\
\text { C=O }\end{array}$ & $\mathbf{O}-\mathbf{C}=\mathbf{O}$ & C1s & O1s & $\mathbf{S i 2 p}$ & $\mathbf{P} 2 p$ \\
\hline KS900 & 57.46 & - & 42.54 & - & 56.97 & 43.03 & - & 87.52 & 8.89 & 1.46 & 1.05 \\
\hline PM900 & 62.28 & - & 37.71 & - & 55.36 & 44.64 & - & 85.50 & 11.57 & - & 1.57 \\
\hline KOH-KSBC & 69.61 & - & 30.39 & - & 56.97 & 43.03 & - & 66.13 & 23.34 & 3.06 & - \\
\hline KOH-PMBC & 65.94 & - & 34.06 & - & - & 71.75 & 28.25 & 77.90 & 16.71 & 5.39 & - \\
\hline $\mathrm{H}_{3} \mathrm{PO}_{4}-\mathrm{KSBC}$ & 66.92 & 16.36 & - & 16.72 & 42.64 & 57.36 & - & 74.14 & 18.75 & 1.26 & 4.03 \\
\hline $\mathrm{H}_{3} \mathrm{PO}_{4}-\mathrm{PMBC}$ & 58.83 & - & 41.17 & - & 10.56 & 89.44 & - & 56.14 & 35.01 & - & 8.84 \\
\hline KOH-KSBM & 37.61 & 21.24 & 41.15 & & 6.77 & 93.23 & - & 69.62 & 28.36 & 2.03 & - \\
\hline КОН-РMBM & 39.64 & 22.44 & 37.92 & & - & 100 & - & 82.08 & 13.74 & 4.18 & - \\
\hline $\mathrm{H}_{3} \mathrm{PO}_{4}-\mathrm{KSBM}$ & 43.14 & 23.55 & 33.31 & & 31.97 & - & 68.03 & 79.68 & 15.03 & 0.61 & 3.36 \\
\hline $\mathrm{H}_{3} \mathrm{PO}_{4}-\mathrm{PMBM}$ & 40.81 & 25.36 & 33.83 & & 21.75 & - & 78.25 & 80.30 & 14.61 & 0.74 & 3.57 \\
\hline
\end{tabular}

\subsubsection{Adsorption Kinetics}

The kinetics shows the rate of solute adsorption by measuring the concentration change as a function of time, keeping constant the initial concentration and mass of adsorbent. Adsorption kinetics helps in determining the time necessary for reaching equilibrium and to elucidate the mechanism of the adsorption process [31]. Its knowledge is of great importance in designing appropriate adsorption technologies [45].

The kinetic model parameters estimated for the adsorption of caffeine and acetaminophen using the activated carbons are presented in Table 5.6 and 5.7 respectively. The pseudo-second order adsorption kinetic model was used in fitting the experimental adsorption data of the activated carbons. The pseudo-second order kinetic model gave predicted equilibrium uptake values $\left(q_{e}\right.$ calc $)$ that were close to the experimental equilibrium uptake $\left(q_{e}\right.$ exp $)$. The biomass-derived activated carbons showed a higher adsorption capacity for both adsorbates in comparison to the biochars and the biochar-derived activated carbons. Among the biomass-derived activated carbons, the $\mathrm{KOH}$ samples had the higher adsorption capacities in comparison to the $\mathrm{H}_{3} \mathrm{PO}_{4}$ samples. This high adsorption capacity can be attributed to the high surface areas and the surface chemistry of the biomass-derived activated carbons. These activated carbons had the highest percentage of carbonyl and hydroxyl groups, which enhance their wettability and enhance their adsorption kinetics. The $\mathrm{KOH} /$ biomass-derived activated carbons 
also had more disordered carbon structure (as explained in the Raman analysis), which plays a significant role in their adsorption capacity. For example, KOH-PMBM had the highest BET surface area of $1596.52 \mathrm{~m}^{2} / \mathrm{g}, 100 \%$ of surface oxygen functional groups in the carbonyl and hydroxyl groups and $\mathrm{I}_{\mathrm{D}} / \mathrm{I}_{\mathrm{G}}$ ratio of 1.10 . From the adsorption results, this activated carbon had the highest adsorption capacity of $167.17 \mathrm{mg} / \mathrm{g}$ and $152.89 \mathrm{mg} / \mathrm{g}$ for caffeine and acetaminophen respectively.

Table 5.6: Kinetic model parameters for the adsorption of caffeine on activated carbons

\begin{tabular}{|c|c|c|c|c|c|c|}
\hline Activated carbon & $\begin{array}{c}q_{e, \exp } \\
(\mathrm{mg} / \mathrm{g})\end{array}$ & $\begin{array}{c}q_{e, \text { calc }} \\
(\mathrm{mg} / \mathrm{g})\end{array}$ & $\begin{array}{c}k \\
(g / m g / m i n)\end{array}$ & $\begin{array}{c}t_{1 / 2} \\
\text { (min) }\end{array}$ & $h(\mathrm{mg} / \mathrm{g} / \mathrm{min})$ & $R^{2}$ \\
\hline KS900 & 52.69 & 54.35 & $0.41 \times 10^{-3}$ & 44.39 & 1.22 & 0.99 \\
\hline PM900 & 39.45 & 42.37 & $0.77 \times 10^{-3}$ & 30.79 & 1.38 & 0.99 \\
\hline $\mathrm{H}_{3} \mathrm{PO}_{4}-\mathrm{KSBC}$ & 21.33 & 21.65 & $7.78 \times 10^{-3}$ & 5.94 & 3.65 & 0.83 \\
\hline $\mathrm{KOH}-\mathrm{KSBC}$ & 13.25 & 13.66 & $0.72 \times 10^{-3}$ & 101.30 & 0.14 & 0.87 \\
\hline $\mathrm{H}_{3} \mathrm{PO}_{4}-\mathrm{PMBC}$ & 3.89 & 5.37 & $2.28 \times 10^{-3}$ & 81.79 & 8.03 & 0.75 \\
\hline KOH- PMBC & 152.80 & 151.52 & $10.89 \times 10^{-3}$ & 0.61 & 250 & 0.99 \\
\hline $\mathrm{H}_{3} \mathrm{PO}_{4}-\mathrm{KSBM}$ & 93.73 & 107.53 & $0.96 \times 10^{-3}$ & 9.68 & 11.11 & 0.93 \\
\hline $\mathrm{KOH}-\mathrm{KSBM}$ & 147.93 & 149.25 & $1.43 \times 10^{-3}$ & 4.70 & 31.75 & 0.99 \\
\hline $\mathrm{H}_{3} \mathrm{PO}_{4}-\mathrm{PMBM}$ & 120.74 & 129.87 & $0.46 \times 10^{-3}$ & 16.83 & 7.72 & 0.99 \\
\hline КOH- РMBM & 167.17 & 166.67 & $5.37 \times 10^{-3}$ & 1.12 & 149.25 & 1.00 \\
\hline
\end{tabular}

Table 5.7: Kinetic model parameters for the adsorption of acetaminophen on activated carbons

\begin{tabular}{lcccccc}
\hline \multicolumn{1}{c}{ Activated carbon } & $\begin{array}{c}q_{e, \text { exp }} \\
(\mathrm{mg} / \mathrm{g})\end{array}$ & $\begin{array}{c}q_{e, \text { calc }} \\
(\mathrm{mg} / \mathrm{g})\end{array}$ & $k(\mathrm{~g} / \mathrm{mg} / \mathrm{min})$ & $\begin{array}{c}t_{1 / 2} \\
(\mathrm{~min})\end{array}$ & $h(\mathrm{mg} / \mathrm{g} / \mathrm{min})$ & $R^{2}$ \\
\hline $\mathrm{KS} 900$ & 32.32 & 35.97 & $0.64 \times 10^{-3}$ & 43.68 & 0.82 & 0.99 \\
$\mathrm{PM900}$ & 10.17 & 11.15 & $0.65 \times 10^{-3}$ & 138.67 & 0.08 & 0.87 \\
\hline $\mathrm{H}_{3} \mathrm{PO}_{4}-\mathrm{KSBC}$ & 43.37 & 43.10 & $0.49 \times 10^{-3}$ & 47 & 0.92 & 0.94 \\
$\mathrm{KOH}-\mathrm{KSBC}$ & 5.90 & 7.39 & $1.99 \times 10^{-3}$ & 68.01 & 0.11 & 0.90 \\
$\mathrm{H}_{3} \mathrm{PO}_{4}-\mathrm{PMBC}$ & 12.04 & 13.41 & $2.37 \times 10^{-3}$ & 31.48 & 0.43 & 0.96 \\
$\mathrm{KOH}_{-} \mathrm{PMBC}$ & 140.98 & 142.86 & $1.55 \times 10^{-3}$ & 4.53 & 31.55 & 0.99 \\
\hline $\mathrm{H}_{3} \mathrm{PO}_{4}-\mathrm{KSBM}$ & 85.41 & 86.21 & $1.29 \times 10^{-3}$ & 8.99 & 9.59 & 0.96 \\
$\mathrm{KOH}_{-} \mathrm{KSBM}$ & 124.21 & 125.0 & $1.10 \times 10^{-3}$ & 7.29 & 17.15 & 0.99 \\
$\mathrm{H}_{3} \mathrm{PO}_{4}-\mathrm{PMBM}$ & 90.80 & 90.09 & $0.58 \times 10^{-3}$ & 19.28 & 4.67 & 0.96 \\
$\mathrm{KOH}-\mathrm{PMBM}$ & 152.89 & 153.85 & $3.88 \times 10^{-3}$ & 1.68 & 91.74 & 1.00 \\
\hline
\end{tabular}


The half-life time $\left(\mathrm{t}_{1 / 2}\right)$ recorded for the biomass-derived activated carbons in adsorbing both caffeine and acetaminophen were less than 20 mins, which implies that these activated carbons will adsorb half of the target contaminants within this period. Meanwhile the biochar-derived activated carbons and the non-activated biochars had showed half-life time that is about two to folds higher than the ones recorded for the biomass-derived activated carbons. This behavior can be attributed to the higher total pore volume of the biomass-derived activated carbons compared to the biochars and biochar-derived activated carbons. The biomass-derived activated carbon had total pore volume in range of $0.63-1.45 \mathrm{~cm}^{3} / \mathrm{g}$ while the biochar-derived activated carbons had total pore volume in the range of $0.25-0.55 \mathrm{~cm}^{3} / \mathrm{g}$. Also, it is noteworthy, that the biomass-derived activated carbons had a higher mesopore volume $\left(0.35-1.35 \mathrm{~cm}^{3} / \mathrm{g}\right)$ in comparison to the biochar-derived activated carbons $\left(0.12-0.43 \mathrm{~cm}^{3} / \mathrm{g}\right)$ and the non-activated biochars $\left(0.07-0.17 \mathrm{~cm}^{3} / \mathrm{g}\right)$. The mesopore acts as a means of access for the adsorbate to the micropores. This therefore, enhance the rate of adsorption of the biomass-derived activated carbons

\subsubsection{Adsorption Isotherms}

The Langmuir (theoretical) and Freundlich (empirical) isotherm equations were used in fitting the experimental data. The Langmuir and Freundlich parameters alongside the coefficient of determination $\left(\mathrm{R}^{2}\right)$ of the linear plots are presented in Table 5.8 and 5.9. From the Tables, a comparison of the $\mathrm{R}^{2}$ values for the two models showed that Langmuir isotherm model provides the best fit for the adsorption of caffeine and acetaminophen unto the activated carbons. The Langmuir isotherm model assumes the surface of the activated carbon is energetically homogenous and that a monolayer surface coverage is formed with no interactions between the molecules adsorbed [31]. The Langmuir constant $\left(q_{m}\right)$ which describes the maximum monolayer adsorption capacity of the adsorbates on to the activated carbons ranged between $12.60-196.08 \mathrm{mg} / \mathrm{g}$ and $13.99-188.68 \mathrm{mg} / \mathrm{g}$ for caffeine and acetaminophen respectively. A comparison of the activated carbons' $q_{m}$ values showed that the biomass-derived activated carbons had the highest maximum adsorption capacities for the adsorbates as compared to the biochar-derived activated carbons and the biochars (KS900 and PM900). 
Table 5.8: Langmuir and Freundlich isotherm parameters for the adsorption of caffeine

\begin{tabular}{ccccccc}
\hline \multirow{2}{*}{$\begin{array}{c}\text { Activated } \\
\text { Carbon }\end{array}$} & \multicolumn{3}{c}{ Langmuir Equation } & \multicolumn{3}{c}{ Freundlich Equation } \\
\cline { 2 - 7 } & $\boldsymbol{q}_{\boldsymbol{m}} \mathbf{( \mathbf { m g } / \mathbf { g } )}$ & $\boldsymbol{b}(\mathbf{l} / \mathbf{m g})$ & $\boldsymbol{R}^{2}$ & $\mathbf{1} \boldsymbol{n}$ & $\boldsymbol{K}_{\boldsymbol{F}}$ & $\boldsymbol{R}^{2}$ \\
\hline $\mathrm{KS} 900$ & 38.02 & 6.42 & 0.99 & 0.06 & 31.28 & 0.55 \\
$\mathrm{PM} 900$ & 38.46 & 3.56 & 0.99 & 0.12 & 26.78 & 0.34 \\
\hline $\mathrm{H}_{3} \mathrm{PO}_{4}-\mathrm{KSBC}$ & 20.16 & 0.53 & 0.89 & 0.26 & 8.10 & 0.28 \\
$\mathrm{KOH}-\mathrm{KSBC}$ & 11.11 & 1.26 & 0.89 & 0.11 & 8.18 & 0.13 \\
$\mathrm{H}_{3} \mathrm{PO}_{4}-\mathrm{PMBC}$ & 12.60 & 0.10 & 0.83 & 0.44 & 2.16 & 0.66 \\
$\mathrm{KOH}_{-} \mathrm{PMBC}$ & 196.08 & 0.63 & 0.93 & 0.53 & 72.20 & 0.75 \\
\hline $\mathrm{H}_{3} \mathrm{PO}-\mathrm{KSBM}$ & 102.04 & 0.63 & 0.99 & 0.22 & 49.77 & 0.83 \\
$\mathrm{KOH}_{4} \mathrm{KSBM}$ & 172.41 & 0.06 & 0.98 & 0.67 & 13.79 & 0.99 \\
$\mathrm{H}_{3} \mathrm{PO}_{4}-\mathrm{PMBM}$ & 101.01 & 0.41 & 0.95 & 0.22 & 45.48 & 0.85 \\
$\mathrm{KOH}-\mathrm{PMBM}$ & 100 & 0.67 & 0.78 & 1.83 & 181.02 & 0.95 \\
\hline
\end{tabular}

$q_{m}$ - maximum monolayer adsorption capacity; $b$ - Langmuir constant

$n$ - Freundlich exponent; $K_{F}$ - Freundlich constant; $R^{2}$ - linear regression coefficient of determination

$\mathrm{Ce}$ - solution concentration at equilibrium $(\mathrm{mg} / \mathrm{l}) ; q_{e}$ - uptake at equilibrium $(\mathrm{mg} / \mathrm{g})$

Table 5.9: Langmuir and Freundlich isotherm parameters for adsorption of acetaminophen

\begin{tabular}{|c|c|c|c|c|c|c|}
\hline \multirow{2}{*}{$\begin{array}{c}\text { Activated } \\
\text { Carbon }\end{array}$} & \multicolumn{3}{|c|}{ Langmuir Equation } & \multicolumn{3}{|c|}{ Freundlich Equation } \\
\hline & $q_{m}(\mathrm{mg} / \mathrm{g})$ & $b(\mathrm{l} / \mathrm{mg})$ & $\overline{R^{2}}$ & $1 / n$ & $\overline{K_{F}}$ & $\overline{R^{2}}$ \\
\hline KS900 & 84.75 & 0.69 & 0.95 & 0.20 & 45.51 & 0.24 \\
\hline PM900 & 44.44 & 0.24 & 0.73 & 0.27 & 16.38 & 0.64 \\
\hline $\mathrm{H}_{3} \mathrm{PO}_{4}-\mathrm{KSBC}$ & 49.02 & 1.71 & 0.99 & 0.15 & 14.19 & 0.90 \\
\hline $\mathrm{KOH}-\mathrm{KSBC}$ & 19.38 & 0.56 & 0.92 & 0.01 & 21.18 & 0.01 \\
\hline $\mathrm{H}_{3} \mathrm{PO}_{4}-\mathrm{PMBC}$ & 13.99 & 0.50 & 0.95 & 0.19 & 6.99 & 0.59 \\
\hline KOH- PMBC & 76.34 & 0.58 & 0.98 & 0.30 & 31.08 & 0.71 \\
\hline $\mathrm{H}_{3} \mathrm{PO}_{4}-\mathrm{KSBM}$ & 129.87 & 0.37 & 0.99 & 0.37 & 40.36 & 0.94 \\
\hline $\mathrm{KOH}-\mathrm{KSBM}$ & 188.68 & 0.52 & 0.91 & 0.54 & 62.52 & 0.77 \\
\hline $\mathrm{H}_{3} \mathrm{PO}_{4}-\mathrm{PMBM}$ & 156.25 & 0.25 & 0.95 & 0.44 & 38.04 & 0.96 \\
\hline KOH- PMBM & 90.91 & 0.63 & 0.99 & 0.33 & 34.52 & 0.95 \\
\hline
\end{tabular}

$q_{m}$ - maximum monolayer adsorption capacity; $b$ - Langmuir constant

$n$ - Freundlich exponent; $K_{F}$ - Freundlich constant; $R^{2}$ - linear regression coefficient of determination

$\mathrm{Ce}$ - solution concentration at equilibrium $(\mathrm{mg} / \mathrm{l}) ; q_{e}$ - uptake at equilibrium $(\mathrm{mg} / \mathrm{g})$ 
The dimensionless constant separation factor $\mathrm{R}_{\mathrm{L}}$, as defined by Weber and Chakkravorti [37] describes the favorable or irreversible adsorption nature of the adsorbates unto the activated carbon [38, 39]. The factor is described in the equation below ;

$$
R_{L}=\frac{1}{1+b \cdot C_{o}}
$$

Where $C_{o}(\mathrm{ppm})$ is the initial concentration of the adsorbate and $b$ is the Langmuir constant. The $\mathrm{R}_{\mathrm{L}}$ value classifies adsorption as irreversible $\left(\mathrm{R}_{\mathrm{L}}=0\right)$, favorable $\left(0<\mathrm{R}_{\mathrm{L}}<1\right)$, linear $\left(\mathrm{R}_{\mathrm{L}}=1\right)$ and unfavorable $\left(\mathrm{R}_{\mathrm{L}}>1\right)$. Figure 5.8 shows the separation factors for both acetaminophen and caffeine adsorbed by the $\mathrm{H}_{3} \mathrm{PO}_{4}$ activated carbons. From the plots, it can be observed that the factor reduces with increase in the initial concentration of the adsorbates. All the $\mathrm{R}_{\mathrm{L}}$ values obtained in this study were $0<\mathrm{R}_{\mathrm{L}}<1$, which implies that nature of the adsorption was favorable. Also, according to Sharma and Forster [40], the low $\mathrm{R}_{\mathrm{L}}$ value shows that the interaction between the adsorbate molecules and the activated carbons are relatively strong.
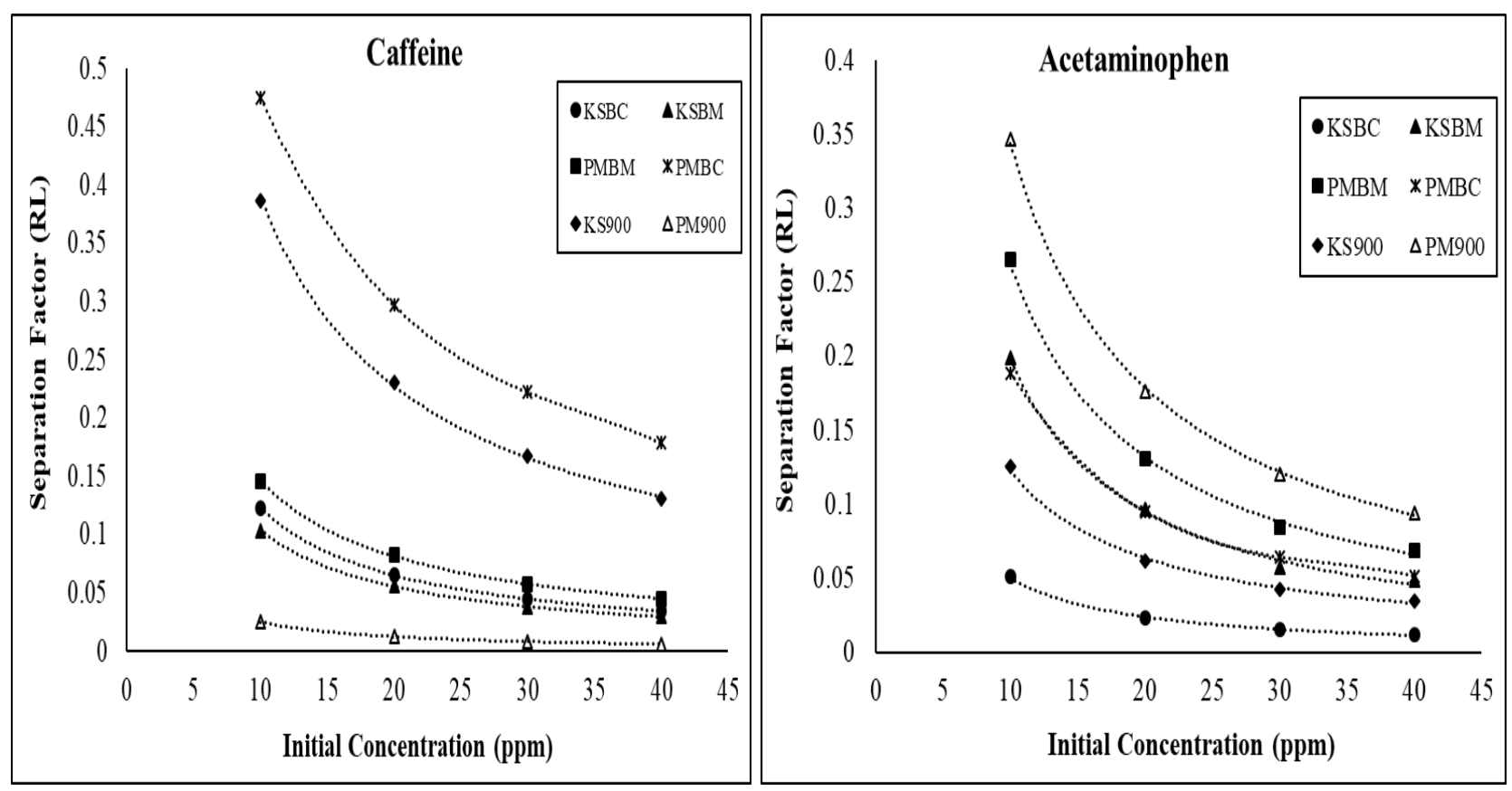

Figure 5.8: Plot of separation factor $\left(R_{L}\right)$ against initial concentration of adsorbates 


\subsection{Conclusion}

In this study, activated carbons produced from herbaceous biomass and biochar using phosphoric acid and potassium hydroxide as the activating agents were characterized for their microstructure, surface functionalities, pore characteristics and adsorption properties. The activated carbons were used in adsorbing pharmaceutical active compounds namely caffeine and acetaminophen.

The result of the study showed that the $\mathrm{KOH}$ samples (both biochar- and biomass-derived activated carbons) had the highest micropore surface areas, which is an important factor for activated carbon adsorption application. The biomass derived activated carbons gave the best activated carbon properties in terms of the surface area and the surface chemistry. The surface areas of the biomass derived activated carbons were higher than the biochar-derived activated carbons. The pore size distributions showed that the biomass-derived activated carbons had mesopores and micropores while the biocharderived activated carbons and the non-activated biochars were purely microporous. Also, the biomassderived activated carbons gave good adsorption characteristics for both caffeine and acetaminophen. This shows that the intermediate production of biochar as a precursor before impregnation and activation may not be necessary. Also, from the result of this study, it can be inferred that the biomass derived activated carbon will be a novel low-cost adsorbent for the removal of emerging contaminants in waste and drinking water treatment. 


\section{References}

[1] R.C. Bansal, M. Goyal, Activated Carbon Adsoprtion CRC Press, Boca Raton, FL, USA, 2005.

[2] P.J. Johnson, D.J. Setsuda, R.S. Williams, CHAPTER 8 - Activated Carbon for Automotive Applications A2 - Burchell, Timothy D, in: Carbon Materials for Advanced Technologies, Elsevier Science Ltd, Oxford, 1999, pp. 235-268.

[3] S. Balci, T. Dogu, H. Yucel, Characterization of Activated Carbon Produced from Almond Shell and Hazelnut Shell, Journal of Chemical Technology and Biotechnology 60 (1994) 419-426.

[4] A. Shaaban, S.-M. Se, N.M.M. Mitan, M.F. Dimin, Characterization of Biochar Derived from Rubber Wood Sawdust through Slow Pyrolysis on Surface Porosities and Functional Groups, Procedia Engineering, 68 (2013) 365-371.

[5] S.-X. Zhao, N. Ta, X.-D. Wang, Effect of Temperature on the Structural and Physicochemical Properties of Biochar with Apple Tree Branches as Feedstock Material, Energies, 10 (2017) 1293.

[6] P. Francesca, M. Sara, T. Luigi, New biosorbent materials for heavy metal removal: Product development guided by active site characterization, Water Research, 42 (2008) 2953-2962.

[7] F. Rodriguez-Reinoso, M. Molina-Sabio, M.T. Gonzalez, The use of steam and CO2 as activating agents in the preparation of activated carbons, Carbon, 33 (1995) 15-23.

[8] T.J. Mays, Chapter 3 - Active Carbon Fibers, in: T.D. Burchell (Ed.) Carbon Materials for Advanced Technologies, Elsevier Science Ltd, Oxford, 1999, pp. 95-118.

[9] O. Ioannidou, A. Zabaniotou, Agricultural residues as precursors for activated carbon productionA review, Renewable and Sustainable Energy Reviews, 11 (2007) 1966-2005.

[10] A. Kumar, H. Mohan Jena, High surface area microporous activated carbons prepared from Fox nut (Euryale ferox) shell by zinc chloride activation, Applied Surface Science, 356 (2015) 753-761.

[11] Tang Shu Hui, M.A.A. Zaini, Potassium hydroxide activation of activated carbon: a commentary, Carbon Letters, 16 (2015) 275-280.

[12] B. Viswanathan, P. Indra Neel, T.K. Varadarajan, Methods of Activation and Specific Applications of Carbon Materials, National Centre for Catalysis Research, Indian Institute of Technology Madras, Chennai, India, 2009.

[13] J. Xu, L. Chen, H. Qu, Y. Jiao, J. Xie, G. Xing, Preparation and characterization of activated carbon from reedy grass leaves by chemical activation with H3PO4, Applied Surface Science, 320 (2014) 674-680.

[14] R. Azargohar, A.K. Dalai, Steam and KOH activation of biochar: Experimental and modeling studies, Microporous and Mesoporous Materials, 110 (2008) 413-421.

[15] J. Park, I. Hung, Z. Gan, O.J. Rojas, K.H. Lim, S. Park, Activated carbon from biochar: Influence of its physicochemical properties on the sorption characteristics of phenanthrene, Bioresource Technology, 149 (2013) 383-389.

[16] U. Tezcan Un, F. Ates, N. Erginel, O. Ozcan, E. Oduncu, Adsorption of Disperse Orange 30 dye onto activated carbon derived from Holm Oak (Quercus Ilex) acorns: A 3k factorial design and analysis, Journal of Environmental Management, 155 (2015) 89-96. 
[17] J. Skousen, C. Brown, T. Griggs, S. Byrd, Establishment and Growth of Switchgrass and other Biomass Crops on Surface Mines, Journal American Society of Mining and Reclamation, 3 (2014) 136156.

[18] J. Lladó, C. Lao-Luque, B. Ruiz, E. Fuente, M. Solé-Sardans, A.D. Dorado, Role of activated carbon properties in atrazine and paracetamol adsorption equilibrium and kinetics, Process Safety and Environmental Protection, 95 (2015) 51-59.

[19] P. Westerhoff, Y. Yoon, S. Snyder, E. Wert, Fate of endocrine-disruptor, pharmaceutical, and personal care product chemicals during simulated drinking water treatment processes, Environ Sci Technol, 39 (2005) 6649-6663.

[20] A.S. Mestre, E. Tyszko, M.A. Andrade, M. Galhetas, C. Freire, A.P. Carvalho, Sustainable activated carbons prepared from a sucrose-derived hydrochar: remarkable adsorbents for pharmaceutical compounds, RSC Advances, 5 (2015) 19696-19707.

[21] J.L. Sotelo, G. Ovejero, A. Rodríguez, S. Álvarez, J. Galán, J. García, Competitive adsorption studies of caffeine and diclofenac aqueous solutions by activated carbon, Chemical Engineering Journal, 240 (2014) 443-453.

[22] A.S. Mestre, J. Pires, J.M.F. Nogueira, A.P. Carvalho, Activated carbons for the adsorption of ibuprofen, Carbon, 45 (2007) 1979-1988.

[23] H. Marsh, F. Rodríguez-Reinoso, Chapter 4 - Characterization of Activated Carbon, in: Activated Carbon, Elsevier Science Ltd, Oxford, 2006, pp. 143-242.

[24] K.Y. Foo, B.H. Hameed, Insights into the modeling of adsorption isotherm systems, Chemical Engineering Journal, 156 (2010) 2-10.

[25] Z. Aksu, F. Gönen, Biosorption of phenol by immobilized activated sludge in a continuous packed bed: prediction of breakthrough curves, Process Biochemistry, 39 (2004) 599-613.

[26] Z. Xu, J. Cai, B. Pan, Mathematically modeling fixed-bed adsorption in aqueous systems, Journal of Zhejiang University Science A, 14 (2013) 155-176.

[27] C. Djilani, R. Zaghdoudi, F. Djazi, B. Bouchekima, A. Lallam, A. Modarressi, M. Rogalski, Adsorption of dyes on activated carbon prepared from apricot stones and commercial activated carbon, Journal of the Taiwan Institute of Chemical Engineers, 53 (2015) 112-121.

[28] K.S.W. Sing, D.H. Everett, R.A.W. Haul, L. Moscou, R.A. Pierotti, J. Rouquerol, T. Siemieniewska, Reporting physisorption data for gas/solid systems with special reference to the determination of surface area and porosity, Pure and Applied Chemistry, 57 (1985) 603 - 619.

[29] S. Lowell, J.E. Shields, M.A. Thomas, M. Thommes, Characterization of Porous Solids and Powders: Surface Area, Pore Size and Density, Springer Netherlands, 2006.

[30] Z. ALOthman, A Review: Fundamental Aspects of Silicate Mesoporous Materials, Materials, 5 (2012) 2874.

[31] A.S. Mestre, J. Pires, J.M.F. Nogueira, J.B. Parra, A.P. Carvalho, C.O. Ania, Waste-derived activated carbons for removal of ibuprofen from solution: Role of surface chemistry and pore structure, Bioresource Technology, 100 (2009) 1720-1726. 
[32] T. Yumak, D. Bragg, E.M. Sabolsky, Effect of synthesis methods on the surface and electrochemical characteristics of metal oxide/activated carbon composites for supercapacitor applications, Applied Surface Science, (2018).

[33] L. Zhao, X. Cao, O. Mašek, A. Zimmerman, Heterogeneity of biochar properties as a function of feedstock sources and production temperatures, Journal of Hazardous Materials, 256-257 (2013) 1-9.

[34] E. Atta-Obeng, B. Dawson-Andoh, M.S. Seehra, U. Geddam, J. Poston, J. Leisen, Physicochemical characterization of carbons produced from technical lignin by sub-critical hydrothermal carbonization, Biomass and Bioenergy, 107 (2017) 172-181.

[35] B. Peng, L. Chen, C. Que, K. Yang, F. Deng, X. Deng, G. Shi, G. Xu, M. Wu, Adsorption of Antibiotics on Graphene and Biochar in Aqueous Solutions Induced by $\pi-\pi$ Interactions, Scientific Reports, 6 (2016) 31920.

[36] S. Yang, L. Li, T. Xiao, D. Zheng, Y. Zhang, Role of surface chemistry in modified ACF (activated carbon fiber)-catalyzed peroxymonosulfate oxidation, Applied Surface Science, 383 (2016) 142-150.

[37] J.-H. Zhou, Z.-J. Sui, J. Zhu, P. Li, D. Chen, Y.-C. Dai, W.-K. Yuan, Characterization of surface oxygen complexes on carbon nanofibers by TPD, XPS and FT-IR, Carbon, 45 (2007) 785-796.

[38] G.H. Oh, C.H. Yun, C.R. Park, Role of KOH in the One-Stage KOH Activation of Cellulosic Biomass, Carbon Science, 4 (2003) 180 - 184.

[39] Y. Sun, J. Cheng, Hydrolysis of lignocellulosic materials for ethanol production: a review, Bioresource Technology, 83 (2002) 1-11.

[40] T. Budinova, E. Ekinci, F. Yardim, A. Grimm, E. Björnbom, V. Minkova, M. Goranova, Characterization and application of activated carbon produced by H3PO4 and water vapor activation, Fuel Processing Technology, 87 (2006) 899-905.

[41] S. Yorgun, D. Y1ld1z, Preparation and characterization of activated carbons from Paulownia wood by chemical activation with H3PO4, Journal of the Taiwan Institute of Chemical Engineers, 53 (2015) 122-131.

[42] A.S. Mestre, C. Freire, J. Pires, A.P. Carvalho, M.L. Pinto, High performance microspherical activated carbons for methane storage and landfill gas or biogas upgrade, Journal of Materials Chemistry A, 2 (2014) 15337-15344.

[43] A. Bazan-Wozniak, P. Nowicki, R. Pietrzak, The influence of activation procedure on the physicochemical and sorption properties of activated carbons prepared from pistachio nutshells for removal of NO2/H2S gases and dyes, Journal of Cleaner Production, 152 (2017) 211-222.

[44] K. Juejun, J. Supunnee, T. Chaiyot, Effect of carbonization temperature on properties of char and activated carbon from coconut shell, Qingdao Daxue Shifanxueyuan Xuebao/Journal of Teachers College Qingdao University, 20 (2013) 269-278.

[45] D. Kołodyńska, R. Wnętrzak, J.J. Leahy, M.H.B. Hayes, W. Kwapiński, Z. Hubicki, Kinetic and adsorptive characterization of biochar in metal ions removal, Chemical Engineering Journal, 197 (2012) 295-305. 


\section{Chapter 6}

\section{Path Forward}

\subsection{Conclusions}

The results reported in this dissertation showed the irrespective of the biomass varieties, the characteristics of pyrolysis products obtained from herbaceous biomass harvested from reclaimed mine land are similar to pyrolysis products obtained from biomass feedstocks harvested on arable land. Also, it can be concluded that pyrolysis temperature significantly affects the thermal stability and physicochemical properties of biochars obtained from herbaceous biomass. Furthermore, it can be concluded that the use of biomass impregnation with $\mathrm{KOH}$ as an activating agent will lead to activated carbons with desirable properties that can be employed for adsorption of pharmaceutically active compounds such as acetaminophen and caffeine.

The results of this dissertation can be used in selecting the appropriate biochars for soil amendment based on the background information of the soil properties. Also, the results can be used as a preliminary data for techno-economic analysis of biochar and activated carbon productions using the herbaceous biomass reported in this dissertation.

Based on the results reported in this dissertation, the potential future research that would be carried out include carrying multicomponent adsorption studies on the use of the activated carbons in adsorbing pharmaceutical pollution from hospital and city discharge. Also, the activated carbons will be used in the adsorption of antibiotic contaminants from livestock housing wastewater. Furthermore, research will be conducted on the adsorption thermodynamics of the activated carbon in order to further elucidate its adsorption mechanism. 
Appendix 1

\section{Appendices}
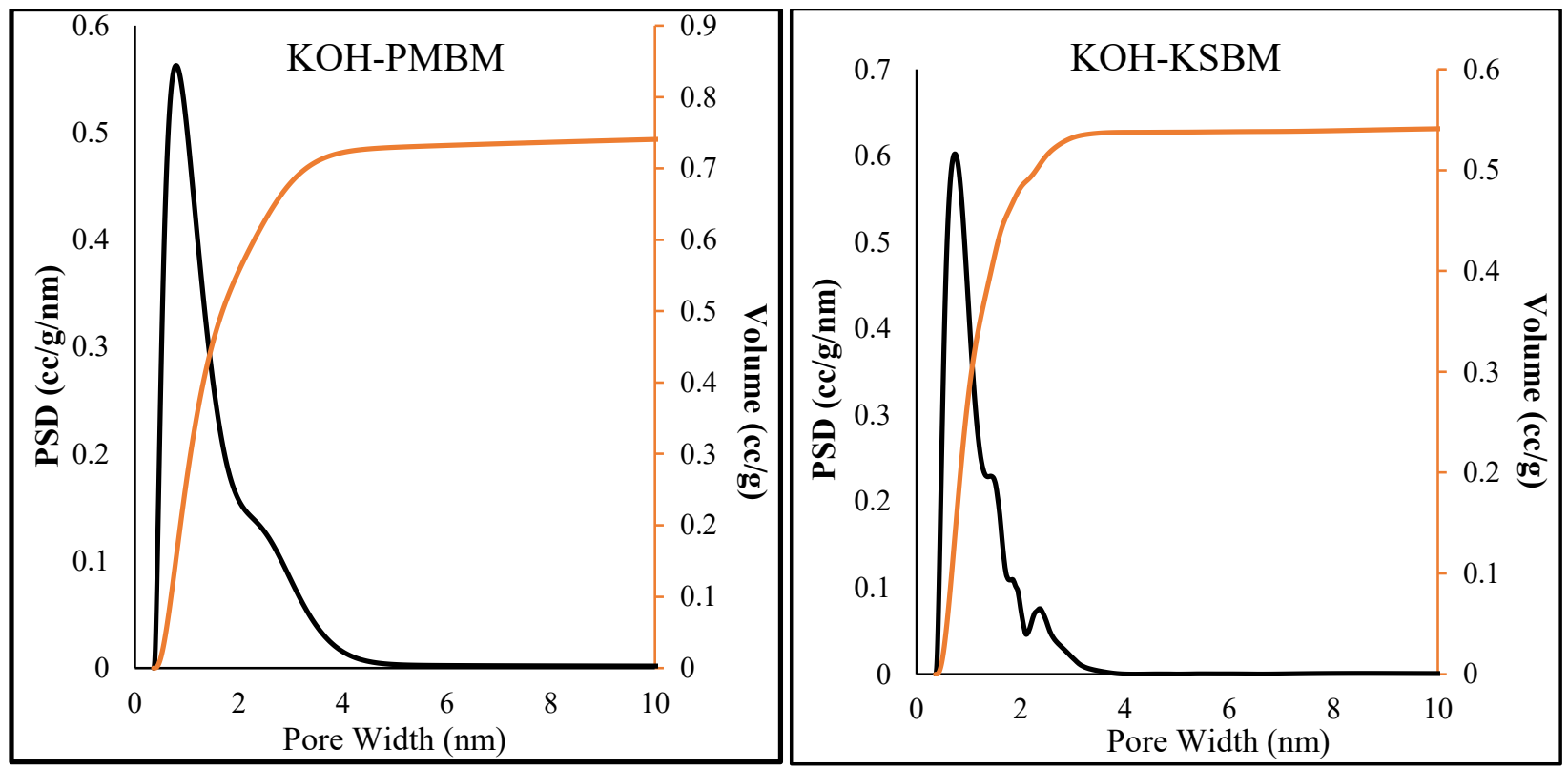

Pore size distribution of biomass-derived activated carbon

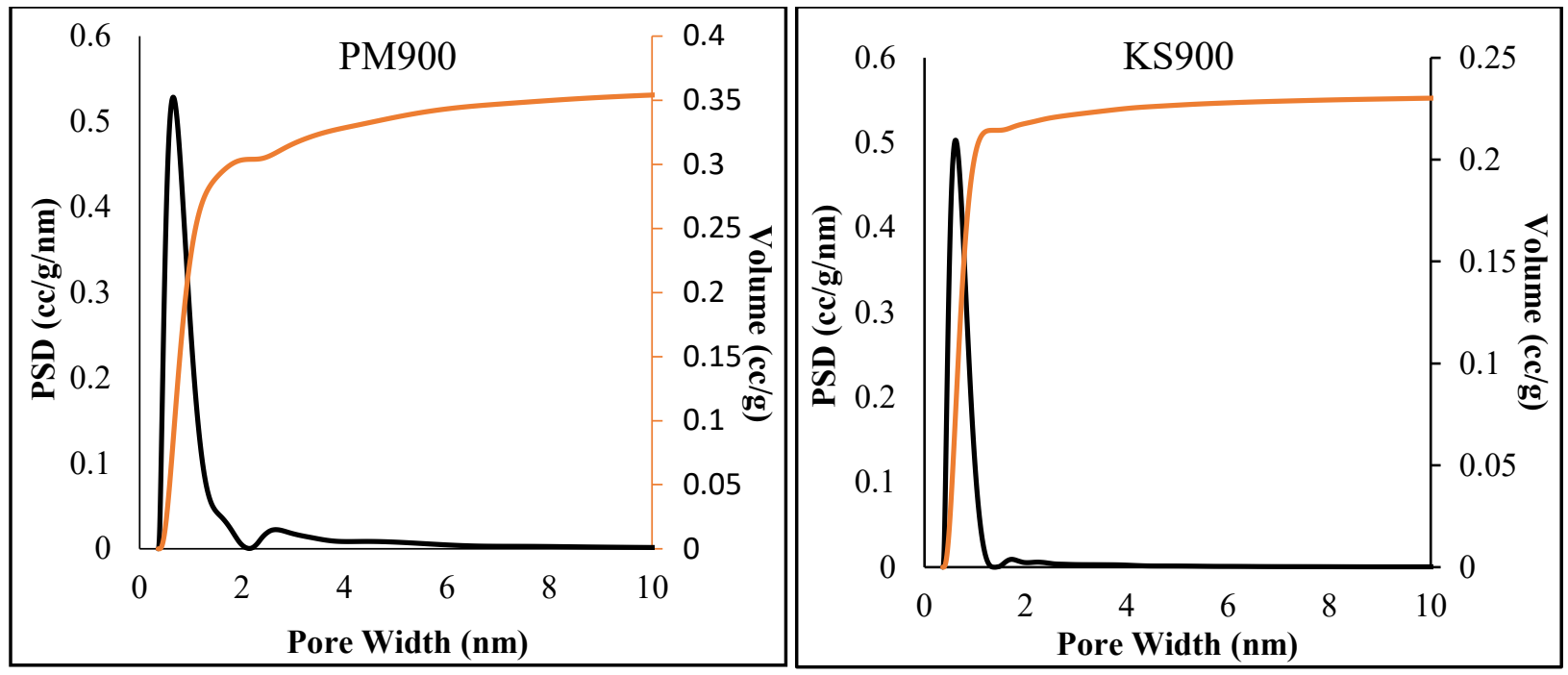

Pore size distribution of biochars 


\section{Appendix 2}
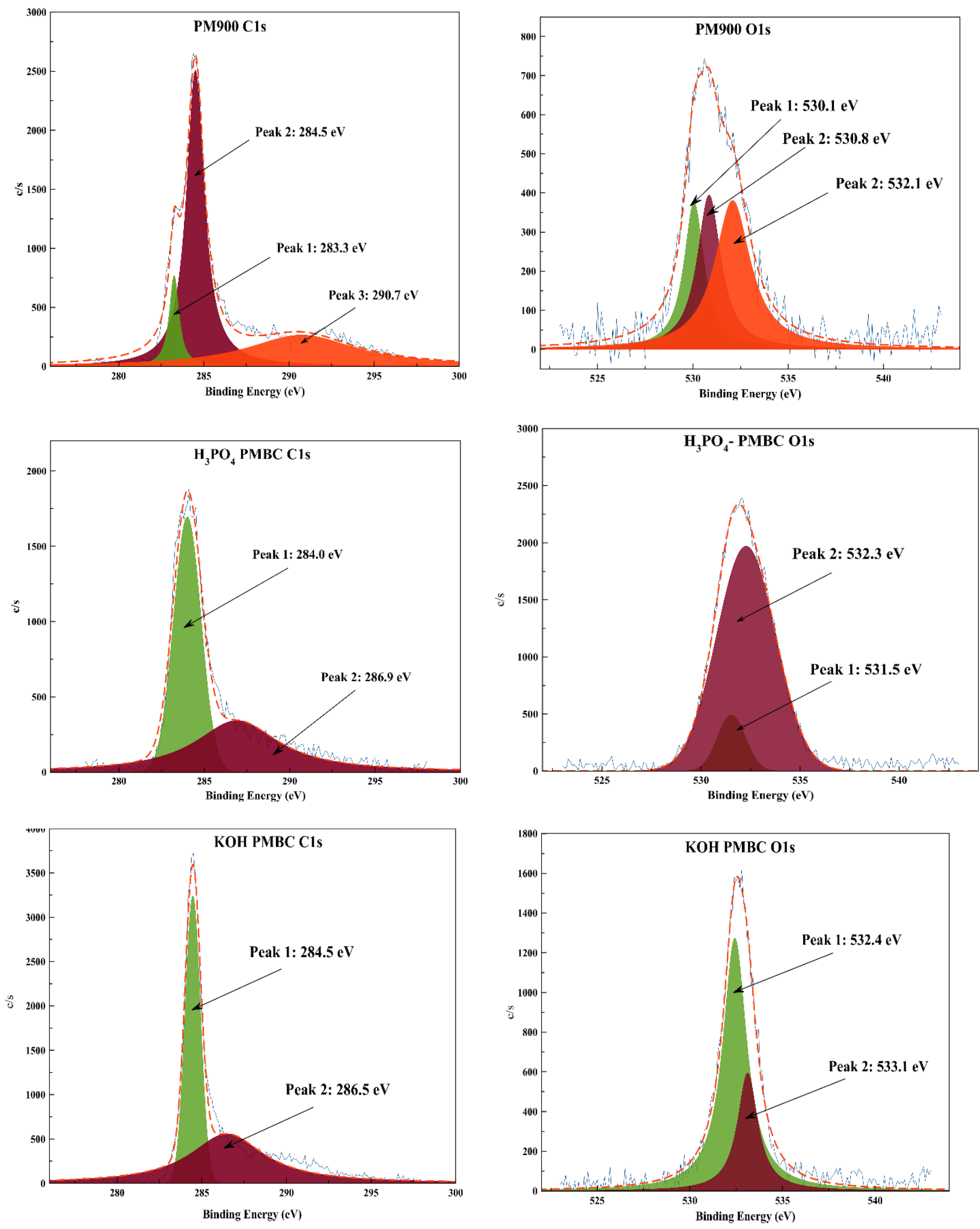

XPS C1s and O1s deconvolution of PM900, $\mathrm{H}_{3} \mathrm{PO}_{4}-\mathrm{PMBC}$ and $\mathrm{KOH}-\mathrm{PMBC}$ 

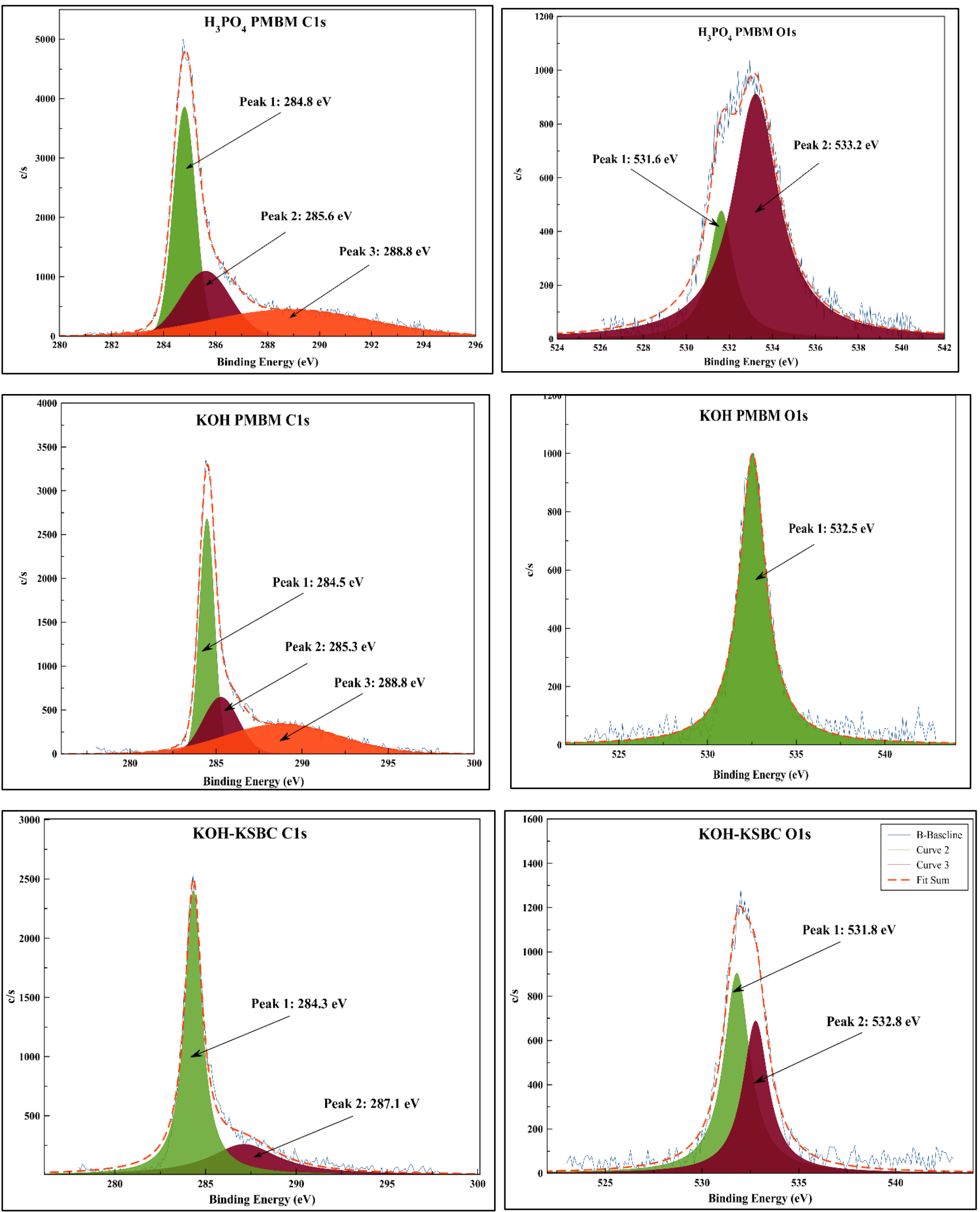

XPS C1s and O1s deconvolution of $\mathrm{H}_{3} \mathrm{PO}_{4}-\mathrm{PMBM,} \mathrm{KOH-PMBM,} \mathrm{and} \mathrm{KOH-KSBC}$ 

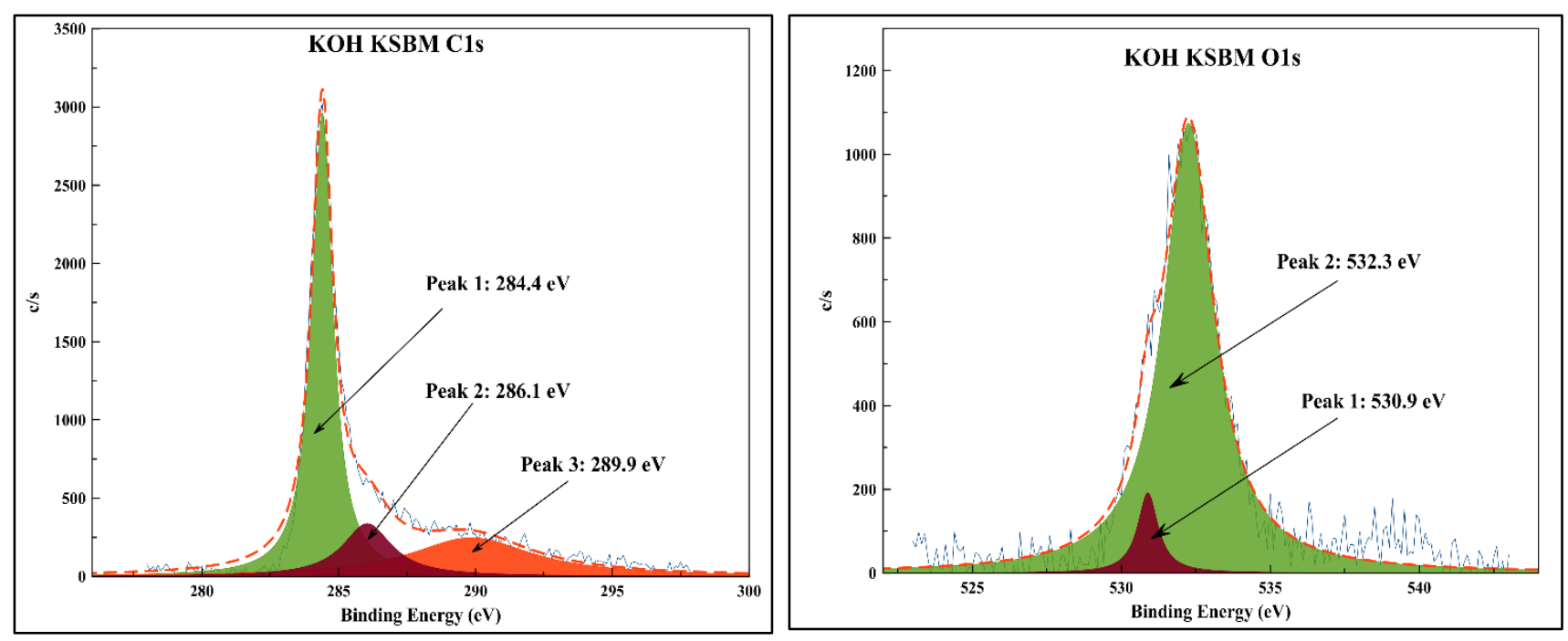

XPS C1s and O1s deconvolution of KOH-KSBM 